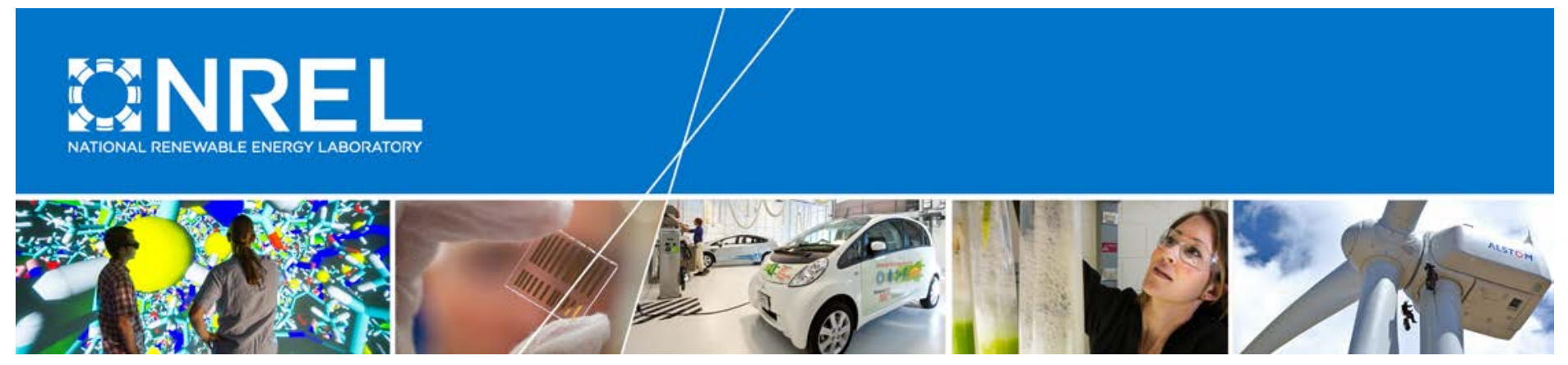

\title{
Advanced Grid-Friendly Controls Demonstration Project for Utility-Scale PV Power Plants
}

Vahan Gevorgian and Barbara O'Neill National Renewable Energy Laboratory

NREL is a national laboratory of the U.S. Department of Energy Office of Energy Efficiency \& Renewable Energy Operated by the Alliance for Sustainable Energy, LLC

This report is available at no cost from the National Renewable Energy Laboratory (NREL) at www.nrel.gov/publications.

Technical Report

NREL/TP-5D00-65368

January 2016

Contract No. DE-AC36-08G028308 


\title{
Advanced Grid-Friendly Controls Demonstration Project for Utility-Scale PV Power Plants
}

\author{
Vahan Gevorgian and Barbara O'Neill
} National Renewable Energy Laboratory

Prepared under Task No. SS13.2030

NREL is a national laboratory of the U.S. Department of Energy Office of Energy Efficiency \& Renewable Energy Operated by the Alliance for Sustainable Energy, LLC

This report is available at no cost from the National Renewable Energy Laboratory (NREL) at www.nrel.gov/publications.

National Renewable Energy Laboratory 15013 Denver West Parkway Golden, CO 80401

303-275-3000 • www.nrel.gov

\section{Technical Report}

NREL/TP-5D00-65368

January 2016

Contract No. DE-AC36-08GO28308 


\section{NOTICE}

This report was prepared as an account of work sponsored by an agency of the United States government. Neither the United States government nor any agency thereof, nor any of their employees, makes any warranty, express or implied, or assumes any legal liability or responsibility for the accuracy, completeness, or usefulness of any information, apparatus, product, or process disclosed, or represents that its use would not infringe privately owned rights. Reference herein to any specific commercial product, process, or service by trade name, trademark, manufacturer, or otherwise does not necessarily constitute or imply its endorsement, recommendation, or favoring by the United States government or any agency thereof. The views and opinions of authors expressed herein do not necessarily state or reflect those of the United States government or any agency thereof.

This report is available at no cost from the National Renewable Energy Laboratory (NREL) at www.nrel.gov/publications.

Available electronically at SciTech Connect http:/www.osti.gov/scitech

Available for a processing fee to U.S. Department of Energy and its contractors, in paper, from:

U.S. Department of Energy

Office of Scientific and Technical Information

P.O. Box 62

Oak Ridge, TN 37831-0062

OSTI http://www.osti.gov

Phone: 865.576.8401

Fax: 865.576.5728

Email: reports@osti.gov

Available for sale to the public, in paper, from:

U.S. Department of Commerce

National Technical Information Service

5301 Shawnee Road

Alexandria, VA 22312

NTIS http://www.ntis.gov

Phone: 800.553 .6847 or 703.605 .6000

Fax: 703.605.6900

Email: orders@ntis.gov 


\section{Acknowledgments}

The authors thank Venkat Banunarayanan and Becca Jones-Albertus of the U.S. Department of Energy's (DOE's) Solar Energy Technologies Office for their continuous support of this project.

In addition, we acknowledge the substantial contributions to this report provided by staff at the Puerto Rico Electric Power Authority (PREPA). We express our gratitude to the Governor's Office and the Puerto Rico Energy Affairs Administration (PREAA) for their continued support of National Renewable Energy Laboratory (NREL) efforts. NREL worked closely with staff from PREPA, PREAA, and the Governor's Office throughout the preliminary stages of the project to ensure accurate understanding of Puerto Rico's electric grid and the status of renewable energy integration. The authors particularly thank Obed Santos of AES; Martin Pérez, Alvin Roman Fernandez, Gregory Rivera-Chico, Hector Montes, Luis Francis, Dolores Reyes, Alfonso Baretty, and Carmen Cruz of PREPA; Victor Peligro and Marcelino Sanchez of GPTech; and José Maeso and Efraín O’Neill (Governor's Energy Affairs Advisor) for their significant contributions and support of this effort. The authors also thank Jennifer DeCesaro from DOE for her support of NREL's work in Puerto Rico.

Finally, the authors acknowledge the substantial contributions to this report provided by staff from the Electric Reliability Council of Texas, including Sandip Sharma and Bill Blevins. And we thank Mahesh Morjaria, Vladimir Chadliev, Dmitriy Anichkov, and Jeff King of First Solar Electric, LLC. 


\section{List of Acronyms}

$\mathrm{ACE}$

AGC

APC

ERCOT

FFR

GPTech

MTR

NREL

PFR

POI

PPC

PREAA

PREPA

PV

ROCOF

SCADA

Siemens PTI area control error

automatic generation control

active power control

Electric Reliability Council of Texas

fast frequency response

Green Power Technologies Corporation

minimum technical requirement

National Renewable Energy Laboratory

primary frequency response

point of interconnection

power plant controller

Puerto Rico Energy Affairs Administration

Puerto Rico Electric Power Authority

photovoltaic

rate of change of frequency

supervisory control and data acquisition

Siemens Power Technologies International 


\section{Abstract}

The National Renewable Energy Laboratory (NREL), AES, the Puerto Rico Electric Power Authority, First Solar, and the Electric Reliability Council of Texas conducted a demonstration project on two utility-scale photovoltaic (PV) plants to test the viability of providing important ancillary services from these facilities. As solar generation increases globally, there is a need for innovation and increased operational flexibility. A typical photovoltaic (PV) power plant consists of multiple power electronic inverters and can contribute to grid stability and reliability through sophisticated "grid-friendly" controls. It may in this way mitigate the impact of its variability on the grid, and contribute to important system requirements more like traditional generators. In FY15, testing was completed on two 20+ MW plants, and a large amount of test data was produced and analyzed that demonstrates the ability of PV power plants to provide various types of new grid-friendly controls. This data showed how active power controls can leverage PV's value from being simply an intermittent energy resource to providing additional ancillary services that range from spinning reserves, load following, ramping, frequency response, variability smoothing and frequency regulation to power quality. Specifically, the tests conducted included variability smoothing through automatic generation control, frequency regulation for fast response and droop response, and power quality. 


\section{Table of Contents}

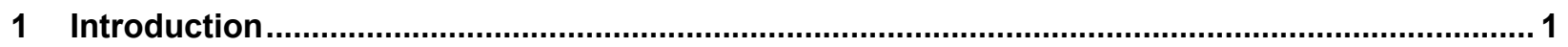

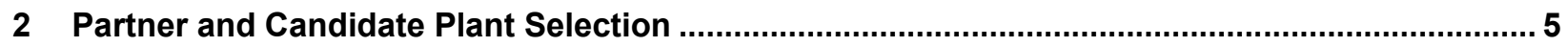

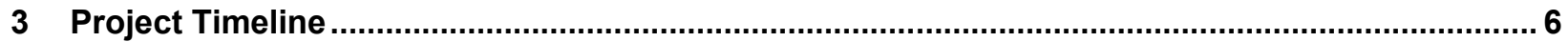

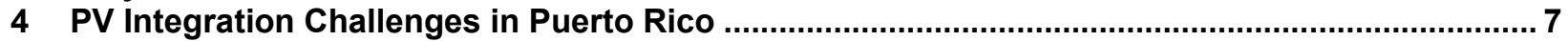

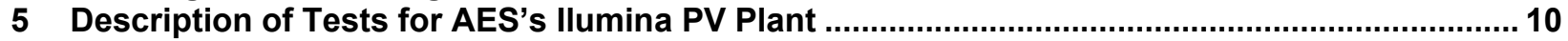

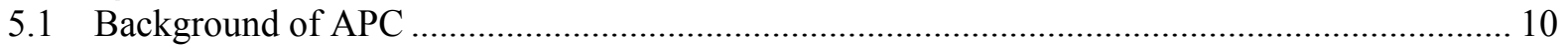

5.2 PREPA's PV Frequency Response and Regulation Requirements ........................................ 12

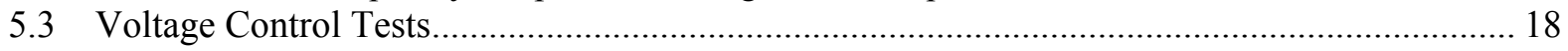

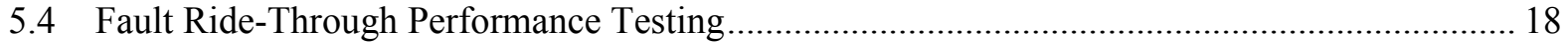

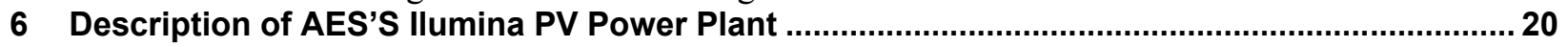

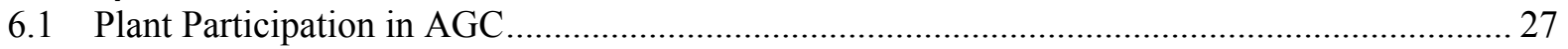

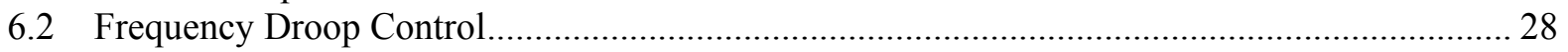

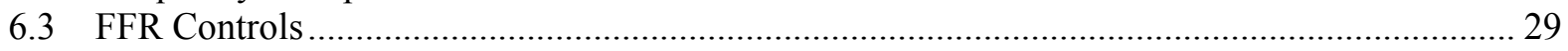

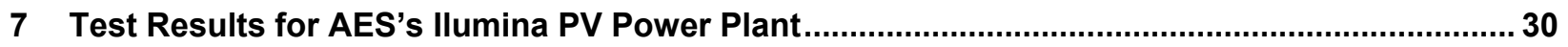

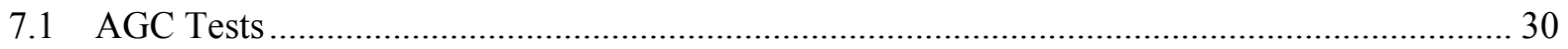

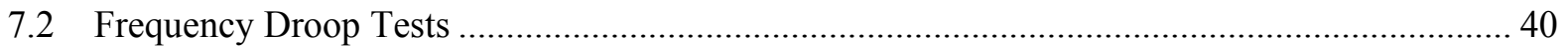

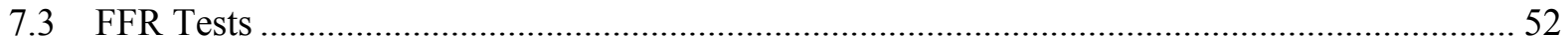

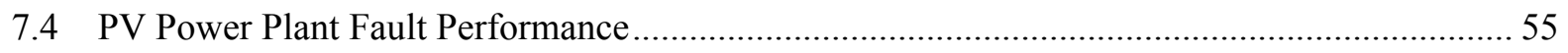

8 Renewables Integration and Ancillary Services in ERCOT ................................................... 58

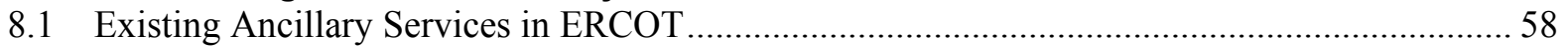

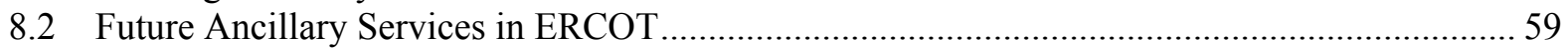

9 Description of First Solar's Pecos Barilla PV Power Plant .....................................................61

10 Description of Tests for First Solar's Pecos Barilla PV Power Plant ........................................6 67

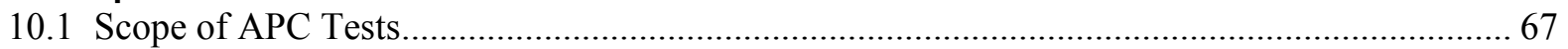

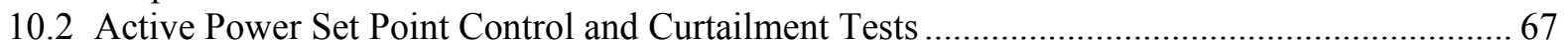

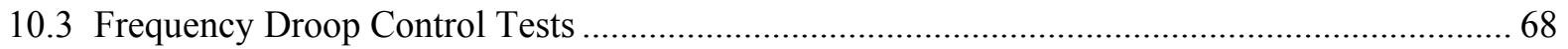

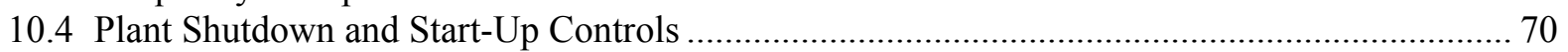

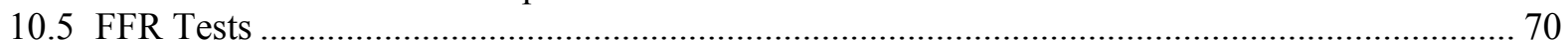

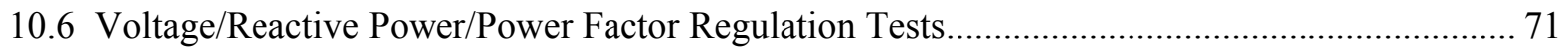

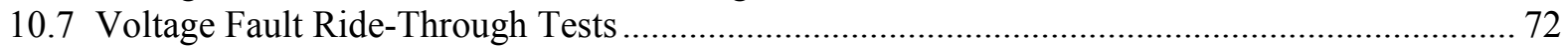

11 Test Results for First Solar's Pecos Barilla PV Power Plant ...................................................... 73

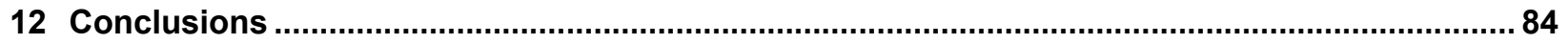

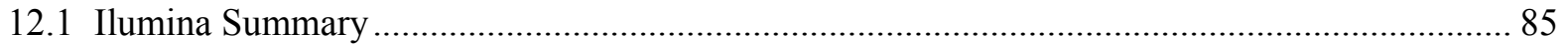

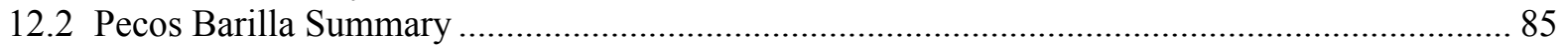

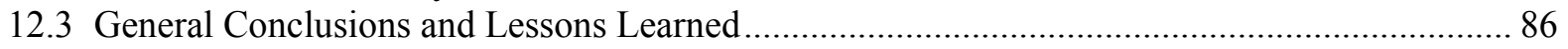

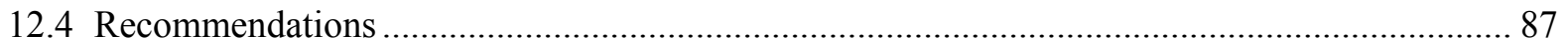

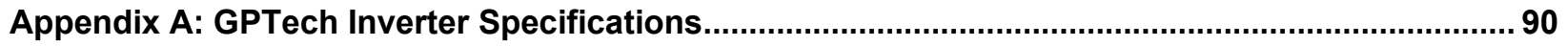

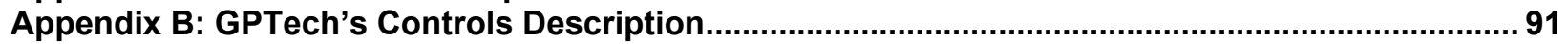

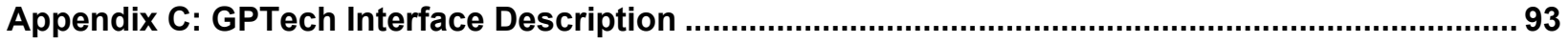




\section{List of Figures}

Figure 1. Components of a typical utility-scale PV power plant. Image from NREL ................................. 2

Figure 2. Bridging the gaps in perspectives. Image from NREL .......................................................... 4

Figure 3. Installed generation capacity in Puerto Rico …......................................................................... 7

Figure 4. PREPA transmission system. Image from PREPA …............................................................ 7

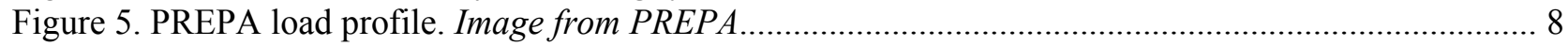

Figure 6. Theoretical frequency response of a conventional generator .................................................. 11

Figure 7. Example of regulation and load following during normal conditions ....................................... 12

Figure 8. PREPA frequency event on November 23, 2013 .............................................................. 14

Figure 9. Theoretical response of the Ilumina PV power plant with up-regulating reserve ........................ 14

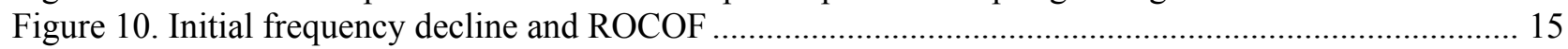

Figure 11. Comparison of the impacts of FFR and droop control on frequency response ......................... 16

Figure 12. Ilumina PV power plant operation with reserve .......................................................... 17

Figure 13. Examples of PREPA 1-hour frequency time series measured in November 2013 ..................... 18

Figure 14. Aerial view of the Ilumina PV power plant. Image from AES ............................................. 20

Figure 15. Single-line diagram of Ilumina's 20-MVA utility interconnection .......................................... 21

Figure 16. Photos of Ilumina PV power plant substation and PV array. Image from NREL ...................... 22

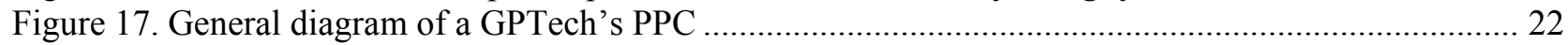

Figure 18. Diagram of the Ilumina PV power plant's remote terminal unit communications...................... 24

Figure 19. AES's Ilumina-PREPA interface description .................................................................... 25

Figure 20. Layout of the Ilumina PV power plant. Images from (left) Google earth and (right) AES ......... 26

Figure 21. Concept of AGC following by PV power plant............................................................... 27

Figure 22. Diagram of PREPA's unit control. Image from PREPA ….................................................... 28

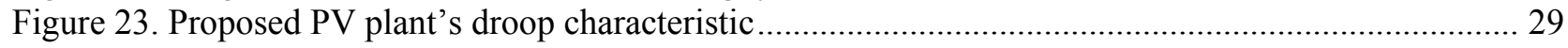

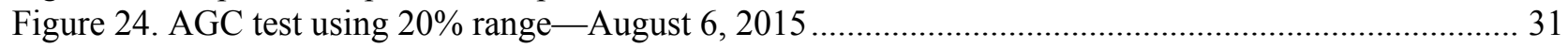

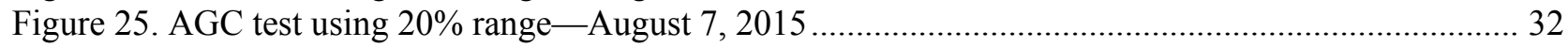

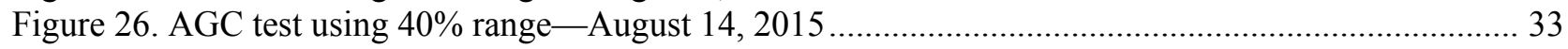

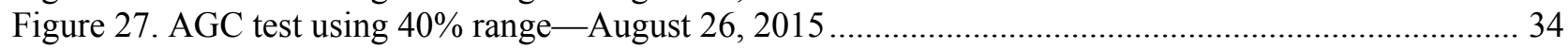

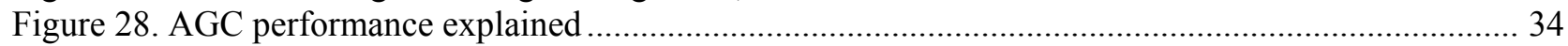

Figure 29. Display of PREPA's AGC units-AES's Ilumina is masked as San Juan 6 CC Gas unit. Image

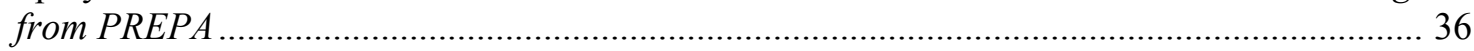

Figure 30. Snapshot of PREPA's AGC display-19-MW set point is sent to Ilumina. Image from PREPA 37

Figure 31. Snapshot of PREPA's AGC display-11.5-MW set point is sent to Ilumina. Image from

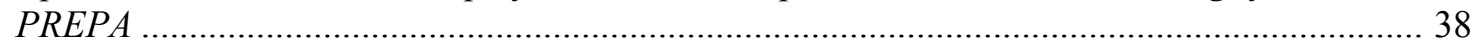

Figure 32. Snapshot of PREPA's AGC units—no conventional units are selected. Image from PREPA ..... 39

Figure 33. Display of PREPA's AGC active units-priority was set to AES's Ilumina. Image from

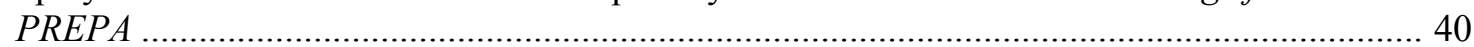

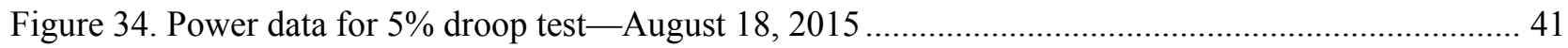

Figure 35. Control error during 5\% droop test-August 18, 2015 .................................................... 42

Figure 36. Measured droop characteristic and control error statistics for 5\% droop test-August 18, 201542

Figure 37. Acceptable droop performance during periods of low variability ............................................ 44

Figure 38. High scatter during periods of solar resource variability ............................................... 45

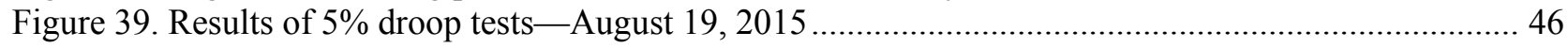

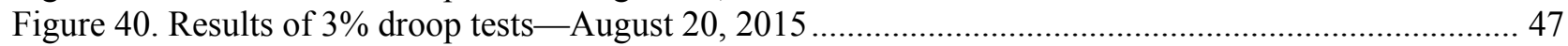

Figure 41. Measured droop characteristic and control error statistics for 5\% droop test-August 19, 201547

Figure 42. Measured droop characteristic and control error statistics for 3\% droop test-August 20, 201548

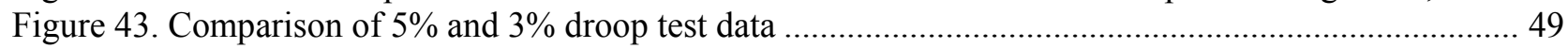

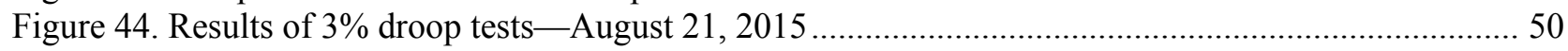

Figure 45. Measured droop characteristics for 3\% tests-August 21, 2015 ....................................... 50

Figure 46. Results of 3\% droop tests-August 24, 2015 ................................................................... 51 


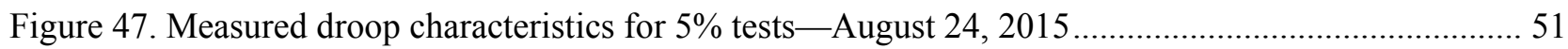

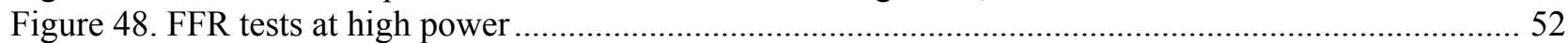

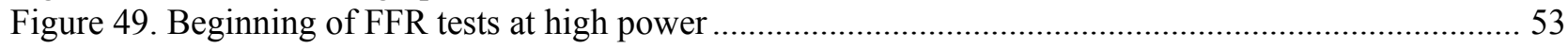

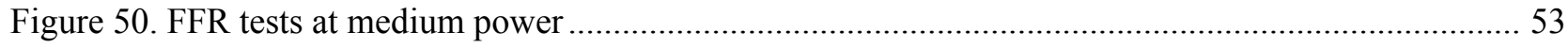

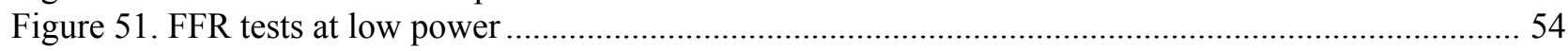

Figure 52. Measured and simulated response of 496-MVA steam turbine generator to frequency

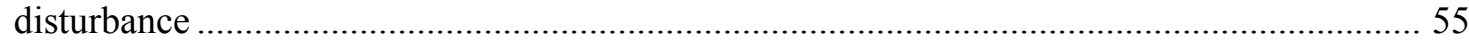

Figure 53. Measured and simulated response of a gas turbine in a combined-cycle power plant ................ 55

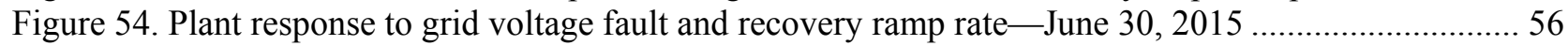

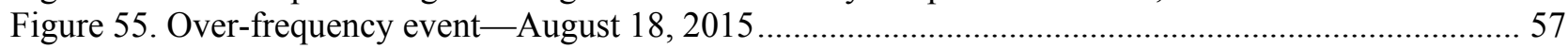

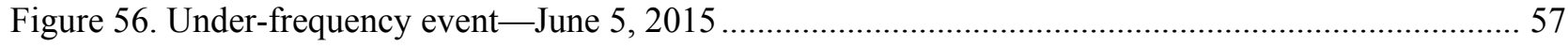

Figure 57. Location of the Pecos Barilla PV power plant in West Texas. Image from First Solar .............. 61

Figure 58. Aerial photo of the Pecos Barilla PV power plant. Image from First Solar ............................... 62

Figure 59. Single-line diagram of Phase 1 of the Barilla PV power plant .................................................. 63

Figure 60. General diagram of the Pecos Barilla PV power plant controls and interfaces. Image from First

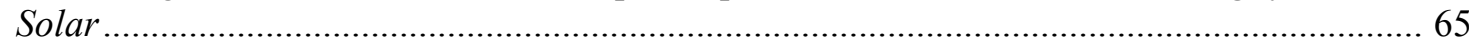

Figure 61. Diagram of the Pecos Barilla PV power plant control system architecture. Image from First

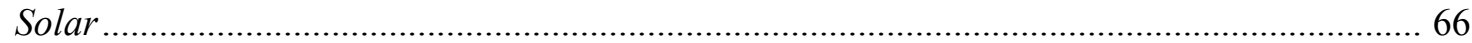

Figure 62. Example of a plant curtailment test. Image from First Solar .................................................. 68

Figure 63. Example of the Pecos Barilla PV power plant frequency droop function. Image from First

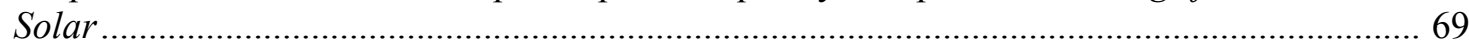

Figure 64. Examples of frequency events measured in the ERCOT grid .................................................. 69

Figure 65. Example of a ramp-rate control test. Image from First Solar .................................................... 70

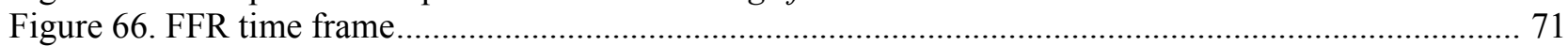

Figure 67. Example of dynamic power factor regulation by a PV power plant. Image from First Solar ...... 72

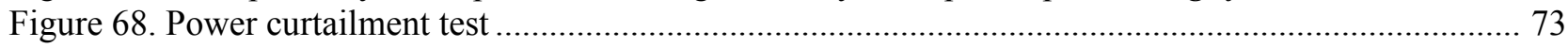

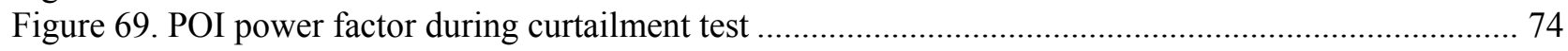

Figure 70. Plant sequential shutdown test —active power ............................................................ 74

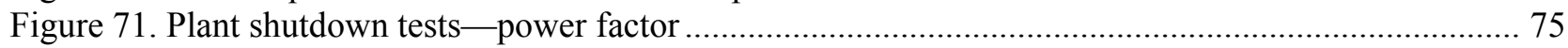

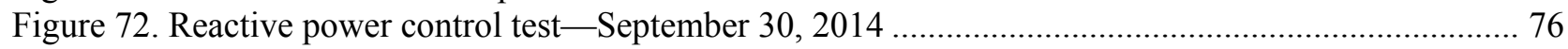

Figure 73. Test of measured reactive power compared to commanded reactive power- September 30,

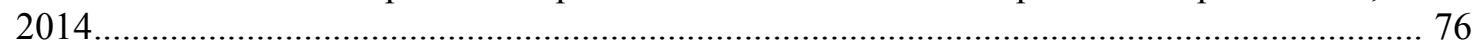

Figure 74. Reactive power control test—measured MVAR and set point............................................... 77

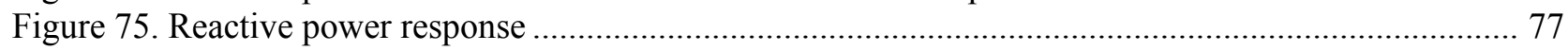

Figure 76. Reactive power control test - measured voltage on $138-\mathrm{kV}$ bus.......................................... 78

Figure 77. Reactive power control test - measured plant active power.................................................. 78

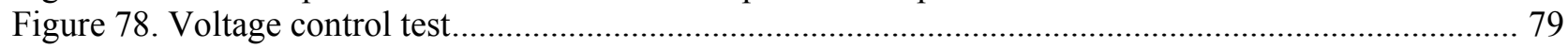

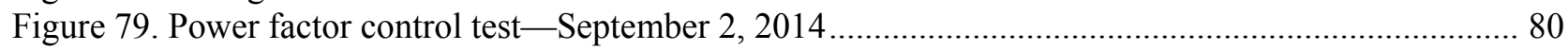

Figure 80 . Voltage in the $138-\mathrm{kV}$ bus during the power factor control test-September 2, $2014 \ldots \ldots \ldots \ldots \ldots . .81$

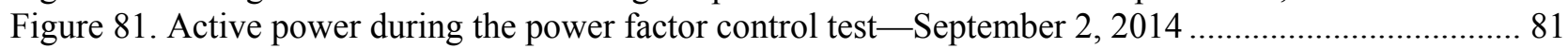

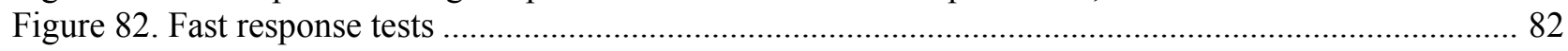

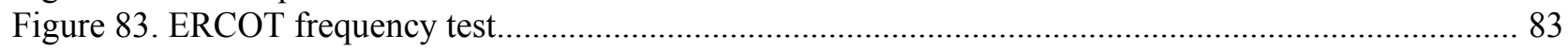

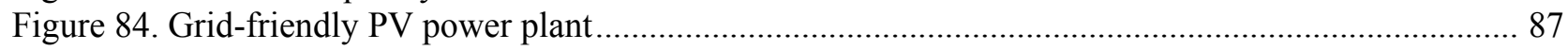

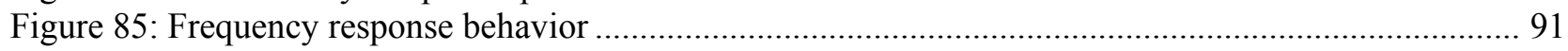

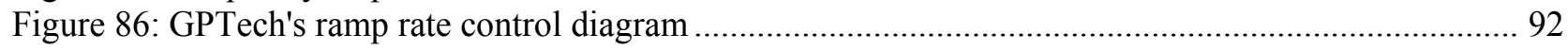

\section{List of Tables}

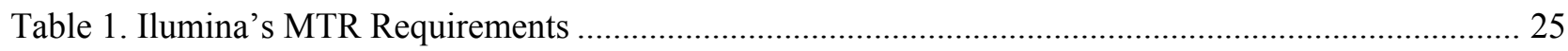

Table 2. ERCOT's Existing and Future Ancillary Services Framework .................................................. 60 


\section{Introduction}

Solar resources are serving an increasing share of U.S. electricity needs. In 2014, installed solar capacity totaled around 18 gigawatts (GW) and in 2015 solar capacity additions are expected to exceed 24 gigawatts [1]. Of all of new generation capacity installed in 2014, solar was responsible for $40 \%$. Though the 2014 capacity represents less than $2 \%$ of electric generation, solar's share of the resource mix is growing. Coinciding with this growth, over the last five years, the estimated average price of solar has fallen by more than $50 \%$ since 2009 . This trend is likely to continue as improvements in balance-of-plant costs take over from the steep decreases seen in panel prices and the total cost of solar energy continues down the curve.

With increasing solar energy coupled with increasing wind energy, traditional power generation resources, specifically fossil thermal, are being displaced. Factors contributing to this include more stringent environmental targets: not only the well-publicized efforts to reduce greenhouse gas emissions, but also mercury and air toxins, particulate matter, nitrous oxides, and sulfur dioxide. The main contributor to many of these emissions are fossil thermal power stations, including steam turbines, gas turbines, and combined cycled plants. These power plants are rotating machines that are synchronized to the electrical grid, whereas wind and solar power plants are connected to the grid through an inverter (converting DC to AC energy) and therefore non-synchronous to the grid's frequency.

While utility-scale solar photovoltaic (PV) power plants are becoming a cost-effective energy resource, there is belief that the increasing penetrations of PV technologies may potentially impact grid reliability. This is due to the variability across timescales and forecast uncertainty of the solar energy resource and impacts both distribution and transmission systems [2,3]. This may cause utilities to severely limit PV installations or increase assigned integration costs when considering a least-cost portfolio of resources. Deployment of utility-scale, grid-friendly PV power plants that incorporate advanced capabilities to support grid stability and reliability is essential for the large-scale integration of PV generation into the electric power grid [4], among other technical requirements, as a means to mitigate the impact of said variability on the electric system. With PV's increased proportion of energy to the generation mix, it should be responsible for an increasing share of the grid's burden of reliability, stability, and high power quality.

A typical modern utility-scale PV power plant is a complex system of large PV arrays and multiple power electronic inverters, and it can contribute to mitigate the impact on grid stability and reliability through sophisticated "grid-friendly" controls. Components of a typical multiMW, utility-scale PV power plant are shown in Figure 1, including power conversion and electrical equipment, such as $\mathrm{PV}$ panels, inverters, switchgear, grid interconnection, power plant controller (PPC), supervisory control and data acquisition (SCADA) and communication systems. 


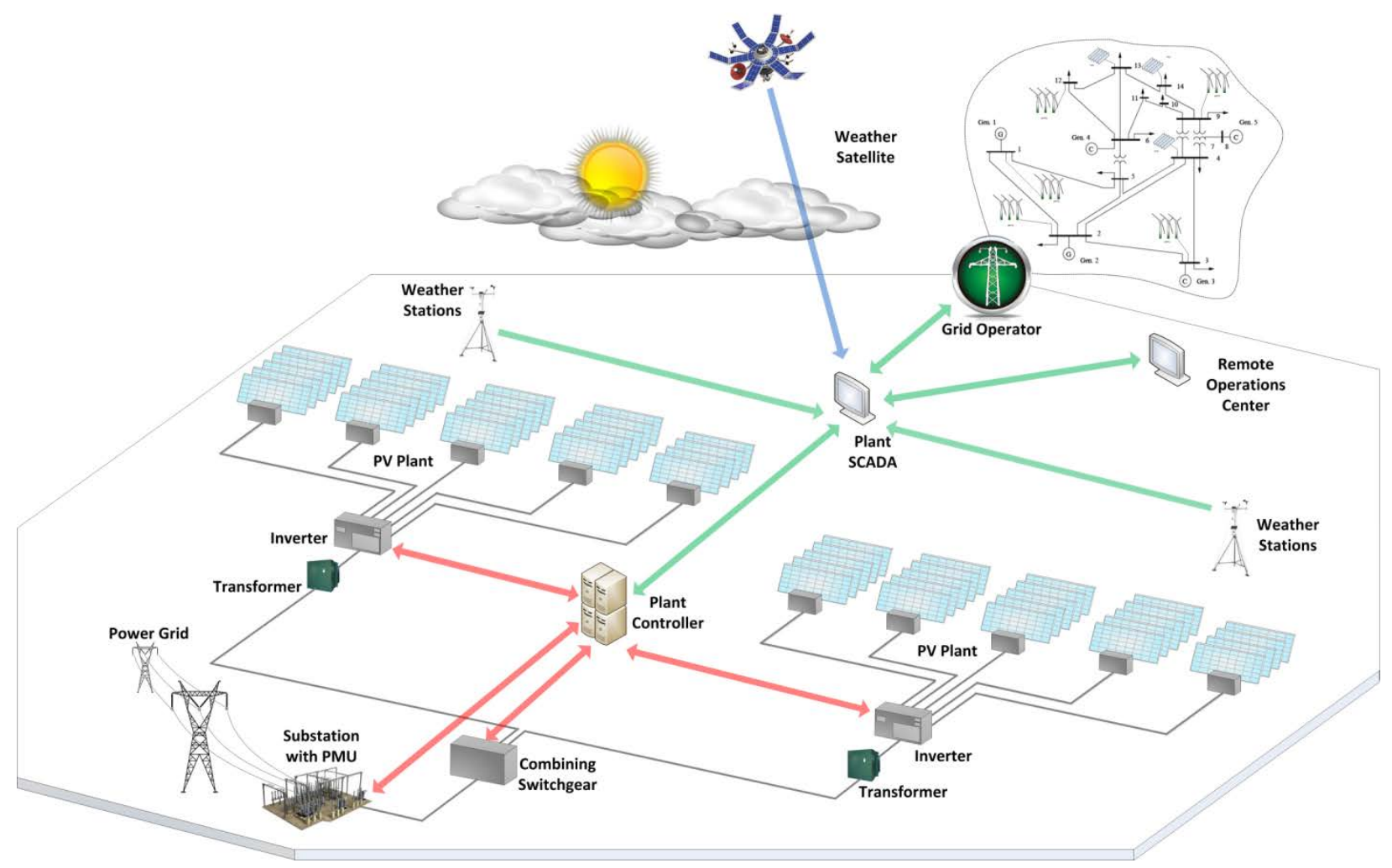

Figure 1. Components of a typical utility-scale PV power plant. Image from NREL

In 2012, the North American Electric Reliability Corporation's (NERC) Integration of Variable Generation Task Force made several recommendations of requirements for variable generators (including solar) to provide their share of grid support, including active power control capabilities $[5,6]$. These recommendations address grid requirements such as voltage control and regulation, voltage and frequency-fault ride-through, reactive and real power control, and frequency response criteria in the context of the technical characteristics and physical capabilities of variable generation equipment:

- Active power control (APC) capabilities include:

○ Ramp-rate limiting controls

- Active power response to bulk power system contingencies

- Inertial response

- Primary frequency response (PFR)

- Secondary frequency response, or participation in automatic generation control (AGC)

- Ability to follow security-constrained economic dispatch (SCED) set points that are sent every 5 minutes.

- Performance during and after disturbances 
- Fault ride-through

○ Short-circuit current contribution

- Voltage, reactive, power factor control and regulation (both dynamic and steady state)

The availability and dissemination of actual test data showing the viability of advanced utilityscale PV controls among all industry stakeholders can leverage PV's value from being simply an intermittent energy resource to providing mitigating ancillary services ranging from variability smoothing to power quality. Strategically partnering with a selected utility and/or PV power plant operator was a key condition for a successful demonstration project. The U.S. Department of Energy's (DOE's) Solar Energy Technologies Office selected the National Renewable Energy Laboratory (NREL) to be a principal investigator in a two-year project aimed to (1) identify a potential partner(s), (2) develop a detailed scope of work and test plan for a field project to demonstrate the capabilities of utility-scale PV power plants to provide ancillary services, (3) facilitate conducting actual demonstration tests, and (4) disseminate test results among industry stakeholders via a joint NREL/DOE publication and participation in relevant technical conferences. The project took place during FY 2014 and FY 2015.

Many of the PV control capabilities that will be demonstrated in this project have already generally been proven to be technically feasible, and a few areas throughout the world have already started to request or require PV power plants to provide some of them. However, in the United States, solar power is rarely recognized as having these capabilities. This may be because of different perspectives among various stakeholders (see Figure 2) [10]. For example, a manufacturer of PV inverters may know that a particular capability is technically feasible, but they may not see a market for it because there is no demand from a developer or requirement from a utility off-taker for the provision of that capability. On the other hand, system operators may desire a particular capability, but they may be unsure of exactly how it performs or whether or not it will actually improve system reliability. PV power plant owners may know what features PV inverters are capable of, but they may choose not to procure them or offer them to an off-taker if the functionality is not required or if it does not result in increased revenue (or, indeed, decreases revenue due to curtailment for headroom). Finally, regulators or market operators may not establish complementary policies or market designs if the markets are receiving enough capabilities and they are provided for free, and they may not be considering how this may change in the future.

With this project's approach to holistic demonstration and dissemination plans, the team sought to close these gaps in perspectives by providing real test data from an actual utility-scale operational PV power plant to all stakeholders. If PV-generated power can offer a supportive product that benefits the power system and is economic for PV power plant owners and customers, this functionality should be recognized and encouraged. 


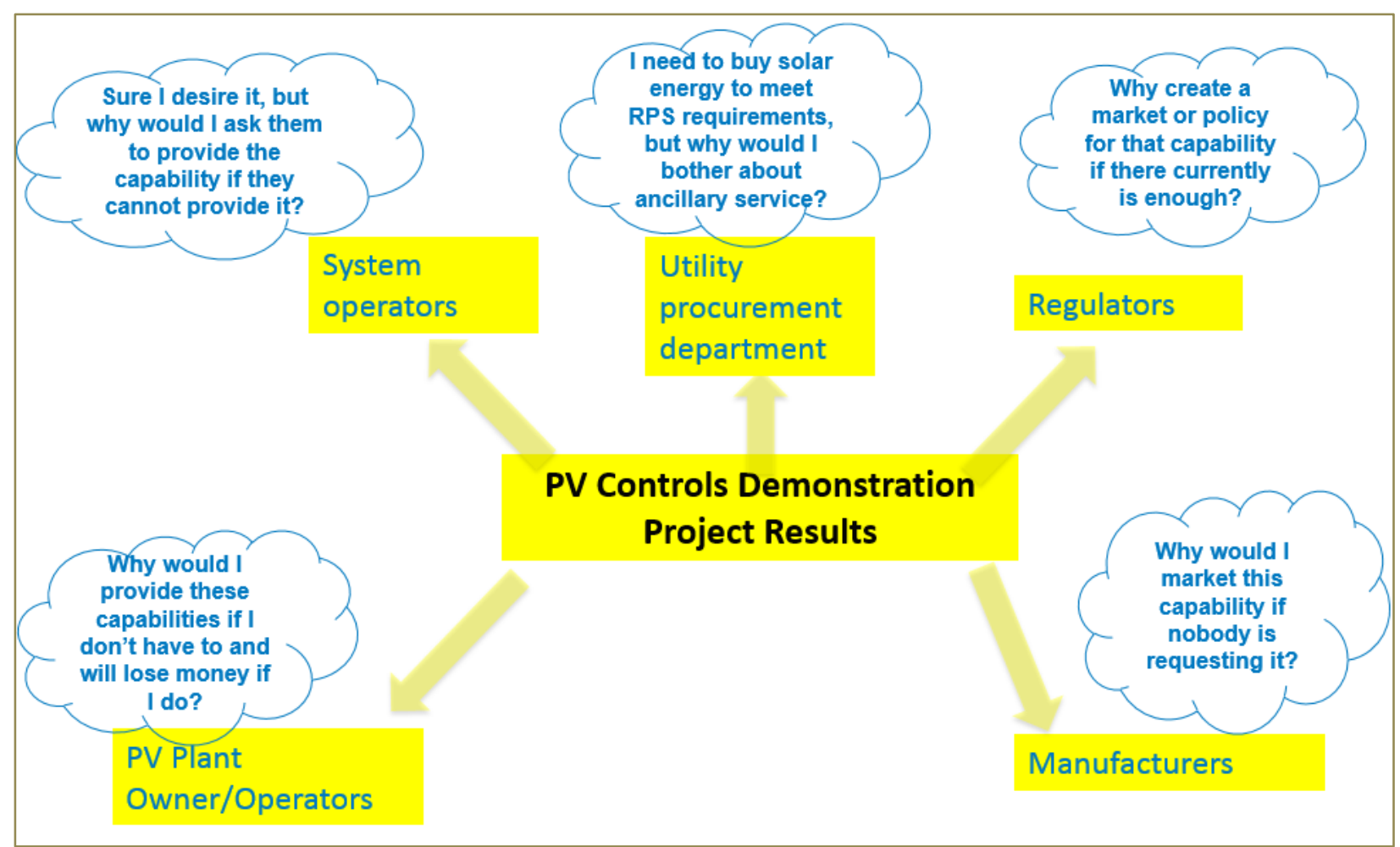

Figure 2. Bridging the gaps in perspectives. Image from NREL 


\section{Partner and Candidate Plant Selection}

The following criteria were used by the NREL team to select partners and their PV power plants for collaboration:

- The partners are willing and motivated to collaborate and have sufficient knowledge and understanding of ancillary services and their impacts on grid reliability.

- The existing PV power plant equipment is suitable for the purpose of this demonstration test project, including that it is:

○ Moderately sized (10 MW-30 MW range $)^{1}$

- Without energy storage ${ }^{2}$

- Without additional power electronic equipment for volt-ampere reactive/voltage control $^{2}$

- With existing active power and voltage controls and/or is easily upgradable for the purposes of this project.

- Test data will provide value for host utility and grid operator.

- Test results are representative and applicable to a large variety of plants and power systems.

\footnotetext{
${ }^{1}$ The demonstration project fund would be paying the owner for revenue losses due to curtailment during these tests, so in this context a moderate size was preferable to a large size.

${ }^{2}$ The purpose of this project was to test the hypothesis that PV plants can contribute grid services without the additional investment and equipment of some form of energy storage, i.e., that most existing plants can do this without much modification.
} 


\section{Project Timeline}

Fiscal year 2014 activities focused primarily on finding collaborative industry partners and planning activities for FY15 testing. First, NREL contacted various industry members to identify potential utility or independent operators as collaborators to demonstrate a PV power plant as an asset to the grid based on the selection criteria above. As a result, two PV power plant owners/operators agreed to become partners with NREL to perform such testing:

1. Ilumina PV power plant owned and operated by AES Corporation. This 20-MW plant is located near Guayama on Puerto Rico’s south coast.

2. Pecos Barilla PV power plant owned and operated by First Solar Electric, LLC. This 22MW plant is located near Fort Stockton in Pecos County in West Texas.

In addition, the Puerto Rico Electric Power Authority (PREPA) and the Electric Reliability Council of Texas (ERCOT) expressed strong interest in this project because of the importance of such advanced controls for the reliable operation of their power systems under high penetration levels of variable generation. Both PREPA's and ERCOT's roles in the project were to review and approve test plans and review test results. In addition, PREPA's role was to actively participate in certain tests conducted in the Ilumina PV power plant.

Test plans for both projects were completed by the NREL team and then approved by the AES/PREPA and First Solar/ERCOT teams, respectively. During FY15, NREL worked with both partner plants to prepare and conduct tests as described in the test plan documents shown in the appendices of this report. Some corrections to the test plan were necessary during the actual test implementation due to various reasons that will be described later in the report.

The original DOE request was to conduct such testing on a single PV power plant; however, NREL decided to work with two partners to minimize the risks associated with many factors (both technical and logistic) that could prevent the project from achieving desired outcomes with only a single counterpart. 


\section{PV Integration Challenges in Puerto Rico}

PREPA has a modern electric power system that serves the entire main island of Puerto Rico and its two adjacent islands of Vieques and Culebra. Currently, the total installed generation capacity in Puerto Rico is close to $6 \mathrm{GW}$, which includes $173 \mathrm{MW}$ of wind and solar PV generation (Figure 3). The bulk of the electric generation in Puerto Rico is still largely petroleum and coal based, with increasing participation by natural gas generators. Puerto Rico's transmission system consists of $230-\mathrm{kV}$ lines (shown in blue) and $115-\mathrm{kV}$ lines (shown in red) as well as $38-\mathrm{kV}$ subtransmission lines and 334 substations (Figure 4).

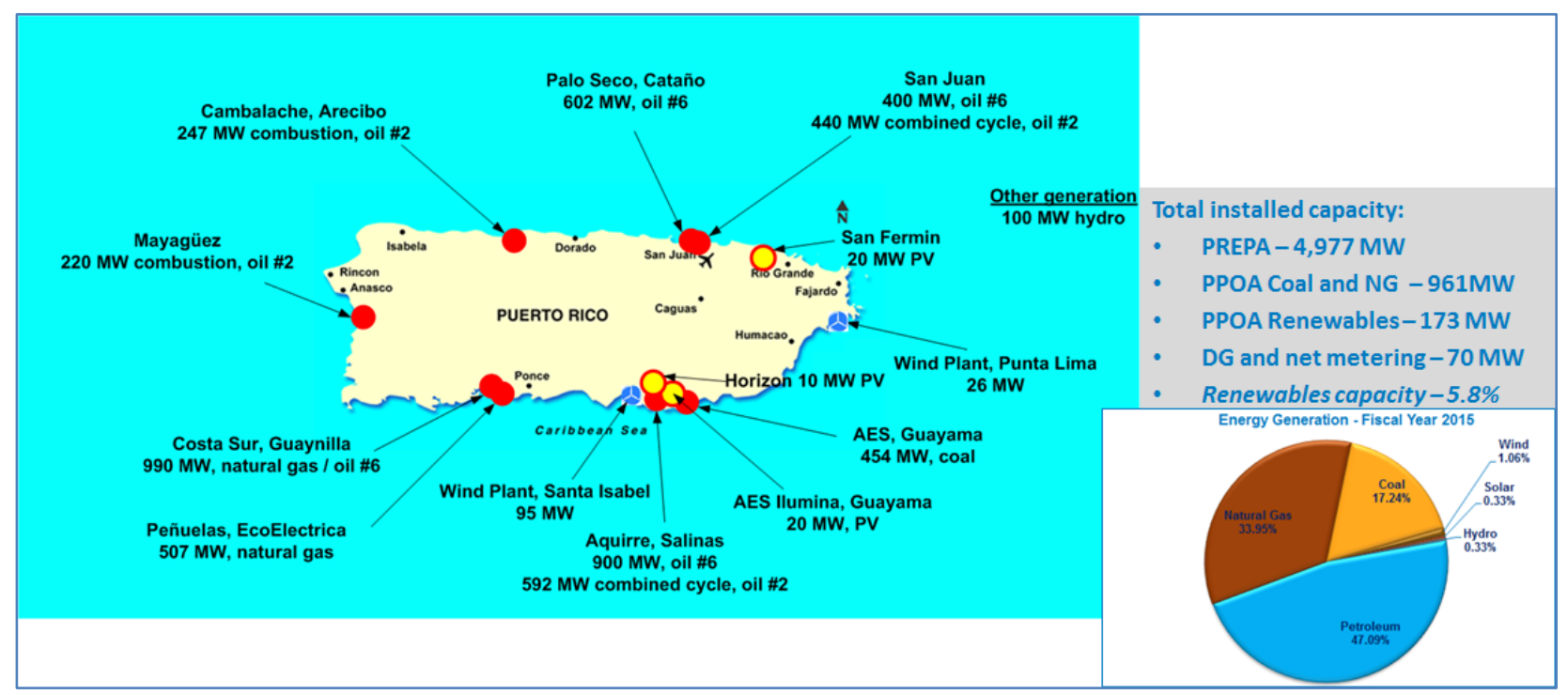

Figure 3. Installed generation capacity in Puerto Rico

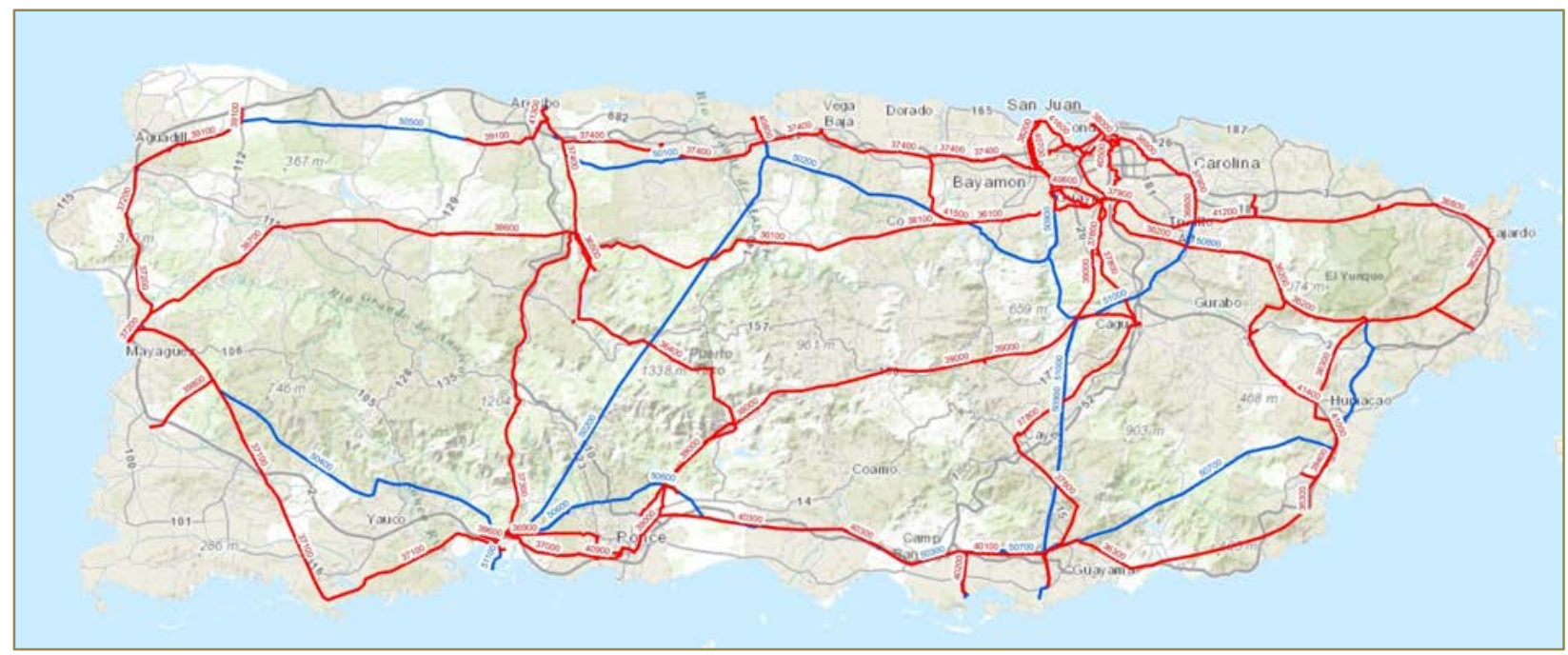

Figure 4. PREPA transmission system. Image from PREPA 
A typical summer workday hourly electrical load profile in Puerto Rico is shown in Figure 5. The graph depicts the historic peak, which occurred in 2005, as well as the 2015 peak, which occurred on Monday, August 24. Electricity demand in Puerto Rico has decreased over the past decade primarily due to economic and fiscal policy changes, as well as some behind-the-meter solar installations. In 2015, the daily peak was around 9 p.m. at 3,023 MW, whereas the daytime peak around 1 p.m. was $5.8 \%$ lower at 2,847 MW.

Puerto Rico exhibits an interesting cycle of a daytime peak followed by a solar and wind power ramp-down followed by an evening system load ramp up reaching a nighttime peak that is higher than the daytime. This cycle is extremely important to the challenges of integrating wind and solar into the Puerto Rican power system. As you can see, the ramp up to the nighttime peak is quite steep. Wind and solar power exhibit steep changes in output as well; for solar, variability can be quite abrupt as weather systems with cloud fronts move quickly and discretely from north to south, in addition to distinct cumulus cloud movements. Thus, as solar and wind increase their share of the resource mix on the Puerto Rican system, the net load variability will be significant.

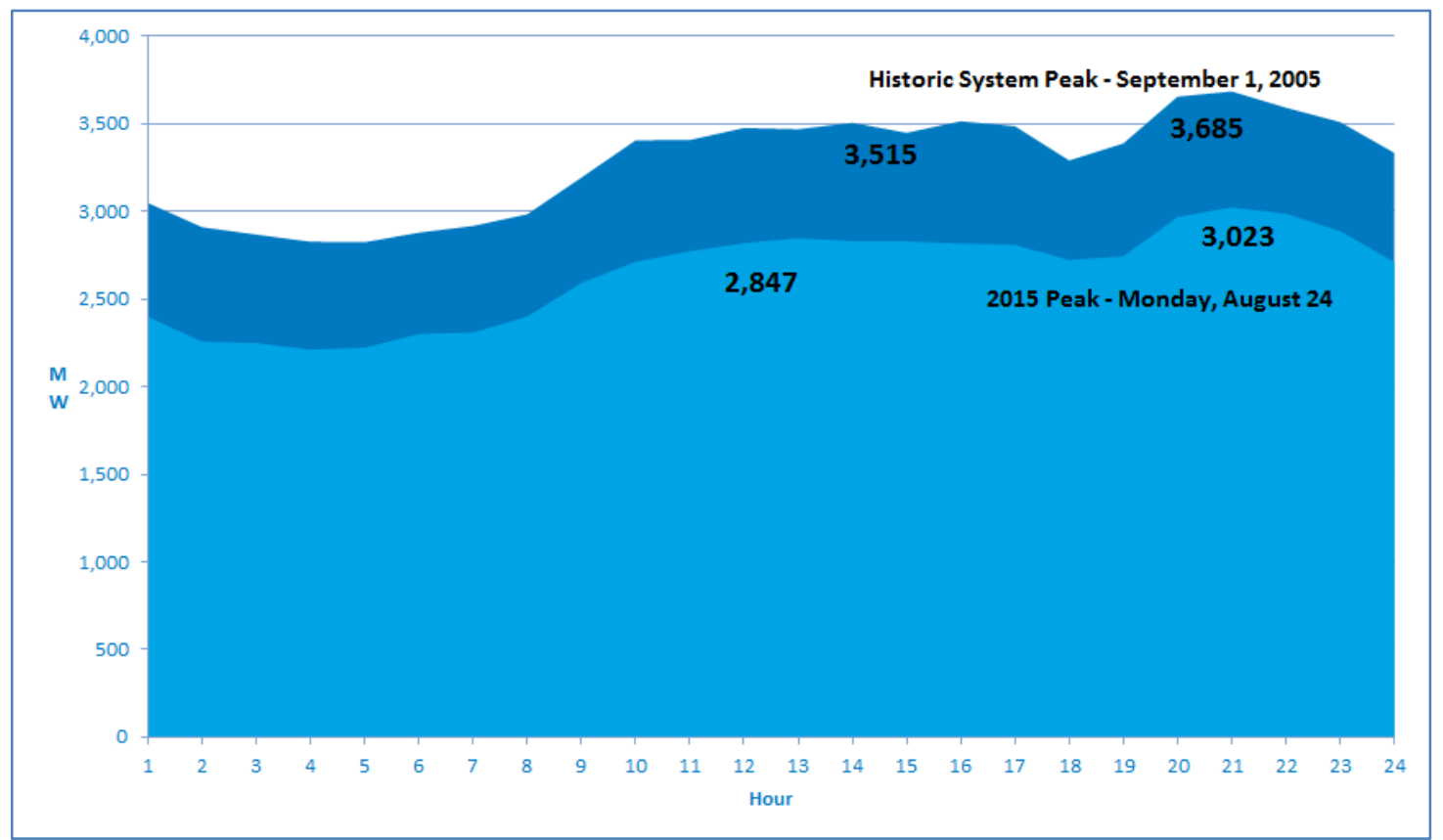

Figure 5. PREPA load profile. Image from PREPA

PREPA is integrating large levels of renewable generation into its electric power system in response to mandates of 2010's local Act 82: Public Policy of Energy Diversification by Means of Sustainable and Alternative Renewable Energy in Puerto Rico Act [7]. The first level of mandated penetration for 2015 was $12 \%$. High levels of renewable generation penetration present reliability and operational challenges for PREPA's power grid that need to be properly addressed to reliably integrate variable renewable generation into the island's electric power system. Establishing appropriate technical requirements for the interconnection of variable renewable generation to the electric grid is an important step in overcoming such challenges. 
PREPA has developed its own set of interconnection requirements (Minimum Technical Requirements, or MTRs) with which all transmission-level utility scale wind and solar PV generators shall comply [8]. A Siemens Power Technologies International (Siemens PTI) study [9] confirmed the importance of 100\% compliance with PREPA's MTRs for the planned 2015 target of 579.4 MW of renewable generation (419.4 MW of PV and 160 MW of wind). In addition, the same study stressed the importance of existing and future renewable generation to provide frequency regulation. From this perspective, it is anticipated that PREPA's MTRs will constantly evolve as the level of renewable penetration increases, modeling tools are improved, and experience with system performance is gained. In this regard, the project funded by DOE's Solar Energy Technologies Program is designed to provide utilities and system operators like PREPA with an opportunity to spur the adoption of and contribute to improve advanced gridfriendly controls of utility-scale PV generation. These goals can be achieved by utilizing data obtained by conducting such tests and demonstrations on a real multi-MW-scale PV power plant.

PREPA's existing MTRs for PV generation already required that utility-scale PV projects should have many grid-friendly controls available, including:

- Low-voltage ride-through and high-voltage ride-through controls

- Voltage regulation controls

- Steady-state and dynamic reactive power controls

- Frequency-fault ride-through

- Frequency response, regulation controls, and ramp-rate controls. 


\section{Description of Tests for AES's Ilumina PV Plant}

PREPA's technical teams from the planning and operations departments indicated that their primary interests are the possibilities, benefits, implementation, and testing of APCs by PV. In particular, the special areas of interest to PREPA include renewable power plant participation in frequency regulation and $\mathrm{AGC}$ and providing fast inertia-like frequency response to arrest rates of grid frequency decline during system contingencies. From this perspective, the APC tests were given the highest priority in this test plan to assist PREPA engineers in their efforts to optimize the integration of large levels of PV generation in Puerto Rico.

\subsection{Background of APC}

Based on the system needs, a PV power plant can provide APC to support reliability in a variety of ways. Generally, the forms of APC use adjustment of current output to aid in the reliability and security of the power grid during certain situations [10]. For adjustment above the present operating point, reserve capacity, also known as head room, is required; for adjustment below, it is not. For example, a generating unit somewhere on the system may have an unplanned outage, causing the generation and load on the system to be out of balance. This contingency disturbance event could be mitigated by PV plant APC adding power to the system if there is PV plant reserve capacity. Similarly, a contingency disturbance event could occur if a large load is disconnected from the system, leaving a surplus of generated power. In this case, PV plant APC could be used to decrease system power. The latter scenario is less common, so generally we focus on the former.

Figure 6 shows the response of a hypothetical conventional generating unit following a large frequency disturbance in the grid caused by another generator trip. This example frequency disturbance is shown in the upper graph of Figure 6. At the very instant of the loss of a large supply of power, this hypothetical synchronous generator will extract kinetic energy from its rotating mass to help slow down the rate of change of frequency (ROCOF) decline and help in maintaining stability (shown by the blue trace in the lower graph of Figure 6). Such natural inertial response from all rotating generators slows down the rate of frequency deviation. Soon after the disturbance, the turbine governor senses the frequency change and provides additional power to replace some of the lost power and arrest the frequency decline (shown by the green trace).

During this dynamic event, the frequency will at some point hit its nadir (the minimum frequency), and as the generation once again meets demand, it will soon stabilize at a new equilibrium point of some off-nominal frequency below $60 \mathrm{~Hz}$. This response is called primary frequency control, and it is used to help in stabilizing the frequency at a steady-state value. Finally, response is needed to return the frequency back to its nominal setting of $60 \mathrm{~Hz}$ and reduce the area control error (ACE), or the difference between scheduled and actual generation. This usually occurs fully within 5 minutes to 15 minutes. This is secondary frequency control, and it is often provided using AGC. The generator AGC response is depicted by the black trace in Figure 6. Overall hypothetical generator action that demonstrates all three responses is shown by the red trace. A similar series of responses occurs during loss-of-load events (i.e., the loss of a large block of load or the loss of a pumped-storage plant during pumping operation). In this case, the electrical frequency increases, and responses by other generators on the grid bring it back down to its nominal setting. 


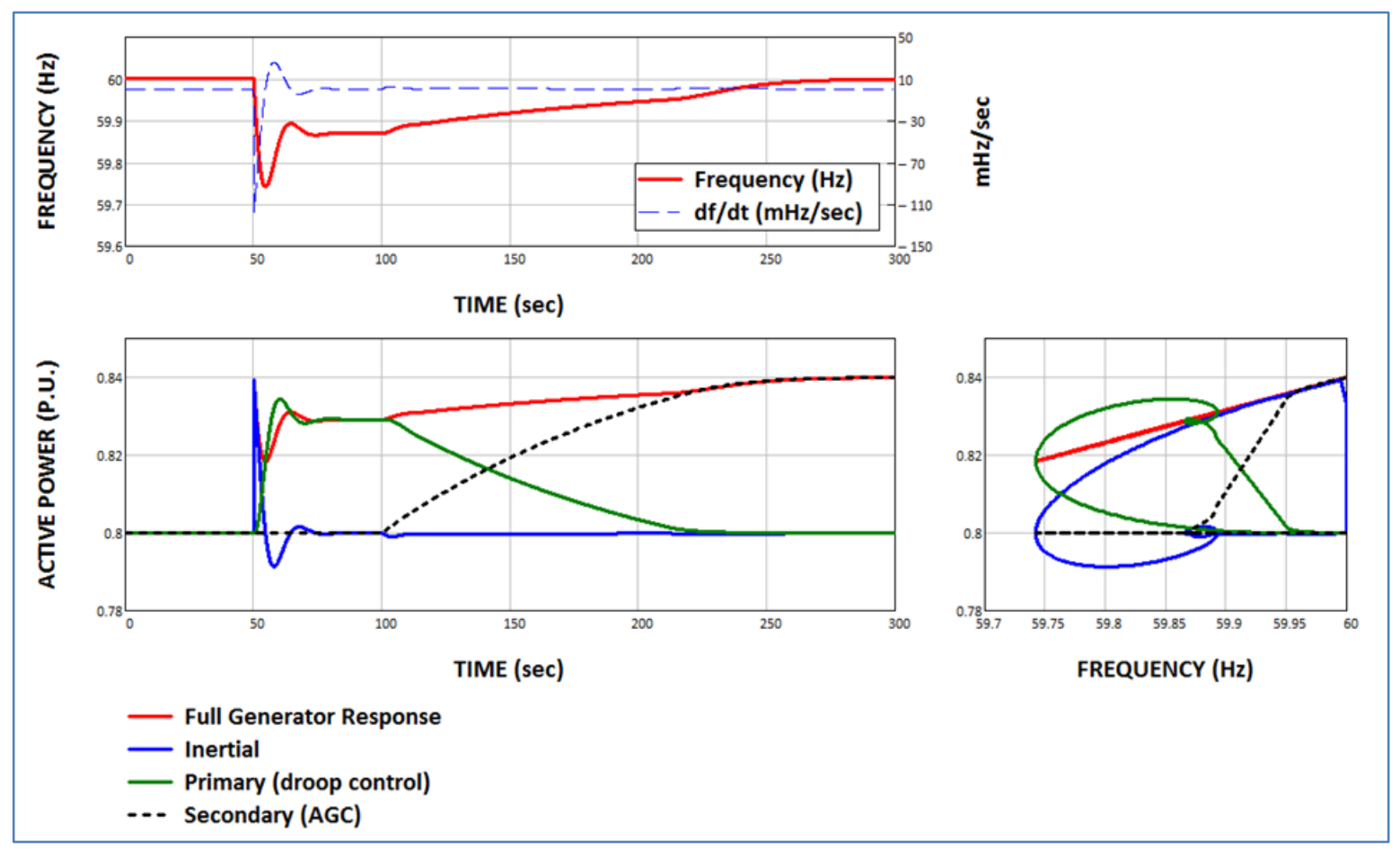

Figure 6. Theoretical frequency response of a conventional generator

The control of active power on the grid is also important to system operators during normal conditions (i.e., when a disturbance has not occurred but normal variations in load and generation are still occurring). The system must maintain the frequency and limit any unscheduled power flow violations at all times. This normal response can happen during different timescales, as shown in Figure 7. Regulation is often provided by generating units that have AGC and that are following signals given directly by the system operator control center to regulate the ACE. Load following is slower and may or may not be automatically scheduled. Regulation corrects the current balancing error; load following follows the anticipated demand.

Although these services are similar to those provided during disturbance events, there are some differences in the type of control needed; therefore, different methods of control might be necessary for each service. The example above shows how a conventional generator would respond. This project is to demonstrate that, with minimal modification and investment, modern inverter-coupled PV generators can respond similarly, that they can be fully capable of providing these various forms of APC and in time frames even faster than conventional generators. 


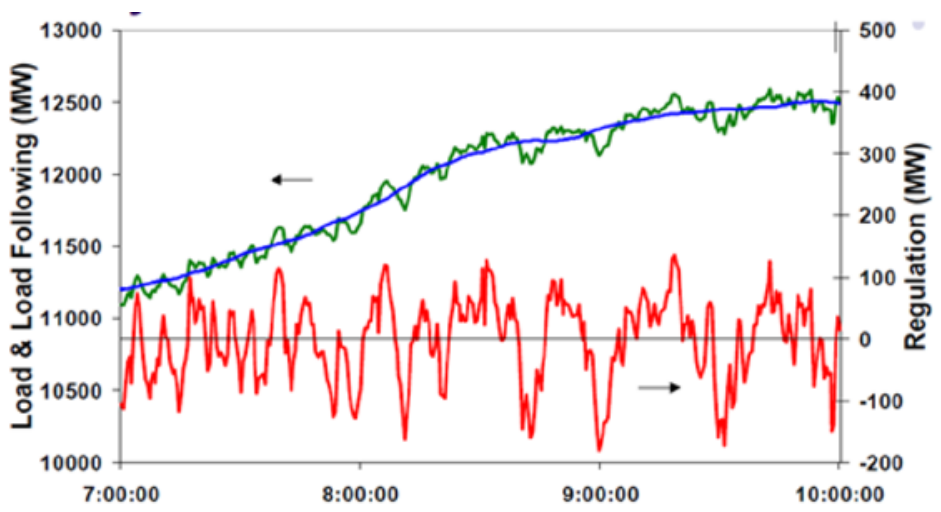

Figure 7. Example of regulation and load following during normal conditions

\subsection{PREPA's PV Frequency Response and Regulation Requirements}

As an isolated island system, PREPA's power system has a lower inertial constant compared to inertial constants of large interconnected power systems, such as on the mainland United States. During peak daytime hours when solar penetration is high and has displaced conventional generation, the available inertia from spinning mass is even lower, because PV generation (unlike wind and conventional generators) does not have any rotating mechanical parts to replace inertia loss. With no mechanical contribution, a PV generation system has a very small time constant, i.e. a fast response to a step change in input on its circuit. This means that PV generators have a significant capability to participate in frequency support and, with additional control loops, to contribute to small-signal stability [11].

A study by Siemens PTI [9] identified PREPA's electric system as particularly sensitive to large frequency excursions because of its inherent low inertia. The same study evaluated the reliability of the PREPA system under large contingencies and concluded that the frequency stability of PREPA's grid can be acceptable if renewable generation meets the MTRs. PREPA's existing MTRs for solar generation requires only the provision of PFR by PV power plants in two different forms:

1. Response with $5 \%$ frequency droop for smaller frequency deviations (less than $0.3 \mathrm{~Hz}$ )

2. Response in the form of $10 \%$ (of rated capacity) of immediate active power change for larger frequency deviations (higher than $0.3 \mathrm{~Hz}$ ). This particular response must be fully deployed within less than 1 second from the time when the frequency deviation exceeds the level of $0.3 \mathrm{~Hz}$.

Frequency droop is the percent change in frequency normalized against the percent change in power output, multiplied by 100 . For example, a $5 \%$ frequency droop response means that a $5 \%$ frequency deviation on the system would result in a $100 \%$ change in power output of the generating unit.

Another form of PV power plants' indirect contribution to frequency stability is ramp-rate control, which is also required by PREPA's MTRs. PV power plants are required to provide both frequency response and ramp-rate control. (The maximum rate of change of power is $10 \%$ of nameplate capacity per minute.) Both controls must be provided simultaneously as long as the 
ramping event does not require the utilization of the frequency-responsive reserve of the PV power plant.

The existing frequency response for PV generation in Puerto Rico is "autonomous" and does not depend on PREPA to provide control signals to adjust the magnitude and speed of the response. A PV PPC is essentially following the actual electrical frequency that is measured by the plant SCADA system. The plant power set point is following the frequency signal all the time except when frequency is within the deadband $( \pm 0.02 \%$ of nominal frequency).

A common interpretation of PREPA's MTRs is that energy storage is required. Because energy storage is currently expensive, especially if necessarily co-located and plant-specific, it was decided to test a number of APC control features for PV power plants that do not require energy storage and can provide potential future benefits to utilities. One such control included operating the plant in curtailed mode with continuous headroom to provide frequency droop response by increasing power output during times when frequency excursions are below nominal.

We explain this concept by using an example frequency event measured by the NREL frequency monitoring system in San Juan, Puerto Rico, on November 23, 2013, as shown in Figure 8. This frequency event was captured by NREL's frequency monitoring system that sampled the voltage in the 120 volt AC wall outlet around Fajardo, Puerto Rico. The NREL monitoring system captures voltage waveforms at a $25 \mathrm{kHz}$ sampling rate, performs Fast Fourier Transform and calculates the electrical frequency of the fundamental voltage component using a $100 \mathrm{~ms}$ window. NREL performed a playback simulation whereby the actual measured frequency experienced in November 2013 was fed to the Ilumina plant controller during its testing in August 2015 to see how the curtailed PV plant would respond.

This particular event was caused by a generator trip in the PREPA grid at approximately 2 a.m., so no PV generation was active during this time; however, this example helps illustrate the response of a PV power plant if it were operating during an event such as this one. The theoretical response to this event from a PV power plant similar in size to the Ilumina PV power plant in accordance with the MTR is shown in Figure 9. This simulated response by PV generation (with no energy storage) was calculated for 1 hour, from 12 p.m. to 1 p.m., on a clear day when the plant was operating in curtailed mode at $18 \mathrm{MW}$ with $2 \mathrm{MW}$ of headroom for upregulation. The plant increased its power output in accordance with 5\% droop when the frequency deviation was outside of the $12-\mathrm{mHz}$ deadband. The plant provided a step increase of power by $10 \%$ of installed capacity when the frequency deviation from normal was greater than $0.3 \mathrm{~Hz}$. The response of the plant to a similar event using the existing controls was measured and documented during the testing activities. 


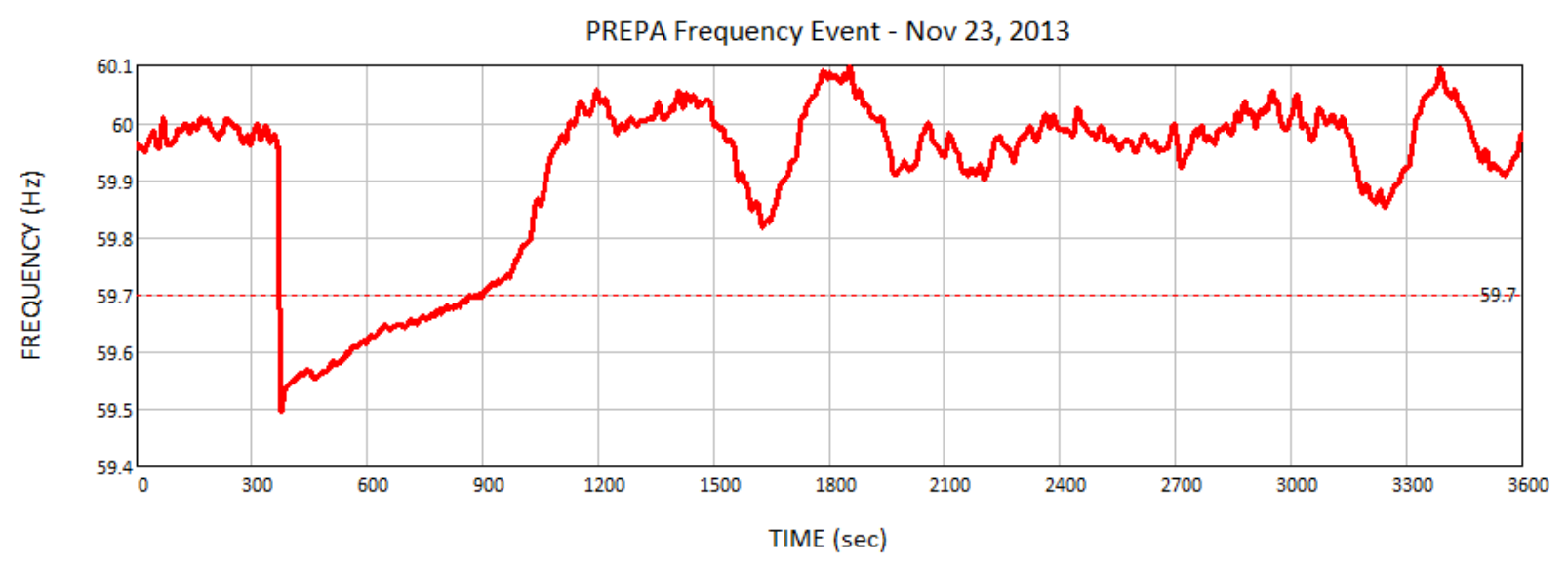

Figure 8. PREPA frequency event on November 23, 2013

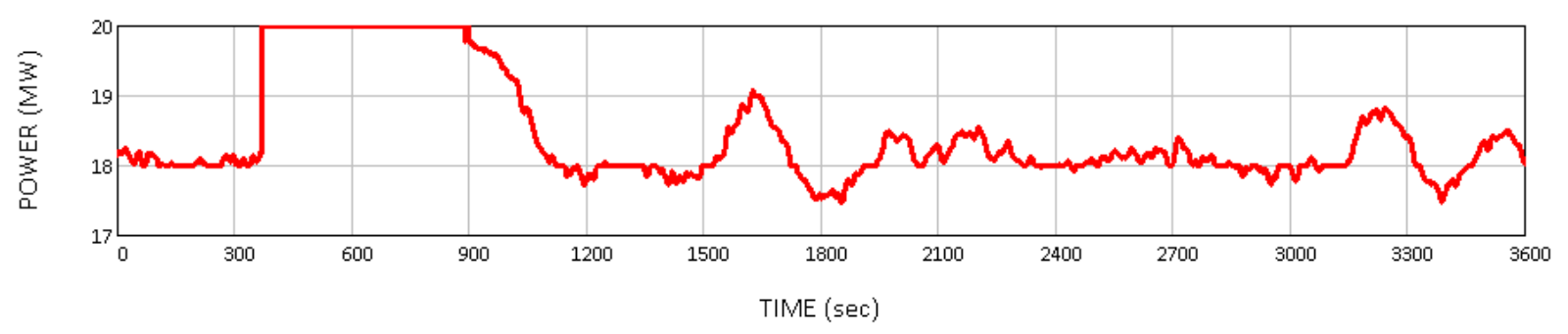

Figure 9. Theoretical response of the llumina PV power plant with up-regulating reserve

To demonstrate this control feature, the plant had to operate in curtailed mode with at least $10 \%$ headroom to be able to provide frequency regulation in both directions in accordance with PREPA's MTRs. (Note that the Ilumina plant was subject to the 2011 version of PREPA's MTRs, which did not require regulation in both directions.) For this purpose, control modifications for the plant PPC were needed to enable curtailed operation and up-regulation. The same demonstration was subsequently conducted for more aggressive droop settings of $3 \%$ and $4 \%$ as well.

The initial ROCOF in the PREPA grid for the same event, shown in Figure 10 as a zoomed-in version of the trace from Figure 8, depended on the level of spinning inertia in PREPA's system. The maximum ROCOF for this event was approximately $30 \mathrm{mHz} / 0.2 \mathrm{~s}$. This ROCOF is an important characteristic that impacts the lowest frequency (frequency nadir $=59.5 \mathrm{~Hz}$ ) that was achieved approximately 7 seconds after the beginning of the event.

The other two important characteristics that impact the minimum frequency are the amount of PFR headroom, droop, and response speed of the PFR. The ROCOF is expected to grow with increasing penetrations of inverter-coupled generation because of the reduced mechanical inertia; thus, it may potentially impact the value of minimum frequency during contingency events similar to the one shown in Figure 10. In this project, we proposed testing a new fast frequency response (FFR) control feature for PV power plants that allows ROCOF reduction to minimize the risk of under-frequency load shedding (UFLS) at high levels of PV penetration. 

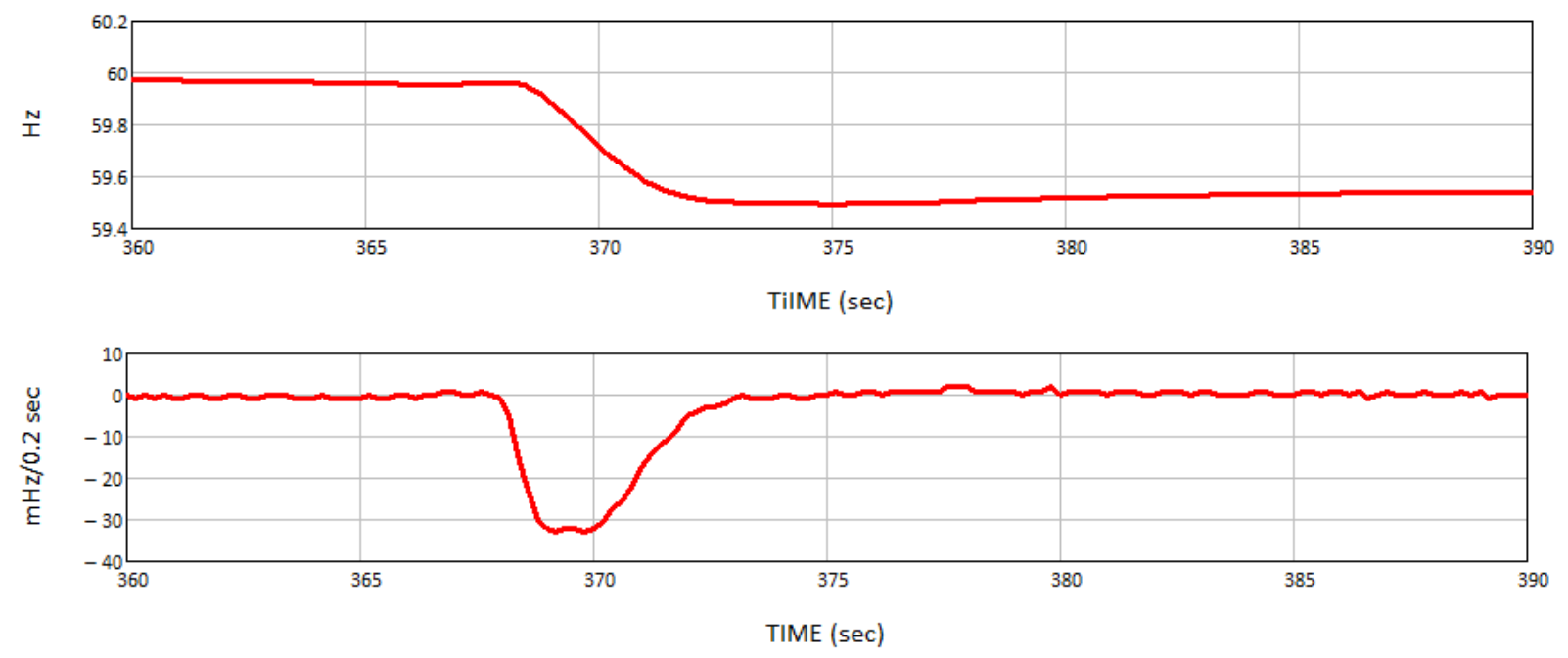

Figure 10. Initial frequency decline and ROCOF

The FFR is intended to supplement the inherent inertial response from synchronous machines and synthetic inertial response from inverter-coupled wind generation. One ERCOT analysis suggests that under certain conditions, the impact of 1 MW of FFR on the overall system frequency response is equivalent to $2.35 \mathrm{MW}$ of PFR [12]. The FFR by PV power plants cannot completely replace inertia. Inertia is provided by rotating mass that is synchronized to the frequency of the power system, and thus is instantaneous in response. Any equipment that detects frequency of the system before responding through a closed loop control is not instantaneous, so is not exactly inertia. The rotational mass of the rotors in wind turbines can synthesize inertial response. But because PV power plants do not have any rotating mass, FFR will only reduce the ROCOF and increase time to the frequency nadir to allow sufficient time for the PFR to deploy, as opposed to affecting the initial ROCOF.

FFR is a response that needs to be deployed automatically and provide a full response as fast as possible after the frequency drops below a preset threshold, e.g., within 0.5 second, according to the proposed FFR requirement in ERCOT's ancillary service market design [13].

The anticipated benefit of FFR control by generators under certain scenarios is shown in Figure 11 using a modeling example for a hypothetical single-area power system. The smoothed-out frequency response of the system (upper graph in Figure 11) to a large generator trip was modeled with remaining generators providing 3\% and 5\% droop response utilizing fast and slow governor controls and also for a case when a generator was providing FFR. The active power increase of a single generator for all control cases is shown in the lower graph of Figure 11. The FFR controls fully deployed the generator's reserve to compensate for a generation loss approximately 5 seconds after the start of the event (a 2-second communication delay in triggering the FFR was introduced), and they kept it sustained until the frequency was restored to its pre-fault level. In this simple example, utilization of FFR resulted in improved frequency nadir compared to $5 \%$ cases, and rapid recovery compared to all droop-only controls. The FFR performance in terms of frequency nadir can be further improved by reducing the communication delay. (In this example it was assumed that the value of exact generation loss was dispatched as a FFR set point, and load did not change during recovery). 


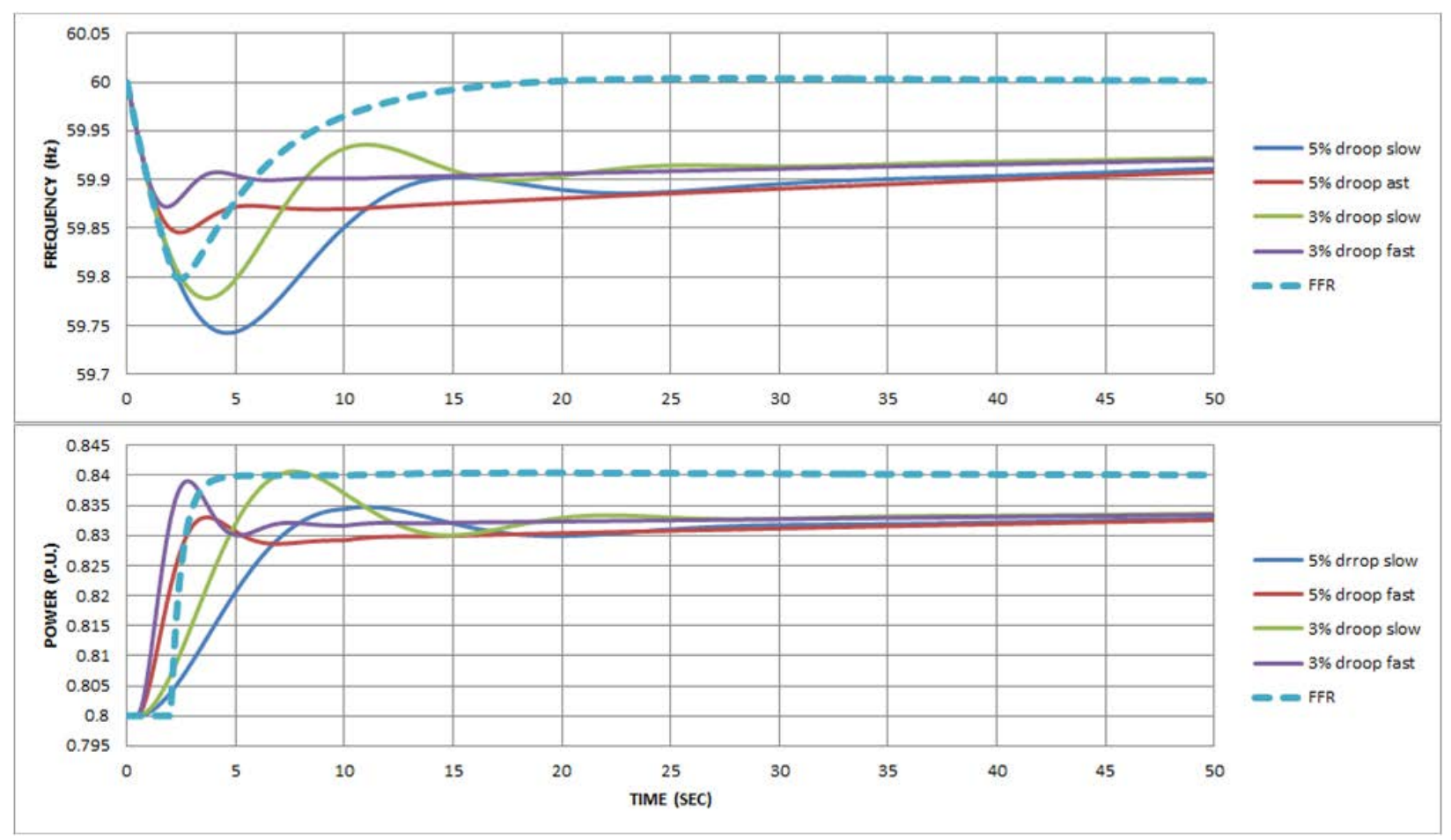

Figure 11. Comparison of the impacts of FFR and droop control on frequency response

During periods of low inertia, the absence of FFR may require much higher capacity of PFR to arrest the fast frequency decline during a contingency event. A concept similar to FFR has been adopted by ERCOT in their design efforts of a future ancillary services market [13]. For this project, we proposed conducting FFR tests on the Ilumina PV power plant. For this purpose, the plant controller needed to be set to deploy available reserve within 0.5 second (or faster) for at least 20 seconds during frequency events similar to the one shown in Figure 8. After completing FFR, the plant controller would return to normal operation. The benefit of FFR testing was to demonstrate the capability of a PV power plant to arrest the rate of frequency decline during contingencies. See Figure 17 and Figure 18 below for more information on the PPC's interface with PREPA and the Ilumina's inverters.

Please note that FFR is not a required service in Puerto Rico, and these tests were hypothetical. The test can theoretically be performed at any frequency level and threshold specified. Then, when the system frequency goes below that threshold, the FFR service should deploy all the reserve until the system frequency is recovered.

Another new APC test proposed under this project was to demonstrate a PV power plant's contribution to AGC. The objective of PREPA's AGC is to balance load and generation in real time to minimize the ACE. A number of studies have shown the feasibility of PV to participate in AGC (for an example, see [14]). Also, the evaluation of the long-term dynamic performance of PREPA's power system at different levels of renewable generation penetration was studied by Siemens PTI in [9]. According to Siemens's work, PREPA's conventional generation can respond in the multi-minute range to sudden changes in renewable generation with adequate secondary reserve from thermal plants and hydro generation. Implementing a solar and wind 
generation forecasting system will further benefit the economics of frequency regulation. PV power plants can also play a role in frequency regulation and contribute to AGC if they are operated with reserve headroom for up-regulation.

An example 2-day output profile of the Ilumina plant is shown in Figure 12 for August 2014 (5minute data). Also shown is the hypothetical curtailed operation with $10 \%$ headroom that allows the plant to respond to the scaled AGC signal from PREPA and provide up- and down-regulation even during morning and afternoon solar ramps.

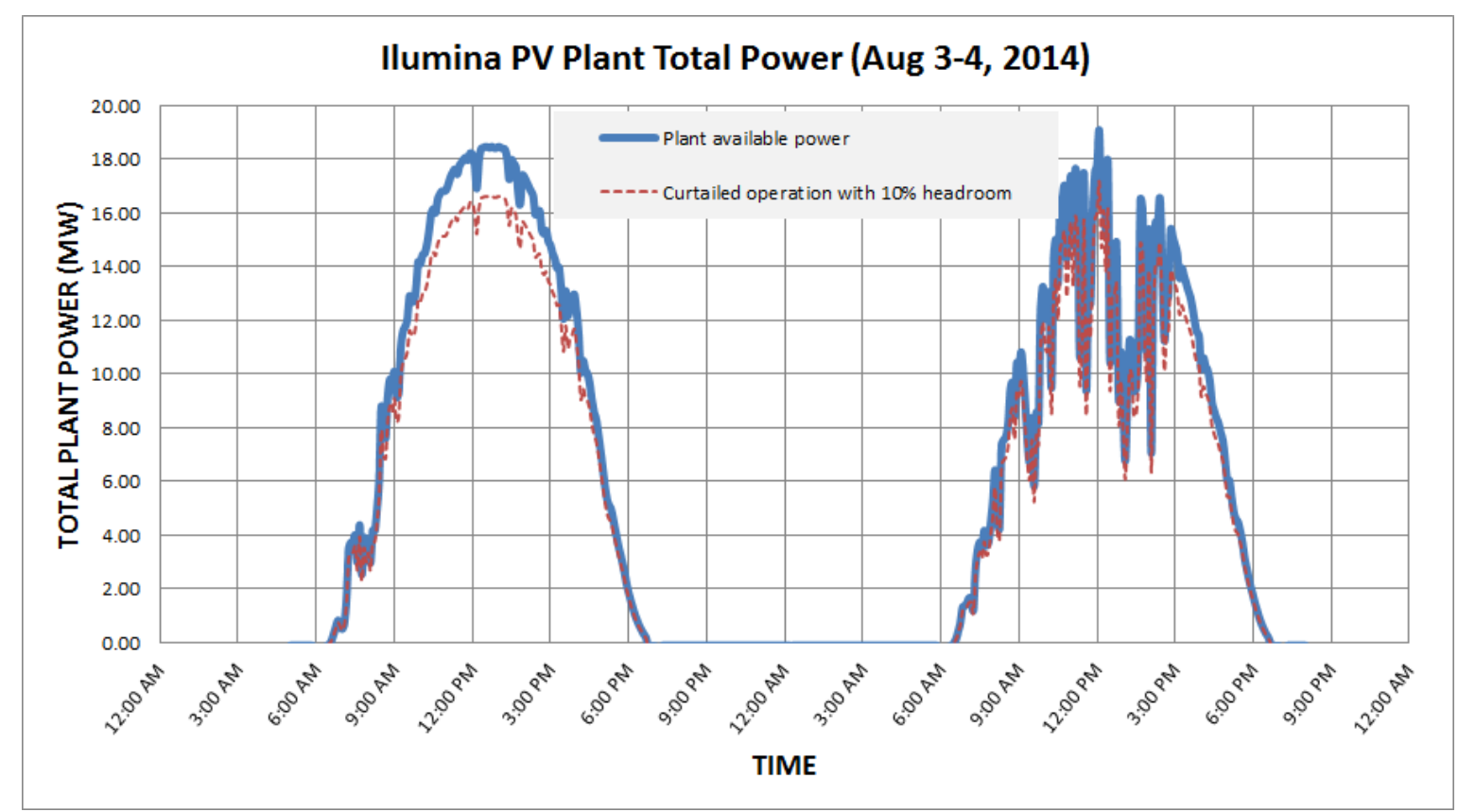

Figure 12. llumina PV power plant operation with reserve

In 2015, for purposes of this testing, PREPA agreed to provide its AGC signal to the Ilumina PPC during a 1- or 2-week time period. The benefits of AGC tests include providing PREPA with data showing how PV generation (without energy storage) can provide secondary regulating reserve to be deployed following a disturbance caused by either solar ramping events or a fault on the power system. Such control by PV can contribute to better frequency stability in the future and will probably help avoid large frequency deviations during steady-state operations similar to the recorded frequency time series shown in Figure 13. 


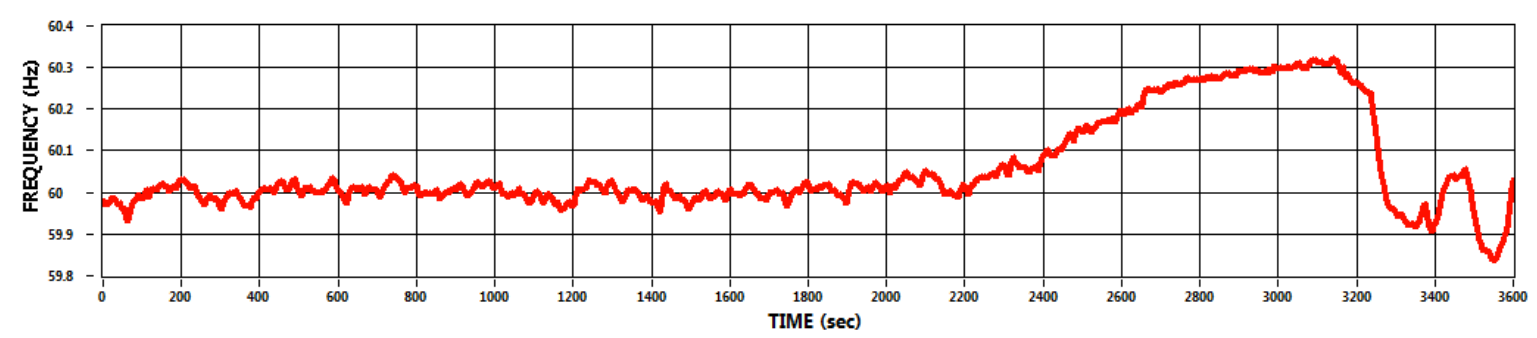

Nov 24, 2013 (7-8am)

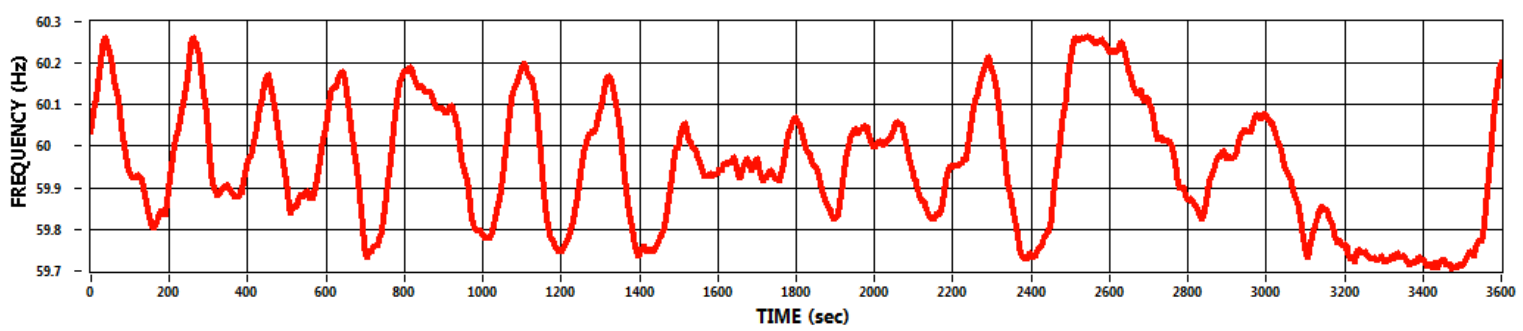

Nov 24, 2013 (8-9am)

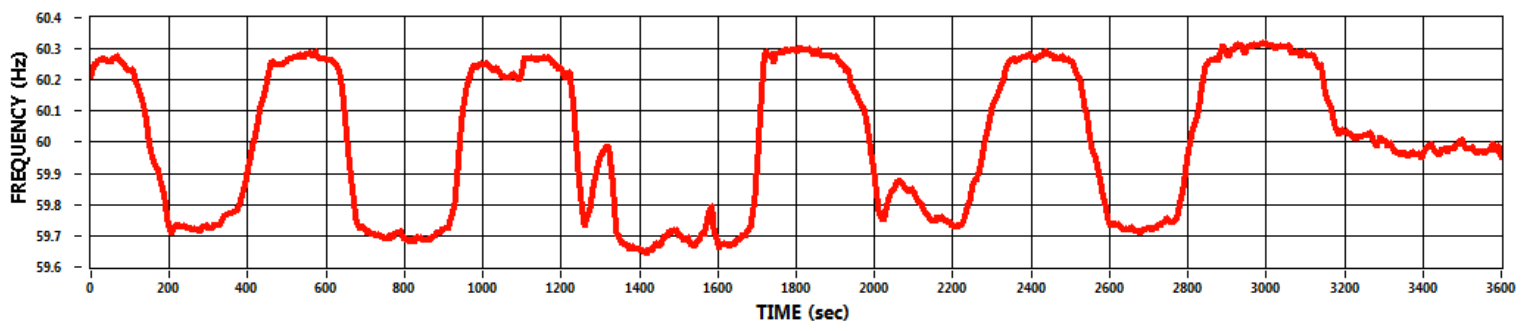

Figure 13. Examples of PREPA 1-hour frequency time series measured in November 2013

\subsection{Voltage Control Tests}

PREPA's MTRs require PV power plants to provide the point of interconnection (POI) voltage control capability by applying a closed-loop voltage regulation system that is equivalent to automatic voltage regulators of synchronous generators. The voltage regulation system must operate only in voltage control mode with reactive droop compensation. Part of PREPA's requirements for Ilumina was to install a digital signal monitoring system, which records values periodically as well as detailed (millisecond) granularity for transient events. This functionality was tested during plant commissioning, and it was not included in the scope of tests under this project.

\subsection{Fault Ride-Through Performance Testing}

PREPA's MTRs require low-voltage ride-through and high-voltage ride-through capability from PV power plants, as shown below in Table 1. The Ilumina plant has power quality fault recorder hardware that captures the transient events; however, these events do not happen very often on the PREPA system, so it was possible that they would not be available for this demonstration test. In a system this big, frequency and voltage are not that closely related. An event may happen from a reclosure action somewhere on the system, but, because of the high amount of 
impedance to this plant, which is far from the largest load concentration, it is rare for the plant to need to utilize its ride-through capability.

The voltage fault ride-through performance of the Ilumina plant was recorded when such events happened on the PREPA grid during the test period. Controlled fault tests are possible, but a special fault-emulating apparatus is required to create such fault conditions on the plant terminals, and these tests were not included in this project. 


\section{Description of AES'S llumina PV Power Plant}

AES's 20-MW Ilumina PV power plant is located in Guayama, Puerto Rico, and has been operating commercially since 2012 . An aerial photo of the plant is shown in Figure 14. Forty inverters (rated for $500 \mathrm{kWac}$ ) from Green Power Technologies Corporation (GPTech) were incorporated in 20 integrated arrangements of $1 \mathrm{MW}$, as shown in the single-line diagram of the plant depicted in Figure 15. The technical specifications for GPTech's PV500 inverters are shown in Appendix A. The plant AC collector system is rated for $13.2 \mathrm{kV}$ and designed in a twoloop configuration for additional reliability. The plant is connected to the PREPA grid at the POI via a 20-MVA step-up 13.2/38-kV transformer. This transformer, which has fans installed on it, is rated 20 MVA for $13.2 \mathrm{kV}$ with natural air cooling and 26.7 MVA with forced air cooling. Due to the installed modules and inverters, the plant rarely reaches/exceeds an apparent power of $20 \mathrm{MVA}$ at the main transformer. A photo of the plant substation, PV panels, and inverter enclosures is shown in Figure 16.

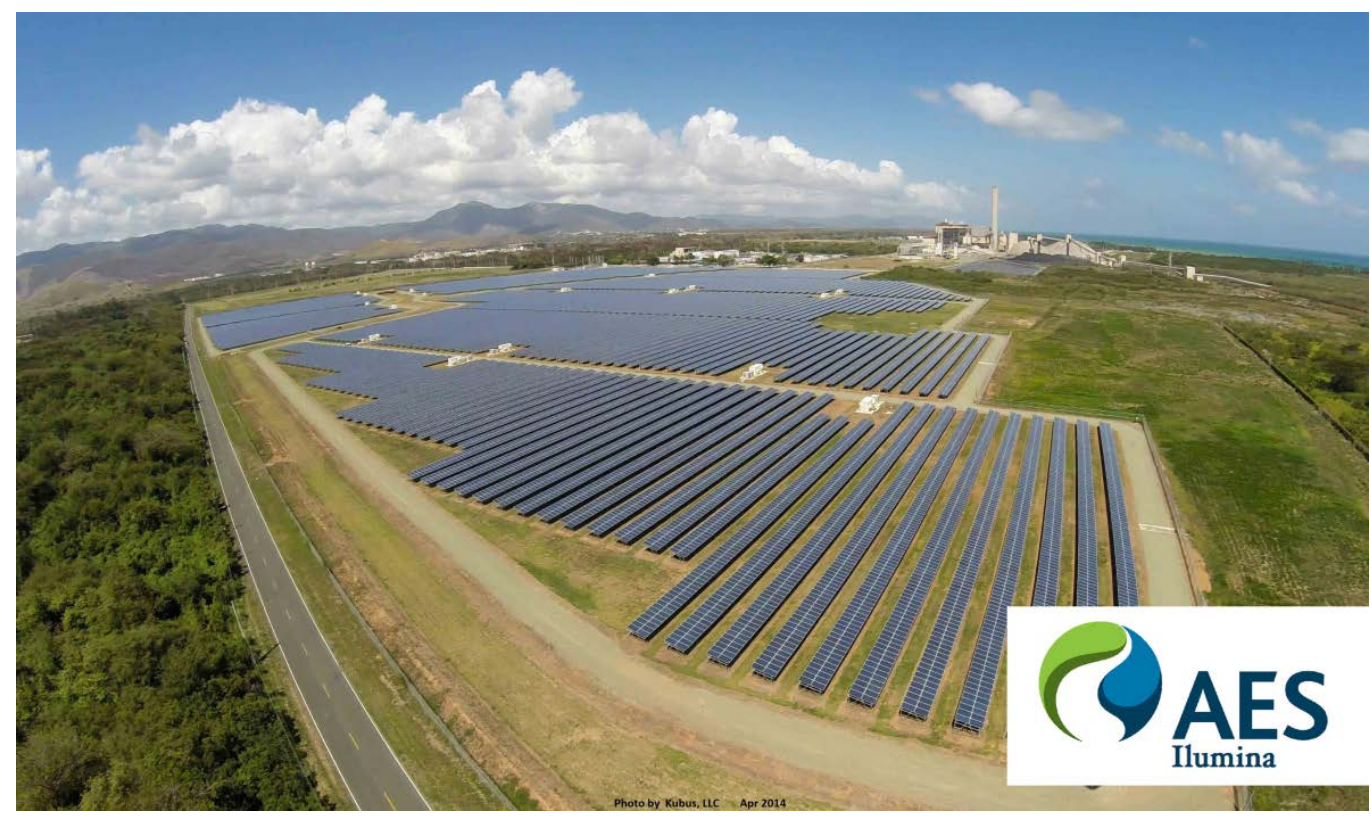

Figure 14. Aerial view of the llumina PV power plant. Image from AES 


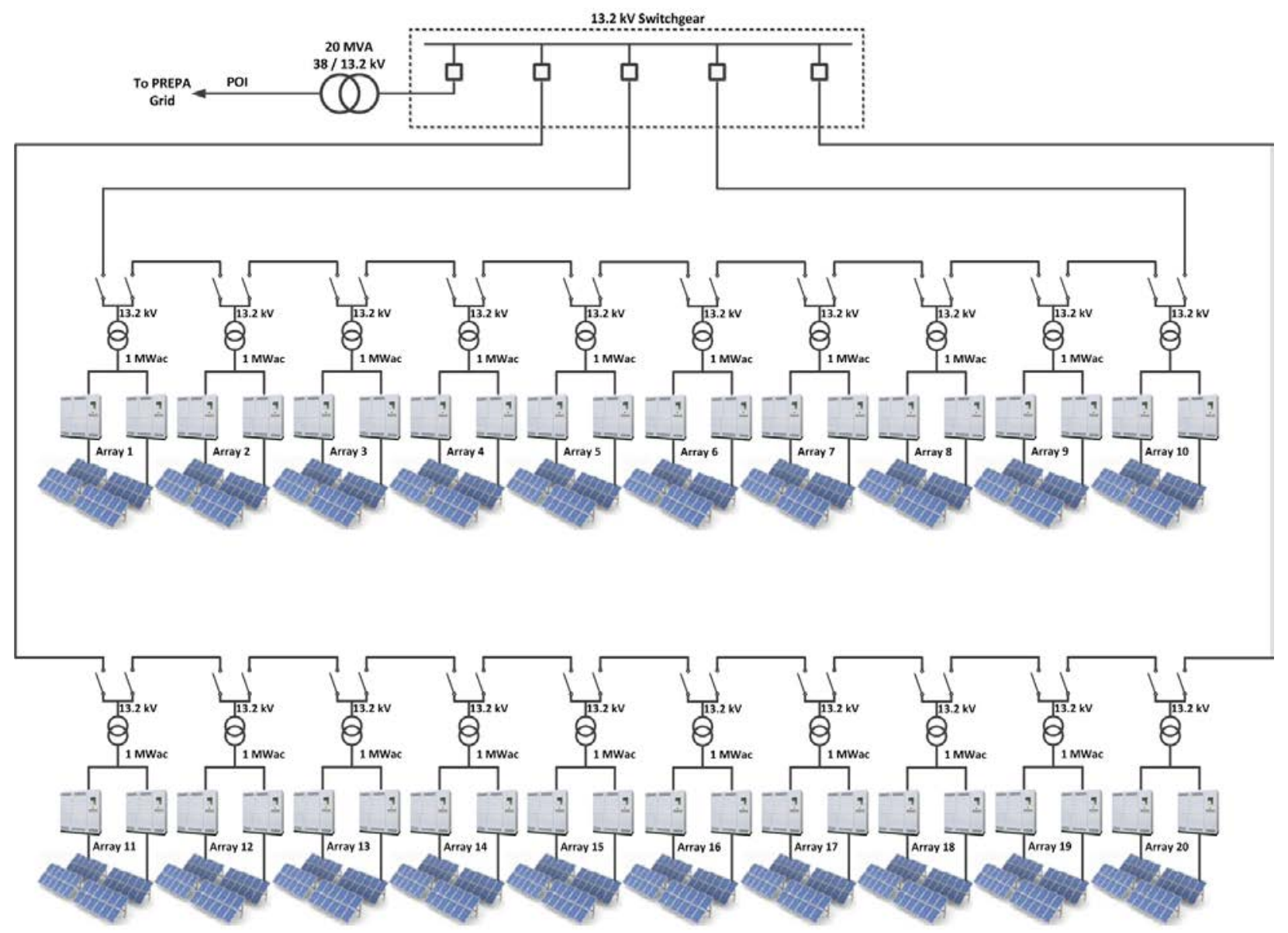

Figure 15. Single-line diagram of llumina's 20-MVA utility interconnection 

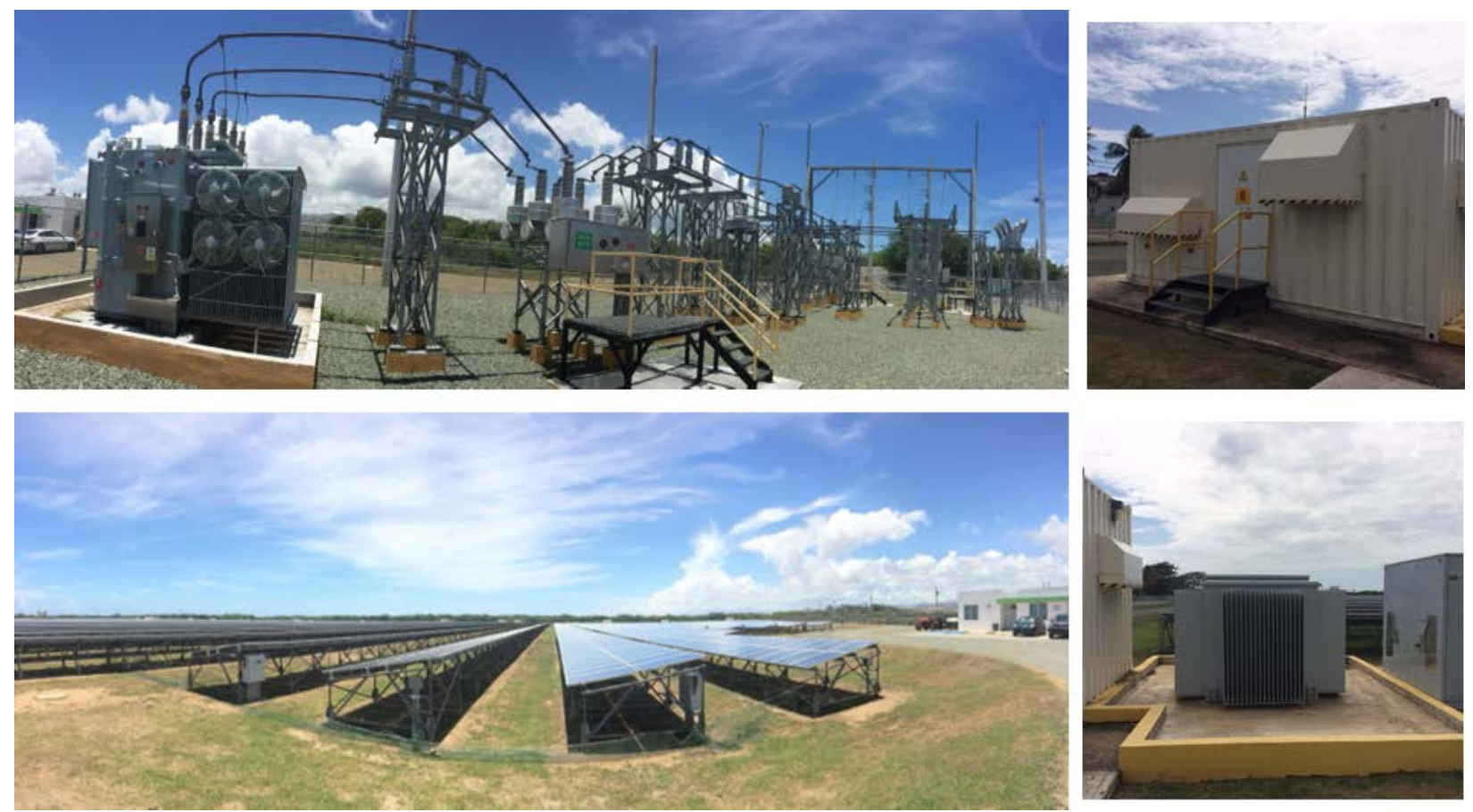

Figure 16. Photos of llumina PV power plant substation and PV array. Image from NREL

A PPC was implemented by GPTech to meet the technical requirements of PREPA. A general diagram of GPTech's plant controller architecture is shown in Figure 17. The PPC has several control functionalities that made it applicable for the purposes of this project. The plant is capable of providing both voltage and frequency regulation.

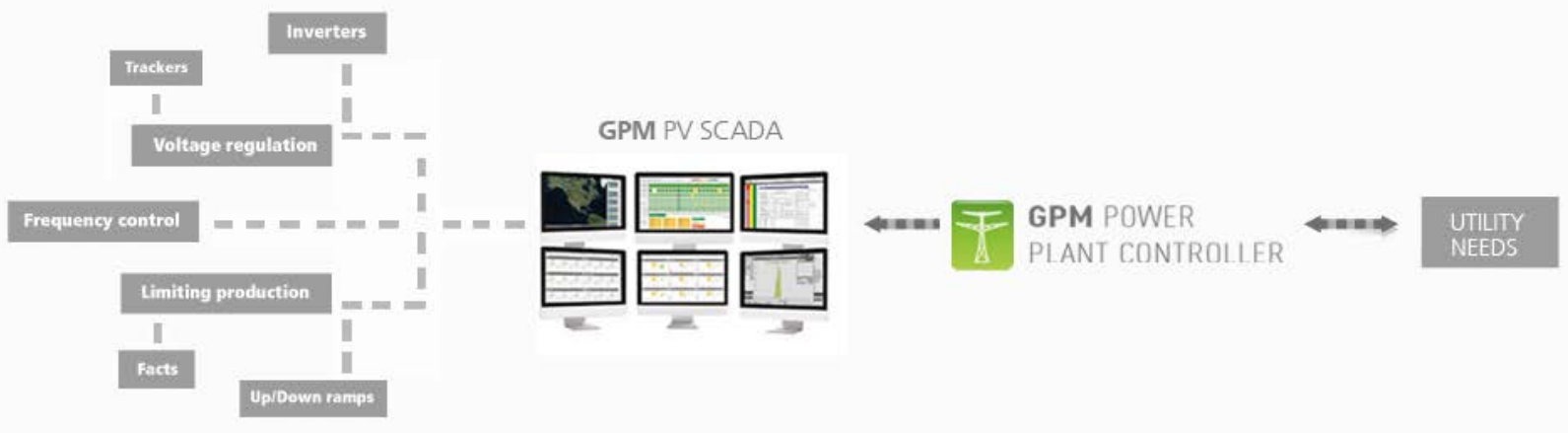

Figure 17. General diagram of a GPTech's PPC

The voltage regulation system is based on the reactive capabilities of the inverters using a closed-loop control equivalent to automatic voltage regulators in conventional generators. Through the SCADA human-machine interface, the plant control system can be set to operate in one of the three modes of automatic voltage regulation: voltage regulation, power factor regulation, or reactive power control. 
The plant is capable of providing various forms of APC. PFR provides change in total plant active power proportional to grid frequency deviations from the scheduled frequency (similar to governor response in synchronous generators). Prior to these tests, only down-regulation to respond to over-frequency was enabled in the PPC. The PPC also has a ramp-rate control feature that is required for a smooth transition from one power output level to another. This PV power plant is able to control the rate of power output change during some circumstances, including:

- Rate of increase of solar power because of irradiance

- Rate of increase of power when an external curtailment of the plant's power output is released

- Rate of decrease in power when an external curtailment limit by the plant is engaged.

This ramp-rate control is independent of meteorological conditions.

The plant is equipped with several medium-voltage (MV) electrical measurements and metering devices on each pair of inverters, each collector loop, and the main plant circuit breaker. PREPA has its own metering equipment in addition to the equipment used by AES. The plant controller implements plant-level logic and closed-loop control schemes with real-time commands to the inverters to achieve fast and reliable regulation. The commands and set points to the plant controller can be provided through the SCADA human-machine interface (HMI) or even through other interface equipment, such as a substation remote terminal unit (RTU). The plant communications system combines a number of real-time protocols for plant control, data collection, monitoring, and visualization (see Figure 18). Communications with PREPA's energy management system is carried out using transmission control protocol and Internet protocol (TCP/IP) via a protected virtual local area network (VLAN). 


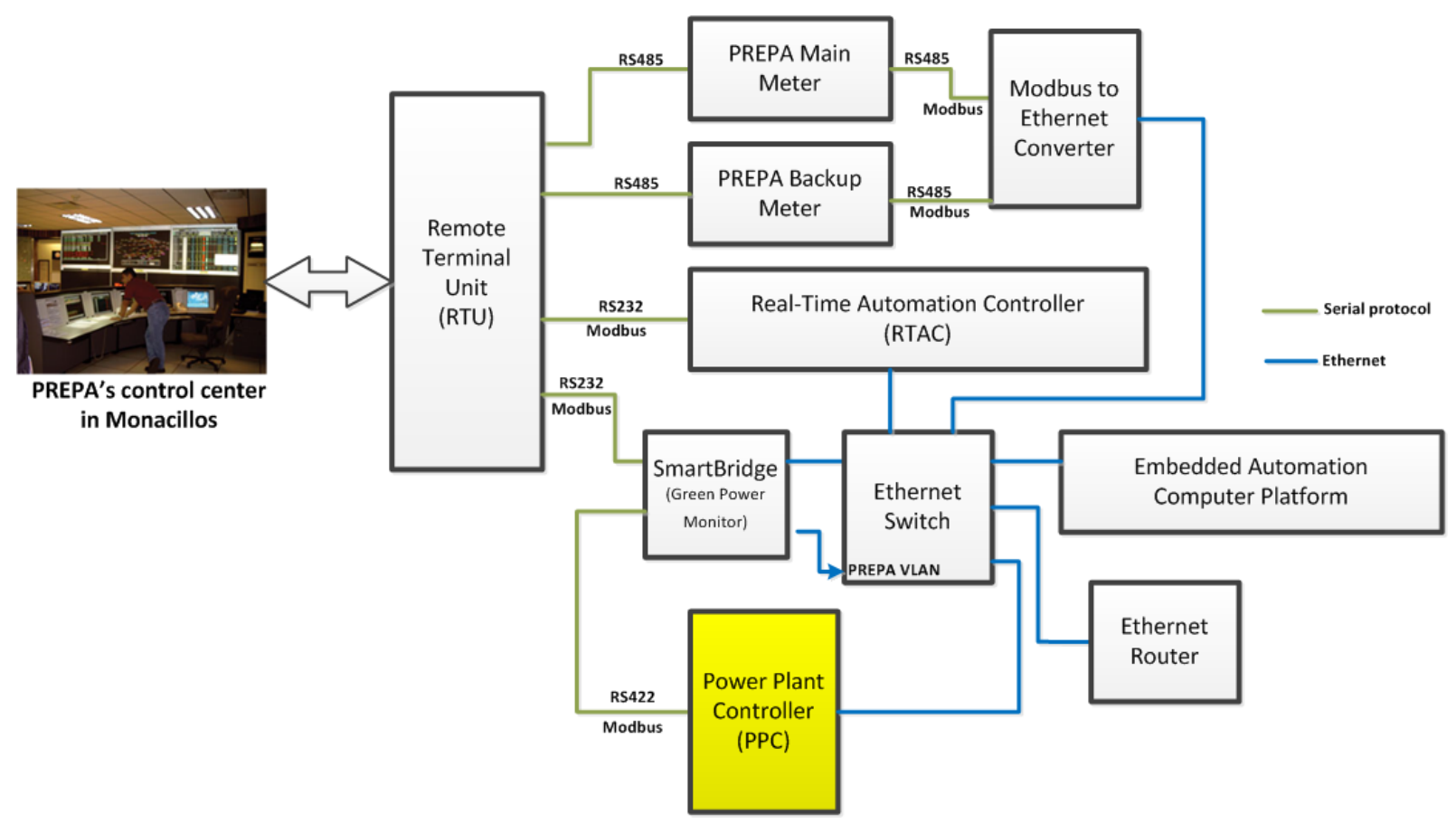

Figure 18. Diagram of the llumina PV power plant's remote terminal unit communications

The structure of the interface between Ilumina PPC and PREPA is shown in Figure 19. The GPTech document describing the algorithm for calculating the available plant capability with respect to frequency response and ramp rates is shown in Appendix B. The GPTech table describing the interface signals is shown in Appendix C. In particular, the data channel named "AES CURTSP MW" from PREPA can be used to set the reference plant power for the purposes of AGC testing. PPC communicates with inverters via SmartBridge every 500 milliseconds.

Issues that needed to be addressed in the demonstration project process included communications protocol compatibility and proper scaling for set point signals. It was clear that dialogue and interaction between the plant operator and the system operator is an important component of implementation of APC capabilities. For example, an issue arose about how to get a precise enough set point to the plant because Schweitzer, the manufacturer of the real-time automatic controller unit, was not involved in this demonstration test and neither PREPA nor AES wanted to risk liability for modifying that unit's programming. Ultimately, PREPA designed a workaround using the remote terminal unit and SmartBridge, but it should be noted that modifying programming logic may be necessary at multiple places in the chain of communications when enabling APC capabilities. 


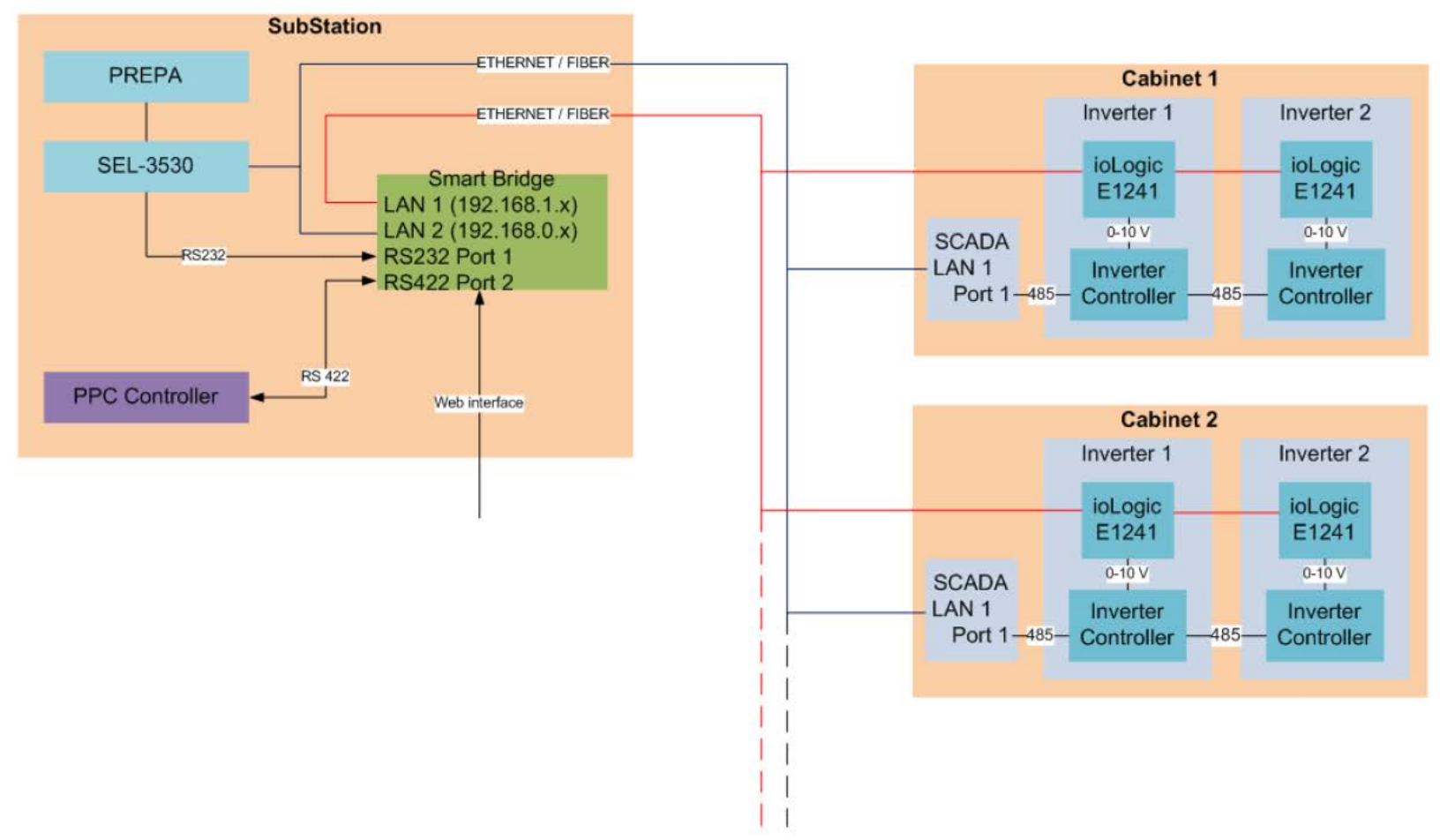

Figure 19. AES's Ilumina-PREPA interface description

It is important to note that AES's Ilumina PV power plant complies with a modified version of PREPA's MTRs (2011). According to the MTRs, the plant has to provide low-voltage ridethrough, high-voltage ride-through, and frequency-fault ride-through in accordance with parameters shown in Table 1.

Table 1. llumina's MTR Requirements

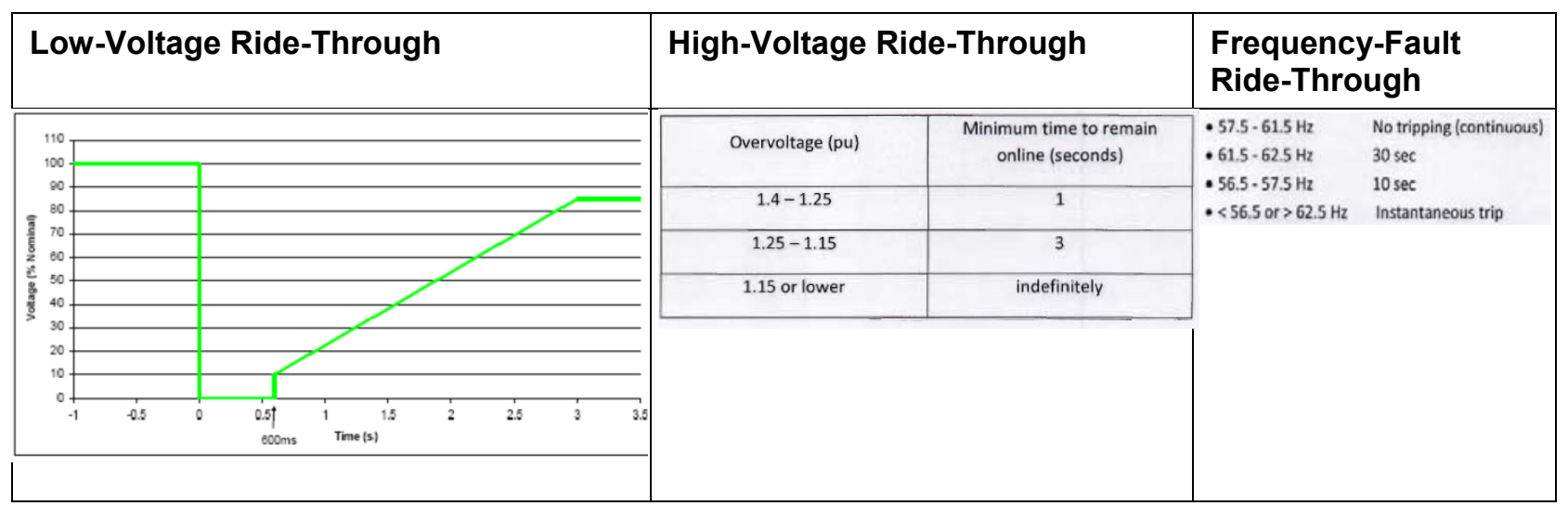

In addition, the plant is supposed to provide dynamic voltage regulation utilizing $0-10 \%$ voltage droop factor with a set point range of $95 \%-105 \%$ of nominal and power factor control within $0.85 /+0.85$ range. The plant has to provide $5 \%$ frequency droop control for down-regulation only and ramp rate control (20\% operating capacity/minute). 
The Ilumina plant has installed pyranometers: pieces of equipment used to measure solar irradiance as well as solar radiation flux density. The plant's PPC has the function of estimating the available peak plant power utilizing those solar irradiance measurements (Figure 20). The plant is divided into five control sectors with individual pyranometers located in each sector. The available power in each sector is estimated by the controller using the following equation:

$$
P_{\text {sector }}=\operatorname{Irr} \times W \text { eight } t_{\text {sector }} \times\left(\frac{N_{\text {available }}}{N_{\text {total }}}\right) \times \text { Scale }+ \text { offset }
$$

Where Irr is the measured solar irradiance (Watt $/ \mathrm{m} 2)$; Weight sector $_{\text {is }}$ the weight of the sector compared to the plant capacity; $N_{\text {available }}$ and $N_{\text {total }}$ are the number of available and total number of inverters, respectively; and Scale and $O f f$ set are unit conversion factors.
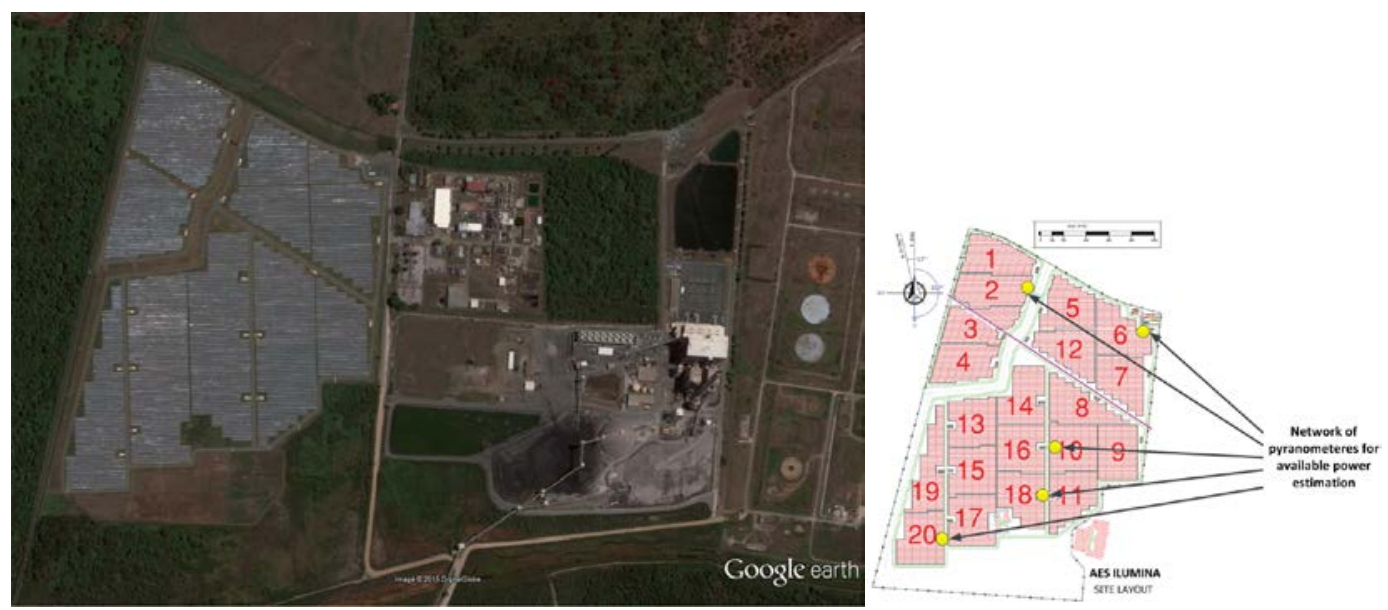

Figure 20. Layout of the Ilumina PV power plant. Images from (left) Google earth and (right) AES

The estimated total available peak plant power is then calculated every 0.5 second as

$$
P_{\text {plant }}=\sum_{k=1}^{5} P_{\text {sector }, k}
$$

This method of calculating peak plant power is based only on irradiance and does not include other parameters that may significantly impact the accuracy of the estimation. In particular, the effect of panel temperatures on plant efficiency is not considered by this method. Other parameters, such as inverter efficiency variations at different load levels, are also important for accurately estimating available power. In addition, dust accumulation on panels caused by various external factors (e.g., nearby traffic and other industrial activities) will also impact the accuracy of the method used to estimate Ilumina's available power. The PPC estimation of available plant power was relatively simplistic for purposes of these tests and hypothetically could be refined to consider the nonlinear factors mentioned above if necessary.

As a result of GPTech's controller software upgrades, the following new control functions for AES's Ilumina PV power plant's PPC were developed, uploaded, and commissioned during June and July 2015. 


\subsection{Plant Participation in AGC}

The purpose of this control is to enable the power plant to follow the active power set point sent by PREPA's AGC system. The set point signal is received by PREPA's RTU in the plant substation and then scaled and routed to the PPC via real-time automation controller (RTAC) and SmartBridge, as shown in Figure 18. In the same time frame, the values of both plant actual power and available peak power are calculated in accordance with equation (2) and are sent back to PREPA's AGC system. For purposes of these tests, when in AGC mode, the PPC initially set the plant to operate at a power level that was $10 \%$ lower than the estimated available peak power to have headroom for following the up-regulation AGC signal (see example in Figure 21). The lower boundary of AGC operation can be set at any level below available peak power, including full curtailment if necessary. After testing AGC with $10 \%$ curtailment, NREL experimented with $20 \%$ and $40 \%$ curtailment. Even lower levels of operation and full curtailment were never tested to reduce the impact on plant revenues, and the cost of the demonstration test.

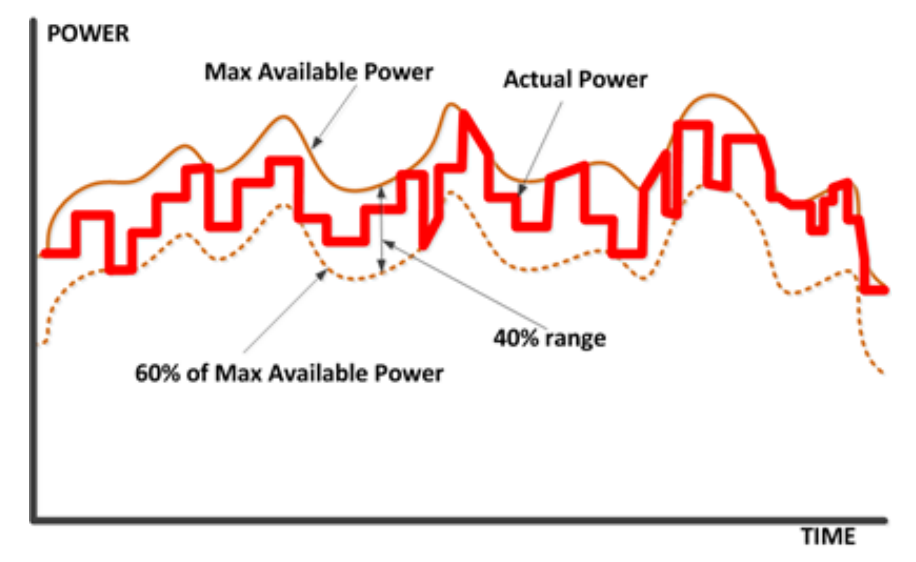

Figure 21. Concept of AGC following by PV power plant

PREPA's AGC was set to send a direct set point signal in the range of 1-20 MW with the step change of $0.5 \mathrm{MW}$. Thus, a 500-kW AGC set point resolution was achieved on this $20-\mathrm{MW}$ PV power plant. PREPA defined the plant in its AGC database by masking it under the identifier of another conventional unit. All ramp-rate settings in the PV power plant PPC were supposed to be disabled during AGC tests.

AGC control logic for a single-area power system with no interconnections (such as PREPA) is based on determining the:

- Island's total desired generation

- Base points for each AGC participating unit

- Regulation obligation for each AGC participating unit.

$\mathrm{ACE}$ is an important factor used in AGC control. For an island system, $\mathrm{ACE}$ is determined as:

$$
A C E=-10 B\left(f_{a}-f_{s}\right)+I_{M E}+I_{T}
$$


Where $B$ is the frequency bias $(\mathrm{MW} / 0.1 \mathrm{~Hz}) ; f_{a}$ and $f_{s}$ are the actual measured and scheduled $(60-\mathrm{Hz})$ frequencies, respectively; and $I_{M E}$ and $I_{T}$ are the meter error correction and time error correction factors, respectively (MW). The $A C E$ value is then used by the AGC control logic to determine the total desired generation that will drive it to zero. The desired generation for each participating generating unit is split into two components: the base point and regulation. The base point for each generating unit is set at its economic dispatch point, and the island's total regulation is calculated as the difference between the total desired generation and the sum of the base points for all AGC participating units. The total regulation for the whole system is allocated among all participating regulating units. Ilumina is considered one plant-level generating unit, and individual inverter outputs are not considered by PREPA's operations. Various unit-specific parameters are used in its regulation allocation, such as ramp rates and operating limits. Figure 22 shows a snapshot of the portion of PREPA's AGC control display when a 19-MW set point was sent to the AES Ilumina's RTU.

Normally, AGC monitors the performance of each unit. A generating unit will continue receiving AGC set points as long as it is following the commanded set point. If the unit does not respond to AGC or moves away by itself, then a control error will be generated and the unit's AGC participation will be blocked.

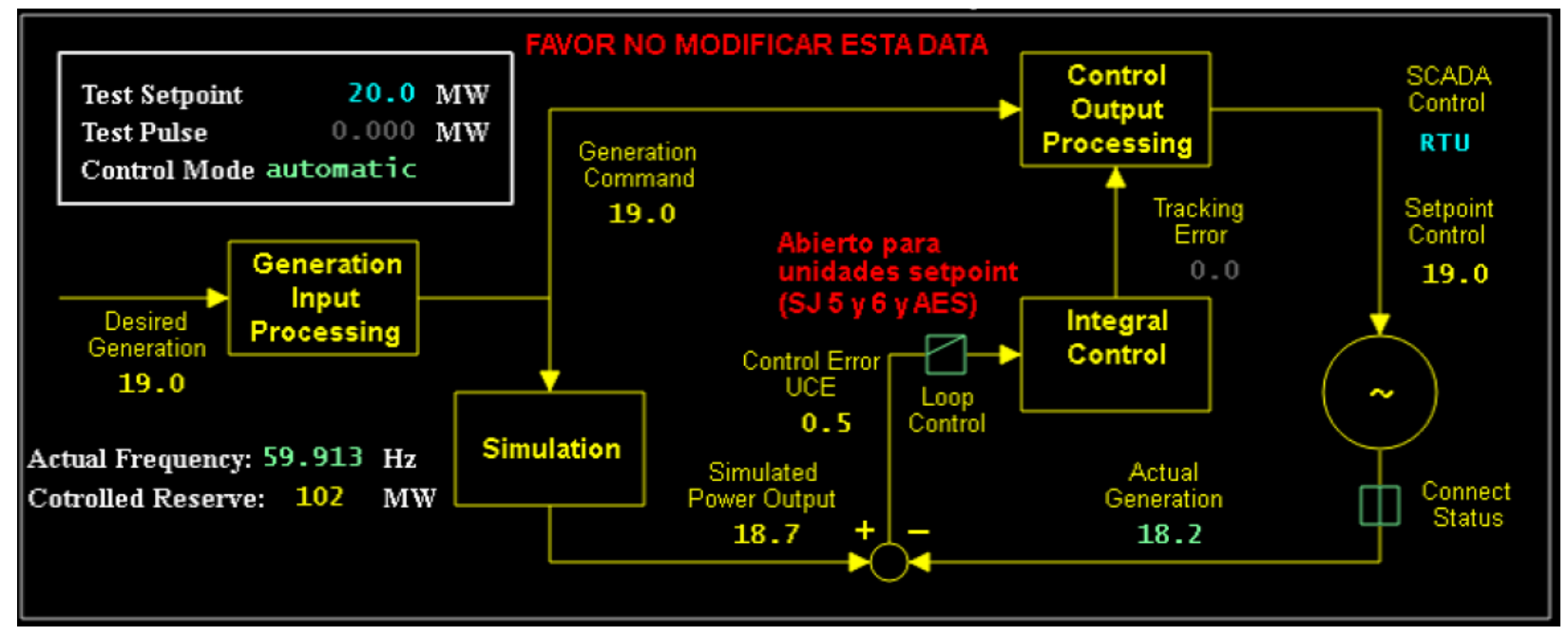

Figure 22. Diagram of PREPA's unit control. Image from PREPA

\subsection{Frequency Droop Control}

The definition of implemented droop control for PV is the same as that for conventional generators:

$$
\frac{1}{\text { Droop }}=\frac{\Delta P / P_{\text {rated }}}{\Delta f / 60 H z}
$$

Plant rated power $(20 \mathrm{MW})$ is used in equation (4) for the droop setting calculations. For the purposes of the droop test, the plant was set to operate at a curtailed power level that was $10 \%$ lower than the available estimated peak power. The PPC was programmed to change the power output of the plant in accordance with a symmetric droop characteristic, shown in Figure 23 at both $5 \%$ and $3 \%$ droop value. The upper limit of the droop curve was the available plant power, 
and the lower limit was at a level that was $20 \%$ below the then-available peak power. The implemented droop curve also had a $\pm 12-\mathrm{mHz}$ frequency deadband.

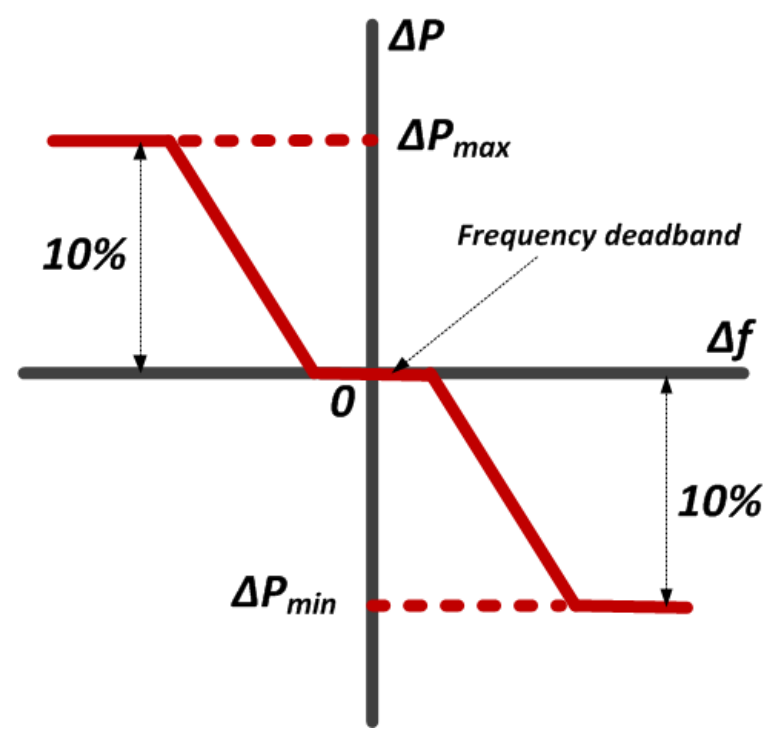

Figure 23. Proposed PV plant's droop characteristic

\subsection{FFR Controls}

The plant controller software was upgraded by GPTech to be able to increase its power output from the curtailed level to the full available power within 500 milliseconds from the beginning of the frequency event. Normally, the FFR is supposed to deploy during severe frequency drops following the loss of a generator. However, for the purposes of this test, the FFR was initiated by an external control signal (simulated step change in grid frequency) to minimize the amount of time when the plant was operating in the curtailed mode. This was done to reduce the impact on plant revenues as a result of curtailed operation. 


\section{Test Results for AES's Ilumina PV Power Plant}

The actual testing on the new PV controls was conducted from July 2015 to August 2015 with participation from all team members, including the plant manager and chief engineer providing test support at the plant, GPTech engineers remotely programming and setting the PPC in the appropriate test mode, the PREPA team providing AGC test support both at the plant and from their energy control center (ECC) in Monacillo, and the NREL team coordinating test activities and analyzing test results.

\subsection{AGC Tests}

AGC tests were conducted during several days in August 2015. As described in Section 6.1, two control ranges were used. During the tests on August 6 and August 7, the plant was set to participate in AGC control during afternoon hours (1 p.m.-4 p.m.), and it was allowed to operate within a power range of $20 \%$ below estimated available peak power (Figure 24 and Figure 25). During this testing period, the plant demonstrated good AGC performance, as shown in both figures, which represent the time series of the measured plant power, grid frequency, AGC set point received from the PREPA energy control center, and the estimated peak and curtailed power levels. The correlation between measured power and the AGC set point for each test is shown as well. During periods of rapid PV power plant production decline due to cloud movement (e.g., the time period between 15:23 and 15:34 in Figure 24), the plant was not able to follow the AGC signal with the same level of precision as it was during periods of low power variability. The long vertical lines in the X-Y plot in Figure 24 represent these time periods of large solar ramp. 

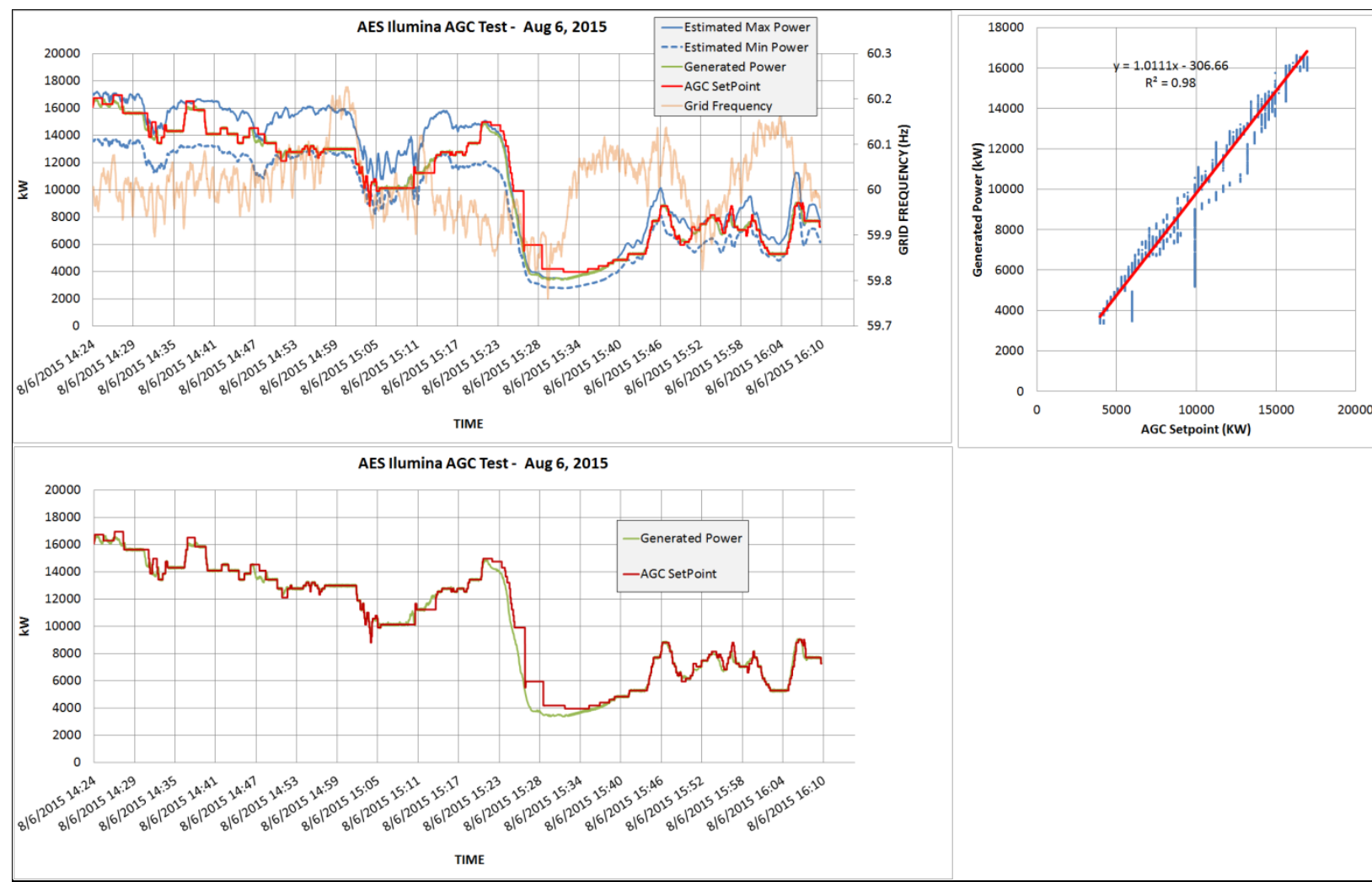

Figure 24. AGC test using $20 \%$ range-August 6, 2015

This report is available at no cost from the National Renewable Energy Laboratory (NREL) at www.nrel.gov/publications. 


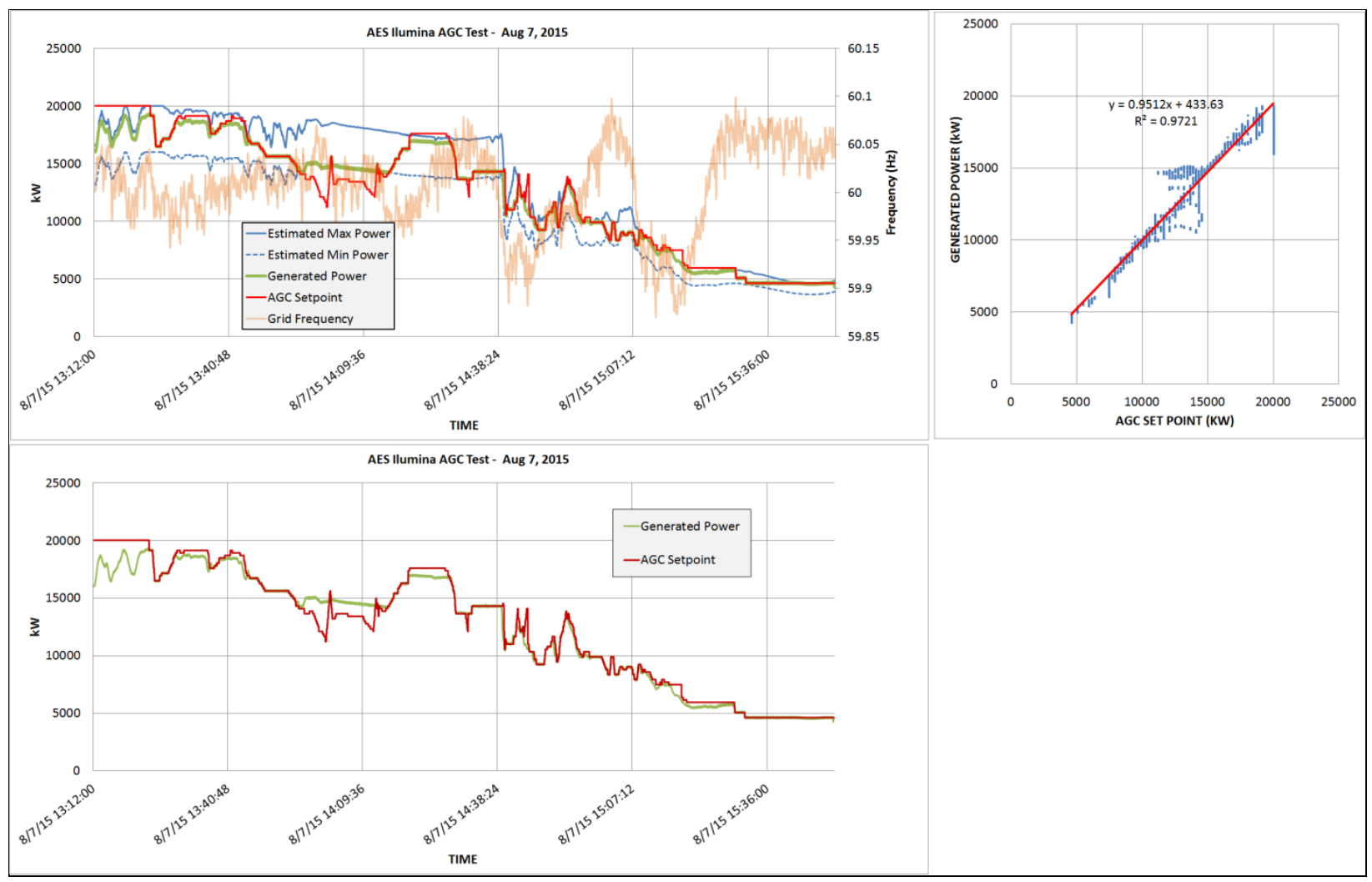

Figure 25. AGC test using 20\% range-August 7, 2015

Upon completion of the $20 \%$ tests, the team decided to increase the operational range of the plant to $40 \%$ below estimated peak available power. This was done to allow more room for curtailment if requested by AGC. As a result, two more AGC tests were conducted on August 14 and August 26 during peak production hours (11 a.m. -2 p.m.). Recorded data for each $40 \%$ test are shown in Figure 26 and Figure 27. For both 40\% tests, the plant demonstrated good AGC performance by following the set point during periods of smooth power production. During periods of solar resource variability, the precision of the AGC performance dropped sharply due to rapid uncontrolled changes in plant power production (e.g., the 10-minute time period starting at 13:58 in Figure 26).

A closer look at the test data also revealed time periods of smooth power production when the plant was not able to reach the set point. A more detailed explanation of this mismatch between set point and actual plant output is explained in Figure 28. Two types of mismatch can be observed in Figure 28 from the August 14 data. The first type took place when AGC set point was close to the value of the estimated plant peak power. The AGC system assumed that there was still some available headroom for up-regulation, because its evaluation was based on the available plant power value that was communicated by the plant PPC. However, as mentioned in Section 6, the method of estimating available peak power based only on pyranometer measurements is subject to uncertainties, because some other important parameters are not considered. As a result, the calculated available power is overly optimistic, and inverters are not able to produce as much power because they are already operating at maximum peak power point. Therefore, the control error appears every time the AGC set point is above the actual peak 
power of the plant, as shown in Figure 28. As mentioned in the discussion following Figure 20, these uncertainties, and hence a source of control error, could be minimized if the plant's available power was better modeled by incorporating significant variables such as panel productivity based on ambient temperature, inverter efficiency, and environmental dust into the calculation of available power. For purposes of this test, NREL did not require GPTech to model this calculation as precisely as would be possible given more time and financial incentive to obtain accurate estimation.

Another source of mismatch between the set point and actual plant power appeared during times when AGC requested less power than the 40\% lower limit. Again, note that this limit was "artificial," and it was set to minimize revenue losses to AES. The plant is fully capable of further curtailing its production in accordance with an AGC order.

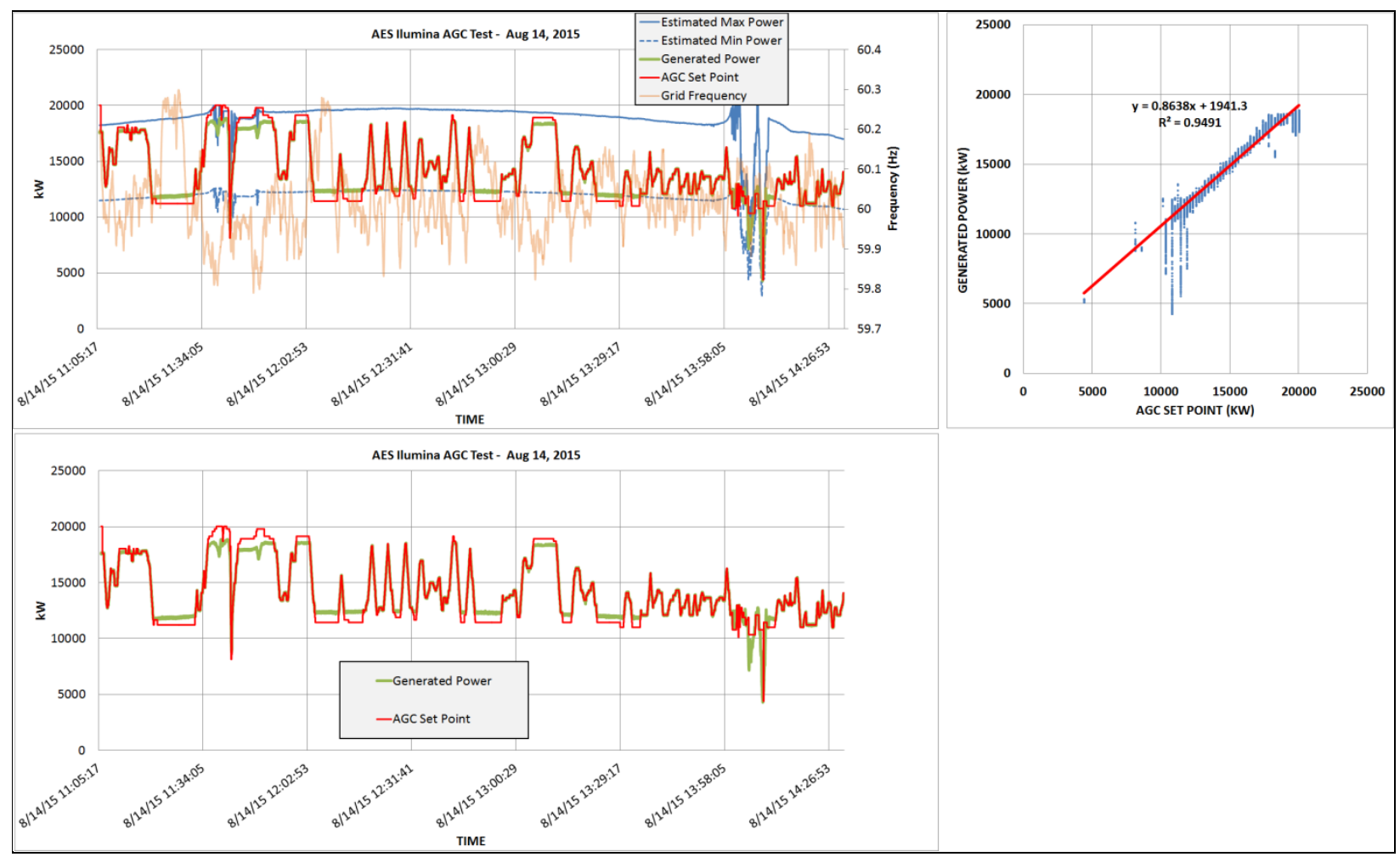

Figure 26. AGC test using $40 \%$ range-August 14,2015 


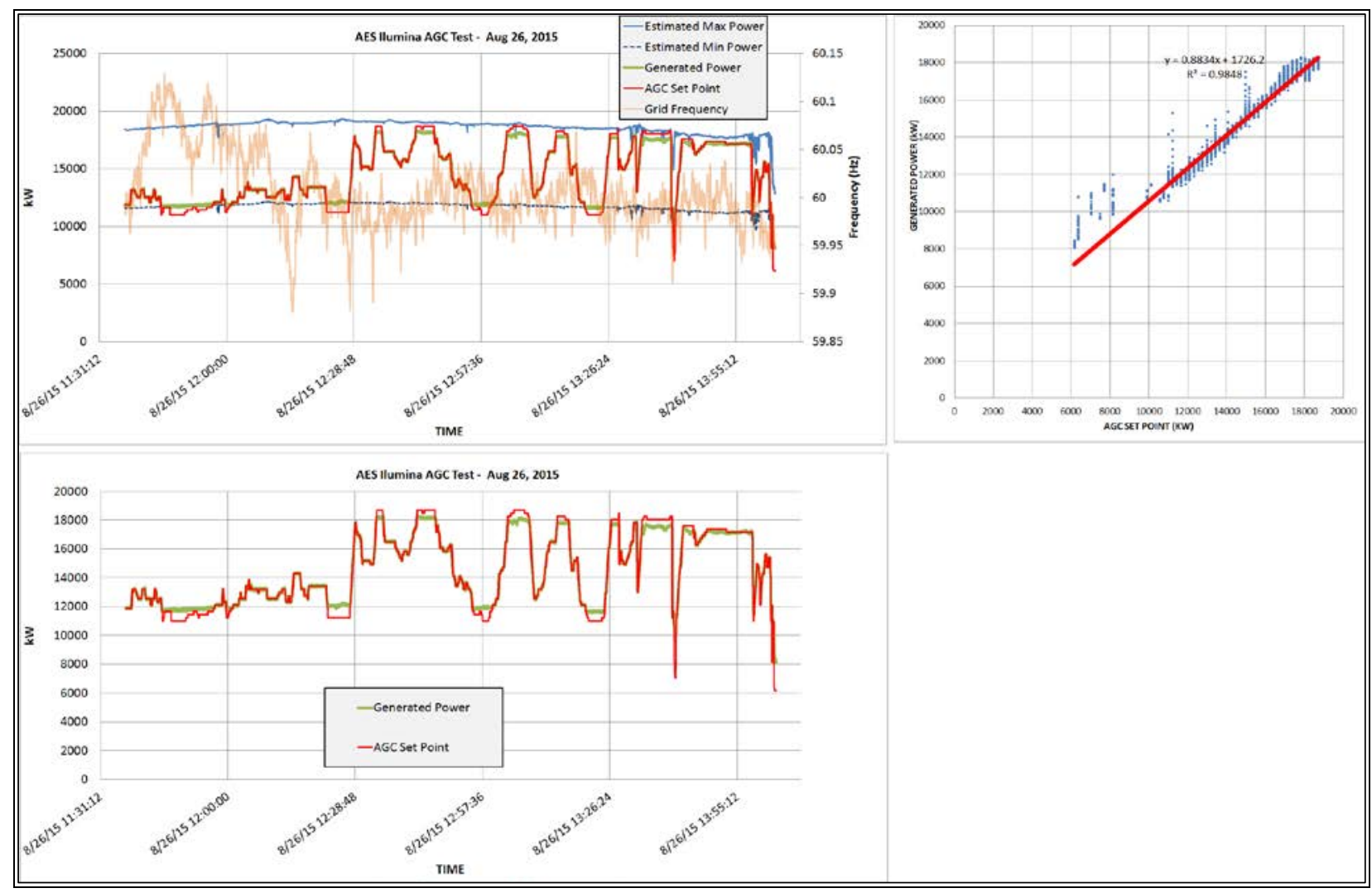

Figure 27. AGC test using 40\% range-August 26, 2015

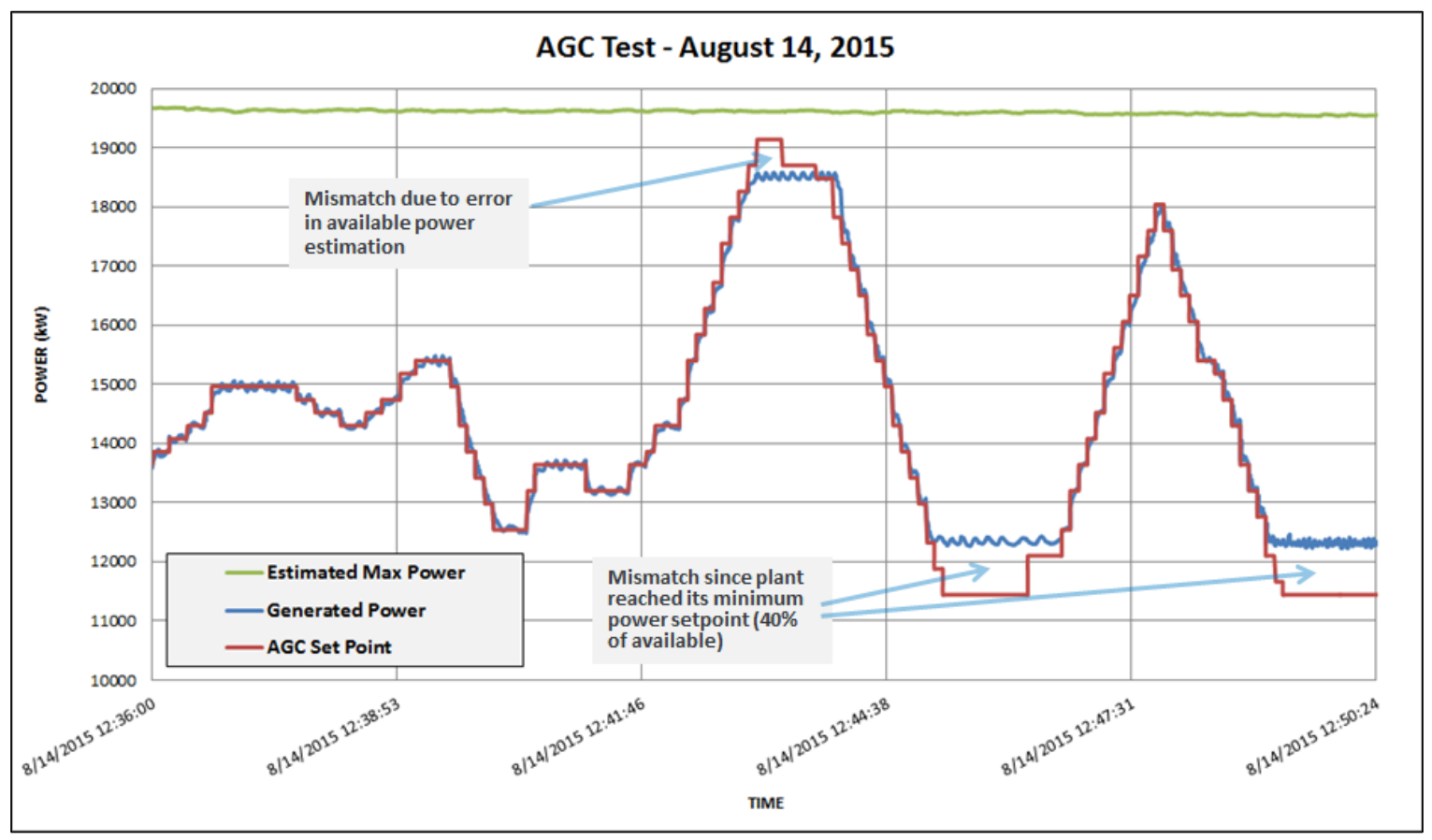

Figure 28. AGC performance explained 
It is remarkable to notice that during a significant amount of time AES's Ilumina PV power plant was the only resource in PREPA participating in AGC. Such periods took place during all four days of AGC testing when the load variations in PREPA's system were small. Other plants were requested to participate in AGC when the contribution from AES's Ilumina was not sufficient for balancing the frequency. Snapshots of PREPA's AGC control displays illustrating different test conditions are shown below as follows:

- Figure 29. The identifier San Juan 6 CC was used to control AES's Ilumina PV power plant. The green circle in the AGC control column indicates the active AGC mode. Also, high and low limits, maximum capacity, desired and actual generation are shown in the corresponding columns.

- Figure 30. This shows the control loop sending a set point of $19 \mathrm{MW}$ to Ilumina when the system frequency was at $59.913 \mathrm{~Hz}$ and the current generation was at $18.2 \mathrm{MW}$.

- Figure 31. Grid frequency was at $60.101 \mathrm{~Hz}$. AGC sent an 11.5-MW set point to reduce plant generation from its current level of $12.2 \mathrm{MW}$.

- Figure 32. Note that all the other generators were not selected for regulation; only Ilumina was regulating the frequency, as shown in Figure 29.

- Figure 33. Ilumina was set to regulate the frequency along with two major units in PREPA's system but with priority given to Ilumina. This means that the AGC sent set points first to Ilumina to control the frequency. If Ilumina was not capable of balancing the frequency, then the AGC would send set points to the other two units (Aguirre2 and ECO PP). 


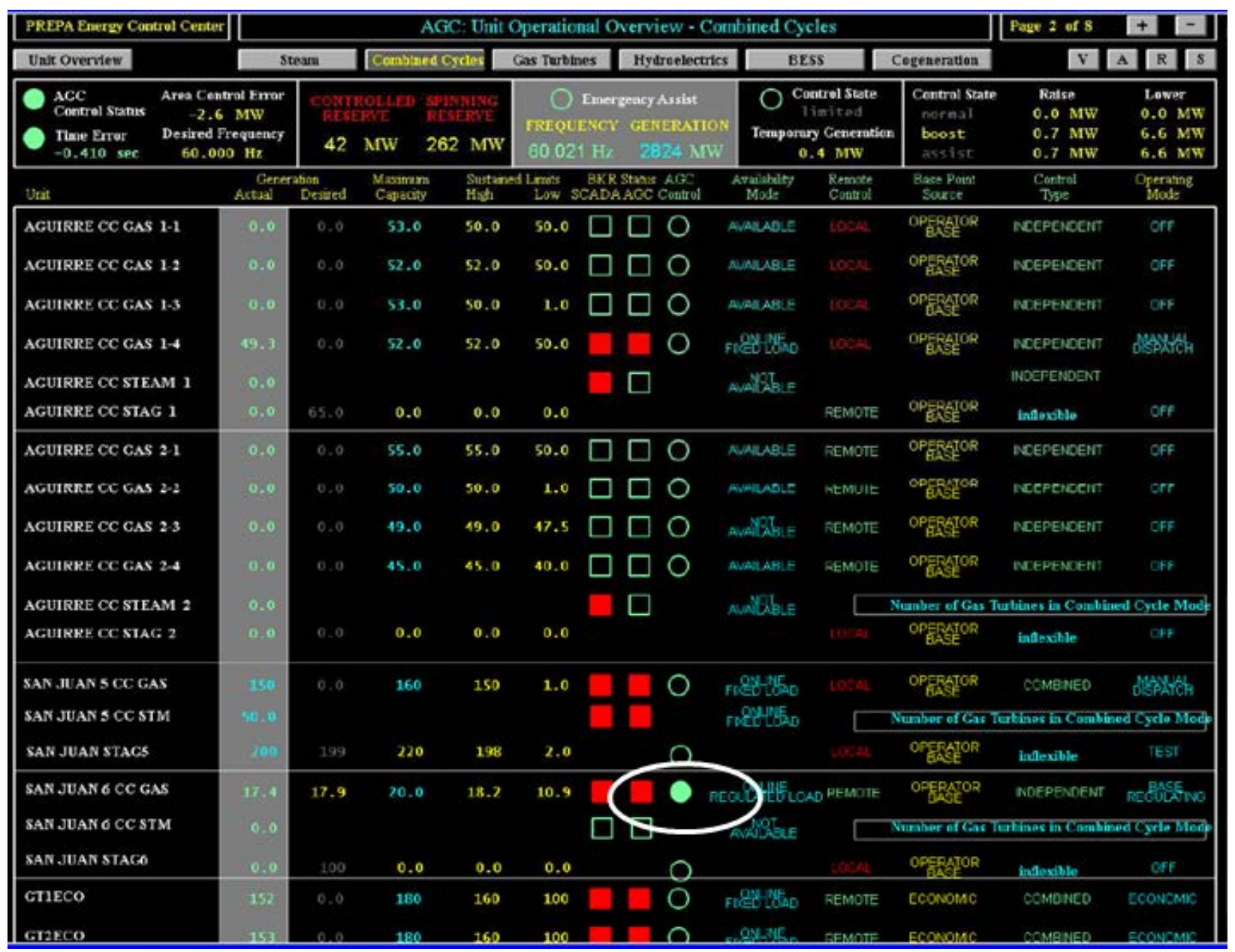

Figure 29. Display of PREPA's AGC units-AES's llumina is masked as San Juan 6 CC Gas unit. Image from PREPA 


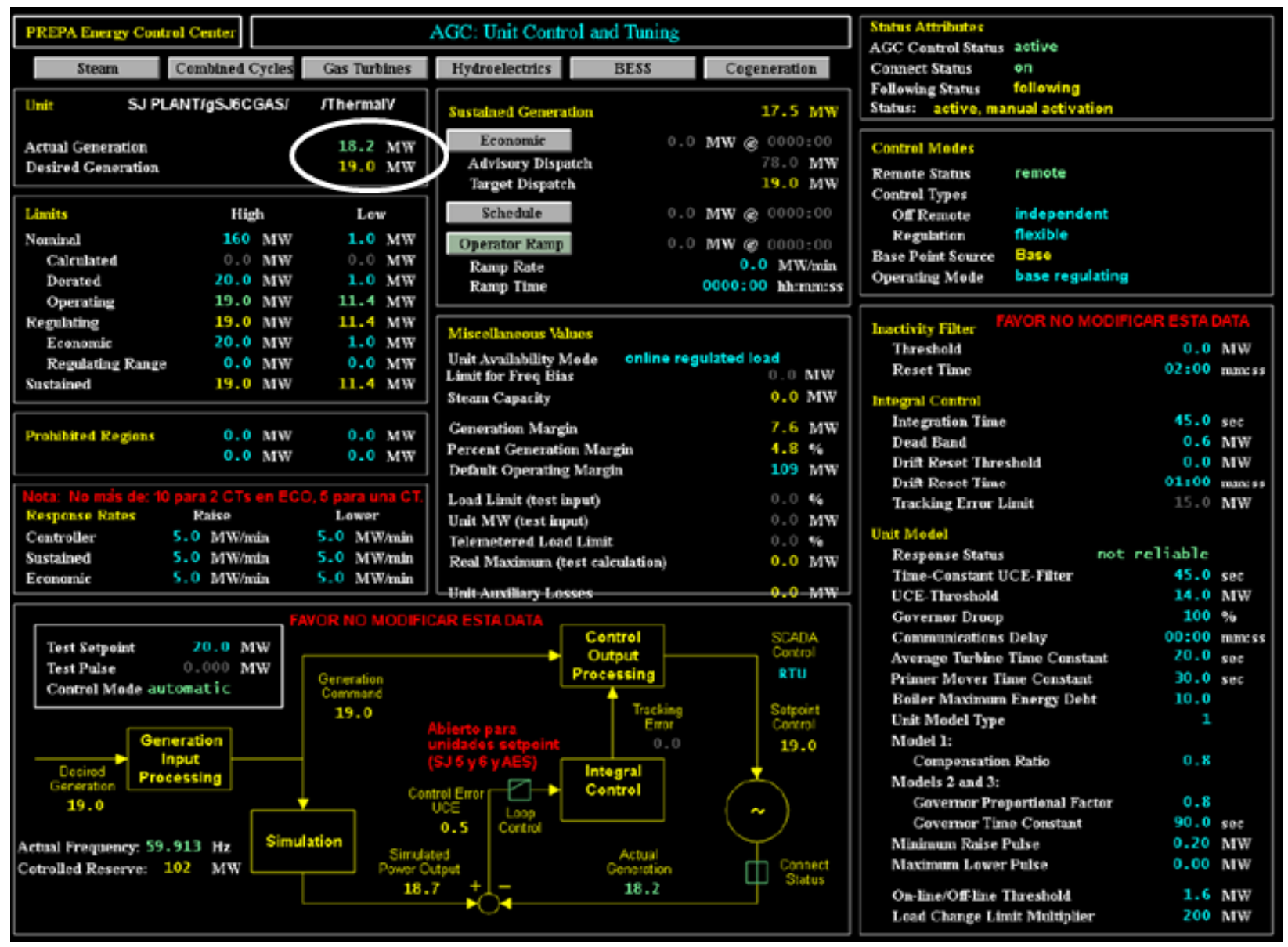

Figure 30. Snapshot of PREPA's AGC display-19-MW set point is sent to llumina. Image from PREPA 


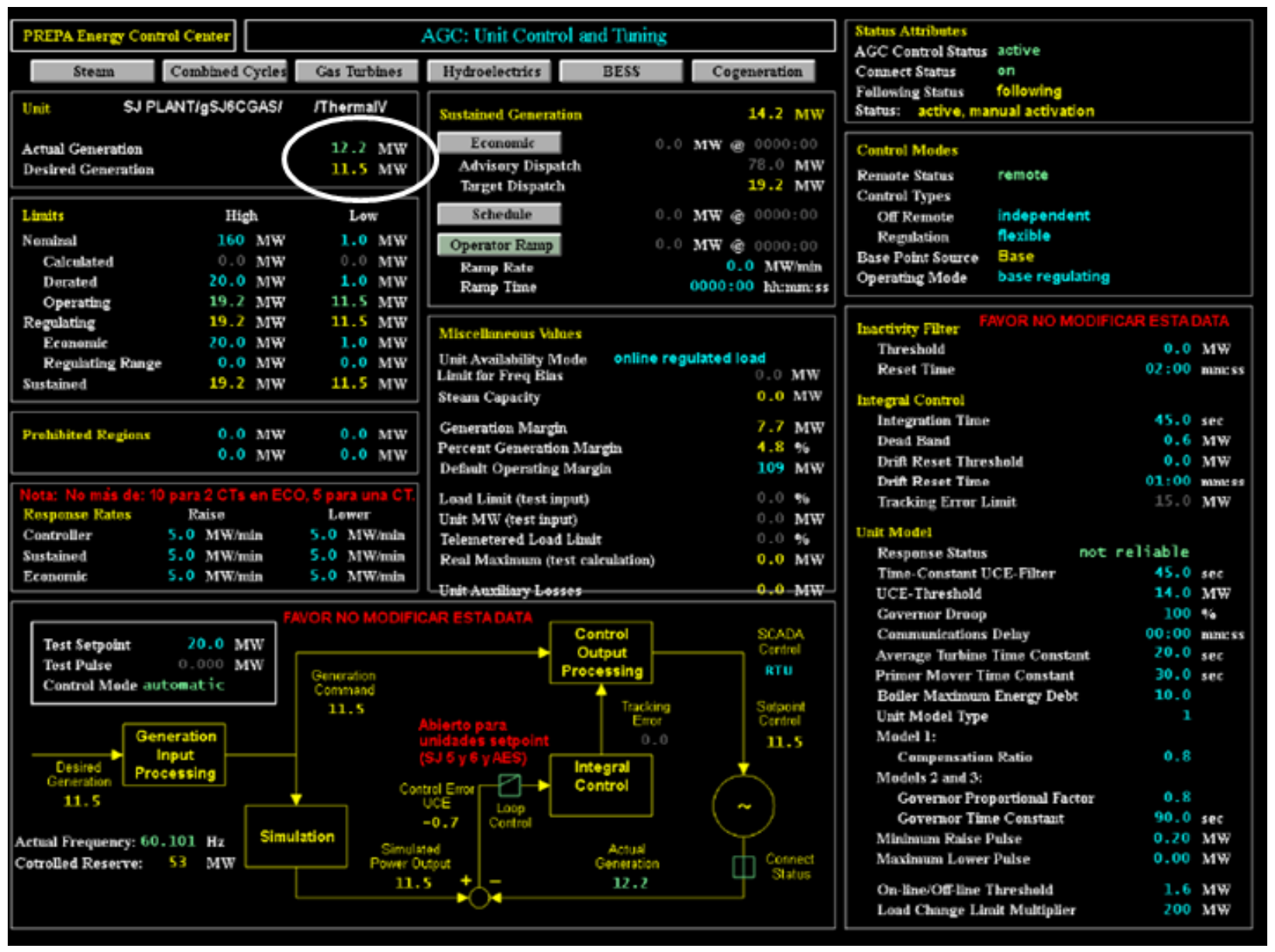

Figure 31. Snapshot of PREPA's AGC display-11.5-MW set point is sent to llumina. Image from PREPA 


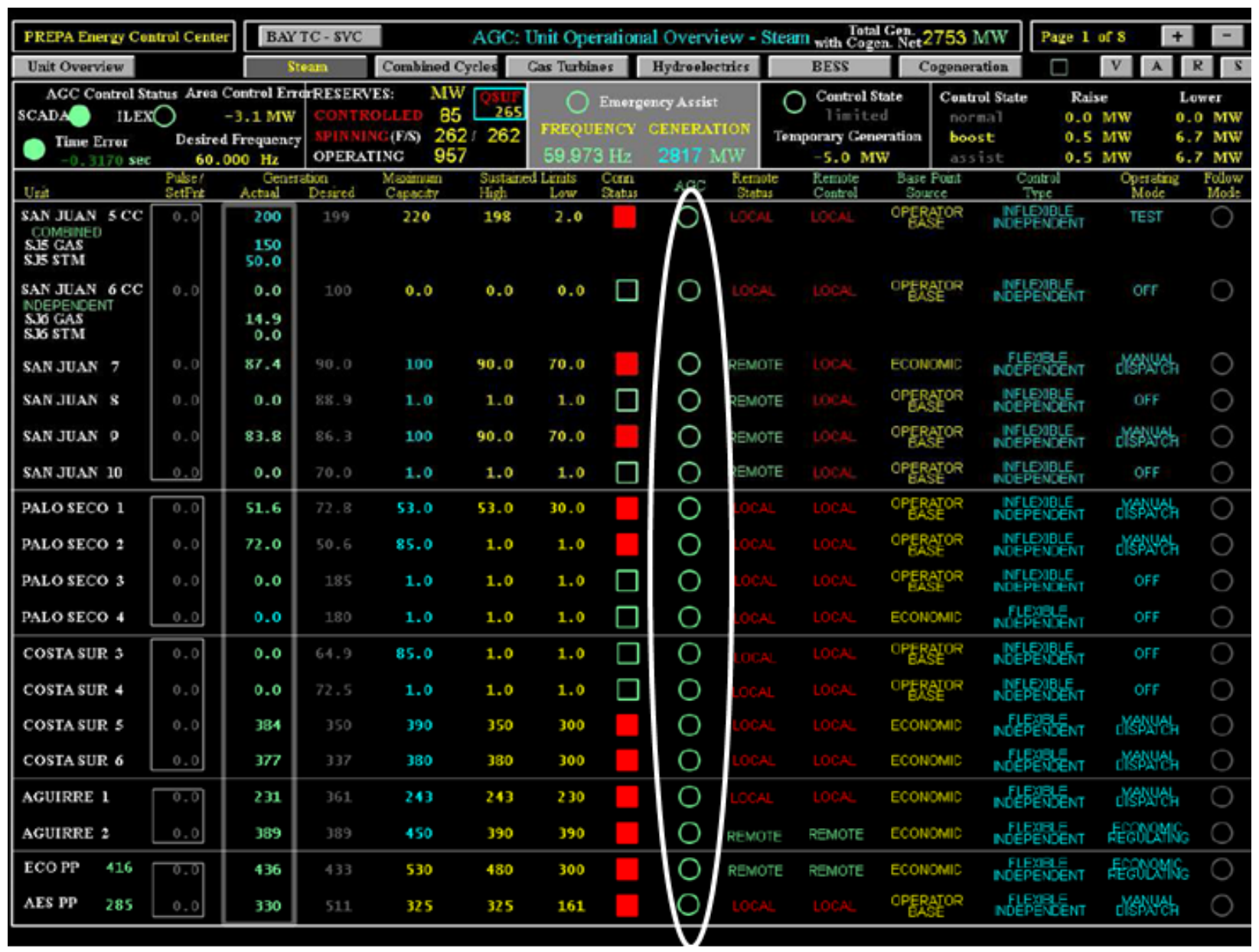

Figure 32. Snapshot of PREPA's AGC units-no conventional units are selected. Image from PREPA 


\begin{tabular}{|c|c|c|c|c|c|c|c|c|c|c|c|c|c|c|c|}
\hline \multirow{2}{*}{\multicolumn{2}{|c|}{$\begin{array}{l}\text { PREPA Energy Control Center } \\
\text { Unit Overview }\end{array}$}} & \multicolumn{2}{|c|}{ BAYTC-SVC } & \multicolumn{9}{|c|}{ AGC: Unit Operational Overview - Steam with Coger Not $2741 \mathrm{MW}$} & \multicolumn{3}{|c|}{ Page 1 of $8+$} \\
\hline & & \multicolumn{2}{|c|}{2 Stcann } & \multicolumn{2}{|c|}{ Combined Cycles } & Cas Turtines & \multicolumn{2}{|c|}{ Hydroolectrics } & BESS & \multicolumn{3}{|c|}{1 Cogeneration } & $\square$ & \multicolumn{2}{|c|}{ 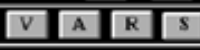 } \\
\hline $\begin{array}{l}\text { AGC Centrol Stat } \\
\text { sCADA ILEX( } \\
\text { Time Error } \\
2.2803 \text { sec }\end{array}$ & $\begin{array}{r}\text { tus Area Co } \\
\text { Dasired } r \\
60.00 \\
\end{array}$ & $\begin{array}{l}\text { ontrol Emo } \\
2.9 \mathrm{MW} \\
\text { Frequency } \\
00 \mathrm{~Hz}\end{array}$ & $\begin{array}{l}\text { FESEK } \\
\text { CONT: } \\
\text { SPINNI } \\
\text { OPERA }\end{array}$ & $\begin{array}{lr}\text { ES: } & \text { MW } \\
\text { OLLED } & 136 \\
\text { NG(T/S) } & 318 \\
\text { IINC } & 1013 \\
\end{array}$ & 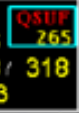 & $\begin{array}{r}\text { Enert } \\
\text { FREQUENCY } \\
60.049 \mathrm{~Hz} \\
\end{array}$ & $\begin{array}{l}\text { Eency Assist } \\
\text { GENERAI } \\
2805 \text { A }\end{array}$ & IION & $\begin{array}{r}\text { Control St } \\
\text { limite } \\
\text { Tenuporay Geat } \\
-0.1 \mathrm{MY}\end{array}$ & $\begin{array}{l}\text { rate } \\
\text { ratioa } \\
\text { a }\end{array}$ & $\begin{array}{c}\text { Contr } \\
\text { nor: } \\
\text { boo } \\
\text { ass } \\
\end{array}$ & $\begin{array}{l}\text { ol State } \\
\text { nal } \\
\text { st } \\
\text { ist }\end{array}$ & $\begin{array}{l}\text { Rats } \\
2.0 \\
134 \\
134 \\
\end{array}$ & $\begin{array}{ll}\text { se } & \text { La } \\
\text { MW } & 2 . \\
\text { MW } & 26 \\
\text { MW } & 26 \\
\end{array}$ & $\begin{array}{l}.0 \mathrm{MW} \\
63 \mathrm{MW} \\
63 \mathrm{MW} \\
\end{array}$ \\
\hline 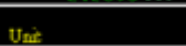 & $\begin{array}{l}\text { Pugel } \\
\text { EctPat }\end{array}$ & $\begin{array}{c}\text { Generac } \\
\text { Actusal }\end{array}$ & Defired & $\begin{array}{l}\text { Mosinum } \\
\text { Carsaty }\end{array}$ & $\begin{array}{l}\text { Sugkere } \\
\text { Hight }\end{array}$ & 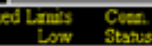 & $A Q C$ & $\begin{array}{l}\text { Renche } \\
\text { Stans }\end{array}$ & $\begin{array}{l}\text { Kenoter } \\
\text { Cortral }\end{array}$ & $\begin{array}{c}\text { Bast } \\
\text { Sor }\end{array}$ & & & (112001 & $\begin{array}{c}\text { Gperaing } \\
\text { Mods }\end{array}$ & PGoow \\
\hline $\begin{array}{l}\text { SAN JUAN } 5 \mathrm{CC} \\
\text { CONEANED } \\
\text { S.15 GAS } \\
\text { SIS STM }\end{array}$ & 0.0 & $\begin{array}{r}200 \\
150 \\
50.0\end{array}$ & 199 & 220 & 198 & 2.0 & 0 & LOCAL & LDCAL & OPE & & Nofes: & $x \in E$ int & TEST & 0 \\
\hline $\begin{array}{l}\text { SAN JUAN } 6 \mathrm{CC} \\
\text { INDEPENDEITT } \\
\text { S.10 GAS } \\
\text { SIG STM }\end{array}$ & 0.0 & $\begin{array}{r}0.0 \\
14.1 \\
0.0\end{array}$ & 100 & 0.0 & 0.0 & 0.0 & $\mathrm{O}$ & Locks & LOCAL & OFE: & ATSOR & RUE:P & XXPE: & off & $\mathrm{O}$ \\
\hline SAN JUAN 7 & 0.0 & 87.4 & 90.0 & 100 & 90.0 & 70.0 & $\mathrm{O}$ & REMOT: & LOCAL & ECOI & OMIC & MEEP & ELE & 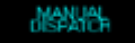 & O \\
\hline SAN JUAN 8 & 0.0 & 0.0 & 88.9 & 1.0 & 1.0 & 1.0 & O & REMOT: & LOCAL & OPE & AT:OR & NUELP & XARE & OFF & $\mathrm{O}$ \\
\hline SAN JUAN 9 & 0.0 & 83.1 & 86.3 & 100 & 90.0 & 70.0 & $\mathrm{O}$ & REMOT: & LOCAL & OFE & $\mathrm{ATER}^{\mathrm{T}}$ & MUFe & ande & disputch & $\mathrm{O}$ \\
\hline SAN JUAN 10 & 0.0 & 0.0 & 70.0 & 1.0 & 1.0 & 1.0 & O & REMOTE & LOCAL & oftE & AITOR & 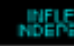 & PDE & orr & 0 \\
\hline PALO SECO 1 & 0.0 & 51.5 & 72.8 & 53.0 & 53.0 & 30.0 & $\mathrm{O}$ & LOCAL & LOCAL & OFE & ATOR & MDEL & XXle: & DASPATCA & ○ \\
\hline PALO SECO 2 & 0.0 & 73.4 & 50.6 & 85.0 & 1.0 & 1.0 & 0 & LOCAL & LOCAL & OPE & $\mathrm{AST}^{\mathrm{T}}$ & Nofe & Nape & DAsistutch & 0 \\
\hline PALO SECO 3 & 0.0 & 0.0 & 185 & 1.0 & 1.0 & 1.0 & $\mathrm{O}$ & LOCA & LOCAL & OFE & ATER & Nók: & apeir & OFF & $\mathrm{O}$ \\
\hline PALO SECO 4 & 0.0 & 0.0 & 180 & 1.0 & 1.0 & 1.0 & O & LOCAL & LOCAL & Econ & Oanc & NEES & GELE & off & 0 \\
\hline COSTA SUR 3 & 0.0 & 0.0 & 64.9 & 85.0 & 1.0 & $1.0 \square$ & 0 & LOCAL & LOCAL & OFE & $\mathrm{ATER}^{-1}$ & $\begin{array}{l}\text { RILE } \\
\text { NOEP }\end{array}$ & $\begin{array}{l}\text { mape } \\
\text { axuent }\end{array}$ & OFF & $\mathrm{O}$ \\
\hline COSTASUR 4 & 0.0 & 0.0 & 72.5 & 1.0 & 1.0 & 1.0 & $\mathrm{O}$ & LOCAL & LOCAL & ofty & ATOQ & NDEF & ARE & orr & O \\
\hline COSTA SUR 5 & 0.0 & 383 & 350 & 390 & 350 & 300 & $\mathrm{O}$ & LOCAL & LOCAL & Econ & OMalc & NóE & GEE & DESPACACA & $\mathrm{O}$ \\
\hline Costa SUR 6 & 0.0 & 375 & 337 & 380 & 380 & 300 & O & LOCAL & LOCAL & Ecot & ounc & $\begin{array}{l}\text { MLEE } \\
\text { MOEP }\end{array}$ & $\begin{array}{l}\text { GEE } \\
\text { EXENT }\end{array}$ & distsextch & ○ \\
\hline AGUIRRE 1 & 0.0 & 231 & 361 & 243 & 243 & 230 & & LOCAL & LOCAL & Ecor & OAdC & NEE & EEIENT & 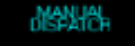 & O \\
\hline AGUIRRE 2 & 0.0 & 389 & 390 & 450 & 390 & 390 & & PEMOT: & REMOTE & Econ & Onde & NGE & GELENT & ECOVOAlNG & \\
\hline ECO PP $\quad 3 / 0$ & 0.0 & 389 & 390 & 530 & 480 & 290 & & REMOT: & REMOTE & Ecor & OMlOC & móp & SEIE & FEQUEAFTO & 0 \\
\hline AES PP & 0.0 & 366 & 511 & 345 & 345 & 161 & & LOCAL & LOCAL & OFE & & móp & GEEENT & 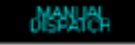 & 0 \\
\hline
\end{tabular}

Figure 33. Display of PREPA's AGC active units-priority was set to AES's llumina. Image from PREPA

\subsection{Frequency Droop Tests}

The 5\% and 3\% frequency droop tests on AES's Ilumina PV power plant were conducted during multiple hours on August 18, August 19, August 21, and August 24. For this purpose, before beginning each test, the GPTech team remotely set the plant controller into droop mode in accordance with the control method described in Section 6.2 with $5 \%$ or 3\% droop value and $10 \%$ power curtailment. The minimum allowed power level for down-regulation was set at $20 \%$ below available power for all droop tests (to minimize plant revenue losses). Also, a $25-\mathrm{mHz}$ frequency deadband was used in the droop characteristic for all tests. The results of the first droop test conducted on August 18 are shown in Figure 34. The upper graph in Figure 34 shows the recorded time series of actual plant power, estimated peak power, and grid frequency. The plant controller forced the plant power to follow the grid frequency in accordance with $5 \%$ droop. The droop response of the plant is more visible if the change in power $(\triangle P)$ and change in frequency $(\Delta f)$ are shown instead of absolute values. The second plot in Figure 34 shows the calculated actual measured and calculated plant $\Delta P$ that corresponds to frequency deviation $\Delta f$. The following equations were used to calculate the values shown in the lower plot in Figure 34:

$$
\begin{aligned}
& \Delta f=f_{\text {measured }}-60 \mathrm{~Hz} \\
& \Delta P_{\text {measured }}=P_{\text {actual }}-P_{\text {max.estimated }}
\end{aligned}
$$




$$
\Delta P_{\text {calculated }}=\frac{\Delta f}{60 \mathrm{~Hz}} \cdot \frac{1}{\text { Droop }} \cdot P_{\text {nom }}
$$

Where $f_{\text {measured }}$ is the actual grid frequency as measured on the plant terminals, $\Delta P_{\text {calculated }}$ is the ideal (or target) response of the plant to grid frequency variations for a given droop setting, and $P_{\text {nom }}$ is the plant's nameplate capacity $(20 \mathrm{MW})$.

It was observed from the data shown in Figure 34 (second plot) that the plant output was following the target droop characteristic most of the time except during periods of large solar ramps. The further examination of the 5\% droop test data is shown in Figure 35, in which control error and 1-second changes in power are plotted. Control error is calculated as a difference between calculated target and actual plant responses:

$$
\text { Error }=\Delta P_{\text {calculated }}-\Delta P_{\text {measured }}
$$

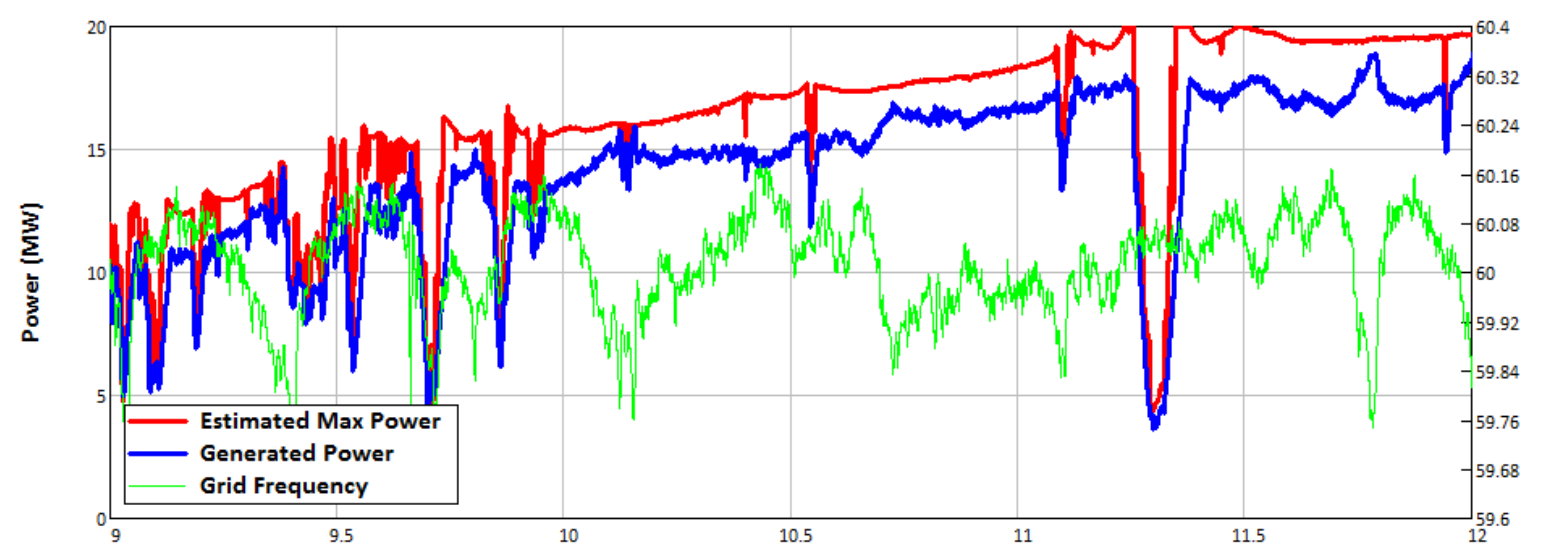

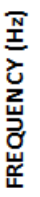

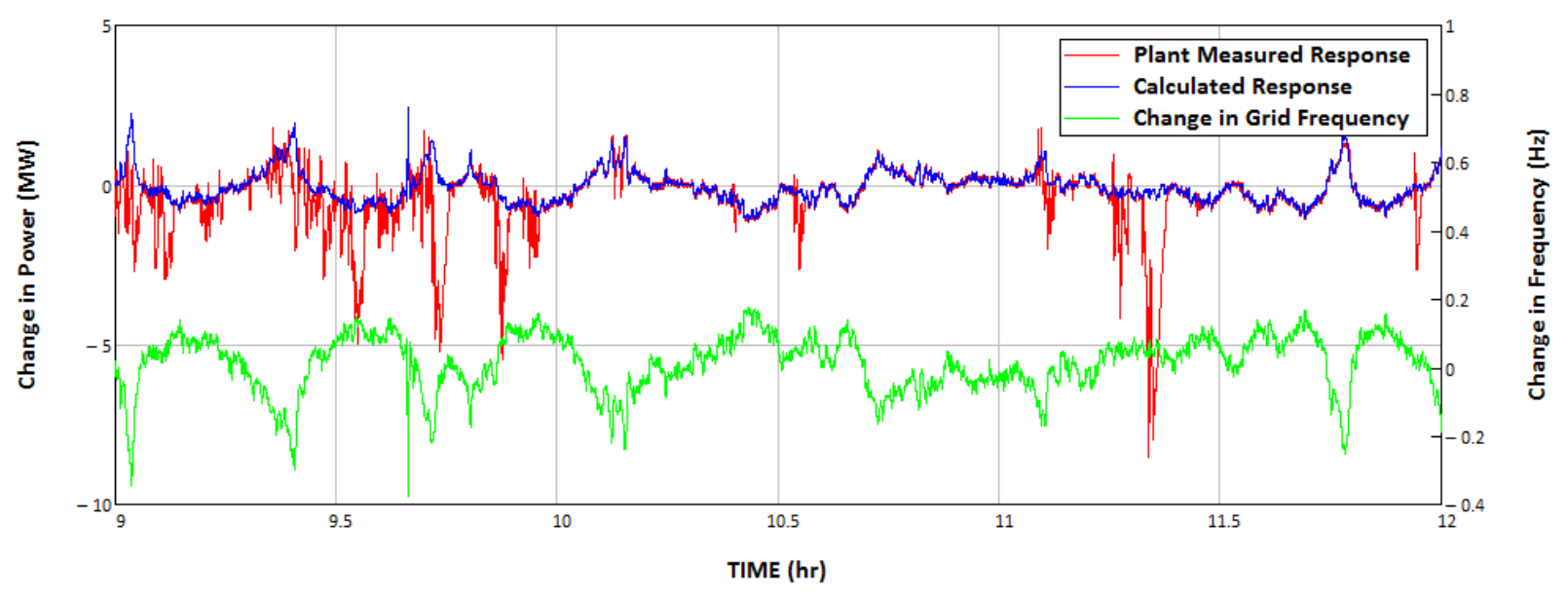

Figure 34. Power data for 5\% droop test-August 18, 2015 


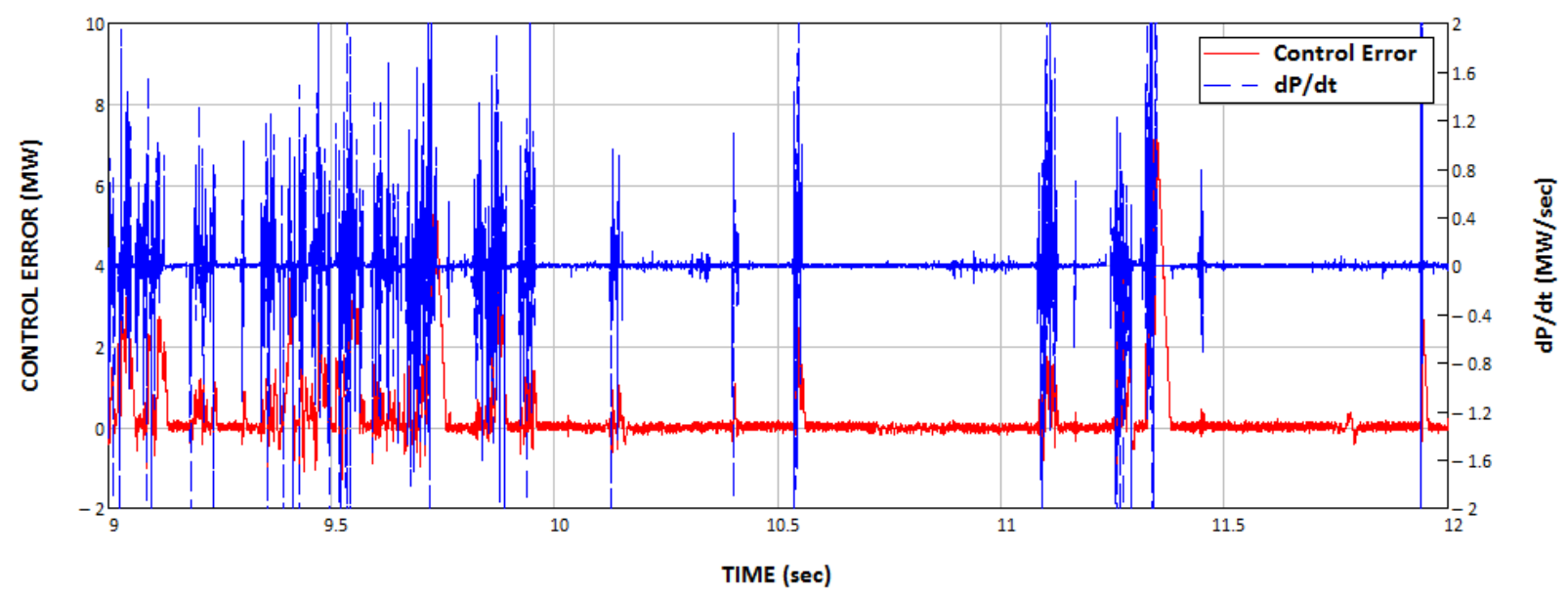

Figure 35. Control error during 5\% droop test-August 18, 2015

As shown in Figure 35, the controller error was at a zero level during periods of smooth production, and it increased significantly during solar ramping events. It resulted in a high scatter of data points around the calculated droop characteristic shown in Figure 36 (first plot), with statistical quantification of control error shown in the second plot. Further, it was decided to split the test data into two parts corresponding to periods of no variability and high variability (Figure 37 and Figure 38, respectively). Indeed, the periods of low variability showed better droop performance by the plant (Figure 37) compared to the periods of high variability (Figure 38).
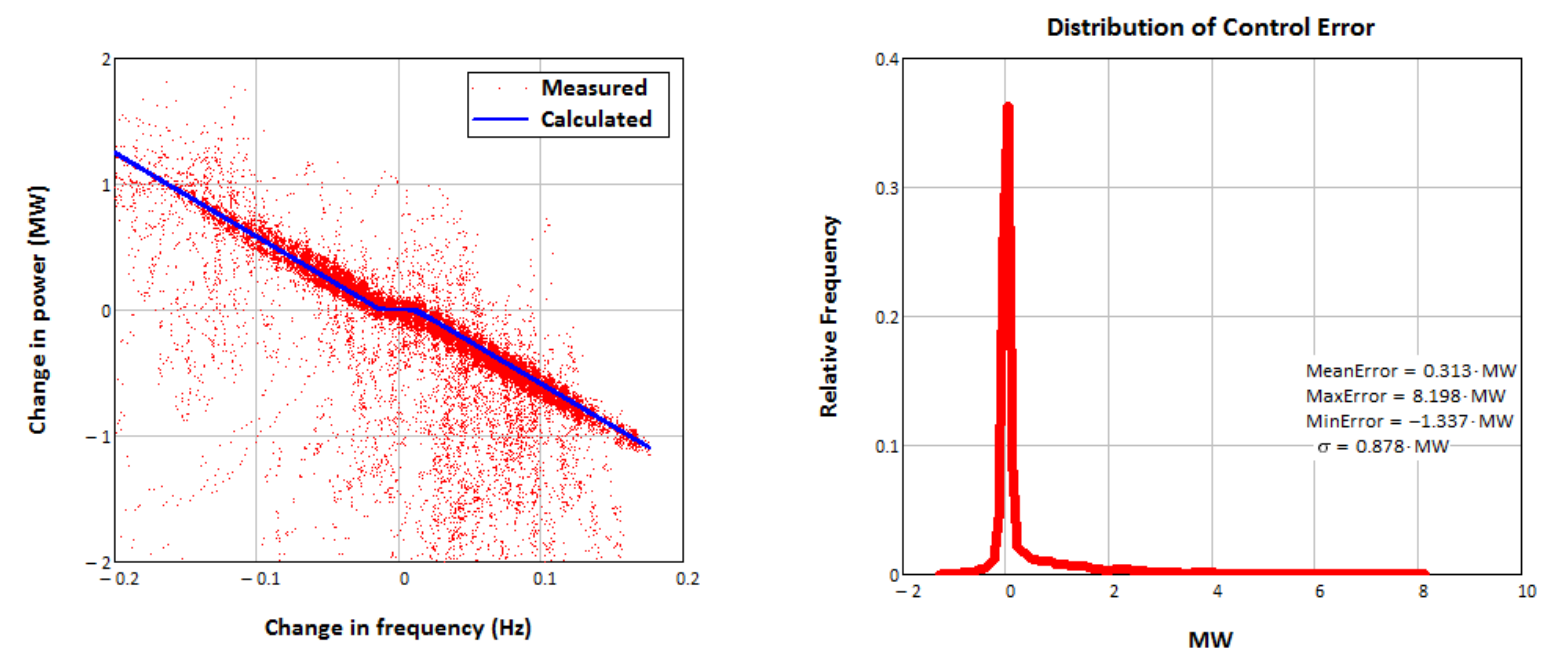

Figure 36. Measured droop characteristic and control error statistics for $5 \%$ droop test-August 18,2015

Anecdotally, upon analysis of the droop tests conducted on August 18, the team concluded that the measured droop performance was unsatisfactory and did not meet the expectation for a converter-coupled generator to provide fast and precise droop response. Further analysis of the controller settings revealed that one crucial parameter in the controller was left unchanged and 
caused such scattered droop performance. This was the ramp-rate limit setting in the PPC that was still active (set at $4 \mathrm{MW} /$ minute) and caused delayed droop response that resulted in high scatter and loss of control precision. The impact of such a ramp rate limit is not critical during the periods of low resource variability, as shown in Figure 37 by the "smooth" subset of the August 18 test data. However, high scatter in droop performance can be observed during the period of high variability, as shown in Figure 38). 

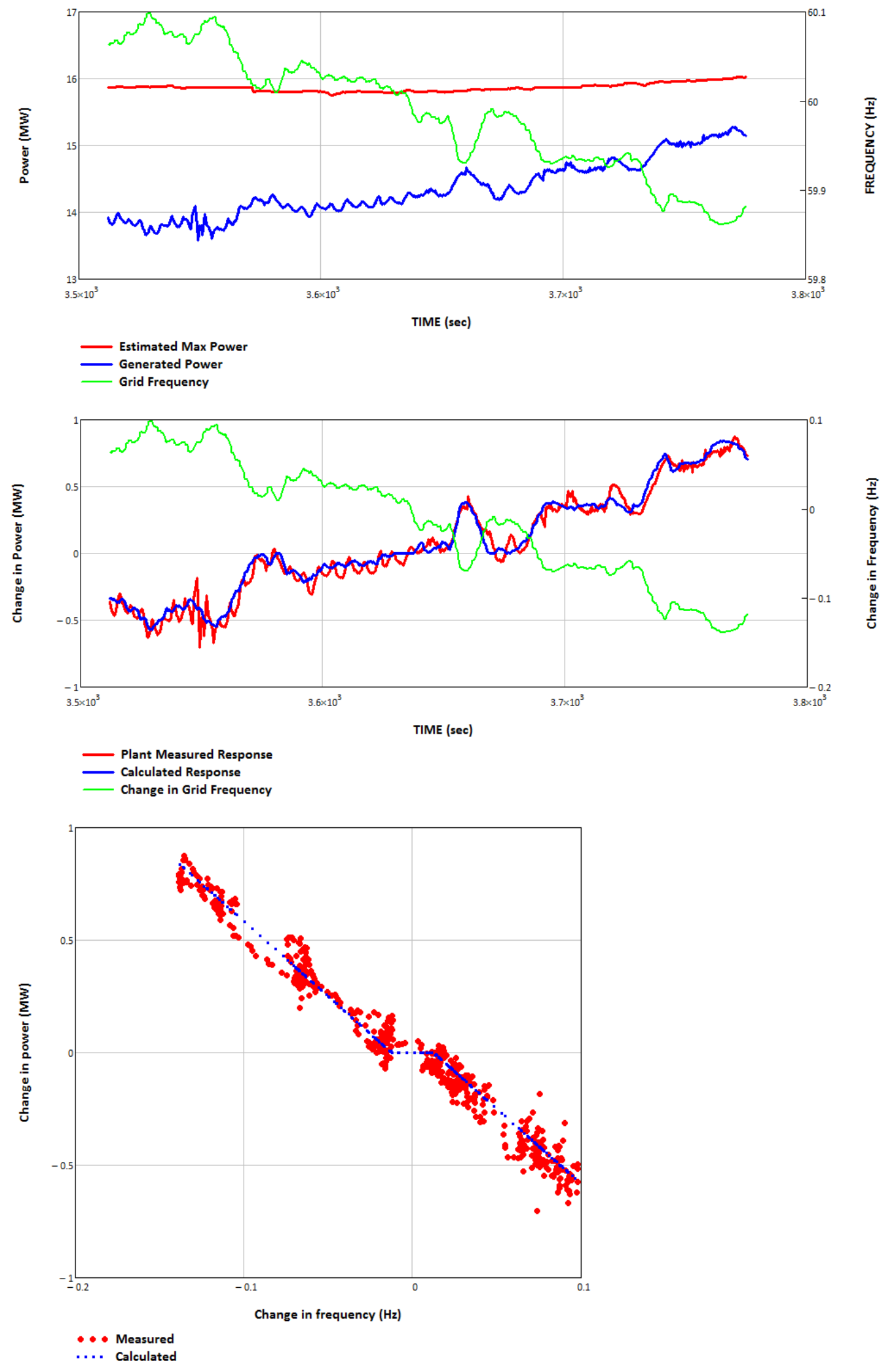

Figure 37. Acceptable droop performance during periods of low variability 

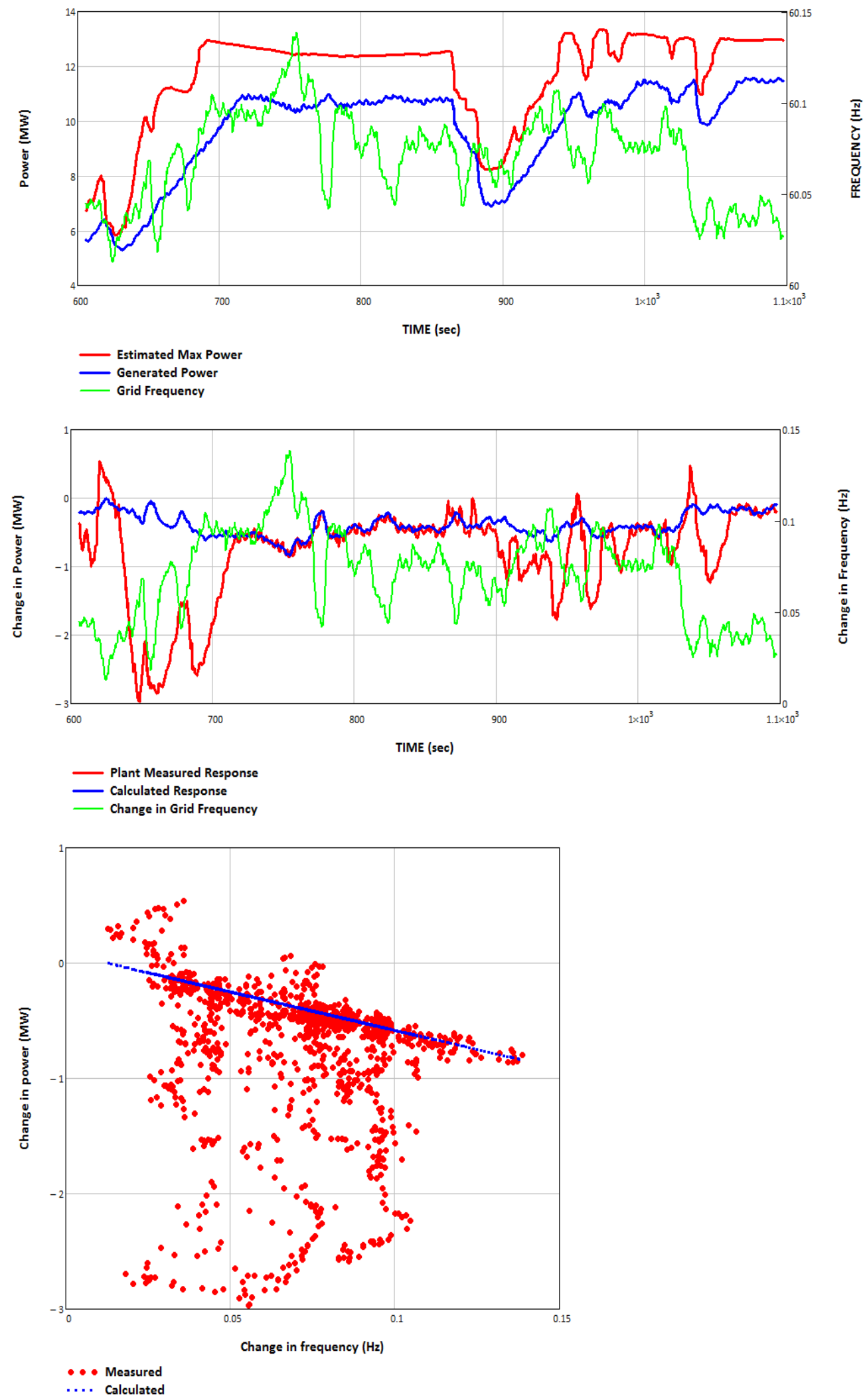

Figure 38. High scatter during periods of solar resource variability 
After this discovery, modifications were made by the GPTech team on August 7 to remove this ramp-rate limitation when the PPC was set to operate the plant in droop control mode. More droop tests were conducted with the modified control during August 19 and August 20 for the 5\% and 3\% droop settings (as shown in Figure 39 and Figure 41, respectively). Without any active ramp-rate limiting, the plant demonstrated much better droop performance with far less scatter, as shown in Figure 41 and Figure 42. The statistical analysis of control error demonstrated much lower standard deviation and $\min / \mathrm{max} /$ mean error values.
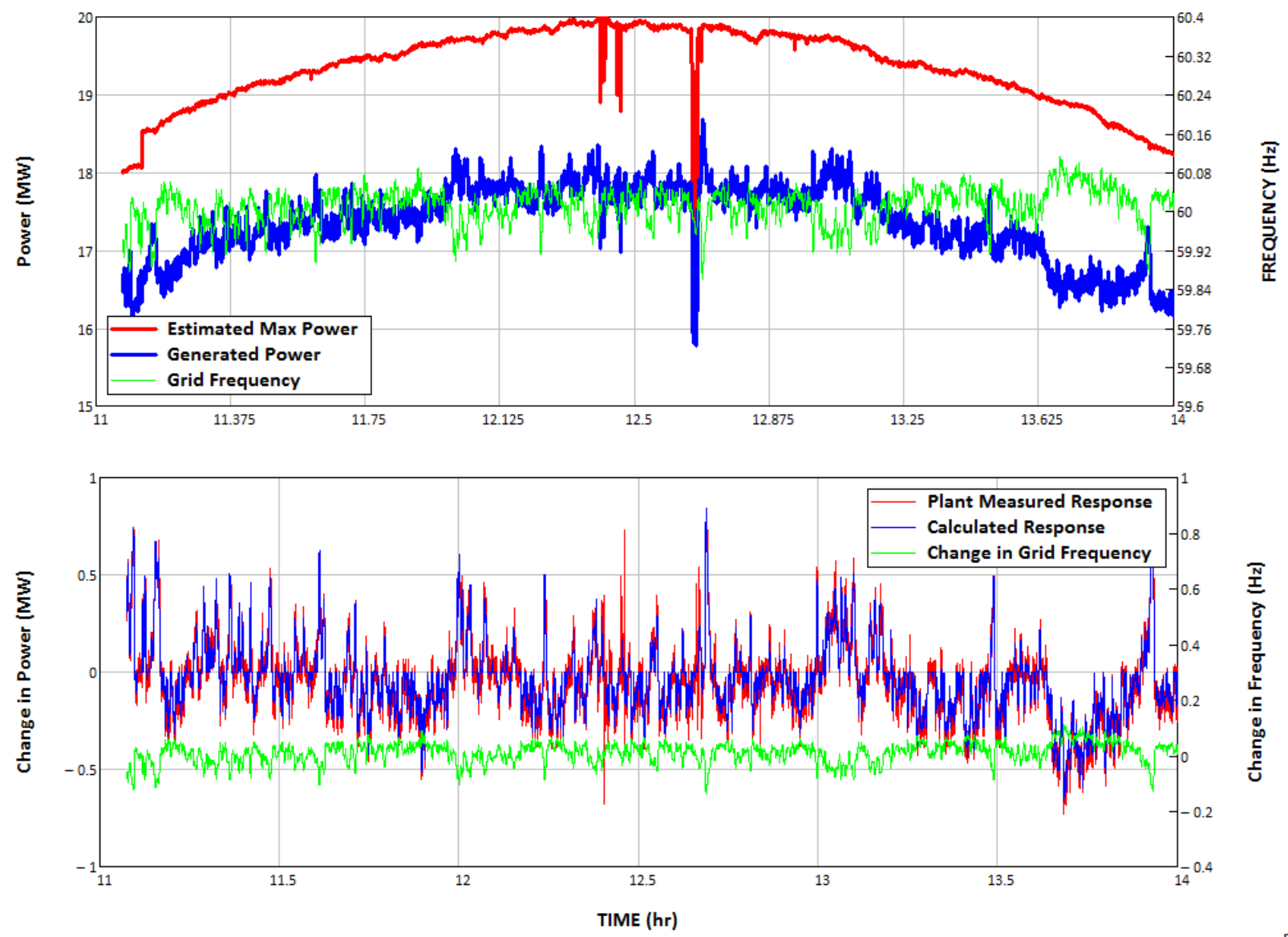

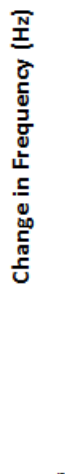

Figure 39. Results of 5\% droop tests-August 19, 2015 


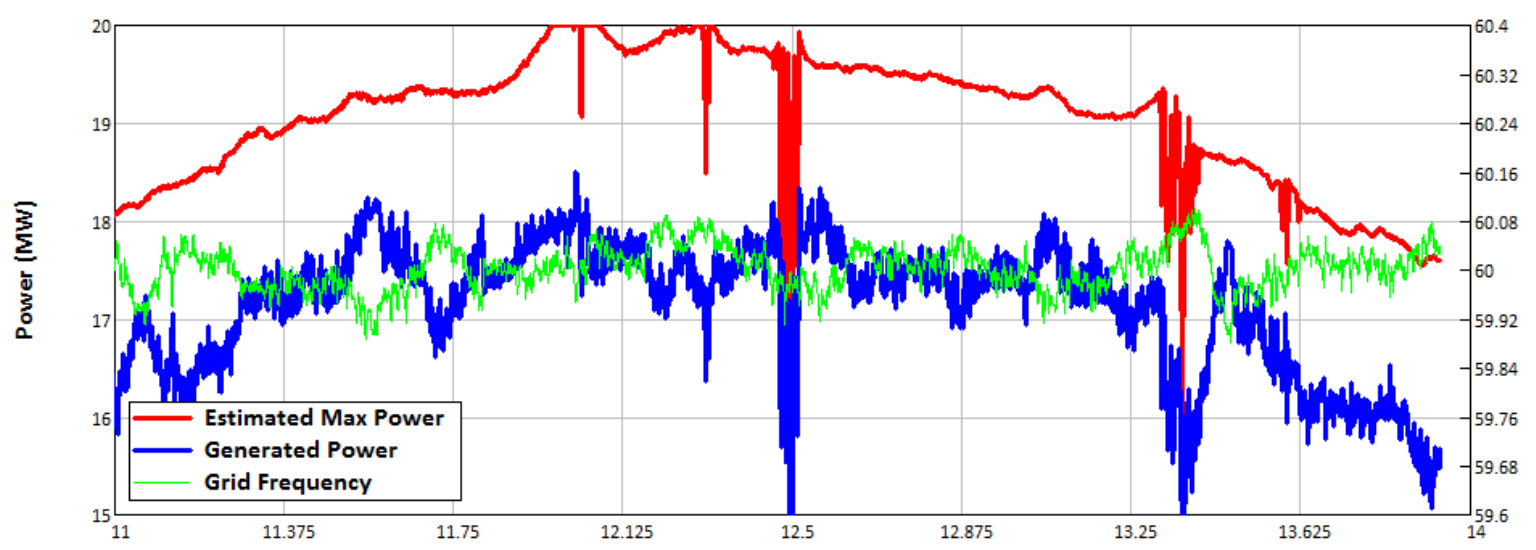

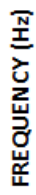

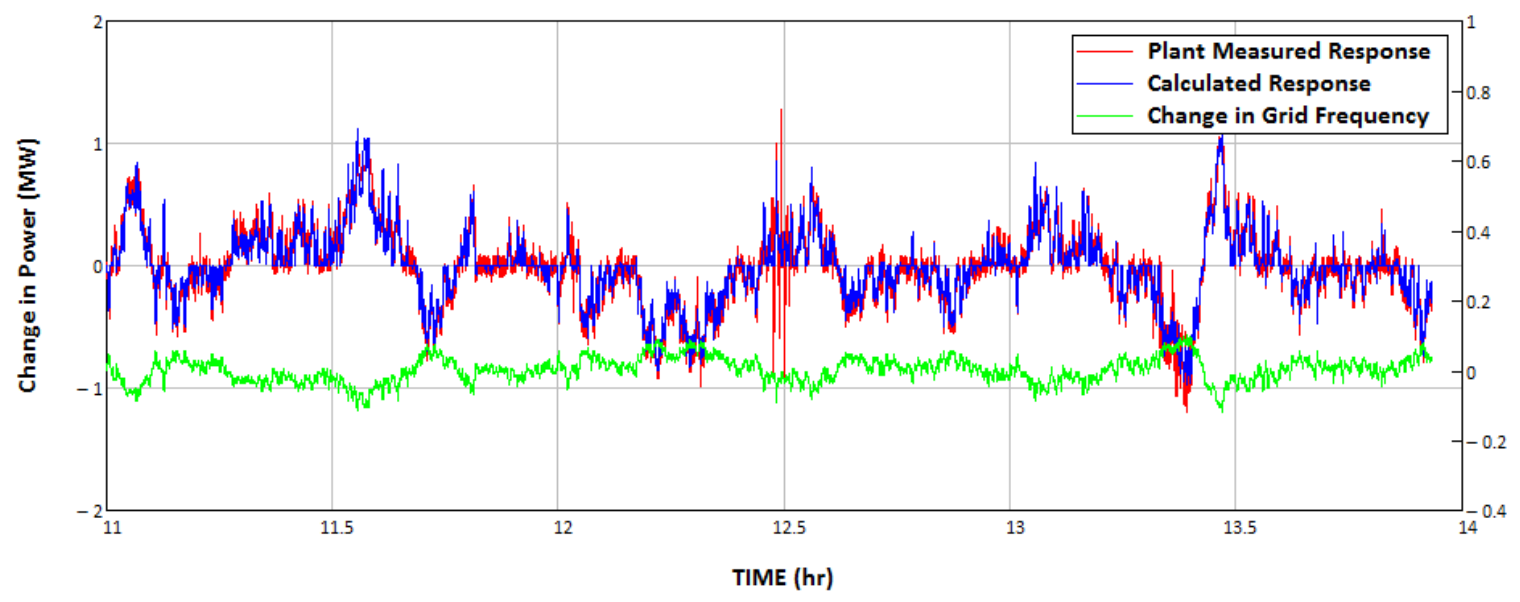

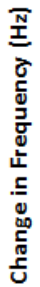

Figure 40. Results of 3\% droop tests-August 20, 2015
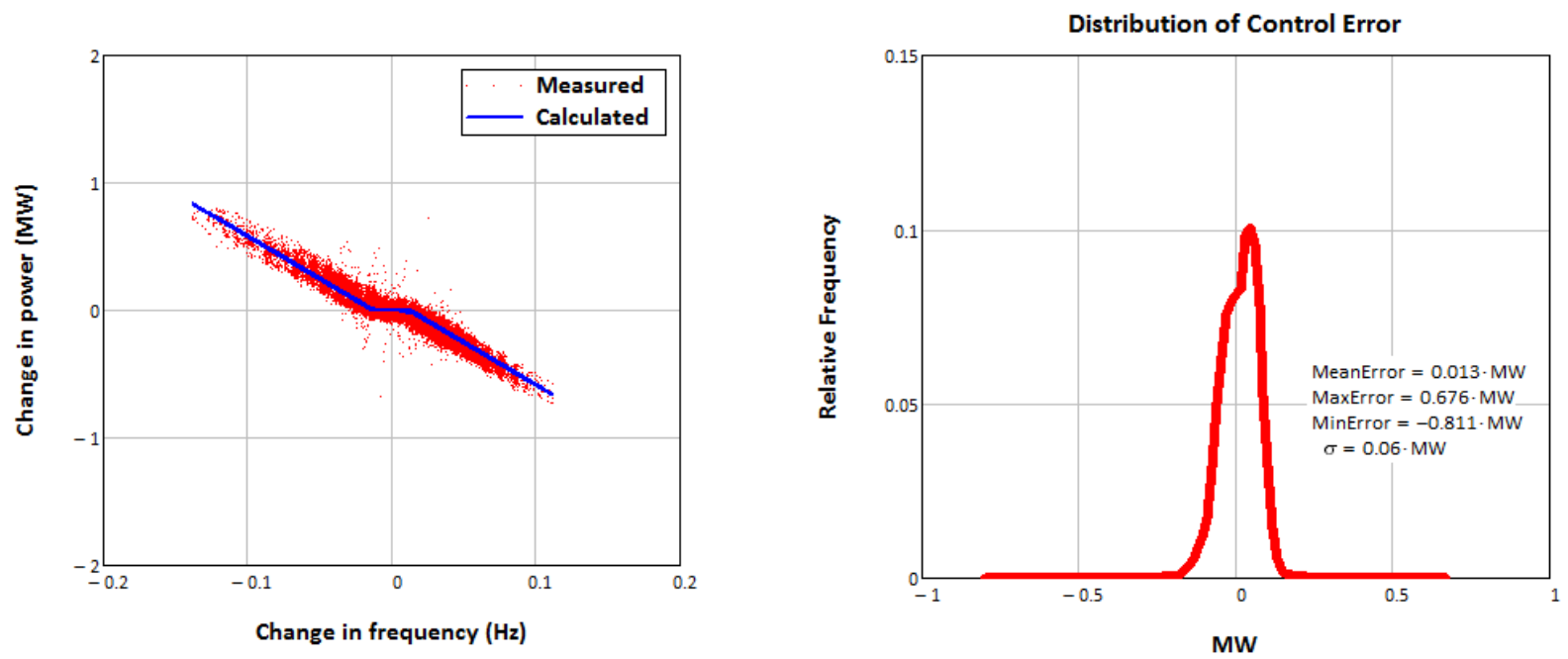

Figure 41. Measured droop characteristic and control error statistics for $5 \%$ droop test-August 19,2015 

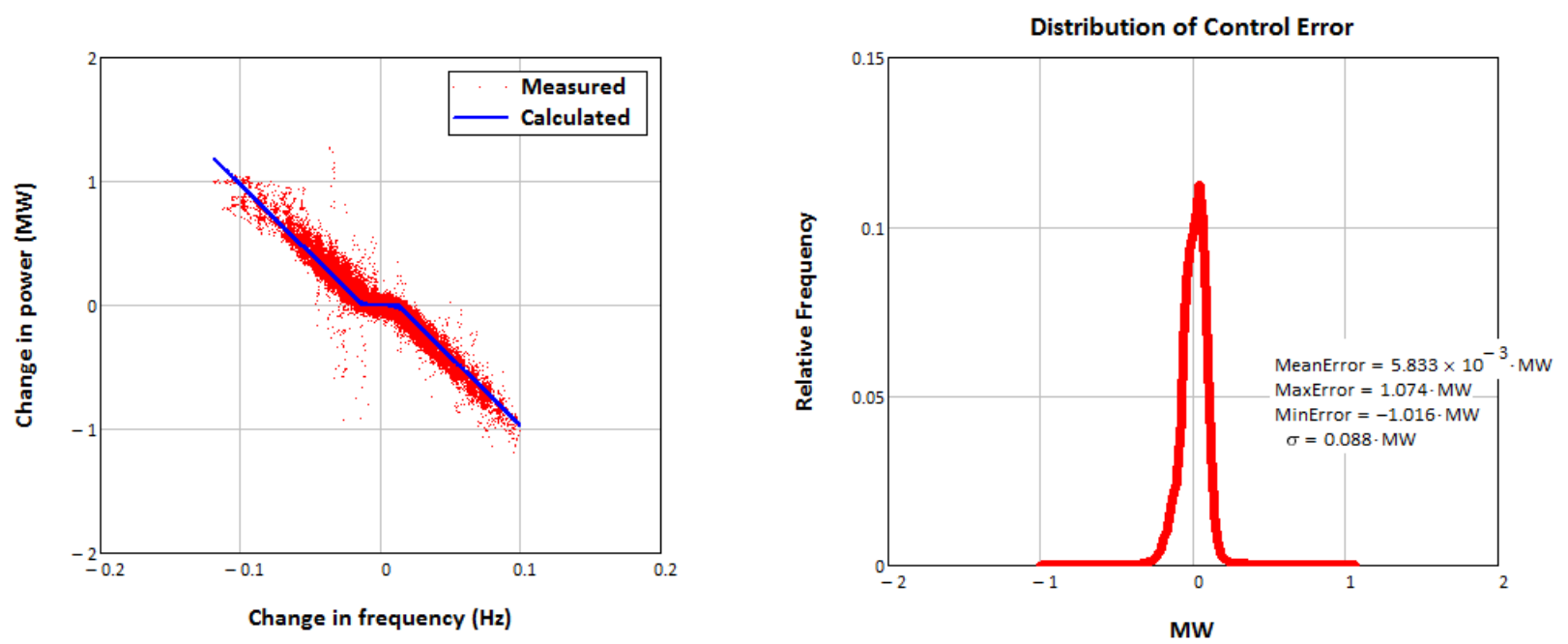

Figure 42. Measured droop characteristic and control error statistics for $3 \%$ droop test-August 20,2015

The results of the tests on both August 19 and August 20 were consolidated and are shown in Figure 43 for $5 \%$ and the more aggressive 3\% droop tests. The measured data points were plotted against calculated ideal droop response for both cases. The grid frequency deviations during both tests were generally within a range of $\pm 0.1 \mathrm{~Hz}$, so it was not possible to test the plant performance during larger frequency fluctuations. 


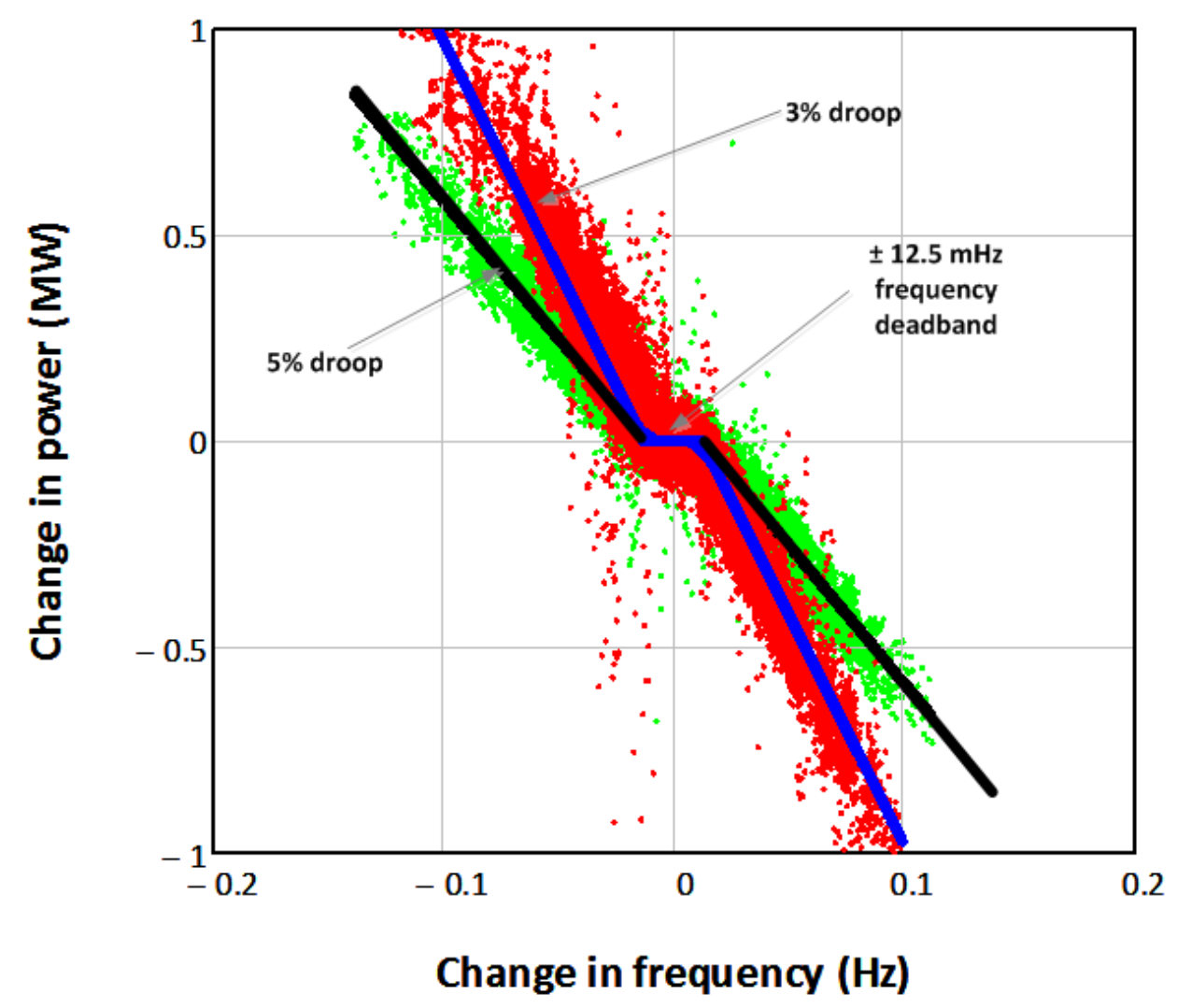

Figure 43. Comparison of $5 \%$ and $3 \%$ droop test data

More 3\% and 5\% droop tests were conducted on August 21 and August 24, respectively. The data for these tests are shown in Figure 44 through Figure 47. These days had much higher shortterm variability of solar resource compared to August 19-20. As a result, the droop performance had more scatter during these periods. 


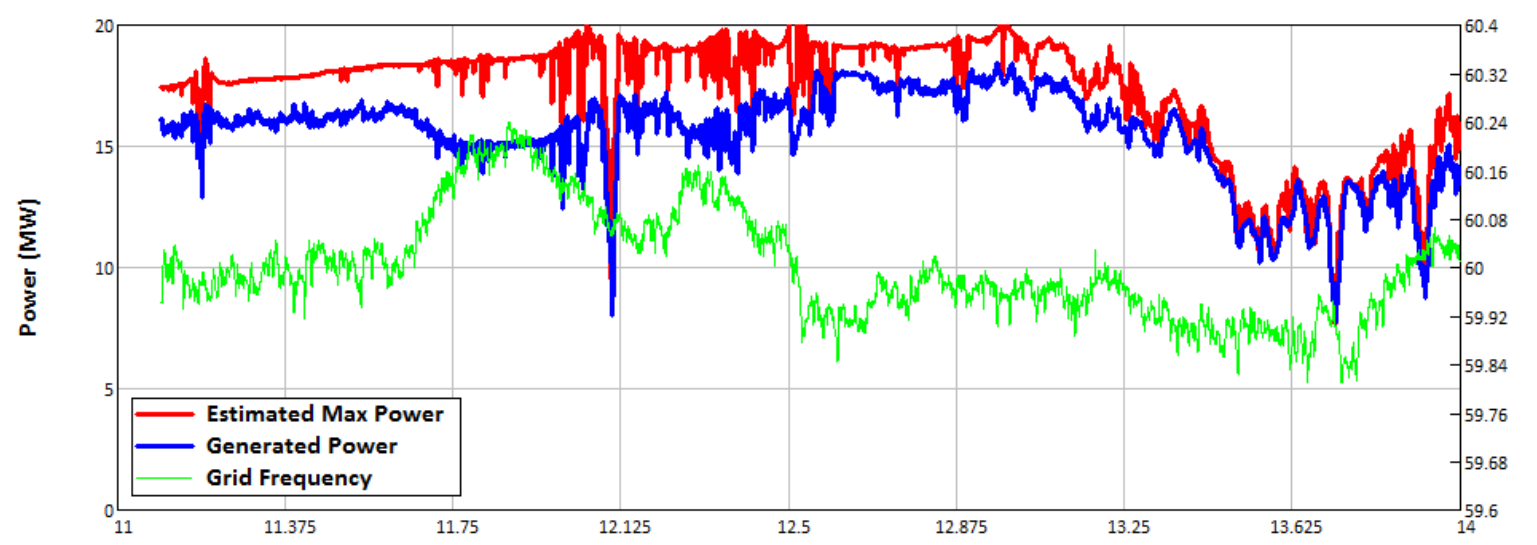

胥

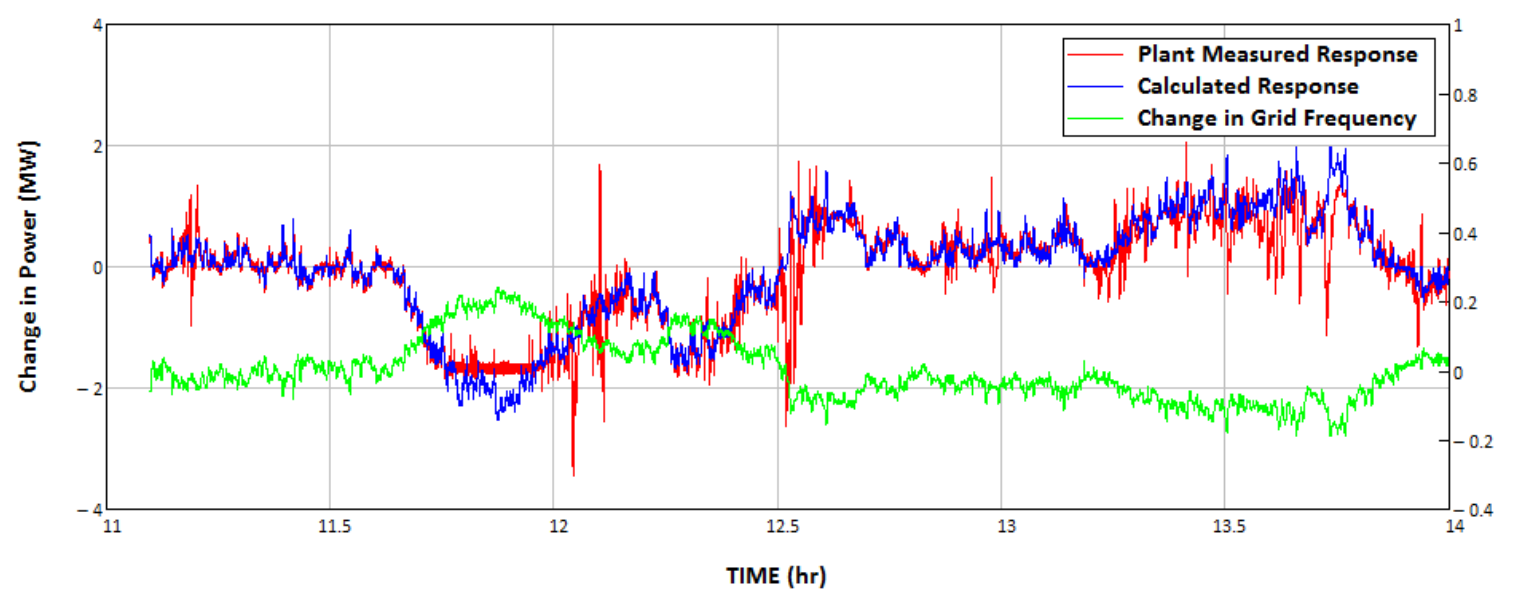

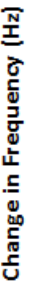

Figure 44. Results of 3\% droop tests-August 21, 2015
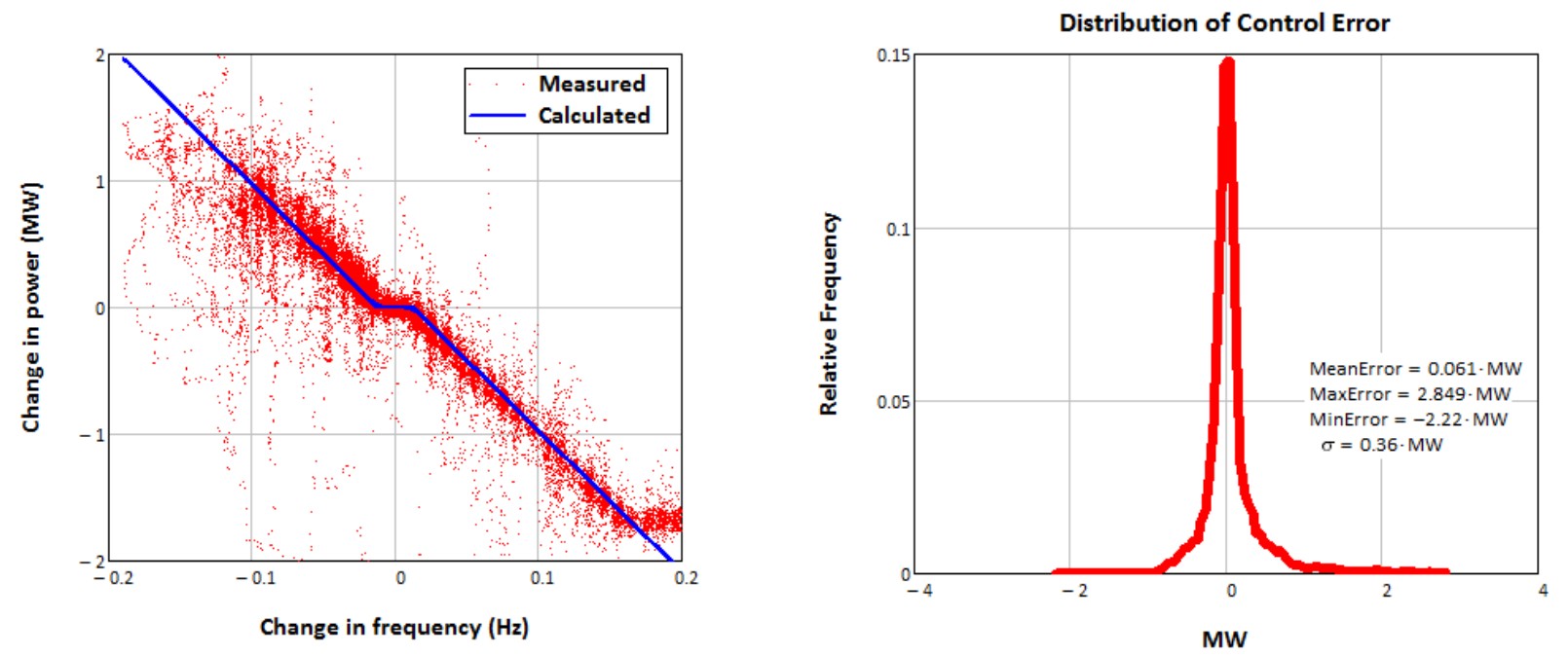

Figure 45. Measured droop characteristics for 3\% tests-August 21, 2015 


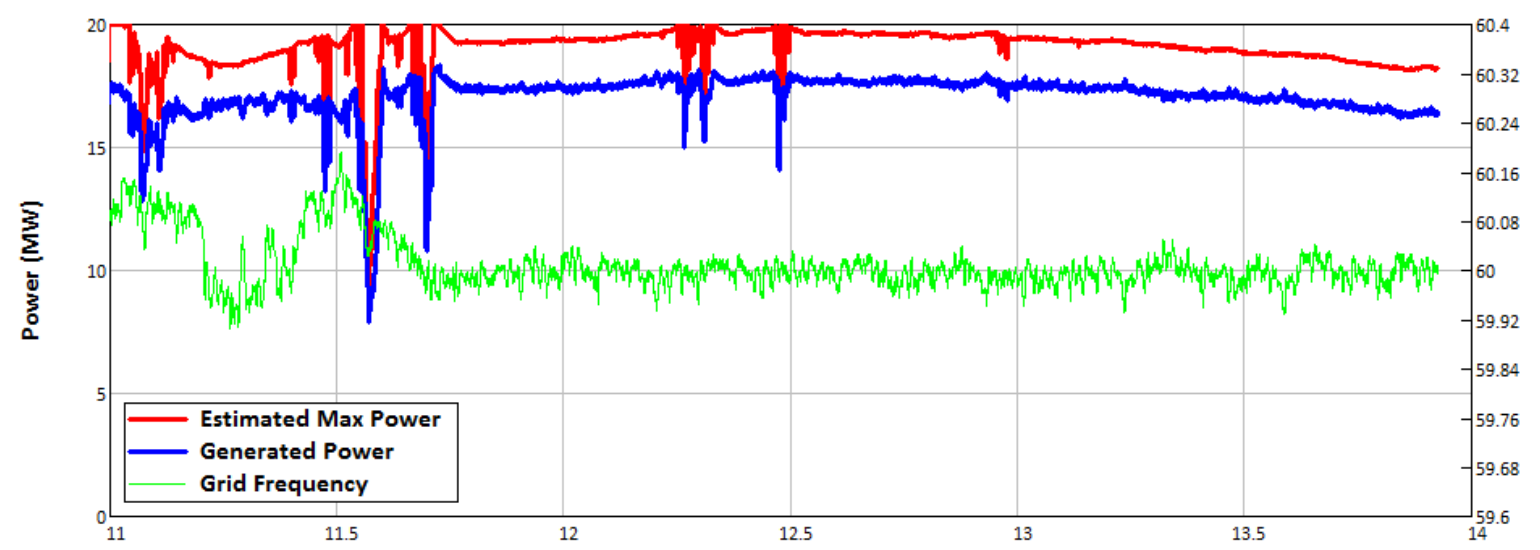

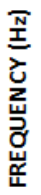

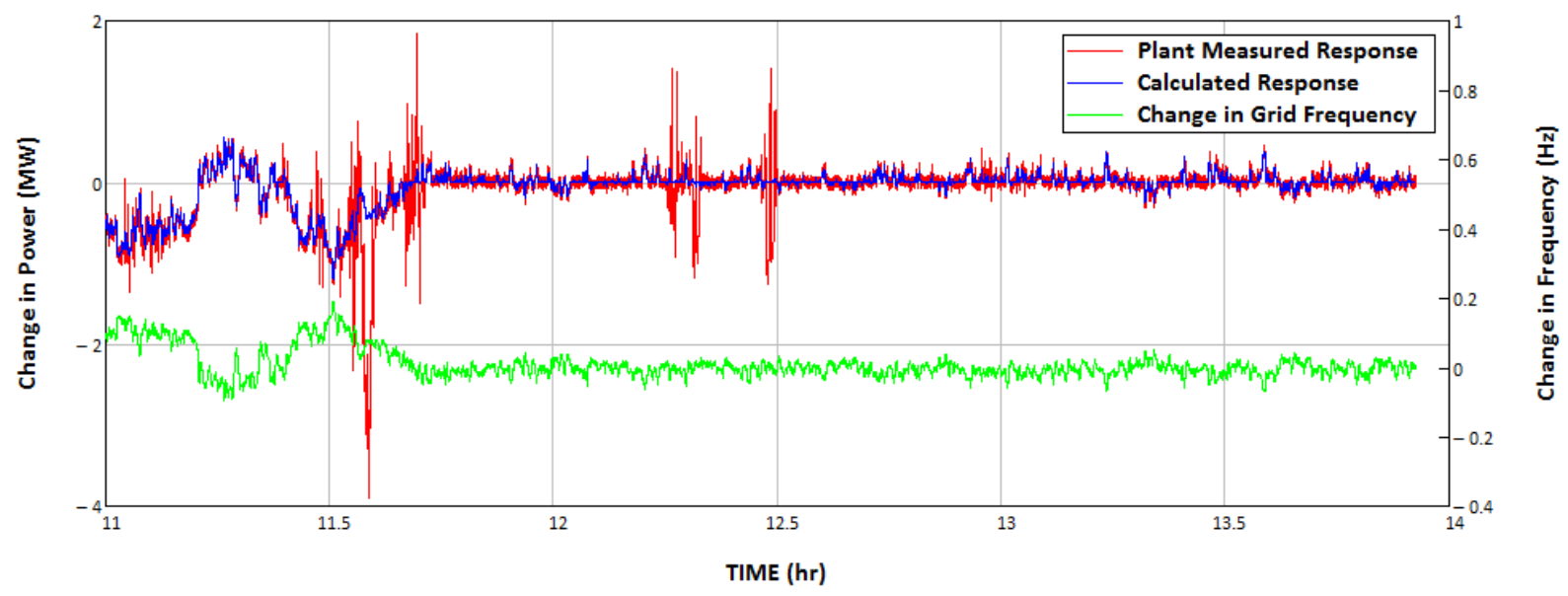

Figure 46. Results of 3\% droop tests-August 24, 2015
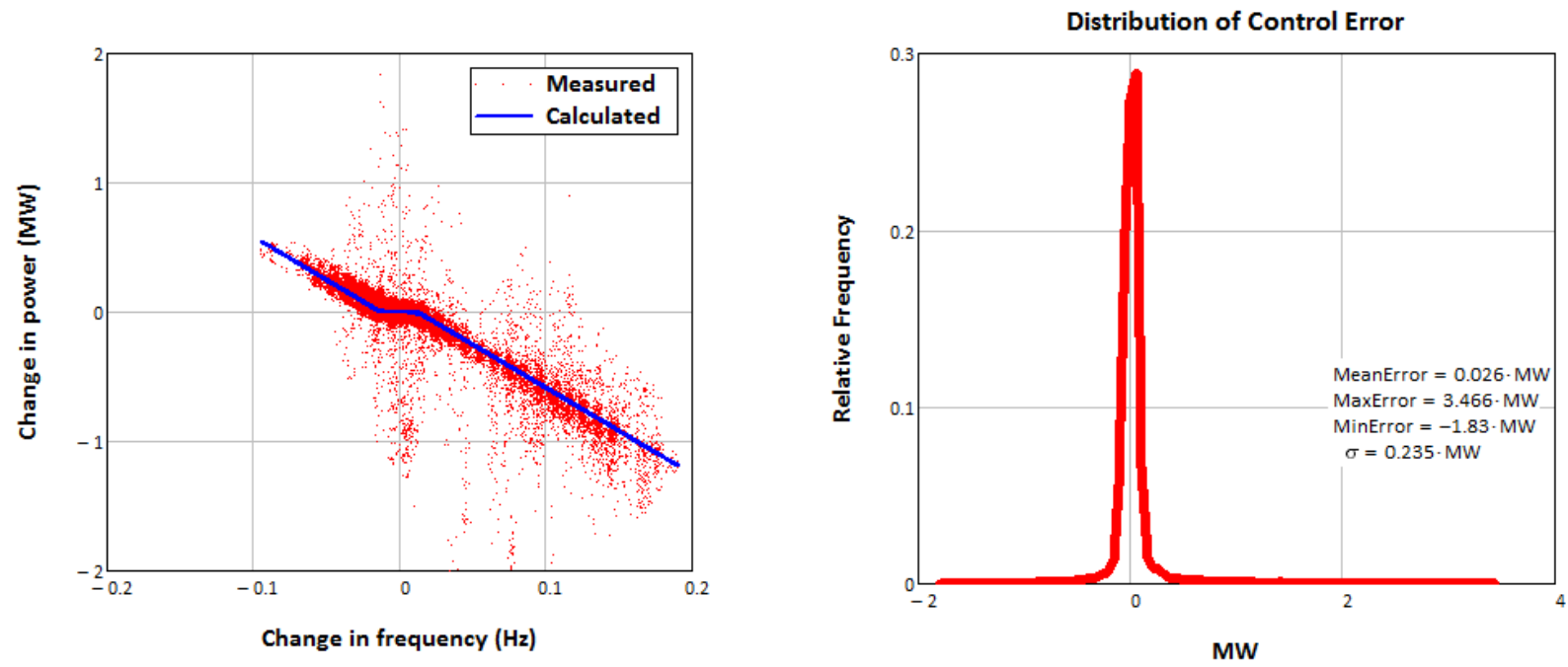

Figure 47. Measured droop characteristics for 5\% tests-August 24, 2015 


\subsection{FFR Tests}

FFR tests were conducted at the Ilumina plant on Aug 12, 2015. The plant was set to operate with $10 \%$ curtailment for these tests. FFR was triggered by providing a step-change control signal to the PPC, simulating a condition of rapid frequency drop. The plant controller was programmed to deploy its curtailed reserve as fast as possible in response to this simulated frequency event. The test was repeated many times during three different production levels: high, medium, and low power. The plant controller was set into "oscilloscope mode" to record the power data at a high sampling rate $(100 \mathrm{~Hz})$. The results of the FFR tests are shown below in Figure 48 through Figure 51. An external frequency trigger simulated a step change in frequency from normal $60 \mathrm{~Hz}$ down to $59 \mathrm{~Hz}$.

As shown below in the figures, the plant essentially deployed all its available reserve within 500 milliseconds from the beginning of the event at any power level. Figure 49 shows the beginning of one event in higher resolution. There was a delay of approximately 50-100 milliseconds between the frequency change and the beginning of the FFR by the plant. Implementing sophisticated control theory and fine tuning the power and current gains could help with minimizing the oscillations shown in the traces below. In general, more care is needed to fine tune and set controls to achieve better long-term performance. But with respect to the speed and power increase of the frequency response, the tests were successful.
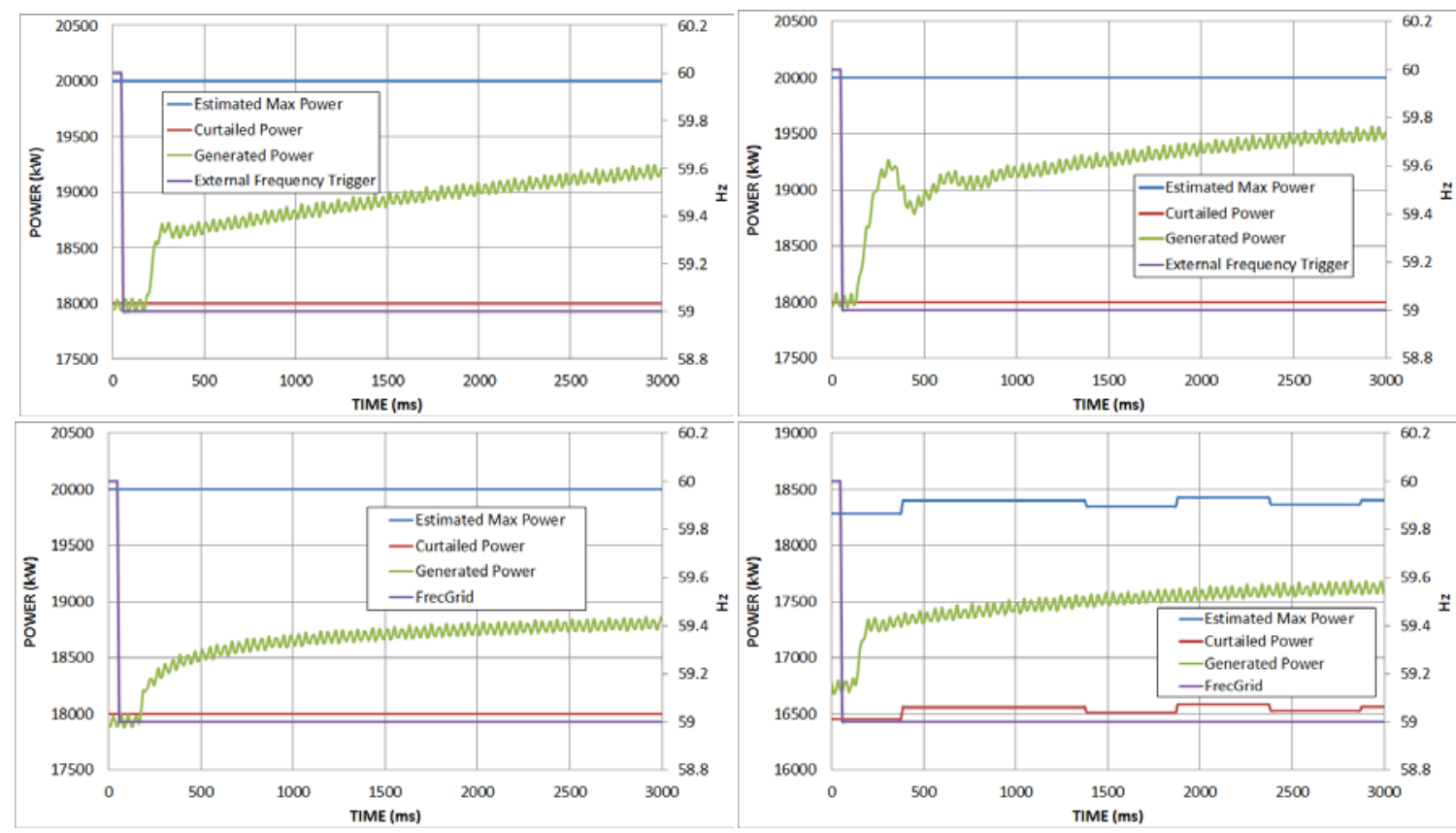

Figure 48. FFR tests at high power 


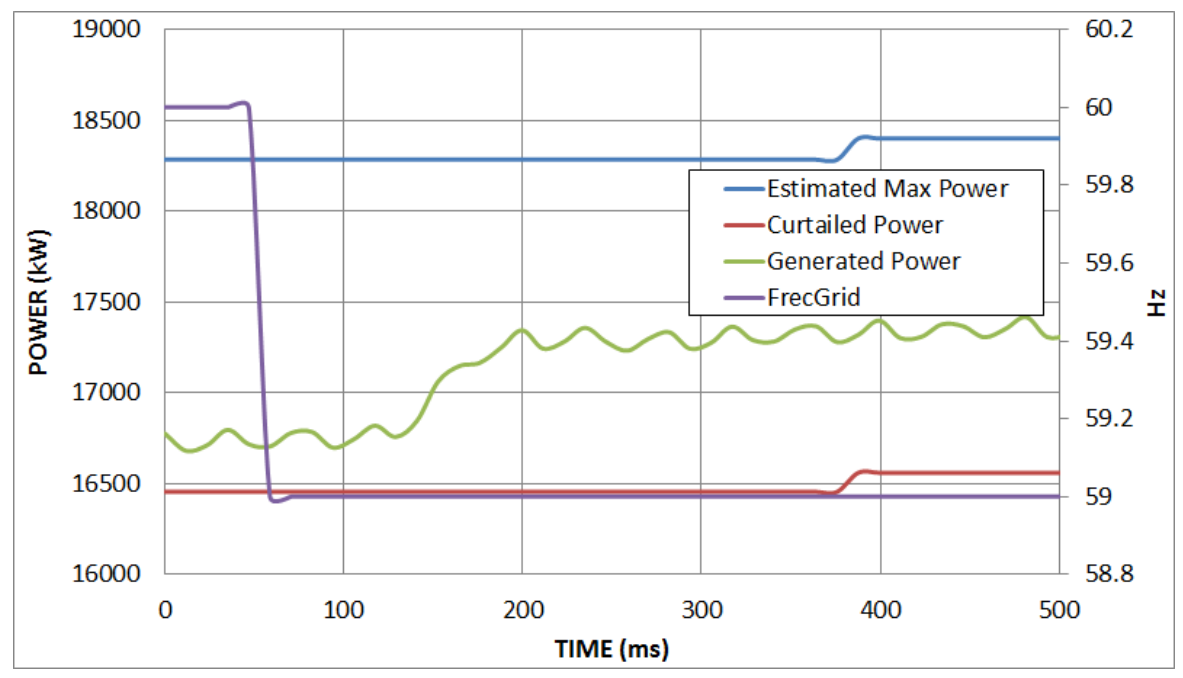

Figure 49. Beginning of FFR tests at high power
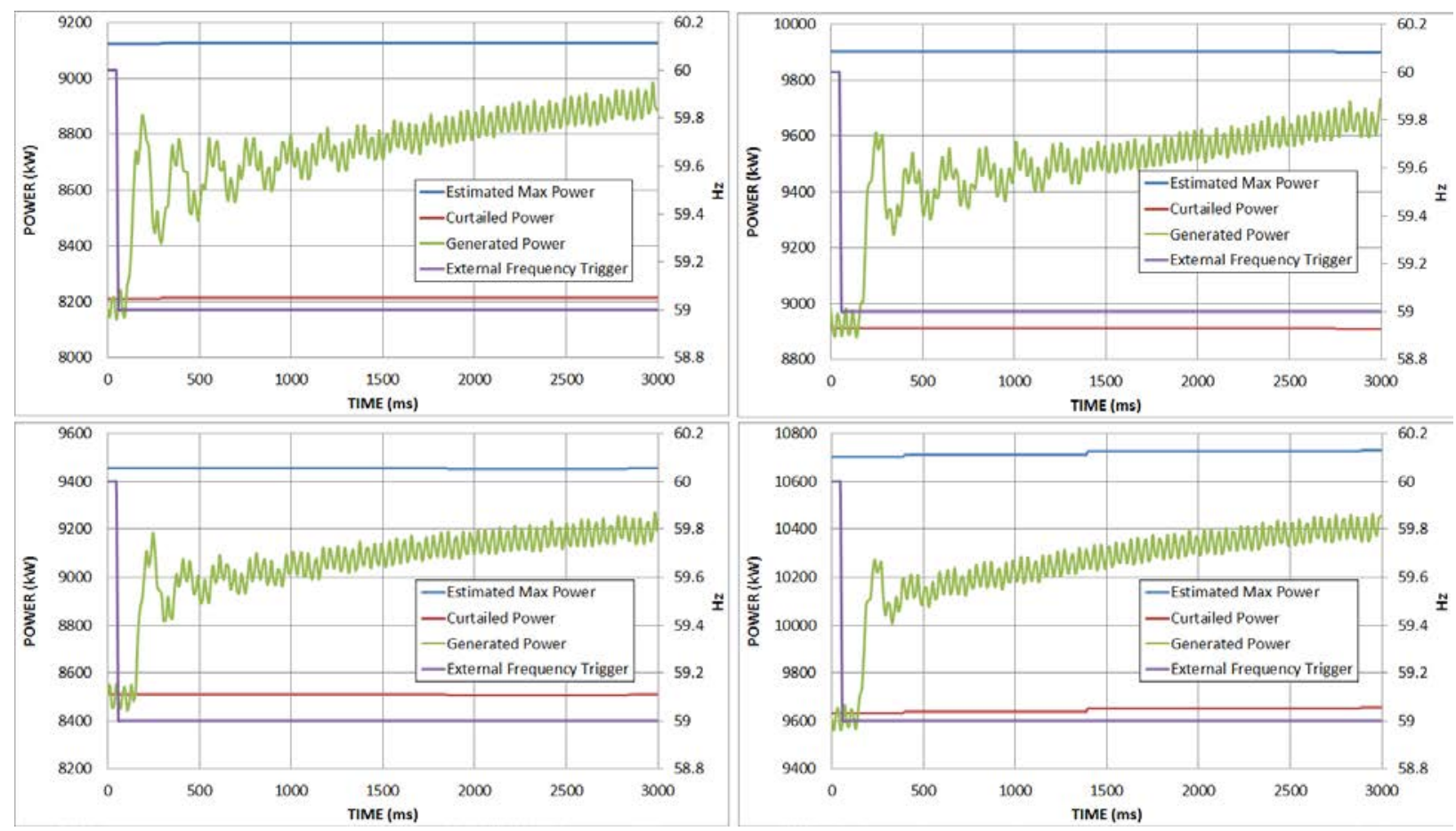

Figure 50. FFR tests at medium power

This report is available at no cost from the National Renewable Energy Laboratory (NREL) at www.nrel.gov/publications. 

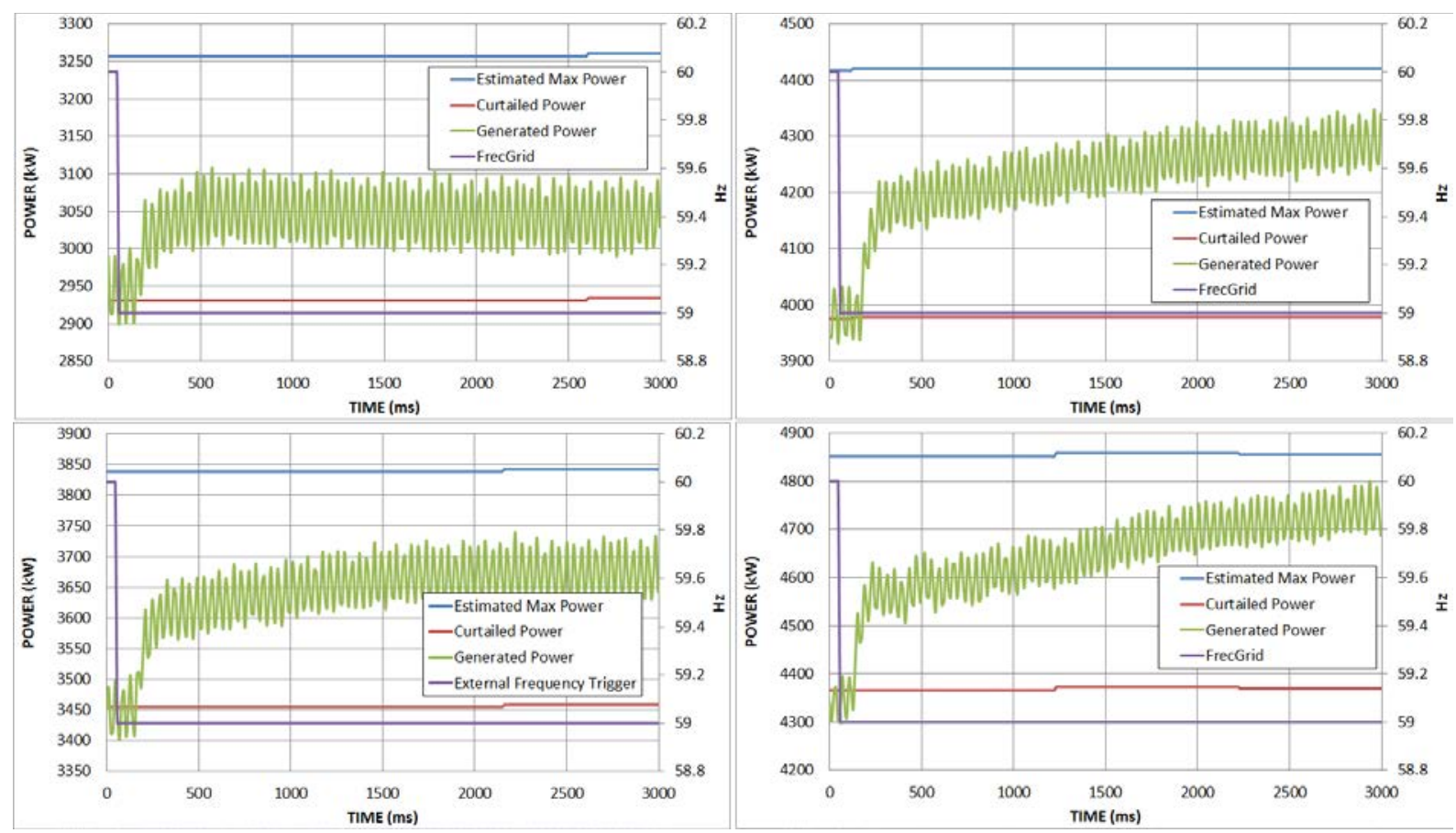

Figure 51. FFR tests at low power

FFR tests demonstrated that PV power plants can provide fast response to frequency events by deploying their reserves and injecting additional power into the grid within a short time interval after a frequency event is detected. This measured response by a PV power plant is significantly faster compared to any synchronous generator conventional power plants. We show some examples of measured and modeled response by conventional thermal plants for comparison to the measured PV power plant response using data from [15]. An example of a response time by a 496-MVA steam turbine is shown in Figure 52 based on results in [16]. A response from a typical gas turbine based on data from [17] is shown in Figure 53. These examples demonstrate superior response characteristics of the inverter-coupled PV power plant compared to rotating generators (sub-second compared to 5 seconds-20 seconds). 


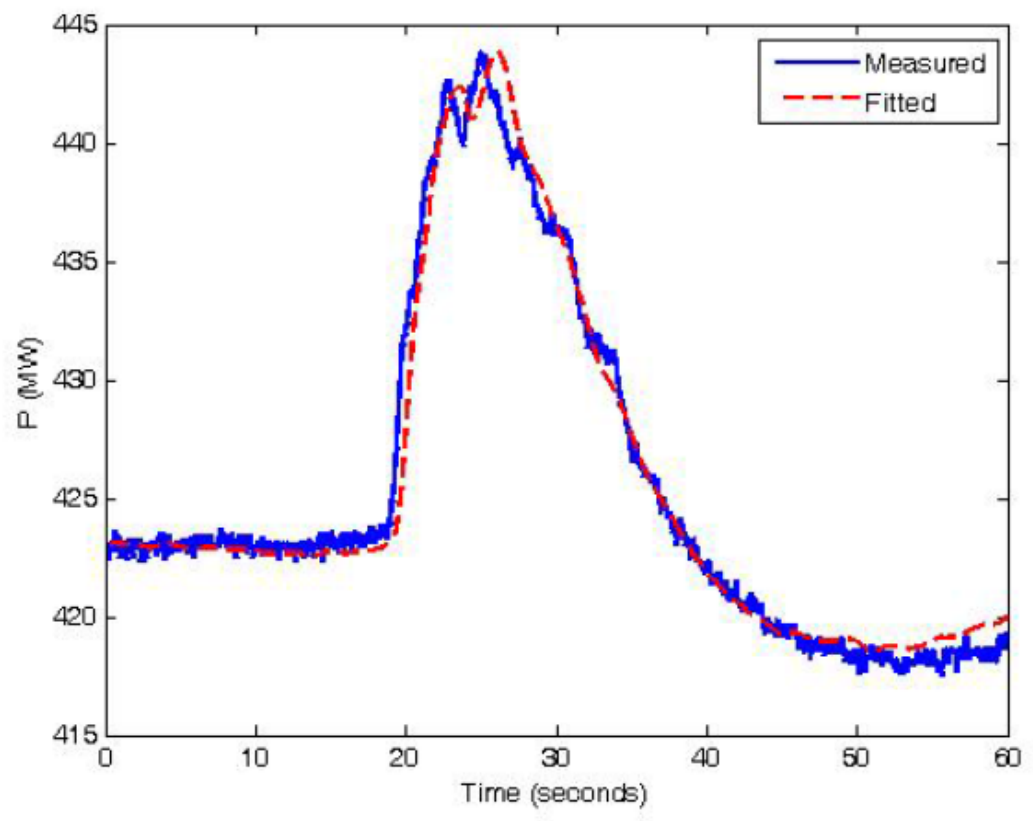

Figure 52. Measured and simulated response of 496-MVA steam turbine generator to frequency disturbance

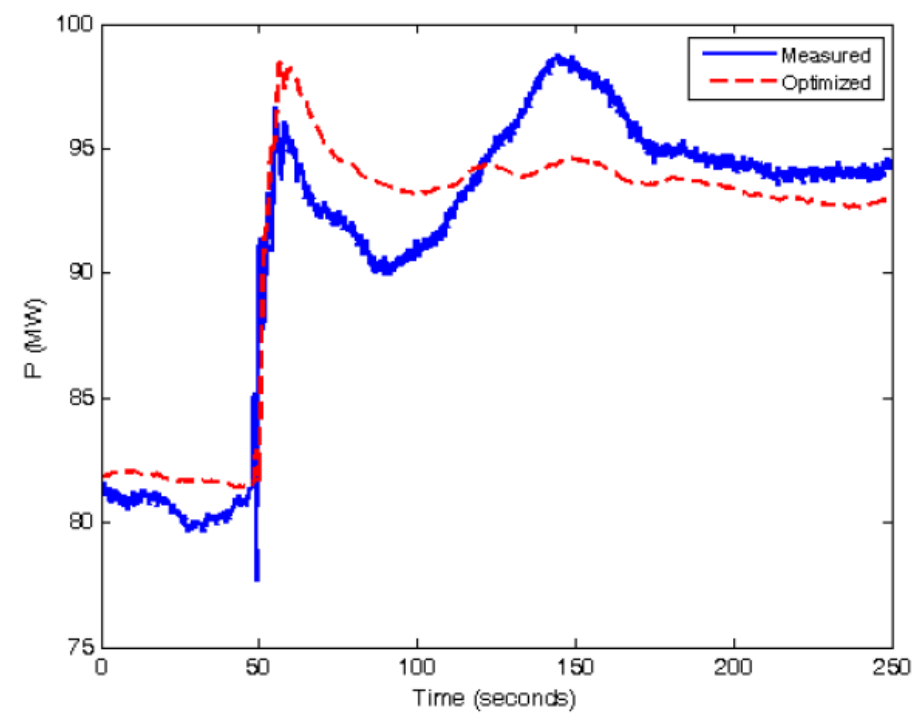

Figure 53. Measured and simulated response of a gas turbine in a combined-cycle power plant

\subsection{PV Power Plant Fault Performance}

As mentioned in Section 5.4, there were no planned tests to demonstrate plant transient performance under grid voltage or frequency-fault conditions. Instead, we utilized the data from PREPA's digital signal monitoring system to capture transient events that were happening in the power system and impacting plant operation. Several interesting events that demonstrated how various controls play a role in Ilumina's operation are described in this section. 
The first event occurred on June 30, 2015, and is shown in Figure 54. One-cycle (16 millseconds) voltage, current, and power data were captured by PREPA's fault recorder on the $13.2-\mathrm{kV}$ side of the plant transformer. This event started at time 0 when a low-voltage event caused the entire PV power plant to trip off. After the fault was cleared, approximately 2 minutes later the plant resumed its operation by slowly ramping its power (at a rate of $4 \mathrm{MW} /$ minute) to the full power available at the moment. This slow recovery demonstrated the action by the plant's ramp-rate limit control function in accordance with PREPA's MTRs.
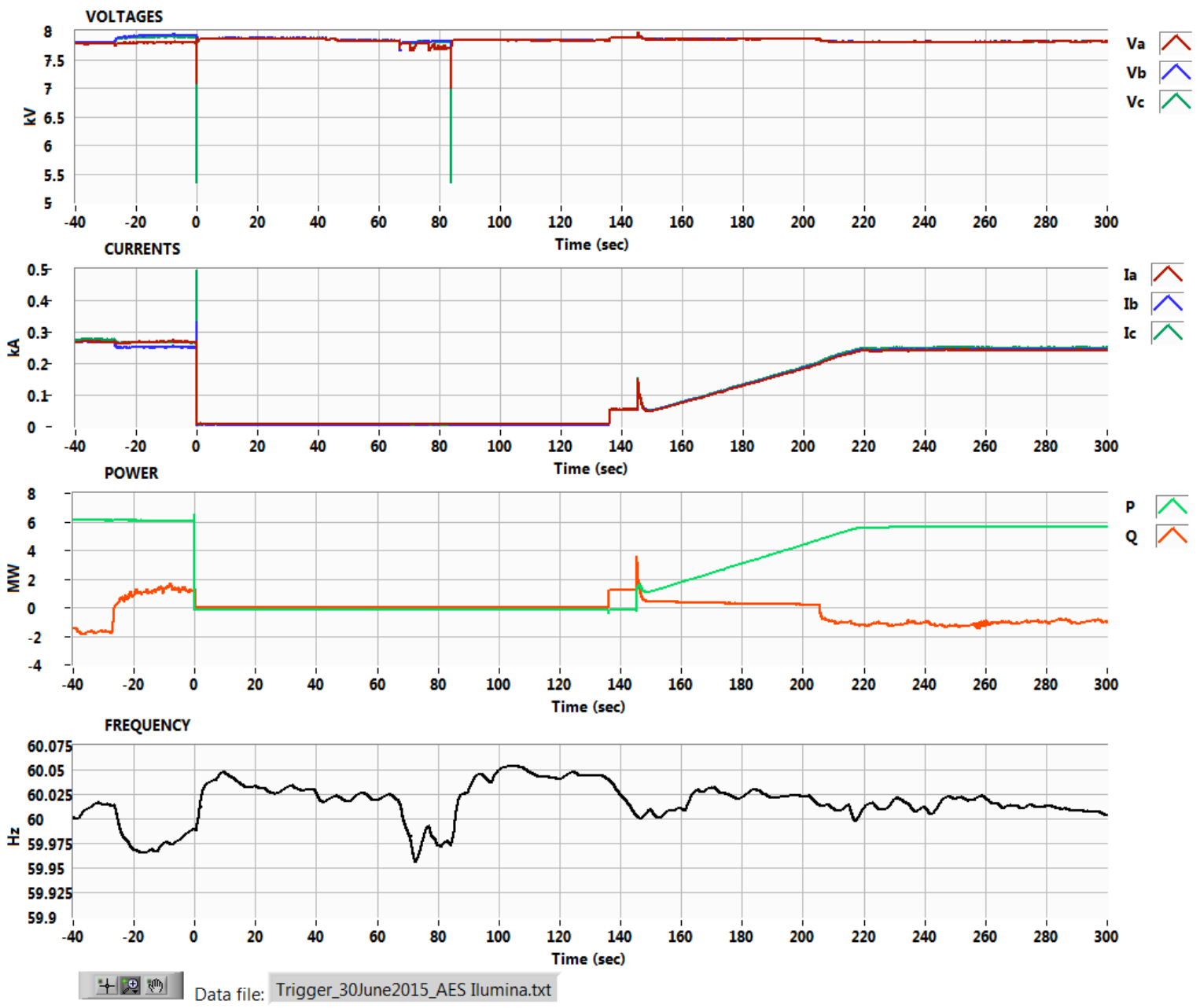

Figure 54. Plant response to grid voltage fault and recovery ramp rate-June 30, 2015

The next event happened on August 18, 2015, when the plant's production was close to its peak. This event started at 0 second when presumably a large load tripped off somewhere in PREPA's power system causing a small voltage transient followed by a rapid rise in frequency, as depicted in Figure 55. The plant rode through this high-frequency time period smoothly and continued producing power while PREPA's AGC control was driving the grid frequency back to its normal level. 

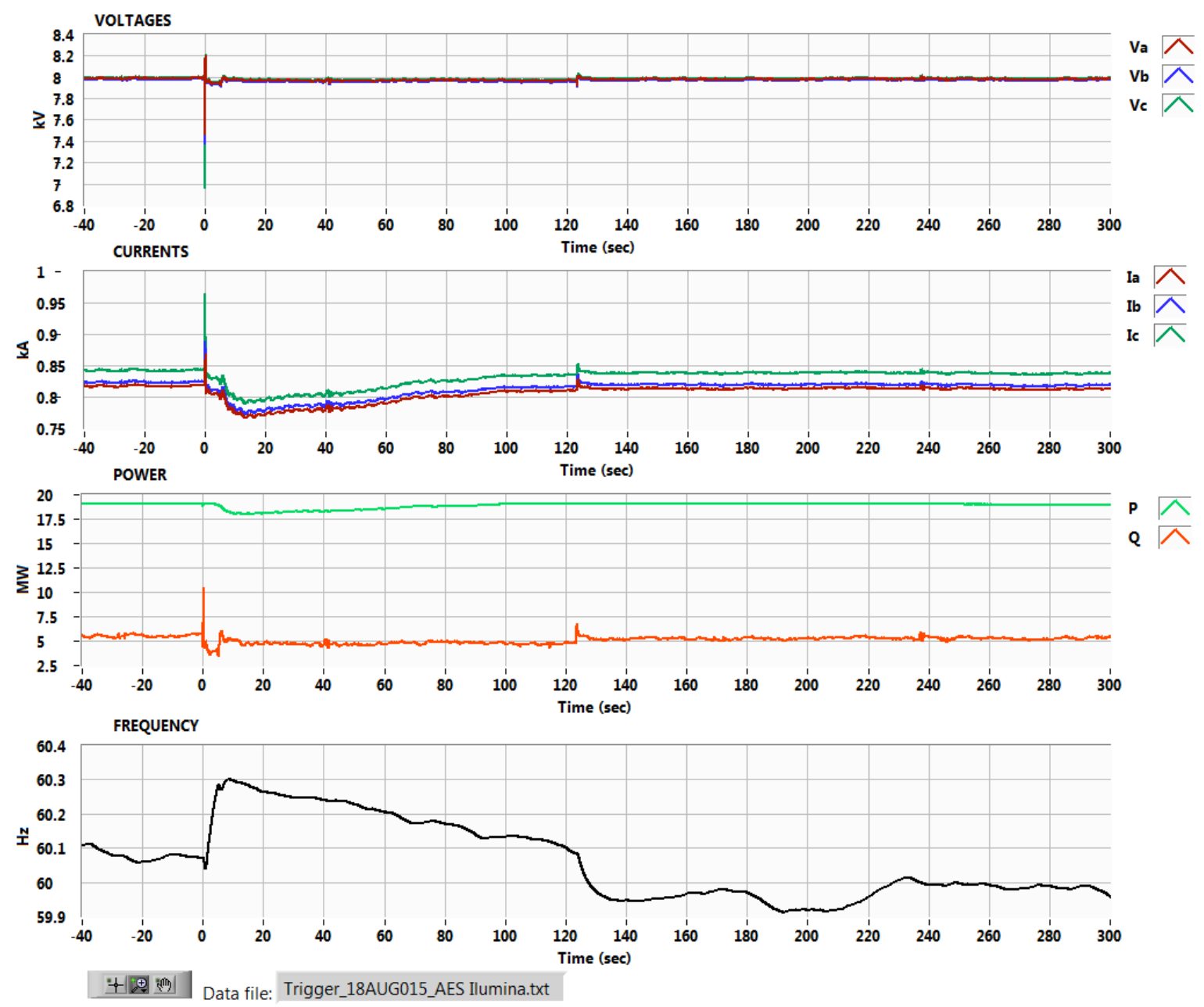

Figure 55. Over-frequency event-August 18, 2015

Another interesting event took place on June 5, 2015, during low production hours when NREL was not in the test phase at Ilumina. This event demonstrated the plant's ability to ride through a low-frequency event, as shown in Figure 56. Grid frequency started declining rapidly at $\mathrm{t}=-15$ seconds, and it reached is minimum point of $59 \mathrm{~Hz}$ after approximately 10 seconds. The plant continued smooth operation throughout the whole under-frequency event while PREPA's AGC was restoring the balance between load and generation in its system. PREPA drove the frequency to its scheduled level approximately 3 minutes after the fault began.

Figure 56. Under-frequency event-June 5, 2015 


\section{Renewables Integration and Ancillary Services in ERCOT}

ERCOT is an independent system operator that serves more than 23 million customers in Texas and represents $85 \%$ of the state's electric load. It is designated by the Public Utility Regulatory Act of Texas, and as such ERCOT operates the interconnected transmission system and wholesale electricity market. As defined by standards from the North American Electric Reliability Corporation (NERC), ERCOT is a single balancing authority interconnection, which means that it cannot generally rely on any neighboring balancing authority for assistance during system events and emergencies. ${ }^{3}$

Texas is home to one of the largest installed renewable energy fleets in the country, particularly wind (approximately $13 \mathrm{GW}$ at the end of 2014) [18]. Solar generation in Texas is also undergoing rapid growth, with total installed capacity approximately $175 \mathrm{MW}$ by the end of 2014 [18].

\subsection{Existing Ancillary Services in ERCOT}

The current ancillary services for active power in ERCOT include responsive reserve service, which is a governor or governor-like response from online resources with reserved headroom; regulating reserve service; and non-spinning reserve service [19]. Under 2014 methodology, ERCOT's responsive reserve service is maintained at 2,800 MW year-round and deploys during generation trip events. The 2015 methodology, which was effective beginning June 1, 2015, maintained different amounts of responsive reserve service based on the expected system conditions. During scarcity conditions, generation resources providing these services will be dispatched by security-constrained economic dispatch and must be capable of delivering full service within 10 minutes. Load resources triggered by under-frequency relays can provide up to $50 \%$ of total responsive reserve service that ERCOT is procuring for any given hour. All generation resources greater than $10 \mathrm{MW}$ must have their governors active with no greater than $5 \%$ droop settings and deadband not to exceed $\pm 36 \mathrm{mHz}$.

ERCOT's regulation service is maintained at $300 \mathrm{MW}-600 \mathrm{MW}$ and is used to control the frequency between 5-minute security-constrained economic dispatch intervals. The load frequency control system sends up-regulation and down-regulation signals to all participating generation every 4 seconds. Recently ERCOT introduced fast-responding regulation service as a subset of regulation for resources that have fast response times (full response within 1 second). Fast-responding regulation service must respond to load frequency control and must self-deploy for sudden frequency events when frequency reaches or goes below $59.91 \mathrm{~Hz}$.

The 30-minute non-spinning reserve service is maintained at $975 \mathrm{MW}-1,500 \mathrm{MW}$ and used to compensate for net load forecast errors, recover regulating reserves, and replace capacity lost during a large generator trip.

\footnotetext{
${ }^{3}$ For more information, see www.ercot.com.
} 


\subsection{Future Ancillary Services in ERCOT}

To enhance its system reliability and continue successful compliance with the standards and requirements of the North American Electric Reliability Corporation, in 2012 ERCOT began considering a significant change and new market design for the entire existing set of ancillary services to better address the challenges of its rapidly changing generation mix [19] and to address FERC Order 755. In particular, a new set of ancillary services associated with various forms of APC and management has been proposed by ERCOT to ensure reliable operation and compliance with regulatory standards. These newly proposed ancillary services include:

- Synchronous inertial response service (SIR),

- Fast Frequency Response Service (FFRS)

○ FFRS1, 0.5-second response at $59.8 \mathrm{~Hz}$, sustained for 10 minutes

○ FFRS2, 0.5 -second response at $59.7 \mathrm{~Hz}$, sustained until recalled by ERCOT

- Primary Frequency Response Service (PFRS)

- Up-regulating and down-regulating Reserve Service (RRS)

- Contingency Reserve Service (CR)

- Supplemental Reserve Service (SR)

The deployment of the reserve categories represented by these six ancillary services is governed primarily by reliability standards of the North American Electric Reliability Corporation, including regulating reserve to meet the CPS1 standard (BAL-001), contingency reserve to meet the Disturbance Control Standard (BAL-002), and primary frequency response to meet the Frequency Response Obligation standard (BAL-003 standard, newly approved by the Federal Energy Regulatory Commission) [19].

Modern PV inverters and PV power plant control systems have advanced control functions that allow PV generation to become a provider of some of the above ancillary services. In particular, the current state of the PV generation technology makes it technically feasible to provide the FFR, PFR and RR services from the above list (providing SIR is not possible for PV because of its lack of mechanical inertia.) The existing and proposed future framework for these ancillary services involving various forms of APC as envisioned by ERCOT [19] is shown Table 2. The table also shows the framework of all proposed ancillary services and their response and delivery times.

The increasing levels of wind power in the Competitive Renewable Energy Zones (CREZ) in the Panhandle region of Texas are causing related transmission system challenges to arise, such as wind power ramping rates, wind resource uncertainty, reactive power characteristics, and so on. To address these challenges, ERCOT has issued its Panhandle Renewable Energy Zone (PREZ) Study Report to identify a number of grid upgrade projects to address the wind build-out and stresses caused by increasing West Texas loads [20]. Continued wind generation expansion has stressed the new CREZ transmission system, particularly the sub-synchronous oscillation on the lengthy series-compensated transmission lines that bring West Texas wind power to load centers farther east. These difficulties contribute to voltage deviations and cause voltage stability issues, ultimately threatening overall system strength, which ERCOT must address through additional 
infrastructure and expense [21]. From this perspective, the reactive power and voltage control capabilities of modern utility-scale PV inverters can play an important role in addressing and/or mitigating some of the voltage stability issues present in West Texas areas.

Table 2. ERCOT's Existing and Future Ancillary Services Framework

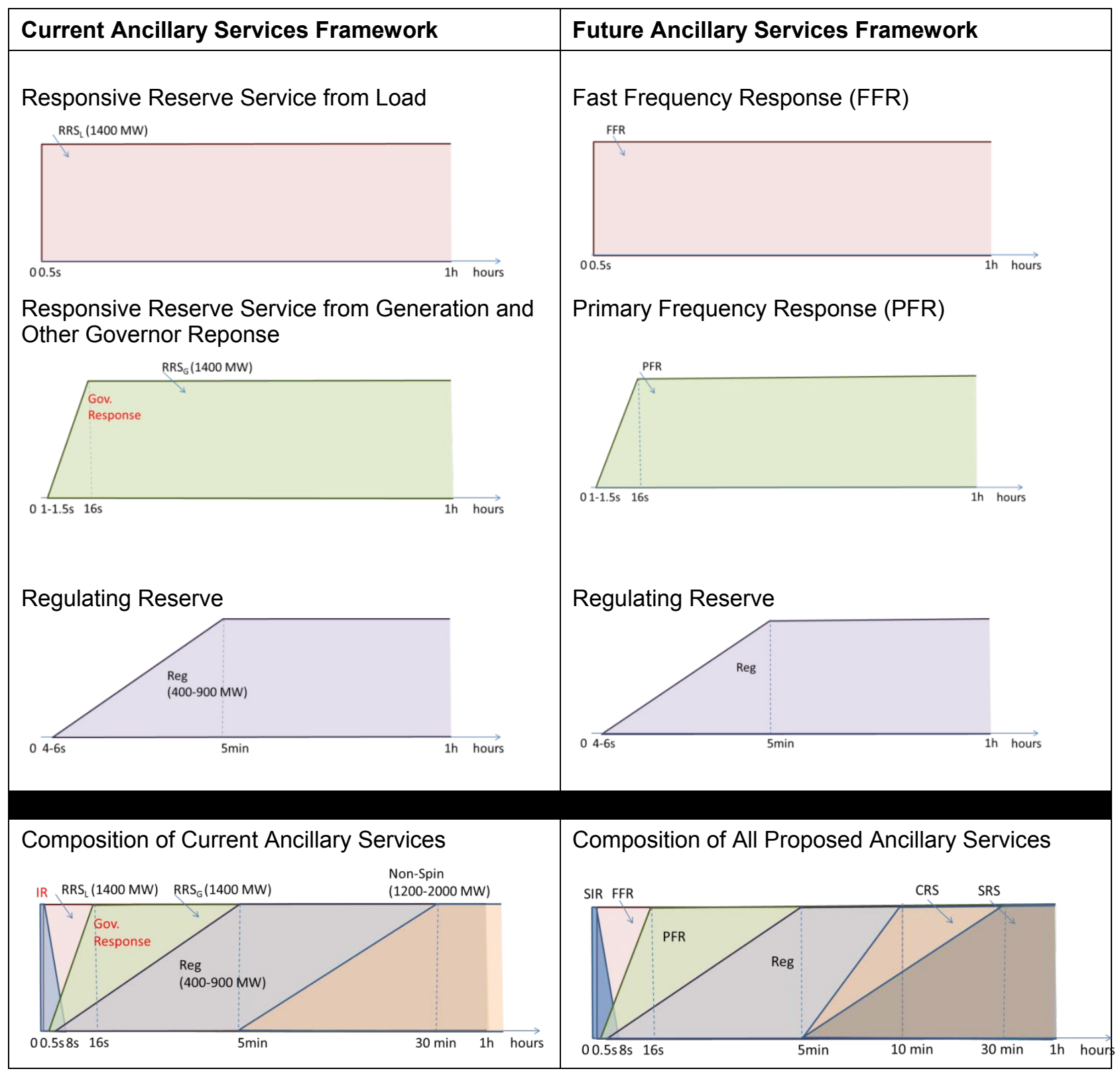

This testing project was intended to demonstrate several ancillary services controls of First Solar's Barilla PV power plant, including the above-mentioned APC features and some voltage and power factor regulation features. The data generated by such tests can demonstrate the capabilities of utility-scale PV generation for addressing some challenges associated with high penetration levels of variable renewable generation penetration in ERCOT. The same data can be used by other utilities and system operators to better understand the role of PV technologies to provide ancillary services to the grid, validate plant models, etc. 


\section{Description of First Solar's Pecos Barilla PV Power Plant}

First Solar is developing a 50- MWac power plant near Fort Stockton, Texas (Figure 57). A new 138/34.5-kV First Solar Hovey substation has been installed and connected to AEP's Barilla Junction substation by a 0.585 -mile $138-\mathrm{kV}$ transmission line. Phase 1 of the Barilla project includes Stage (A), $22 \mathrm{MW}$ (SMA inverters only), and Stage (B), an additional $32 \mathrm{MW}$ consisting of $8 \mathrm{MW}$ of General Electric inverters. Phase 2 will include an additional 20 MWac of solar PV generation. Reactive compensation in the form of capacitor banks is used to meet the large generator interconnection requirements (LGIA) at the POI [22]. A 4.75-MVAR switched capacitor bank will be used to meet the LGIA power factor requirement of \pm 0.95 at the POI for Phase 1. Another 4.75-MVAR capacitor bank will be installed for Phase 2.

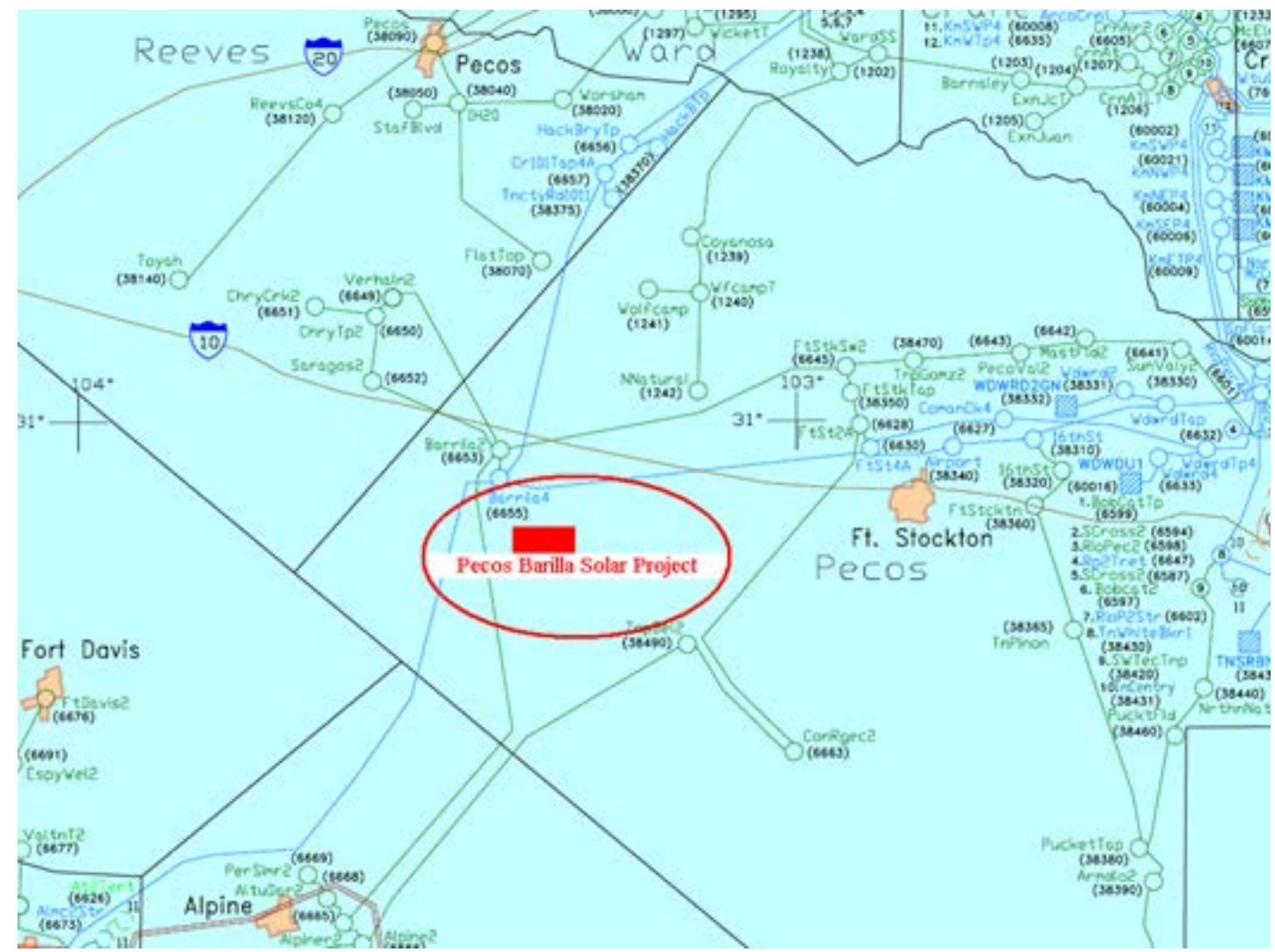

Figure 57. Location of the Pecos Barilla PV power plant in West Texas. Image from First Solar

An aerial photo of the plant is shown in Figure 58. Figure 59 shows a single-line diagram of Phase 1 of the Pecos Barilla PV power plant. Phase 1 consists of 28 inverters, each rated at 880 $\mathrm{kVA}$. Pairs of inverters are connected to individual three-winding inverter transformers to step up the inverter voltage to $34.5 \mathrm{kV}$. Electrical power from these inverters is aggregated to the plant transformer, which further steps up the voltage from $34.5 \mathrm{kV}$ to the $138-\mathrm{kV}$ transmission level. 


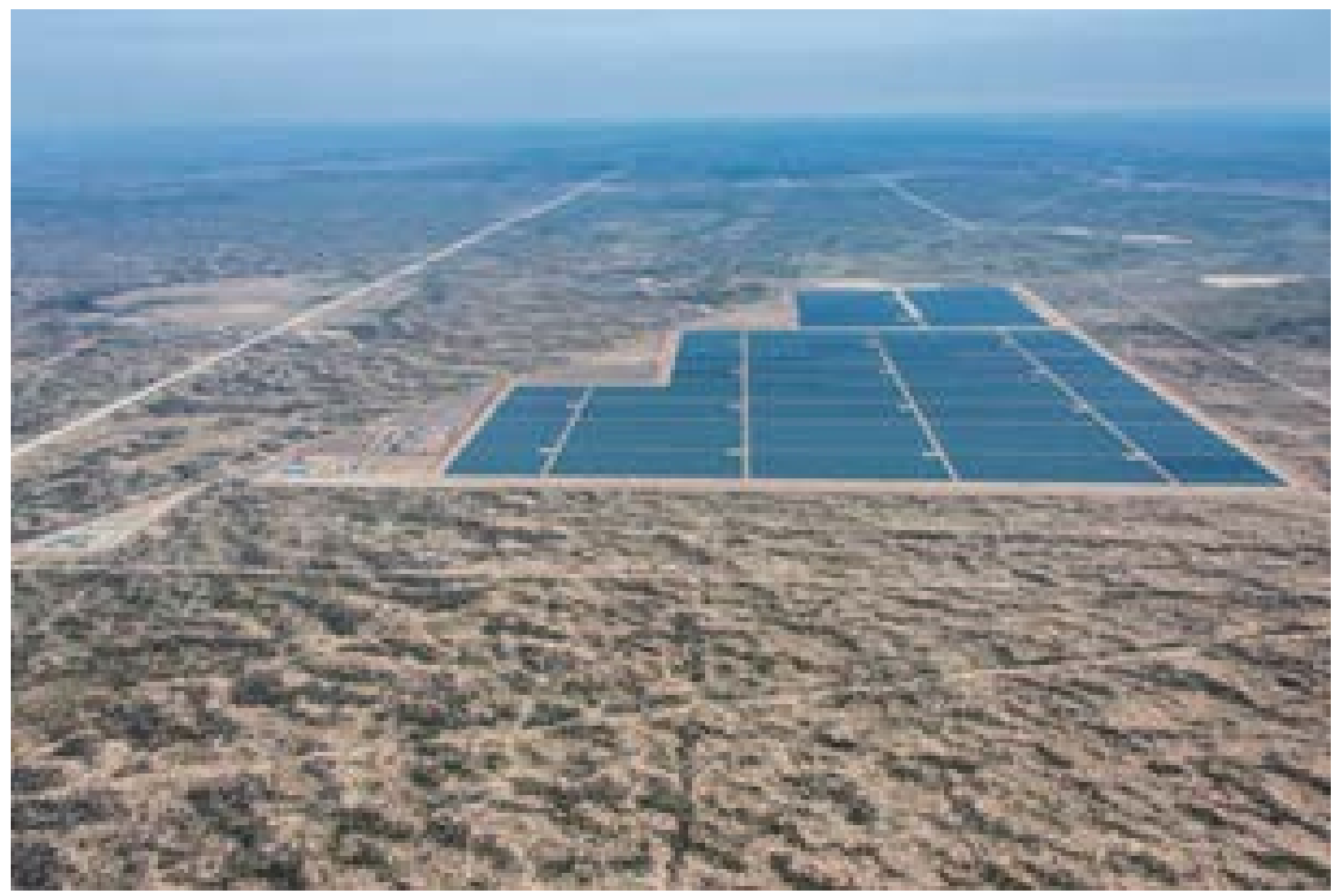

Figure 58. Aerial photo of the Pecos Barilla PV power plant. Image from First Solar 


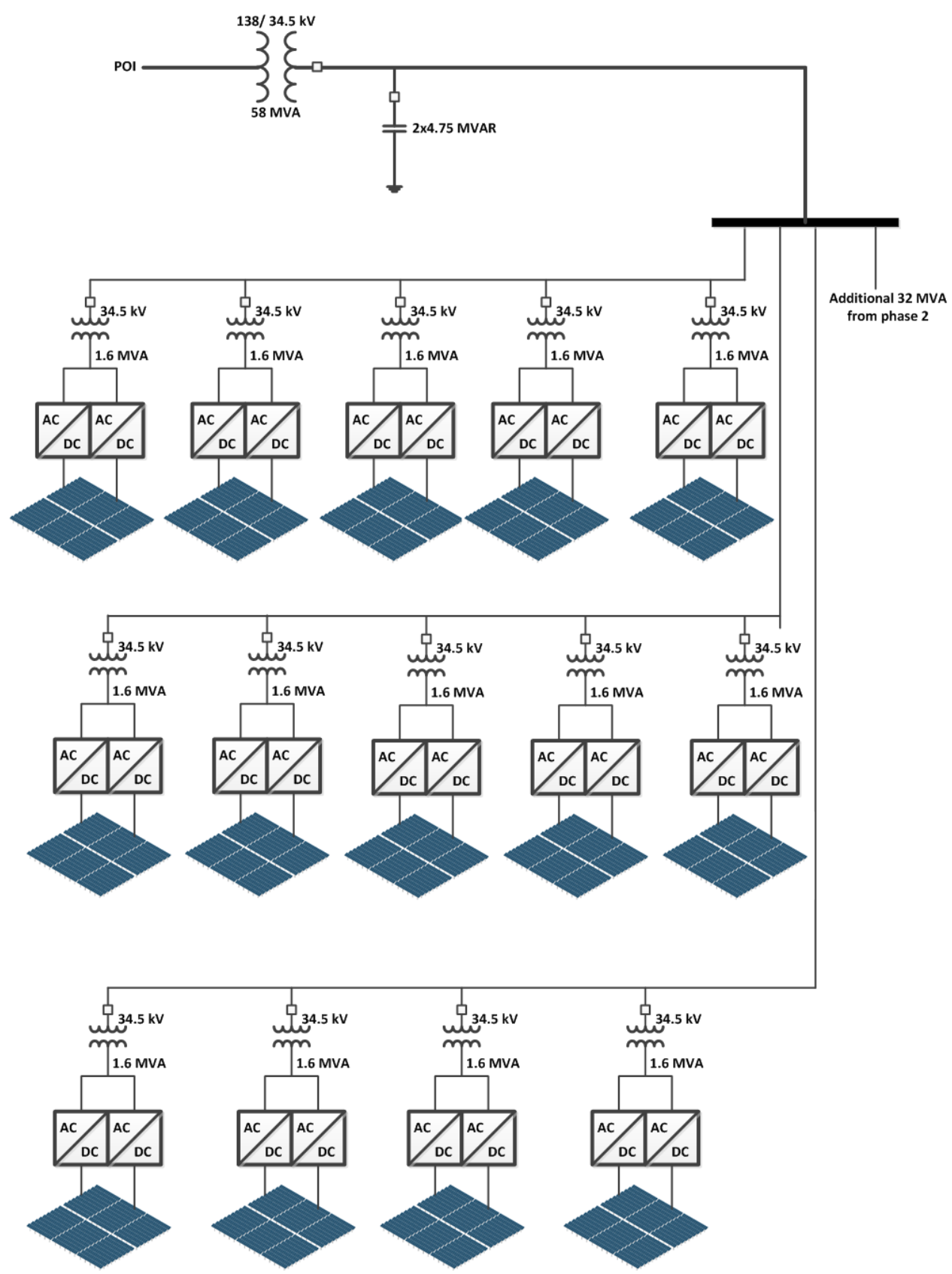

Figure 59. Single-line diagram of Phase 1 of the Barilla PV power plant

A key component of this grid-friendly PV power plant is a plant-level controller developed by First Solar. It is designed to regulate real and reactive power output from the PV power plant so that it behaves as a single large generator. Although individual inverters comprise the plant, with each inverter performing its own energy production based on local solar array conditions, the function of the plant controller is to coordinate the power output to provide typical large powerplant features, such as APC and voltage regulation (through reactive power regulation) [4]. 
First Solar's PPC is capable of providing the following plant-level control functions:

- Dynamic voltage and/or power factor regulation of the solar power plant at the POI

- Real power output curtailment of the solar power plant when required so that it does not exceed an operator-specified limit

- Ramp-rate controls to ensure that the plant output does not ramp up or down faster than a specified ramp-rate limit, to the extent possible

- Frequency control (governor-type response) to lower plant output in case of an overfrequency situation or increase plant output (if possible) in case of an under-frequency situation

- Start-up and shutdown control.

The PPC implements plant-level logic and closed-loop control schemes with real-time commands to the inverters to achieve fast and reliable regulation. It relies on the ability of the inverters to provide a rapid response to commands from the PPC. Typically, there is one controller per plant controlling the output at a single high-voltage bus (referred to as the POI). The commands to the PPC can be provided through the SCADA human-machine interface or even through other interface equipment, such as a substation remote terminal unit.

Figure 60 illustrates a general block diagram overview of the First Solar control system and its interfaces to other devices in the plant. The PPC monitors system-level measurements and determines the desired operating conditions of various plant devices to meet the specified targets. It manages capacitor banks and/or reactor banks, if present. It has the critical responsibility of managing all the inverters in the plant, continuously monitoring the conditions of the inverters and commanding them to ensure that they are producing the real and reactive power necessary to meet the desired settings at the POI [4].

A conceptual diagram of the plant control system architecture is shown in Figure 61. The plant operator can set an active power curtailment command to the controller. In this case, the controller calculates and distributes active power curtailment to individual inverters. In general, the inverters can be throttled back only to a certain specified level of active power and not any lower without causing the DC voltage to rise beyond its operating range. Therefore, the PPC dynamically stops and starts inverters as needed to manage the specified active power output limit. It also uses the active power management function to ensure that the plant output does not exceed the desired ramp rates, to the extent possible. It cannot, however, always accommodate rapid reductions in irradiance caused by cloud cover. 


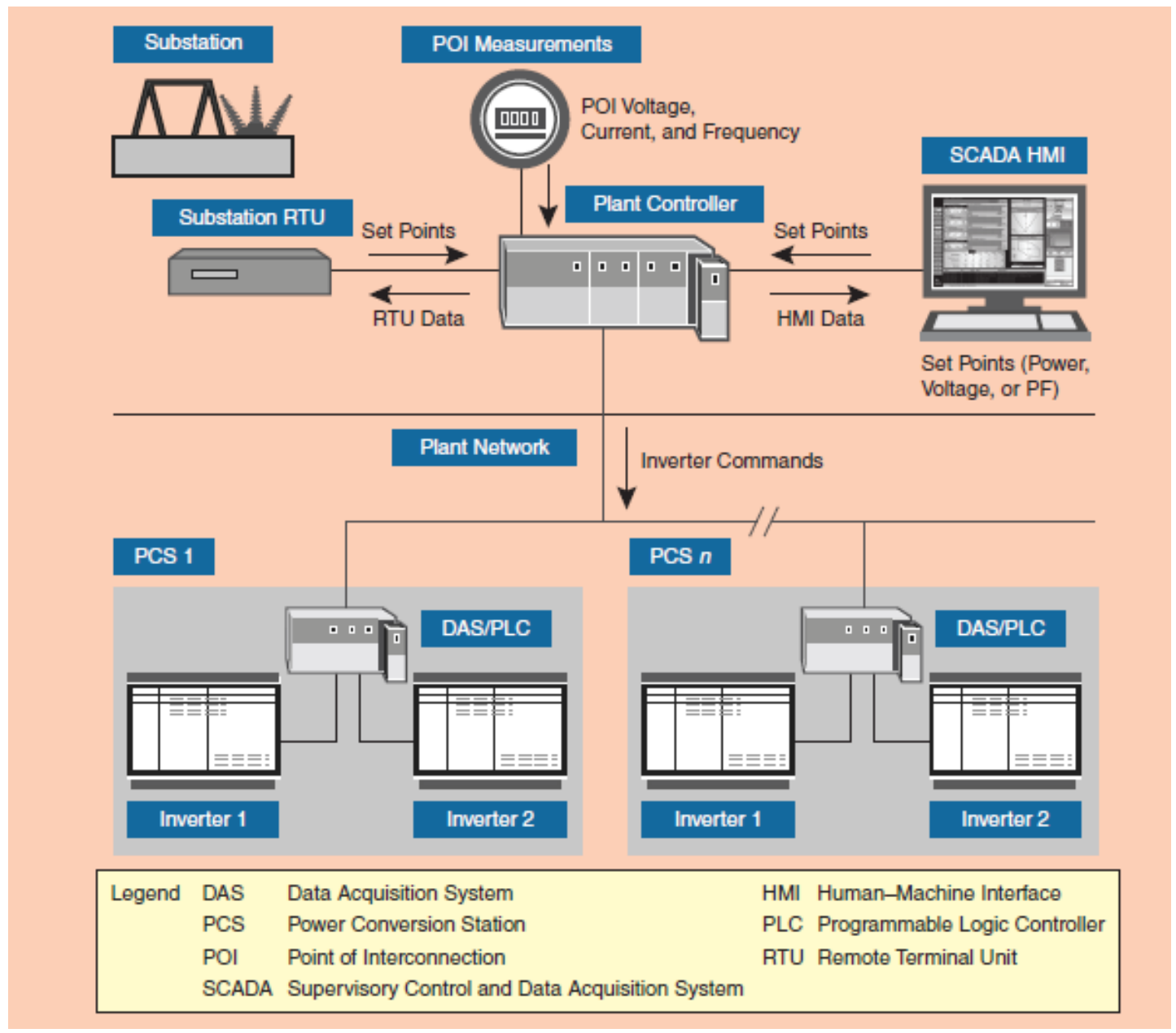

Figure 60. General diagram of the Pecos Barilla PV power plant controls and interfaces. Image from First Solar 


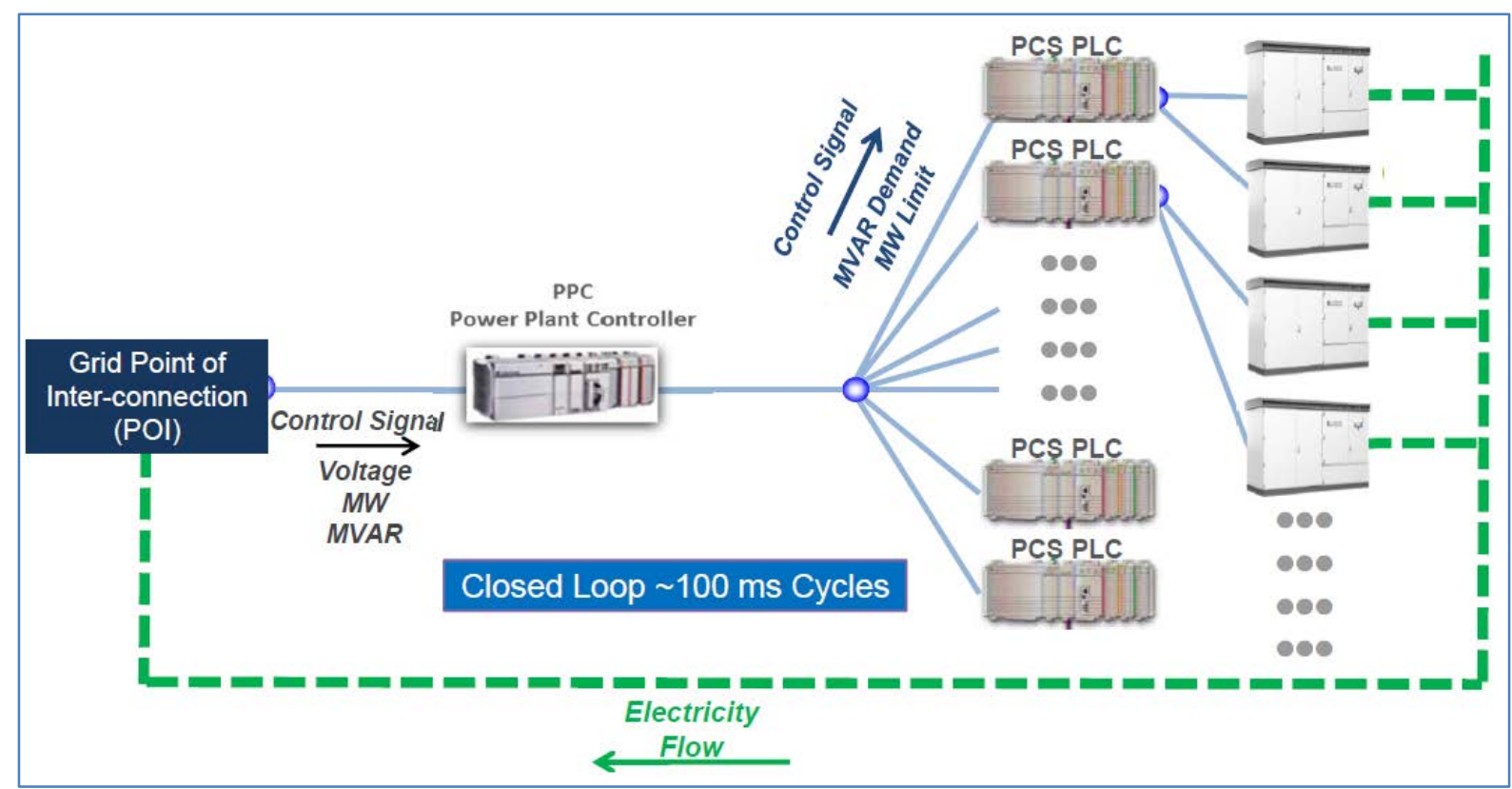

Figure 61. Diagram of the Pecos Barilla PV power plant control system architecture. Image from First Solar 


\section{Description of Tests for First Solar's Pecos Barilla PV Power Plant}

ERCOT's technical team indicated that they are interested in the possibilities, benefits, implementation, and testing of APC by PV. In particular, the special areas of interest for ERCOT include renewable power plant participation in PFR; AGC; and providing fast, inertia-like frequency response to arrest the rate of grid frequency decline during system contingencies. From this perspective, the APC tests were given the highest priority in this test plan to assist ERCOT engineers in their efforts to optimize the integration of large levels of PV generation in Texas.

\subsection{Scope of APC Tests}

The purpose of APC testing is to demonstrate a PV power plant's ability to provide services in four different forms:

- Active power set point control (or power curtailment control) during normal operation

- Frequency droop control for both up and down frequency regulation

- Plant shutdown and start-up controls

- FFR control.

\subsection{Active Power Set Point Control and Curtailment Tests}

Through the First Solar SCADA human-machine interface, the controller can be set to control the active power output of the plant at levels lower than the estimated available power from solar irradiation. When the control system detects an active curtailment flag from ERCOT, it sends specified set point commands for each inverter individually to lower its output to achieve the desired set point by using a closed-loop control mechanism. It is important to note that in some cases the PPC will turn off certain inverters to achieve this desired set point because the output of each inverter cannot be lowered below a certain threshold without causing an operating condition of high DC voltage.

Figure 62 illustrates measured data from a PV power plant at different locations operating at approximately $90 \mathrm{MW}$ of power [4]. In this case, the curtailment limit was initially changed from $100 \mathrm{MW}$ to $82.5 \mathrm{M}$. The PPC turned down the inverters (and turned off some of them, if required) to achieve the new set point. The turndown of power was gradual to meet the specified ramp-rate limit. The curtailment limit was reduced again, to approximately $75 \mathrm{MW}$, and the controller responded as expected. When the limit was raised, the controller adjusted the output of the inverters to increase the total plant output. Finally, when the limit was raised to $100 \mathrm{MW}$, the plant was no longer curtailed, because the plant was producing less than the limit. 


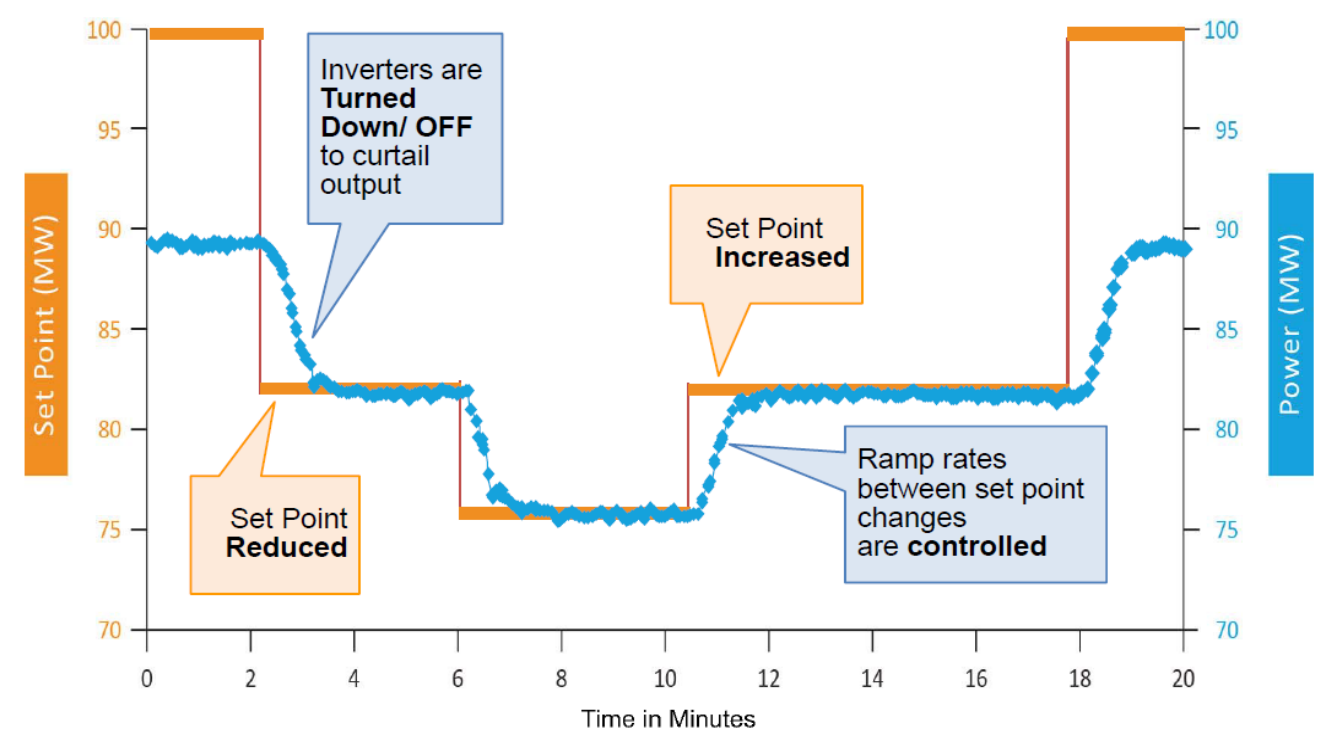

Figure 62. Example of a plant curtailment test. Image from First Solar

In a similar way, the plant under curtailed conditions can respond to up-regulation and downregulation signals sent from the ERCOT load frequency control system every 4 seconds, and it can also respond to low-frequency events.

In all the control actions, the controller's command to each inverter is unique, given the specific conditions each inverter is experiencing. For example, when the plant is under curtailment, the PPC can release the power limit of the individual inverters if the total output of the plant starts falling below the set point. So in case of a cloud passage, which results in a reduction of the output of part of the plant, the controller can make the adjustment to increase the output of other inverters that are not impacted.

\subsection{Frequency Droop Control Tests}

After the plant's ability to provide the desired amount of power reserve under curtailed operation is demonstrated, the plant could be tested for the provision of frequency droop control to handle unusual grid situations. For example, in case of above-normal frequency, the controller will reduce the active power of the plant, as illustrated in Figure 63. If the plant is under curtailment, the power can also be increased if the below-normal frequency is detected. Note that all the parameters illustrated in the figure are configurable and are shown here for illustrative purposes only.

The frequency droop functionality can be demonstrated during large under-frequency and overfrequency events that take place in the power system. Three time series of example underfrequency events that happened in the ERCOT grid as a result of generation loss are shown in Figure 64. In this particular example, for a frequency event shown in red, the responsive load reserve was activated to arrest further frequency decline and avoid under-frequency load shedding. The PV power plant demonstrated its ability to provide a response in accordance with the $5 \%$ droop setting during similar events. 


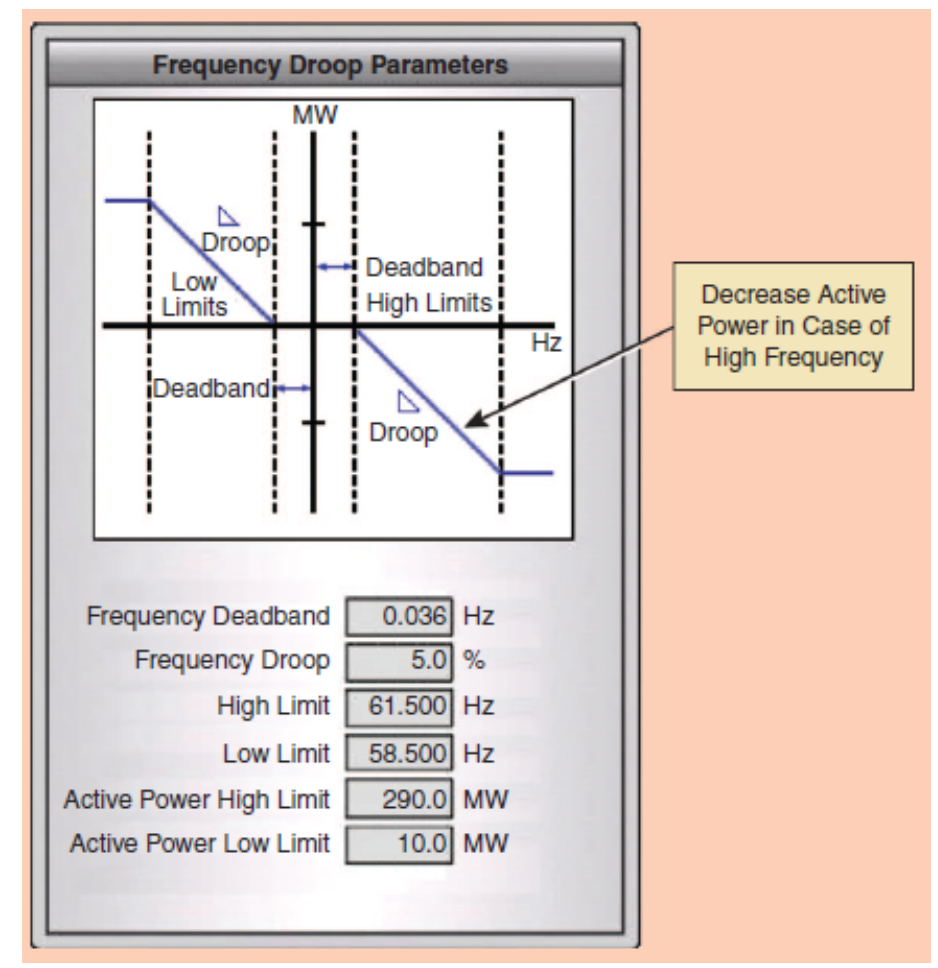

Figure 63. Example of the Pecos Barilla PV power plant frequency droop function. Image from First Solar

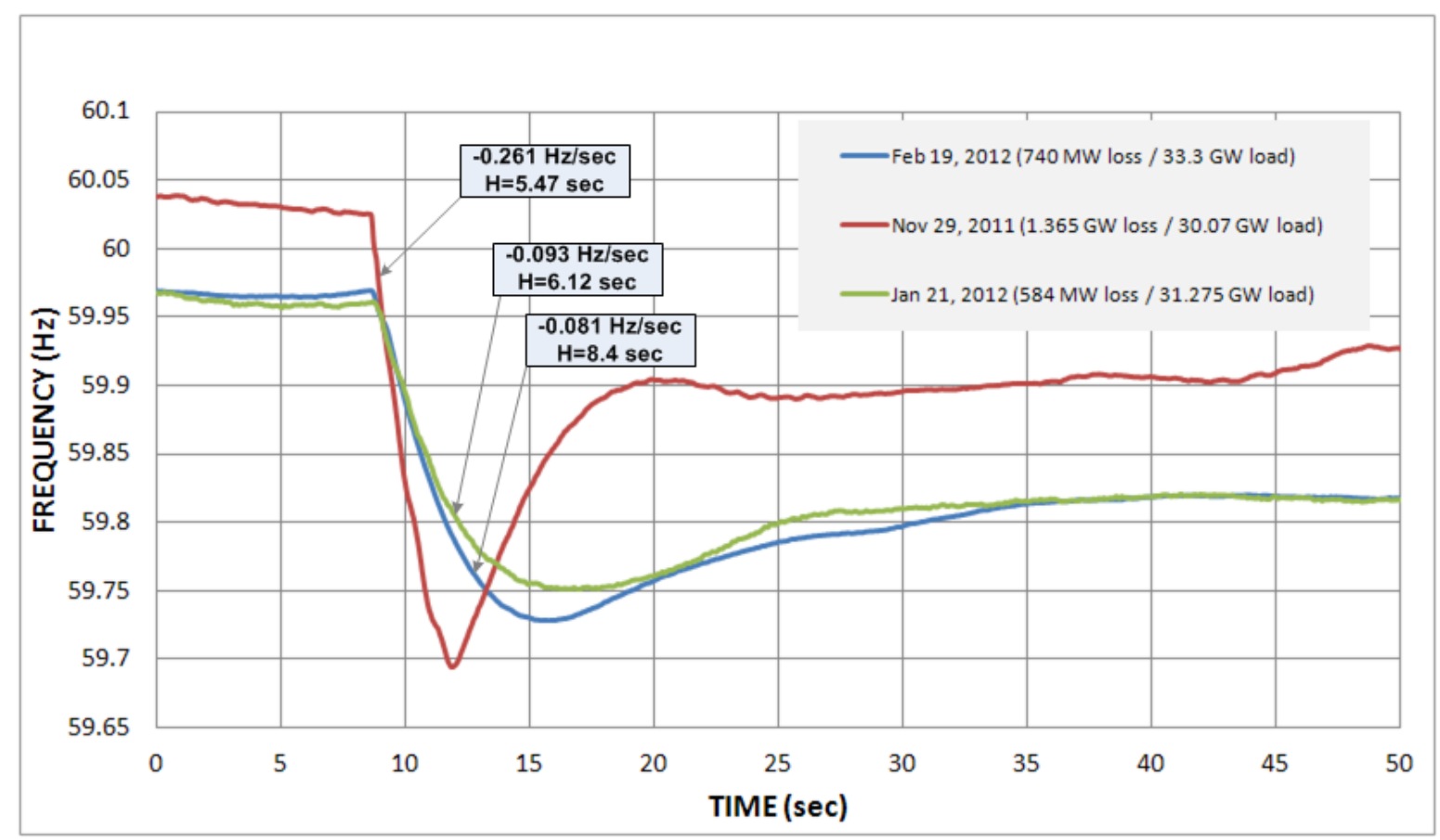

Figure 64. Examples of frequency events measured in the ERCOT grid 


\subsection{Plant Shutdown and Start-Up Controls}

Another function related to active power management is illustrated in Figure 65, which shows the reaction of the plant when it is shut down and started up. The field data in this case illustrates when one block ( $30 \mathrm{MW})$, which is under the control of the PPC, is commanded to shut down. The active power management function reduces plant output while maintaining the required ramp rate. As mentioned earlier, some inverters are turned down, and others are shut down. Note that the control is quite effective even with moderately varying irradiance conditions. Figure 65 also illustrates the plant start command, resulting in the controller gradually increasing the plant output by adjusting the inverters' output and turning on the inverters in sequence. The Barilla plant was tested under similar conditions to demonstrate its ability to reduce and decrease its power in accordance with the preset ramp limit.

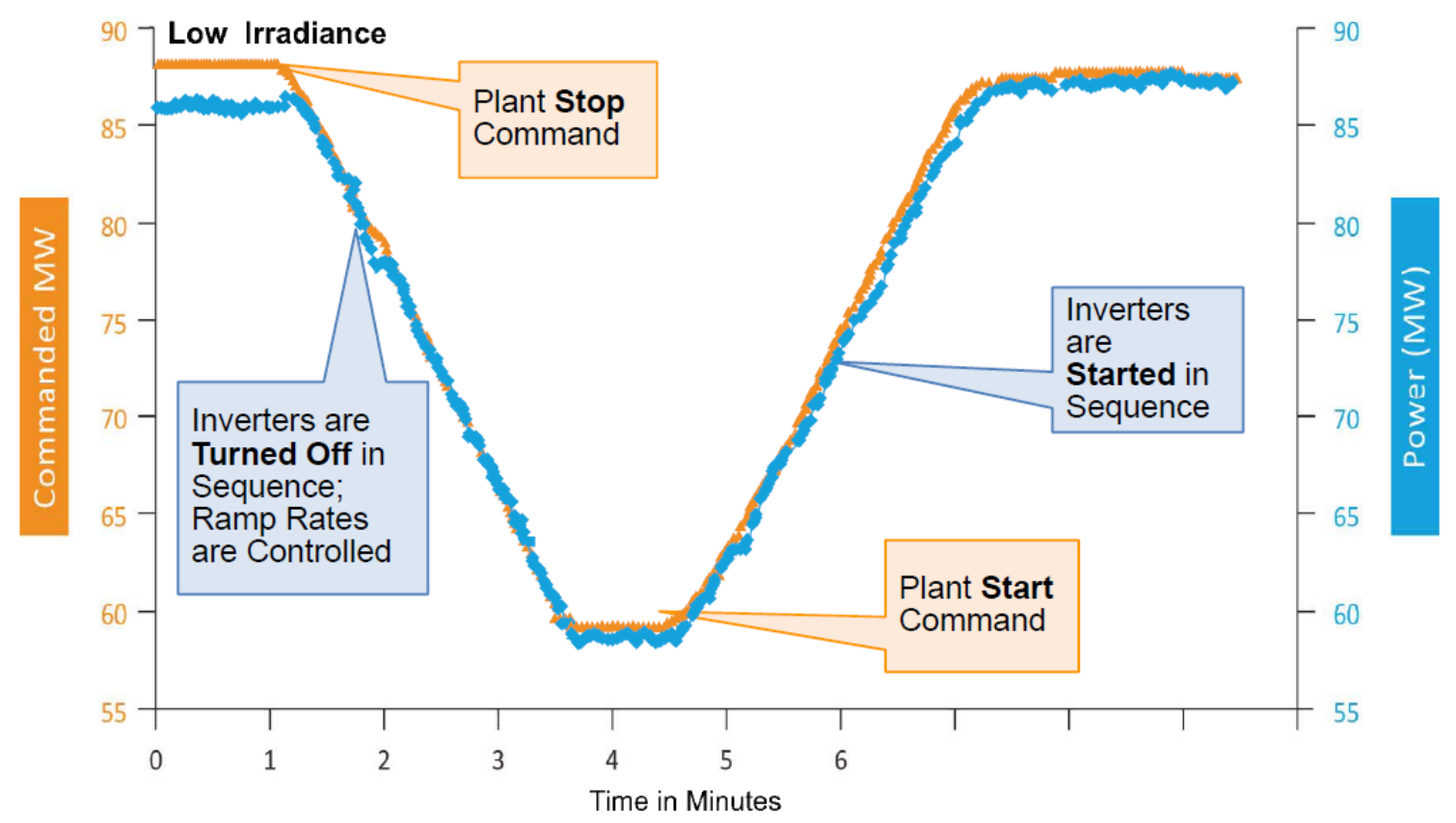

Figure 65. Example of a ramp-rate control test. Image from First Solar

\subsection{FFR Tests}

The initial ROCOF in the ERCOT grid for the same events shown in Figure 64 depends on the level of spinning inertia in the ERCOT system. ROCOF is an important characteristic that impacts the lowest frequency that is achieved approximately 7 seconds- 10 seconds after the beginning of an event. The other two important characteristics that impact the minimum frequency are the amount of PFR headroom and the droop and response speed of the PFR. The ROCOF is expected to grow with increasing penetrations of inverter-coupled generation because of reduced mechanical inertia; thus, it may potentially impact the value of minimum frequency during contingency events similar to the ones described in Figure 64. In this project, we proposed testing a new FFR control feature for PV power plants that allows ROCOF reduction to minimize the risk of under-frequency load shedding at high levels of PV penetration.

The FFR is intended to supplement the inherent inertial response from synchronous machines and synthetic inertial response from inverter-coupled wind generation. As mentioned above in 
the discussion following Figure 10, one ERCOT analysis suggests that under certain conditions, the impact of $1 \mathrm{MW}$ of FFR on the overall system frequency response is equivalent to $2.35 \mathrm{MW}$ of PFR [11]. FFR from PV will reduce the ROCOF and increase time to the frequency nadir to allow sufficient time for PFR to deploy, as opposed to affecting the initial ROCOF. FFR is a response that needs to be deployed automatically and provide full response within 0.5 second (Figure 66) after the frequency drops below a preset threshold of $59.8 \mathrm{~Hz}$.

During periods of low inertia, the absence of FFR may require much higher capacity of PFR to arrest the fast frequency decline during the contingency event. For this purpose, the PPC needed to be set to deploy available reserve within 0.5 second (or faster) during the frequency events for at least 10 minutes. In the meantime, the PFR would be deployed to its full capacity within 10-20 seconds. FFR stays deployed for at least 10 minutes or until the FFR resource is recalled by ERCOT. When completed, the PPC would return to normal operation. The benefit of the FFR testing was to demonstrate the capability of the PV power plant to arrest the rate of frequency declines during contingencies.

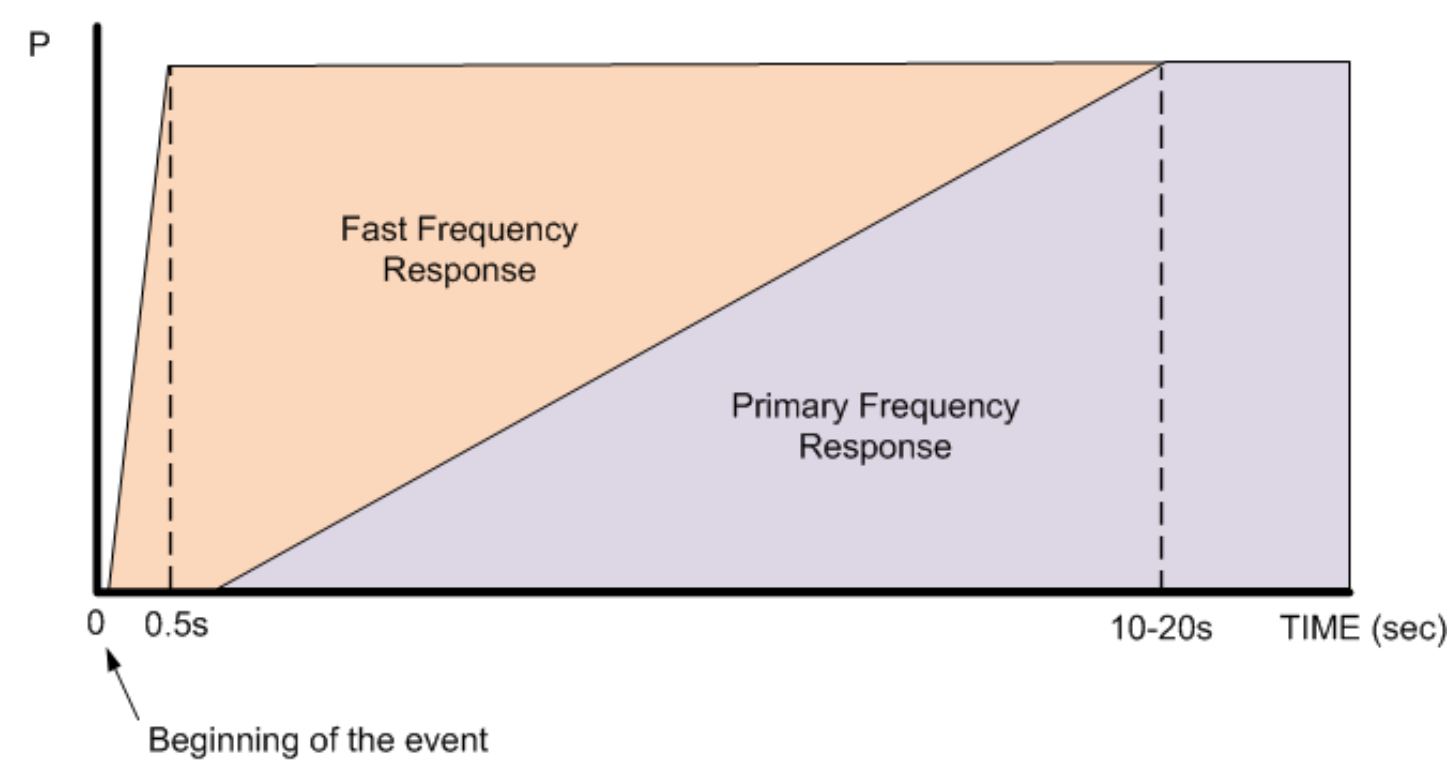

Figure 66. FFR time frame

\subsection{Voltage/Reactive Power/Power Factor Regulation Tests}

Through the SCADA human-machine interface, the plant control system can be set to operate in one of the three modes of automatic voltage regulation: voltage regulation, power factor regulation, or reactive power control. The plant can operate in only one of the three operating modes at any time. In the voltage-regulation mode, the controller maintains the specified voltage set point at the POI by regulating the reactive power produced by the inverters as well as other devices such as capacitor banks. In the power-factor regulation mode, the controller maintains the specified power factor. The operation of the controller is illustrated in Figure 67, which shows field data from a PV power plant producing active power at that time. Figure 67 illustrates the response of the plant when the power factor set point was changed from 0.98 to 1.0. The 
controller commanded the inverters to change their reactive power output to meet the new power factor set point using a closed-loop control mechanism. The figure illustrates that the inverters responded very rapidly. Within a few seconds $(<4 \mathrm{~s})$ the new set point was achieved in a closedloop control mode. More specifically, the rise time to reach $90 \%$ of the steady-state value shown in the figure was approximately $3.2 \mathrm{~s}$.

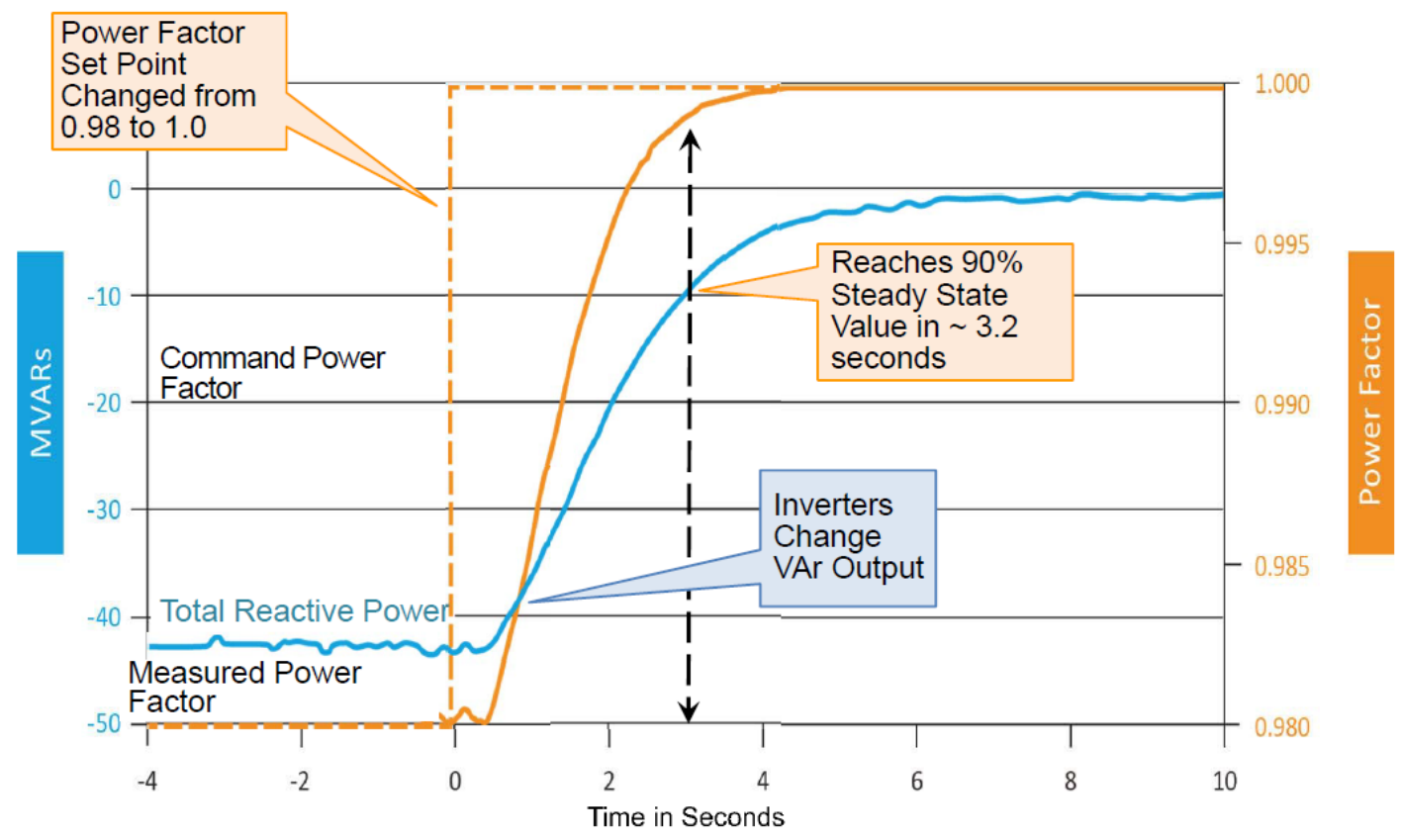

Figure 67. Example of dynamic power factor regulation by a PV power plant. Image from First Solar

\subsection{Voltage Fault Ride-Through Tests}

A significant benefit of utility-scale PV systems that incorporate fault ride-through capability is that they do not trip off during system disturbances but continue to provide power when the grid needs it. The ability to ride through specific low and high voltages or low- and high-frequency ranges is being designed effectively into all modern variable generators. Most utility-scale inverters have this capability. With proper design practices, a PV power plant is engineered to ensure that all components in addition to inverters also have the ability to ride through short-term grid events. It was outside the scope of the current test plan to conduct voltage fault ride-through tests, because such tests require a special fault emulator to create voltage fault conditions at the plant POI. 


\section{Test Results for First Solar's Pecos Barilla PV Power Plant}

In this section we present a summary of test results that were conducted in First Solar's Pecos Barilla PV power plant during 2014 and 2015. Some of the tests were conducted during the 2014 commissioning of the plant utilizing standing control features (such as power curtailment, plant shutdown, and reactive power control tests). More voltage and reactive power control tests were conducted in August 2015 utilizing custom controls developed for the purposes of this project (such as FFR and droop control for up-regulation).

An example of an active power set point control (or controlled power curtailment) test is shown in Figure 68. During this almost 1-hour test during peak production hours, the plant was commanded to curtail its production following the set point steps of various magnitude down to a very low power level, and then it was commanded to ramp back up to full production. A 1$\mathrm{MW} /$ minute ramp rate was applied by the PPC during both the ramp-down and ramp-up portions of the test. The PPC was set to maintain a constant 0.99 power factor at the POI during this test. Power factor time series are shown in Figure 69 for both the power-reducing (upper plot) and power-increasing (lower plot) portions of the test. These power factor time series demonstrated the plant's ability to independently control active and reactive power at different power levels whereby the power factor is controlled by constantly adjusting the reactive power level of the plant.

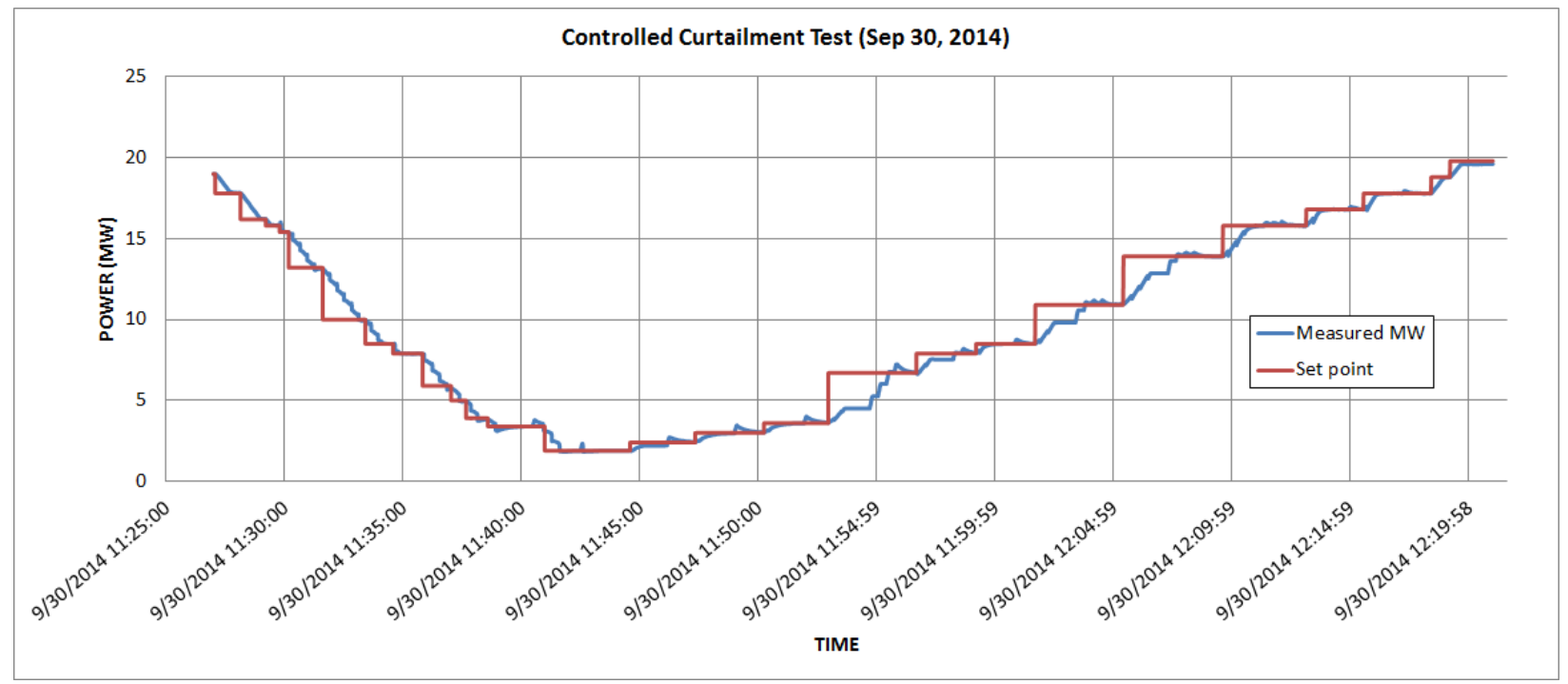

Figure 68. Power curtailment test 


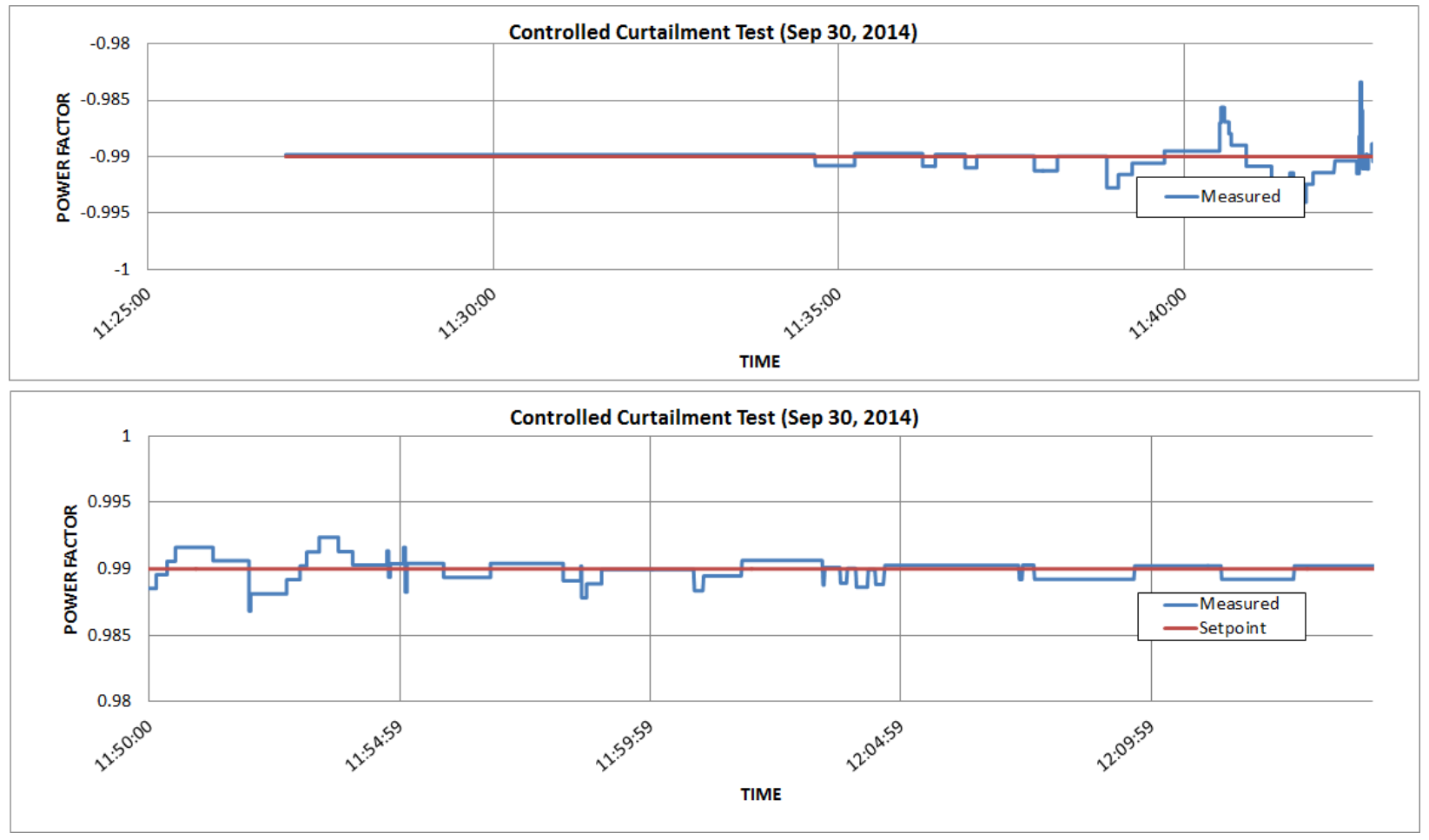

Figure 69. POI power factor during curtailment test

The sequential inverter shutdown test was conducted on September 2, 2014, to bring plant production from peak to zero power by sequentially shutting down the inverters during a 10minute interval (Figure 70). During this test, the power factor measured at the POI was maintained at the preset level of approximately 0.99 during almost the duration of the tests, as shown in Figure 71.

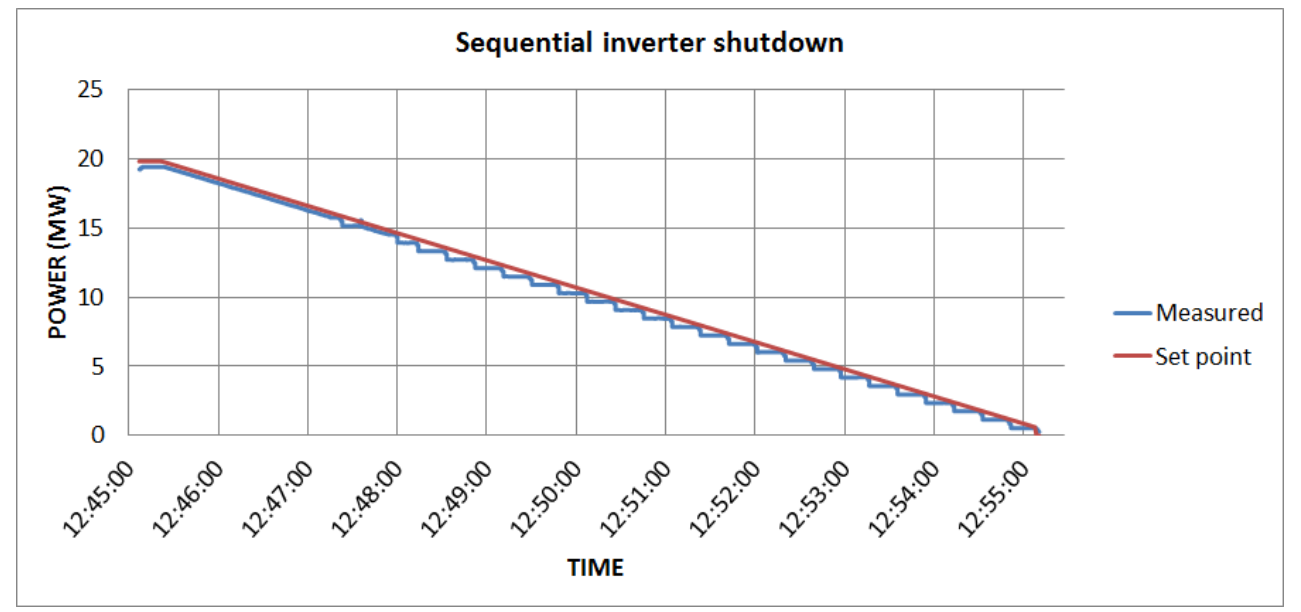

Figure 70. Plant sequential shutdown test-active power 


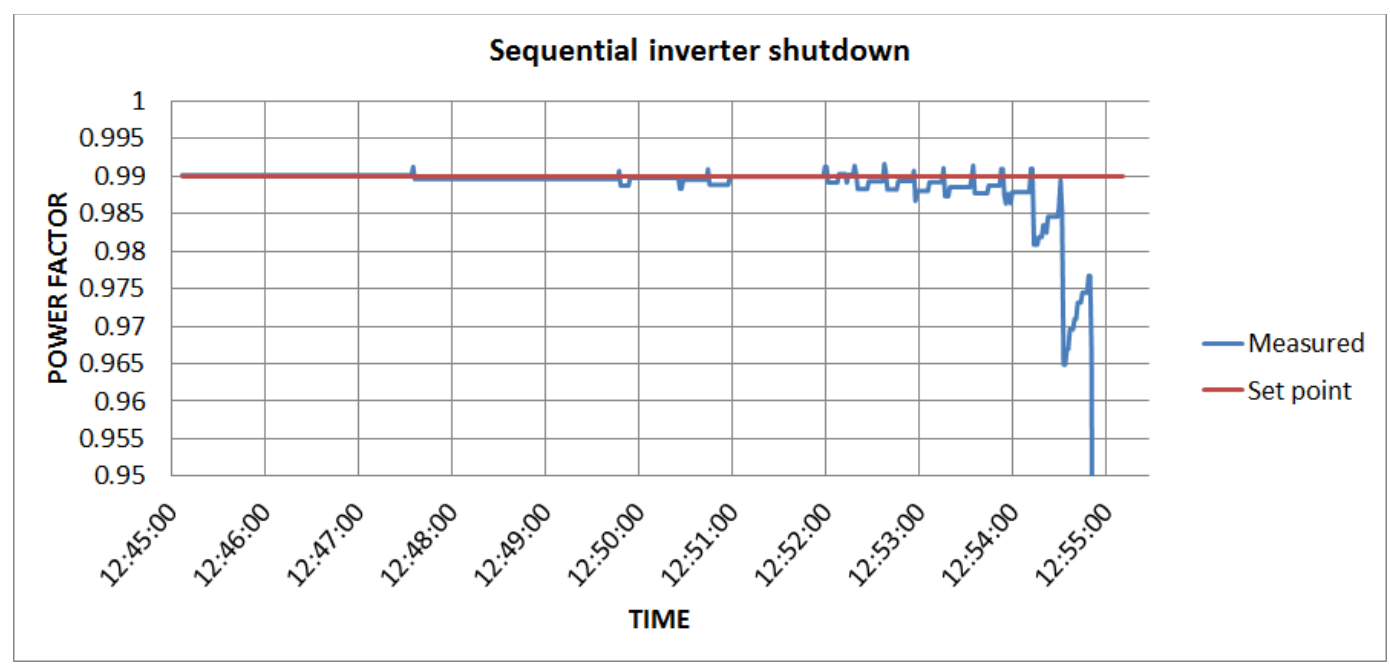

Figure 71. Plant shutdown tests-power factor

Several reactive power control tests were conducted in 2014 and 2015. An example reactive power control test from September 30, 2014, is shown in Figure 72. The plant reactive power was commanded to absorb and produce reactive power in accordance to the red plot in the upper graph within \pm 6 MVAR range during peak production hours. As shown in the same graph, the actual measured reactive power at the POI followed the set point precisely. Both the measured $34.5-\mathrm{kV}$ bus voltage (line-to-line) and active power are shown in the two lower graphs, respectively. The precision of reactive power control during this test is described by the X-Y plot shown in Figure 73 with the linear regression trend line.

Results of another reactive power control test conducted on August 14, 2015, are shown in Figure 74 through Figure 77. In this case that PPC was set to respond to the reactive power command with an approximate rate of $1 \mathrm{MVAR} /$ second. The response of the plant measured at the POI to the commanded reactive power set point is shown in Figure 74 for the whole duration of the test. Figure 75 shows a more detailed view of the first commanded reactive power step of 2.4 MVAR. It took approximately 4 seconds for the plant to achieve steady state. Both measured voltage (138-kV bus, line-to-neutral) and active power are shown in Figure 76 and Figure 77, respectively. 

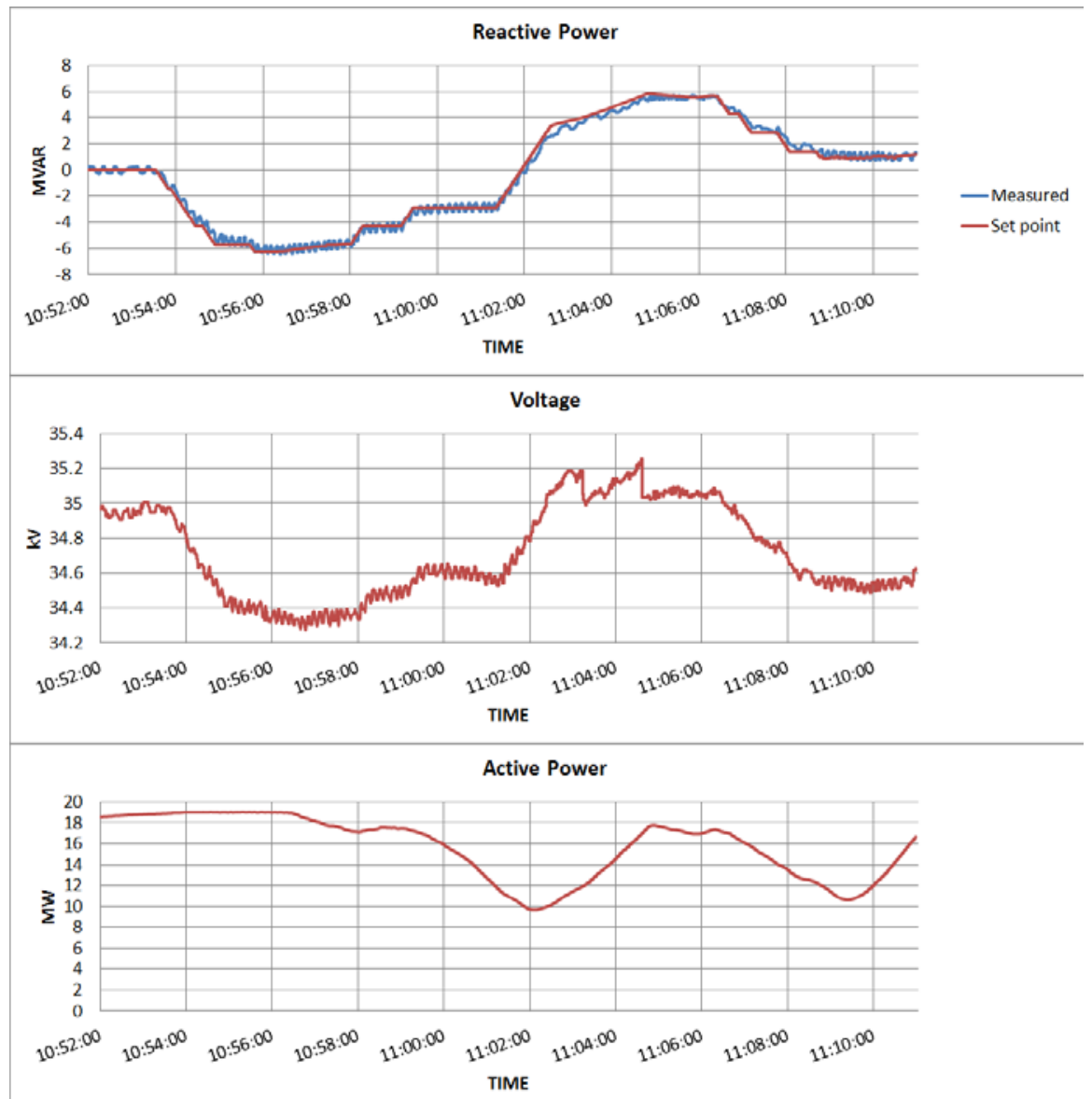

Figure 72. Reactive power control test-September 30, 2014

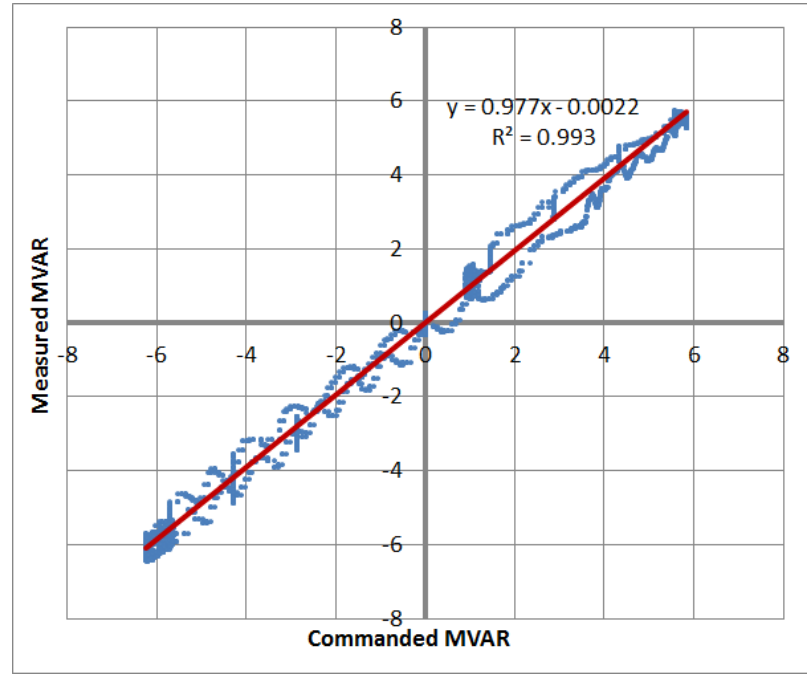

Figure 73. Test of measured reactive power compared to commanded reactive powerSeptember 30, 2014 


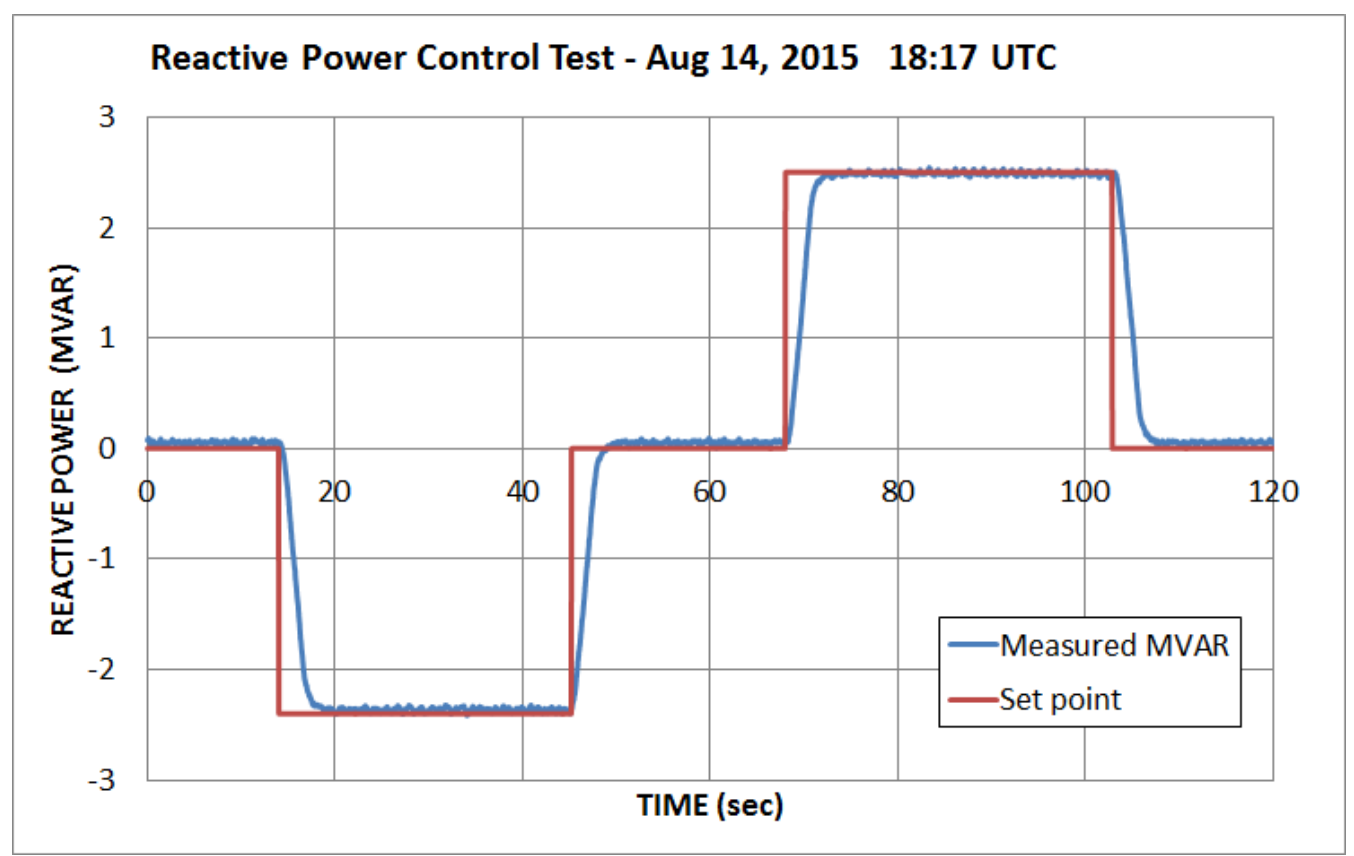

Figure 74. Reactive power control test-measured MVAR and set point

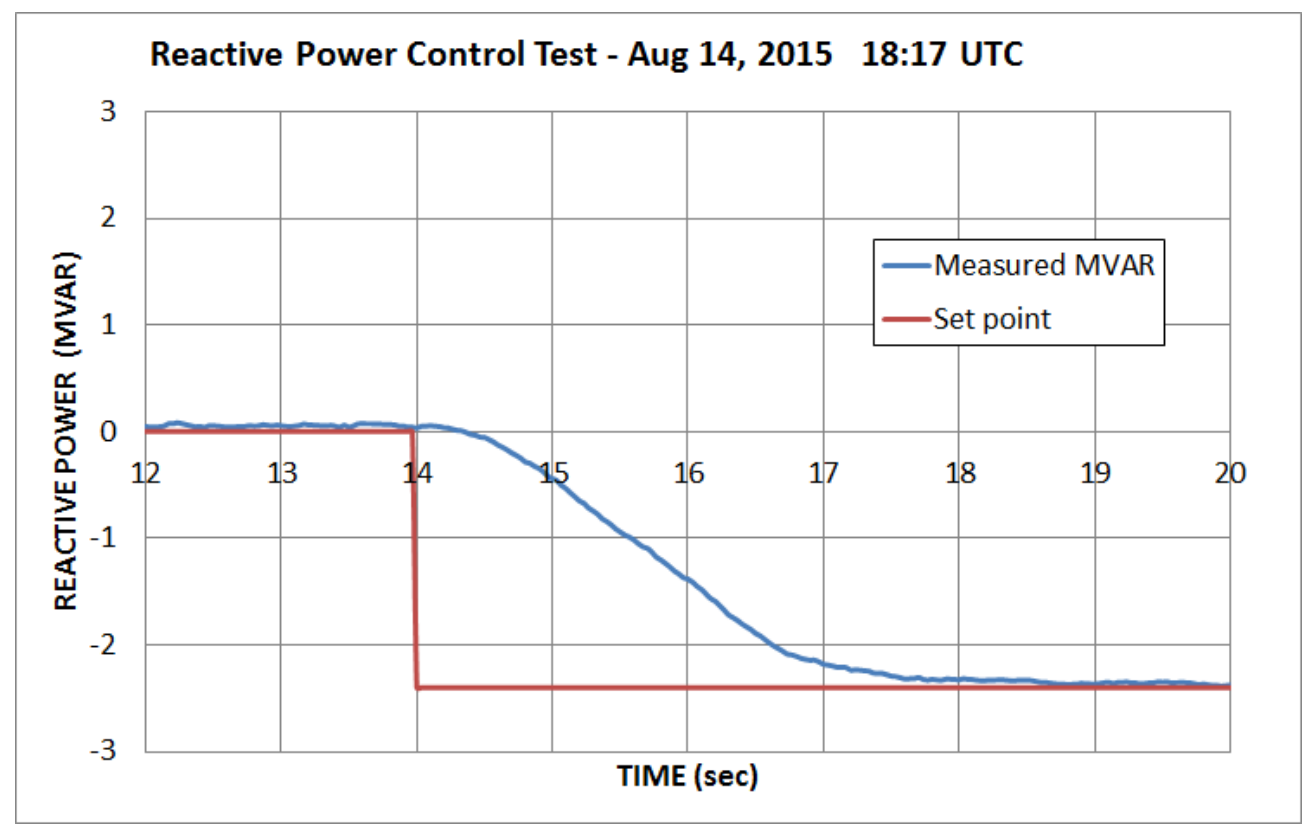

Figure 75. Reactive power response 


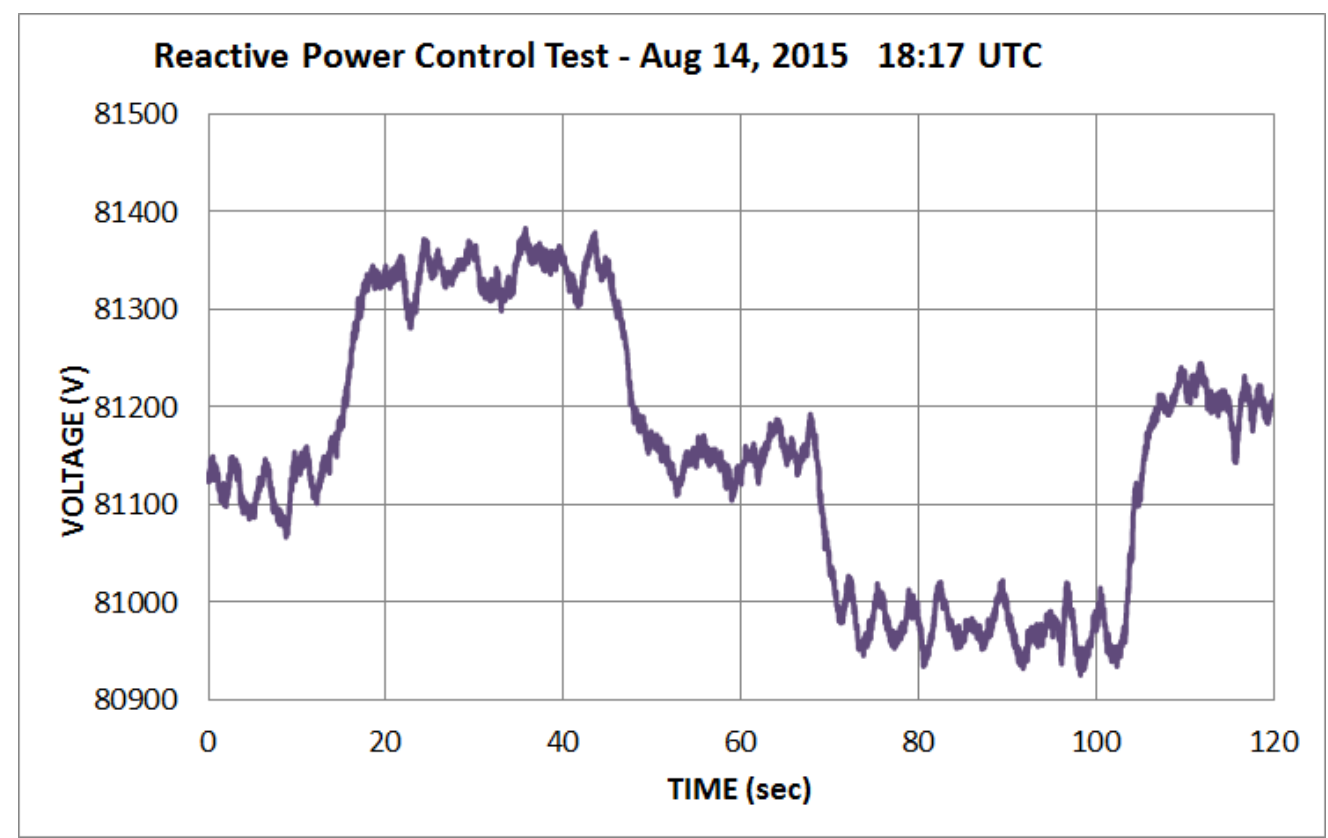

Figure 76. Reactive power control test-measured voltage on 138-kV bus

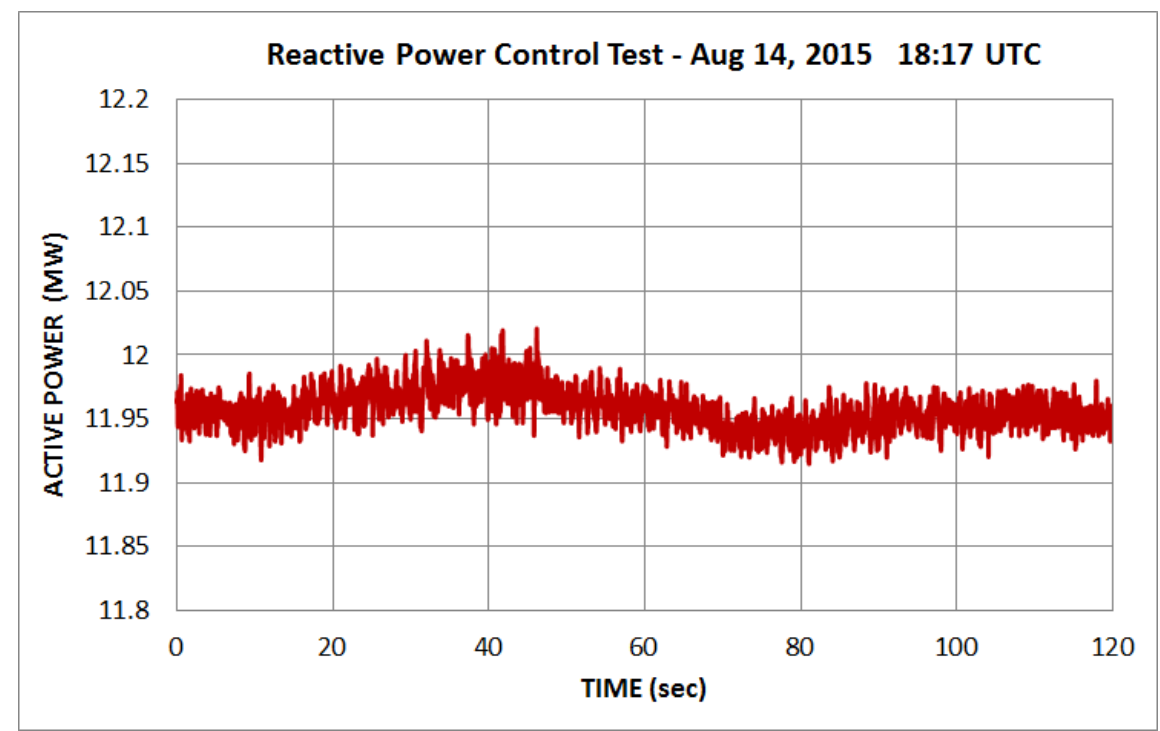

Figure 77. Reactive power control test-measured plant active power

A voltage control test in Pecos Barilla plant was conducted on August 20, 2015. As shown in Figure 78 , the POI voltage on the $138-\mathrm{kV}$ bus was commanded to increase $1 \%$ from a level of 81 $\mathrm{kV}$ (line-to-neutral) to approximately $81.85 \mathrm{kV}$. It took less than 1 second for the voltage to settle at the new set point. 


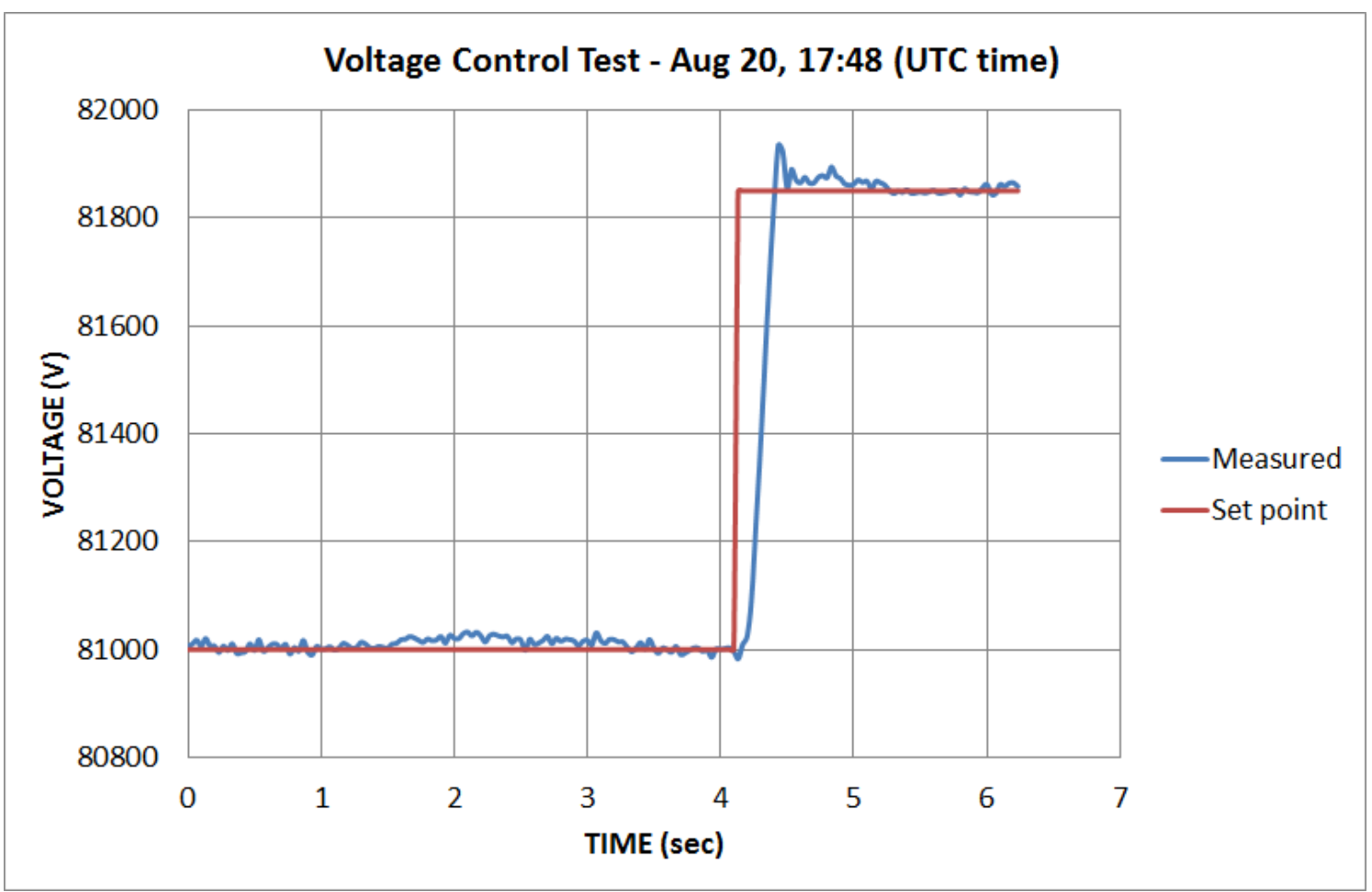

Figure 78. Voltage control test

Similarly, a number of power factor control tests were conducted in the Pecos Barilla plant. Result of one such test conducted on September 2, 2014, are shown in Figure 79 through Figure 81 . During 30 minutes, the plant power factor at the POI was commanded to vary within a range of \pm 0.95 . Time series for the periods with positive and negative power factors were split into two separate plots, as shown in Figure 79. The power rate limit was implemented in the controller, so it took approximately 30 seconds to achieve the commanded value for both the positive and negative cases. The POI voltage (138-kV bus) and active power ruing this test are shown in Figure 80 and Figure 81, respectively. 

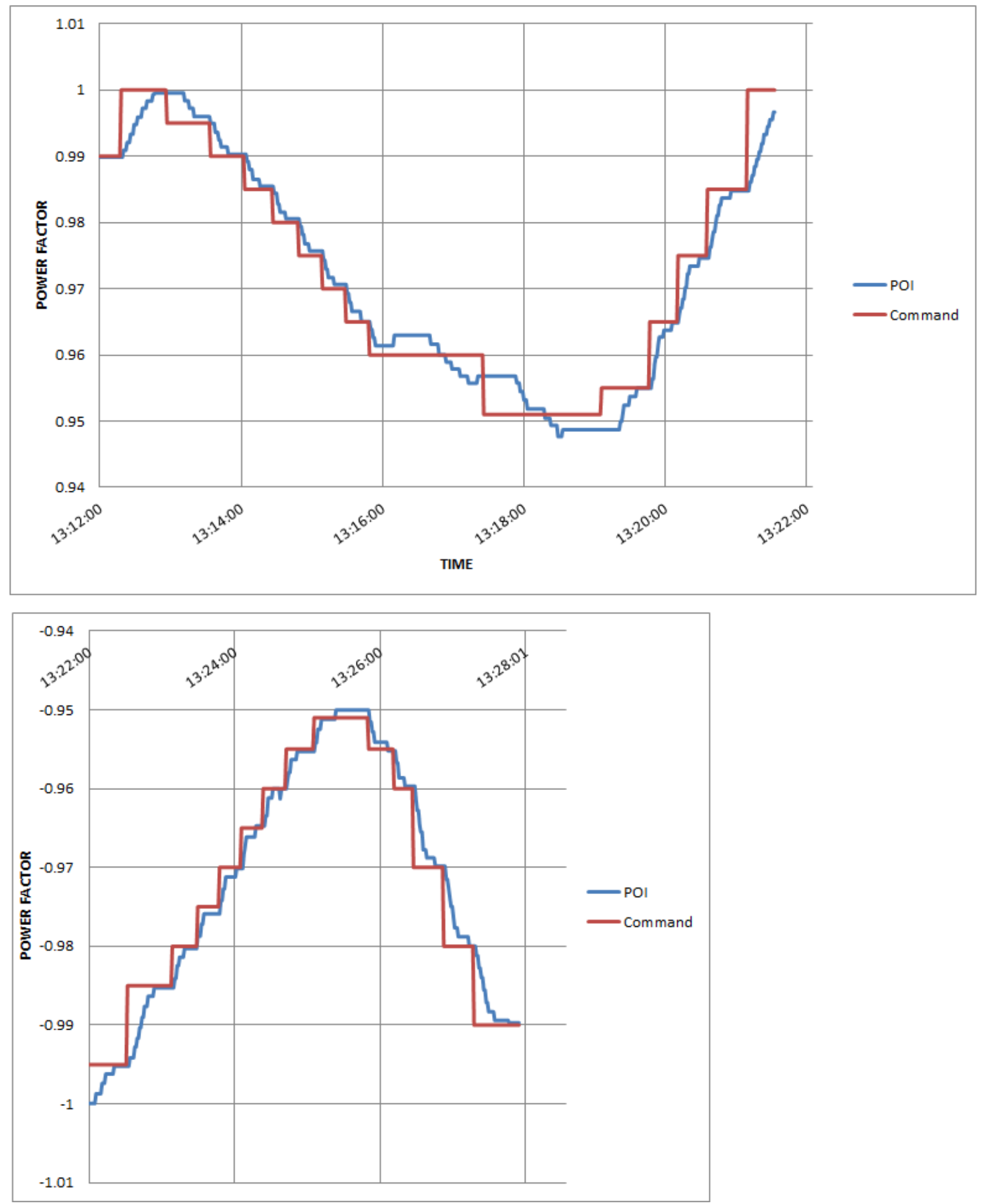

Figure 79. Power factor control test-September 2, 2014 


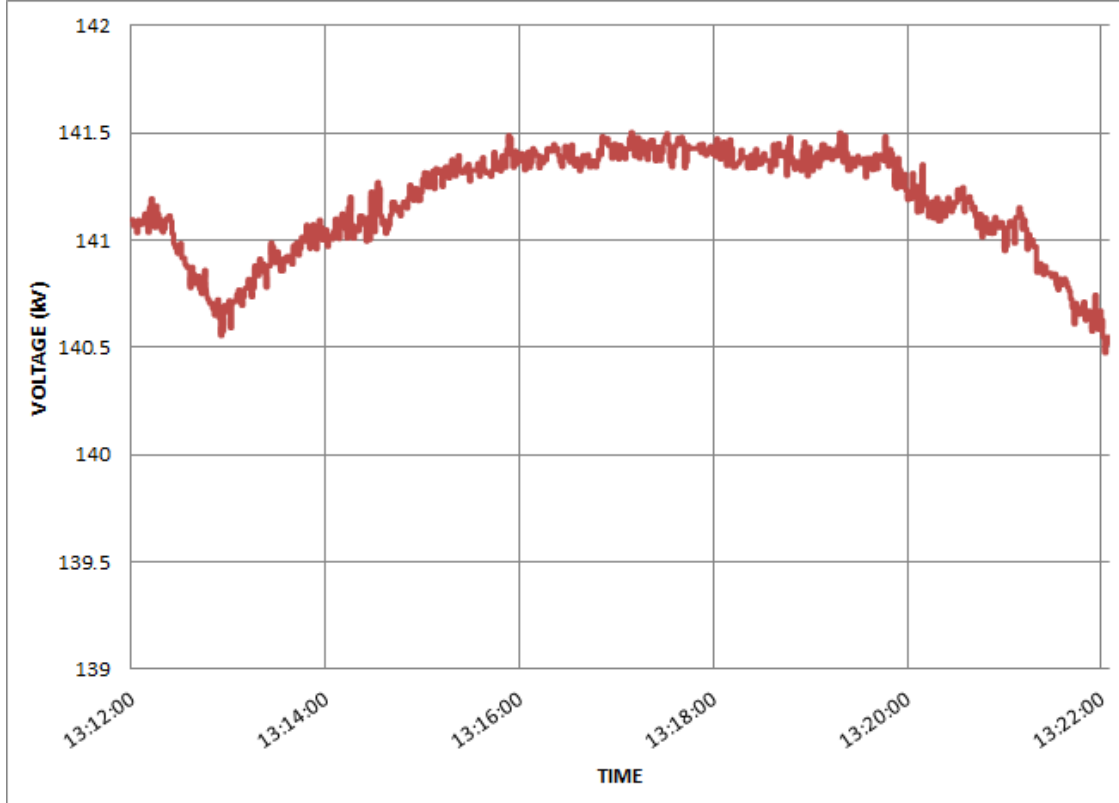

Figure 80 . Voltage in the 138-kV bus during the power factor control test-September 2, 2014

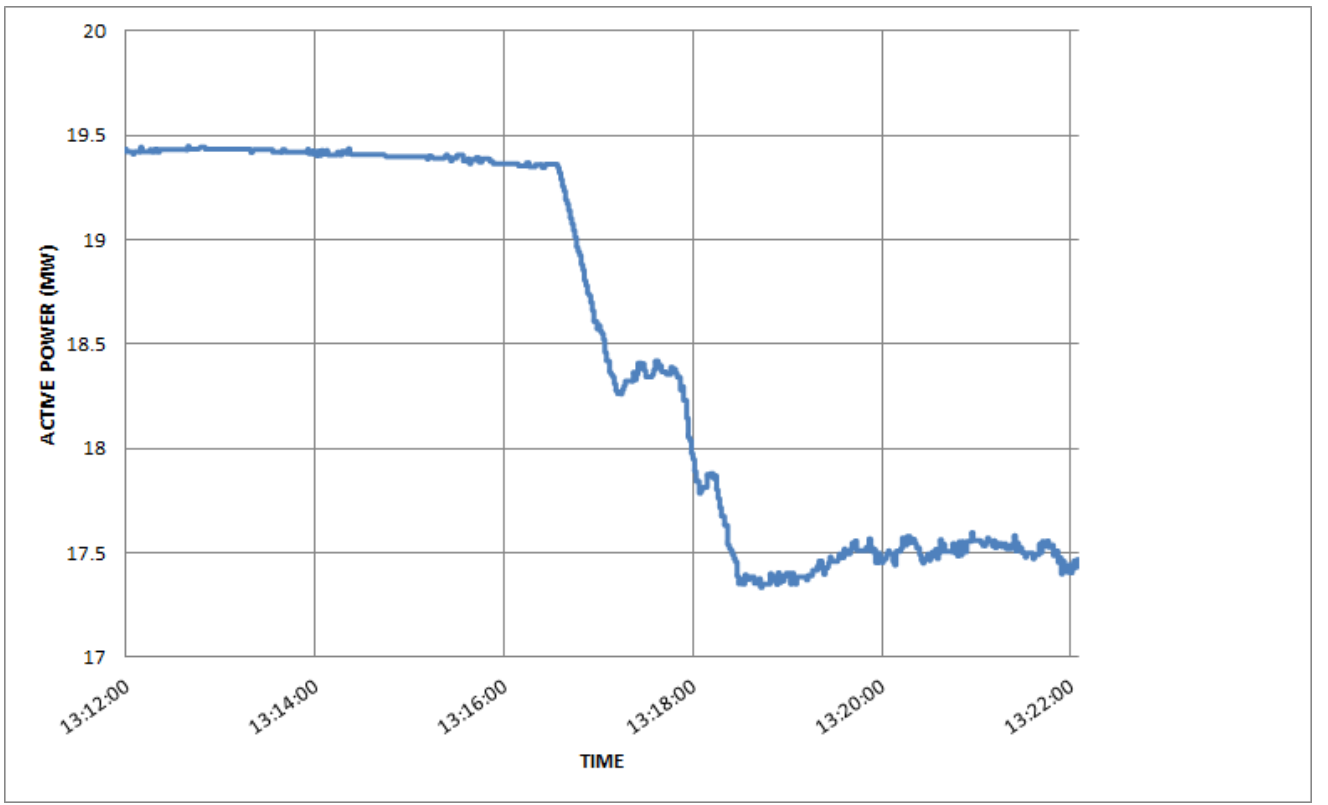

Figure 81. Active power during the power factor control test-September 2, 2014

An example of an FFR test conducted on August 14, 2015, is shown in Figure 82. In this case, the plant was operating at $12 \mathrm{MW}$ with almost $50 \%$ curtailment (more than $23 \mathrm{MW}$ of peak power was available during this test). The plant was commanded to deploy all of its active power reserve and then curtail again to 50\% during this 30-second test. As shown in Figure 82, it took 2.5 seconds for the plant to achieve peak production and 2.5 seconds to curtail back to $12 \mathrm{MW}$. This is a fast response, but it is obviously slower than the response time of 500 milliseconds for FFR considered by ERCOT in its future market design. In principle, the plant is capable 
responding faster, but it was limiting itself at slower response time due to the internal ramp-rate limit of the SMA inverters. Unfortunately, it was not an easy task to increase this internal ramp limit within the projected time frame.

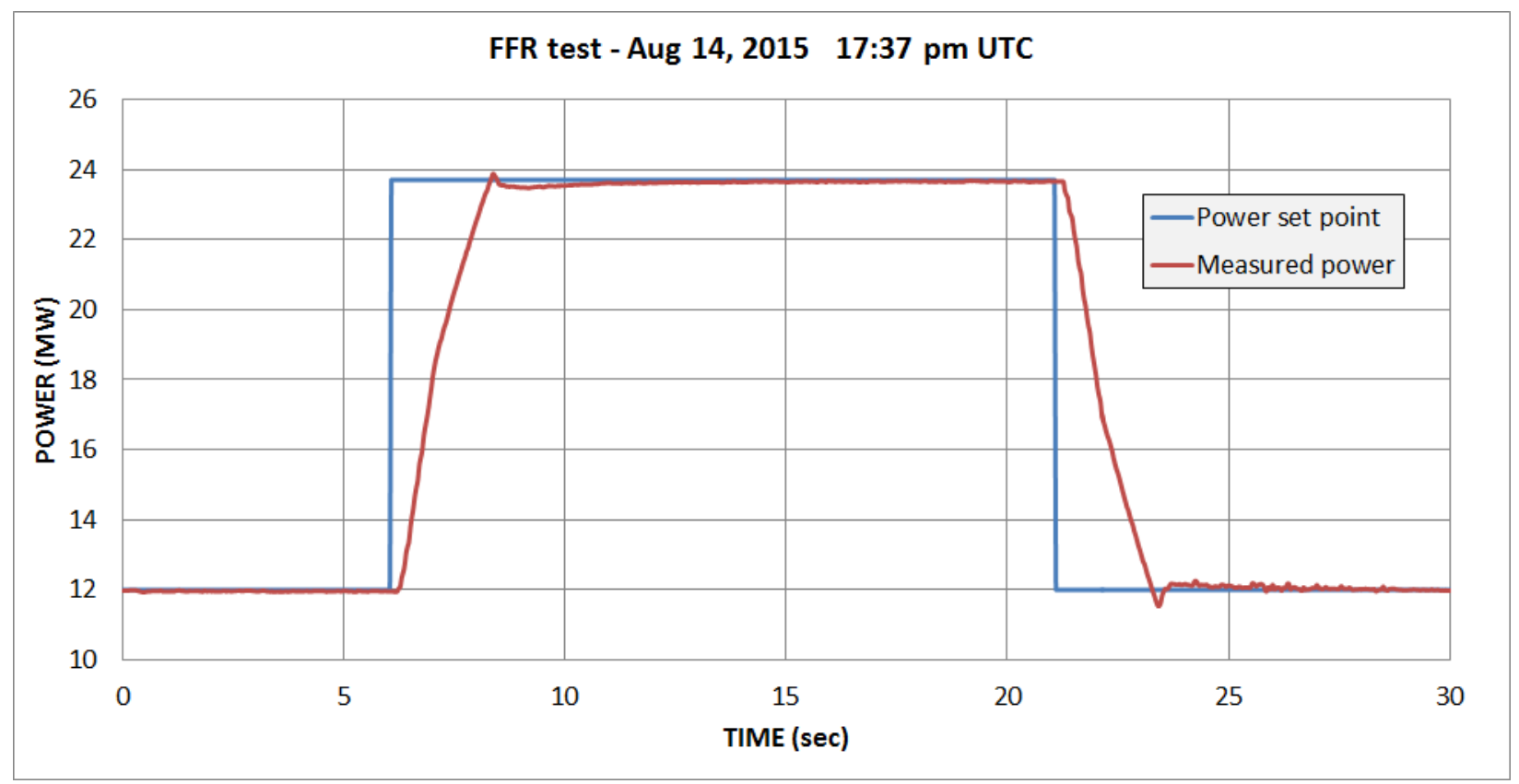

Figure 82. Fast response tests

Another test of active power control was conducted on August 14, 2015 (Figure 83). This test was intended to demonstrate the droop response of the Pecos Barilla PV power plant during a large frequency event. The frequency time series from an actual event in ERCOT measured on November 29, 2011, was provided to the PPC to emulate its frequency response. This particular event was caused by the loss of $1.365 \mathrm{GW}$ of generation during the period of $30.07 \mathrm{GW}$ load. Obviously, a load-shedding scheme was triggered during this event when the frequency nadir reached $59.7 \mathrm{~Hz}$, which resulted in fast increase of the frequency to the settling level at $59.9 \mathrm{~Hz}$.

For this particular test, the plant was set to operate with a very aggressive $1.67 \%$ droop setting and $36-\mathrm{mHz}$ deadband. The plant was operating in curtailed mode at the level of approximately $12 \mathrm{MW}$ when the event started. It started increasing its power in response to the frequency decline right after the frequency change was greater than the $36-\mathrm{mHz}$ deadband (right graph in Figure 83). The expected response from the plant corresponding to the droop setting is indicated by the green dotted line. As shown in Figure 83, the plant was not able to follow the desired droop response with a high level of precision. This is because of the same internal ramp-rate limit of the SMA inverters as in the FFR test. First Solar will be improving this response characteristic in the near future. 

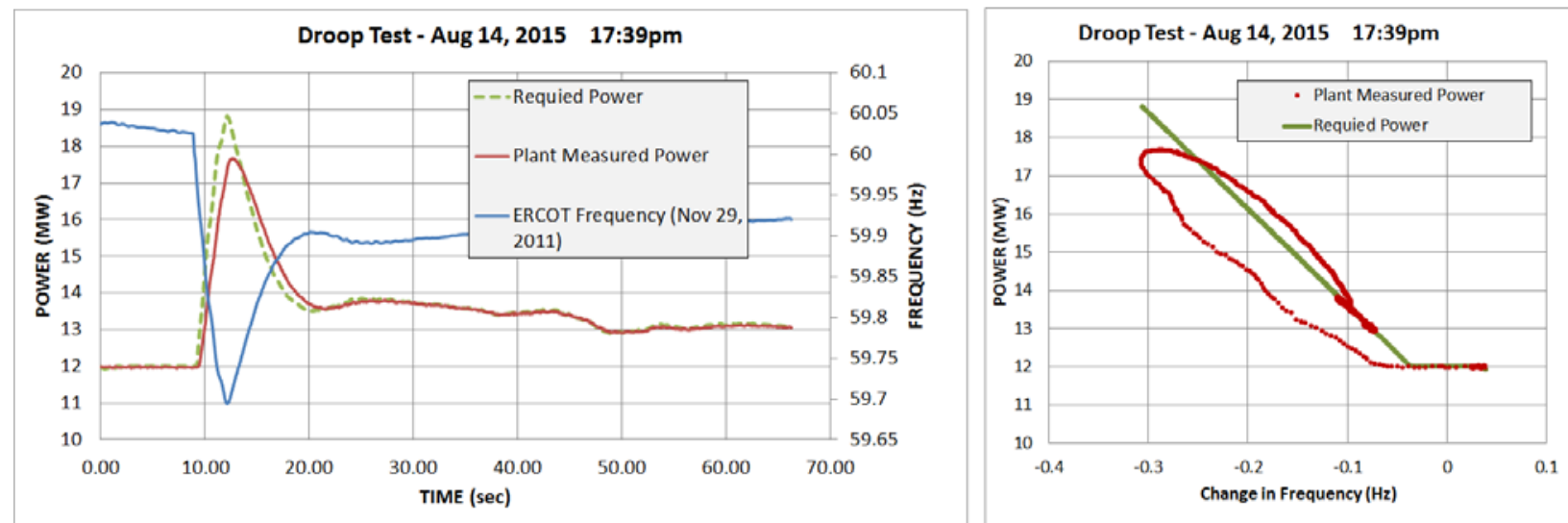

Figure 83. ERCOT frequency test 


\section{Conclusions}

The focus of this project was on demonstrating the controls of utility-scale PV power plants to provide various types of active and reactive power controls for ancillary services.

Active power control capabilities for inverter-connected plants such as PV power plants have been acknowledged and available for a number of years. However, many of these capabilities have not been proven in a real commercially operational setting by interfacing with the plant operator on the ground as well as the system operator (either utility off-taker or transmission system operator). This project, funded through DOE's Solar Energy Technologies Office, gained valuable real experience for all industry players with (1) the PV power plants' implementations of these capabilities, (2) the system operators' communications acceptance of the signals and use of the signals, (3) the iterative loop for the system operators to send back appropriate information (i.e., set point), (4) the logic of the PV power plant controllers to respond to the set points, and (5) the PV power plants' return of more up-to-date information (i.e., plant capability) to complete the iterative loop.

In the case of frequency response, there are two scenarios: (1) a plant has headroom and can increase its output in response to frequency deviation outside of a defined deadband on the low side, or (2) the plant does not have headroom and can only reduce output in response to frequency deviation on the high side. In the first case, headroom is achieved by the PPC by initially computing its estimation of maximum capability via pyranometer readings and other factors (ideally, ambient temperature, inverter efficiency, environmental factors, and custom scaling factors). Assuming that the plant will be reimbursed for energy not generated to be available for these ancillary services, the maximum power estimation will likely need to be refined and validated.

The headroom parameter can be communicated to the system operator as a block, e.g., $2 \mathrm{MW}$, or as a percentage, e.g., 10\%, at which level the plant will operate until it gets a command to do differently (either as a set point command or as an autonomous response to its own frequency reading of the system such as in droop response).

A suite of ancillary services are available through active power control capabilities of inverterconnected plants, and it is important that system operators prioritize the responses desired by PV power plants and under specified conditions because they may be in conflict. A real example of that encountered during the course of this demonstration project was the ramp-rate limiting factor that negatively impacted the response time in droop mode. Although the ramp-rate limit is a part of PREPA's MTR for Ilumina, as PREPA was a party to these tests, that limit needed to be turned off during droop response, but that fact had not been communicated clearly to the controller manufacturer, GPTech, who was remotely modifying the PPC to achieve test results.

PV plants can operate in one of three modes that are achieved by controlling the levels absorbed or produced of reactive power by PV inverters: voltage regulation, power factor regulation, and reactive power control mode. The plants can operate in only one of the three operating modes at any time, and seamless transition from one mode to another is possible (although not demonstrated in this work). In voltage-regulation mode, the controller maintains the specified voltage set point at the POI by regulating the reactive power produced by the inverters as well as 
other devices such as capacitor banks. In power-factor regulation mode, the controller maintains the specified power factor. In reactive power control mode, the controller can maintain desired levels of reactive power at the POI (absorbing, producing or zero level) based on the reactive power set point.

\subsection{Ilumina Summary}

The following testing activities were performed at AES's PV plant in Puerto Rico:

- Three new controls were implemented and demonstrated on AES's Ilumina 20-MW PV power plant.

- The AGC tests included:

- Four days of testing

- Approximately 15 hours in AGC mode at peak production hours (10 a.m.-11 a.m. and 2 p.m. -3 p.m.)

○ The demonstration of fast and accurate AGC performance.

- The FFR tests included:

- The demonstration of fast performance

- The indication that more control tune-ups might be necessary in the future.

- The 3\% and 5\% droop tests included:

- The demonstration of fast and accurate droop performance during periods of low variability

○ The demonstration of more scattered performance during fast solar ramps

○ The indication of possible improvement with fine-tuning the controller.

\subsection{Pecos Barilla Summary}

The following testing activities were performed at First Solar's Barilla PV plant in West Texas:

- Active power curtailment tests with power factor control

- Plant sequential shutdown tests while maintaining POI power factor

- Reactive power control tests (both absorbing and producing)

- Voltage control tests

- Power factor control tests

- Fast frequency response tests

- Frequency droop tests 


\subsection{General Conclusions and Lessons Learned}

General conclusions include the following:

- Accurate estimation of available peak power is important for the precision of AGC control.

- It makes sense to include specifications for such estimations into future interconnection requirements. (This is a lesser problem for plants that have energy storage.)

- System-level modeling exercises will be needed to determine the exact parameters of each control feature to maximize the reliability benefits to PREPA and ERCOT.

- All hardware components enabling PV power plants to provide a full suite of gridfriendly controls are already in existence in many utility-scale PV plants. It is mainly a matter of implementing controls and/or communications upgrades to fully enable these. Issues to be addressed in the process include communications protocol compatibility and proper scaling for set point signals. Although these are not significant barriers, dialogue and interaction between the plant operators and the system operators is an important component of implementation of APC capabilities. Modifying programming logic may be necessary at multiple places in the chain of communications.

- Fine-tuning the PPC to achieve rapid and precise response is an important step and is non-trivial. It may be easier with newer equipment because of the faster response times of newer inverters and controller systems.

- FFR response by a PV plant requires precise tuning of PI controllers for fast response times and avoiding unintentional oscillation of the output active power as shown in section 7.3

- For optimum FFR performance, the exact amount of generation loss must be dispatched to participating PV plants as an active power set point, so the pre-fault frequency can be quickly recovered. This will require a low-delay communication infrastructure to deliver information on the exact generation loss to the utility control center with consecutive distribution of proper active power set points to all participating PV plants that provide FFR.

- Many utility-scale PV power plants are already capable of receiving curtailment signals from grid operators; each plant is different, but it is expected that the transition to AGC operation mode will be relatively simply with modifications made only to a PPC and interface software (Figure 84).

- Fast response by PV inverters makes it possible to develop other advanced controls, such as power oscillation damping.

- PV power plants without energy storage are capable of providing many services to the grid, but market mechanisms and/or new interconnection requirements are needed to incentivize curtailed operation for any up-regulation service. 


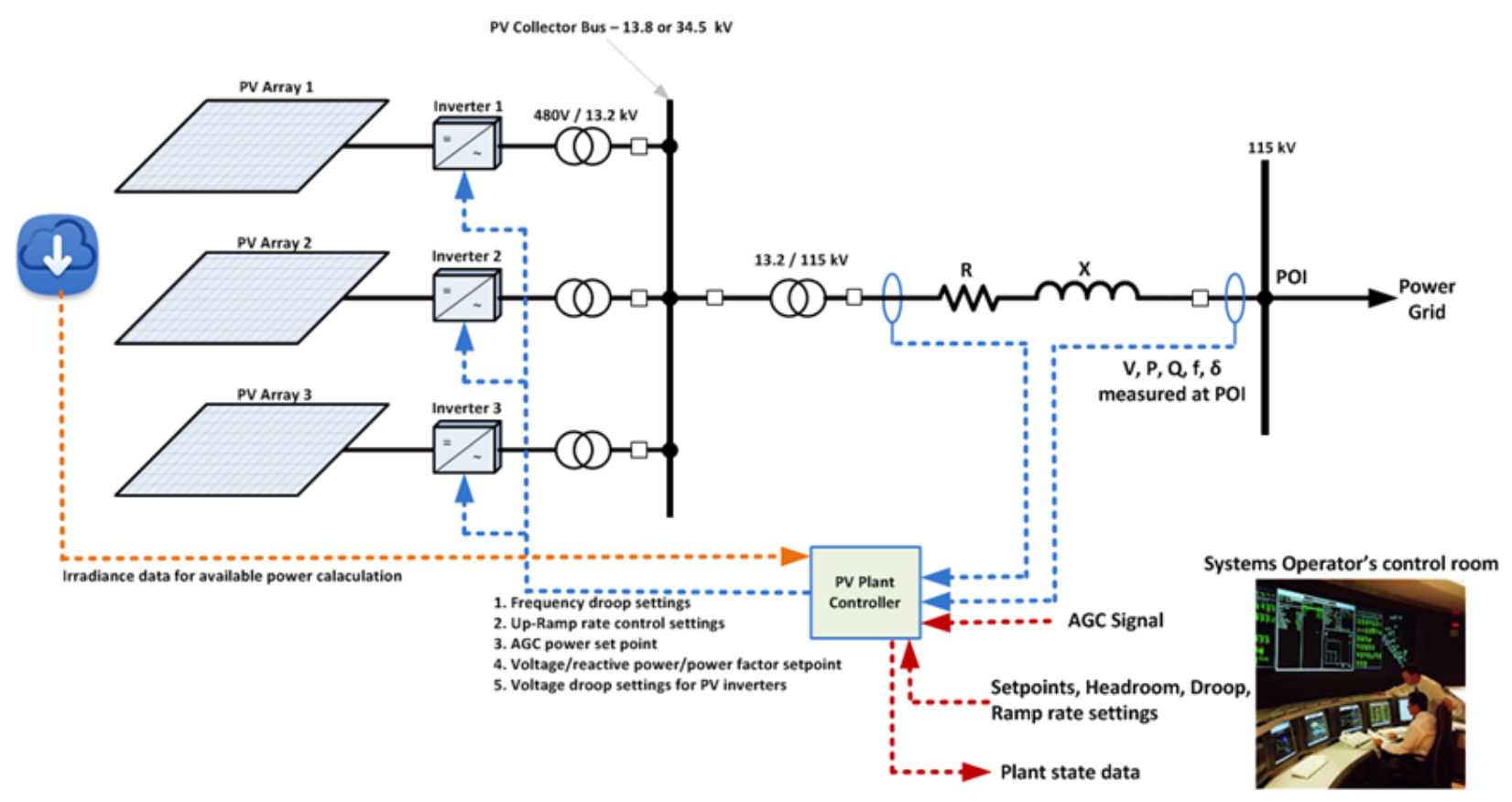

Figure 84. Grid-friendly PV power plant

\subsection{Recommendations}

PV's value should be leveraged from being simply an intermittent energy resource to providing mitigating ancillary services ranging from variability smoothing to power quality.

Many of the PV control capabilities that were demonstrated in this operational project have already generally been proven to be technically feasible. Like a few other places globally, U.S. system operators should start to request or require PV power plants to provide some of them to contribute to system reliability. As solar penetrations increase, it will become more and more important that solar power plants do not negatively impact reliability. Either mandating grid services or providing revenue for them via ancillary service payments is the next step to encouraging PV power plant owners to procure advanced inverter or power plant controller features. Regulators and market operators should ensure that plant owners are operating on a level-playing field with clear requirements or incentive streams. Future higher penetrations of variable generation will warrant this.

This project's demonstration and dissemination of results will foster awareness of solar plant capabilities by providing real test data to stakeholders. If PV-generated power can offer a supportive product that benefits the power system and is economic for PV power plant owners and customers, this functionality should be recognized and encouraged. 


\section{References}

1. Solar Energy Industries Association (SEIA) website: www.seia.org

2. M. Lave, J. Kleissl, A. Ellis, and F. Mejia. "Simulated PV Power Plant Variability Impact of Utility-Imposed Ramp Limitations in Puerto Rico.” In IEEE 2013 PV Specialists Conference Proceedings (Piscataway, NJ: Institute of Electrical and Electronics Engineers, 2013).

3. E. Ela, V. Diakov, E. Ibanez, and M. Heaney. Impacts of Variability and Uncertainty of Solar Photovoltaic Generation at Multiple Timescales. (Technical Report) NREL/TP-550058274 (Golden, CO: National Renewable Energy Laboratory, May 2013). Accessed September 17, 2014: http://www.nrel.gov/docs/fy13osti/58274.pdf.

4. M. Morjaria, D. Anichkov, V. Chadliev, and S. Soni. "A Grid-Friendly Plant." IEEE Power and Energy Magazine May/June (2014).

5. North American Electric Reliability Corporation. Integration of Variable Generation Task Force Report (Washington, DC: 2012).

6. A. Ellis, R. Nelson, E. Engeln, R. Walling, J. McDowell, L. Casey, E. Seymour, W. Peter, C. Baker, and B. Kirby. Reactive Power Interconnection Requirements for PV and Wind Plants: Recommendations to NERC. (Technical Report) SAND2012-1098 (Albuquerque, NM: Sandia National Laboratories, February 2012).

7. Offices of the Legislative Services of the Legislature of Puerto Rico. Act No. 82: Public Policy of Energy Diversification by Means of Sustainable and Alternative Renewable Energy in Puerto Rico Act (July 2010). Accessed September 17, 2014: http://www.oslpr.org/download/en/2010/A-0082-2010.pdf.

8. V. Gevorgian and S. Booth. Review of PREPA Technical Requirements for Interconnecting Wind and Solar Generation. (Technical Report) NREL/TP-5D00-57089 (Golden, CO:

National Renewable Energy Laboratory, October 2013).

9. Siemens PTI Study Team. PREPA Renewable Generation Integration Study. (Technical Report) R017-14 (Schenectady, NY: February 2014). Accessed September 17, 2014: http://www.aeepr.com/Docs/Siemens\%20PTI\%20Final\%20Report\%20\%20PREPA\%20Renewable\%20-\%20final-11.pdf.

10. E. Ela, V. Gevorgian, P. Fleming, Y.C. Zhang, M. Singh, E. Muljadi, A. Scholbrook, J. Aho, A. Buckspan, L. Pao, J. Singhvi, A. Tuohy, P. Pourbeik, D. Brooks, and N. Bhatt. Active Power Control from Wind Power: Bridging the Gaps. (Technical Report) NREL/TP-5D0060574 (Golden, CO: National Renewable Energy Laboratory, January 2014). Accessed September 17, 2014: http:/www.nrel.gov/docs/fy14osti/60574.pdf.

11. Y. Liu, J. Garcia, and S. Hadley. Wind/PV Generation for Frequency Regulation and Oscillation Damping in the Eastern Interconnection (EI). (Technical Report) ORNL/TM2013/587 (Oak Ridge, TN: Oak Ridge National Laboratory, December 2013). Accessed September 17, 2014: http://info.ornl.gov/sites/publications/files/Pub47594.pdf.

12. J. Matevosyan. "Future Ancillary Services Development in ERCOT." Presentation. In IEEE Power and Energy Society General Meeting Proceedings (Piscataway, NJ, 2014).

13. ERCOT. Future Ancillary Services in ERCOT: Concept paper, ver. 1.0 (Austin, TX: April 2014). http://www.ferc.gov/CalendarFiles/20140421084800-ERCOT-ConceptPaper.pdf. 
14. S. Lu, X. Guo, P.V. Etingov, C. Jin, D. Meng, and N. Samaan. NV Energy Large-Scale PV Integration Study: Intra-Hour Dispatch and AGC Simulation. (Technical Report) PNNL22069 (Richland, WA: Pacific Northwest National Laboratory, January 2013). Accessed September 17, 2014: http://www.pnnl.gov/main/publications/external/technical reports/PNNL-22069.pdf.

15. IEEE PES Task-Force on Turbine-Governor Modeling. Dynamic Models for TurbineGovernors in Power Systems Studies. (Technical Report) IEEE PES-1 (Piscataway, NJ, 2013).

16. P. Pourbeik, C. Pink, and R. Bisbee. "Power Plant Model Validation for Achieving Reliability Standard Requirements Based on Recorded On-Line Disturbance Data." In Proceedings of the IEEE Power and Energy Society Power Systems Conference and Exhibition (Piscataway, NJ: March 2011).

17. Electric Power Research Institute. Automated Model Validation for Power Plants Using OnLine Disturbance Monitoring. (Technical Report) 1016000 (Palo Alto, CA: 2009). http://my.epri.com/portal/server.pt?Abstract_id=000000000001016000.

18. ERCOT. 2013 Annual Report on the Texas Renewable Energy Credit Trading Program. (Technical Report) (Austin, TX).

19. ERCOT. Future Ancillary Services in ERCOT: ERCOT Concept Paper. Draft Version 1.1. (Austin, TX: 2013). Accessed September 17, 2014: http://www.ercot.com/content/news/presentations/2014/ERCOT_AS_Concept Paper Version_1.1_as of 11-01-13_1445_black.pdf.

20. ERCOT. Panhandle Renewable Energy Zone (PREZ) Study Report (Technical Report) (Austin, TX: April 2014).

21. C. Reeder. "Texas Public Utility Commission Opens Investigation into Transmission Upgrades and Grid Stability Related to Renewable Generation.” June 11, 2014. Accessed September 17, 2014: http://www.martindale.com/natural-resources-law/article HuschBlackwell-LLP 2163286.htm.

22. AEP. Interconnection Study for New Generation. (Technical Report) 12INR0059 Report for generation, Texas transmission planning (New York: BNB Renewable Energy Holdings, LLC, April 5, 2013. 


\section{Appendix A: GPTech Inverter Specifications}

\section{POWER PV500}

Three-phase photovoltaic inverter for grid connection

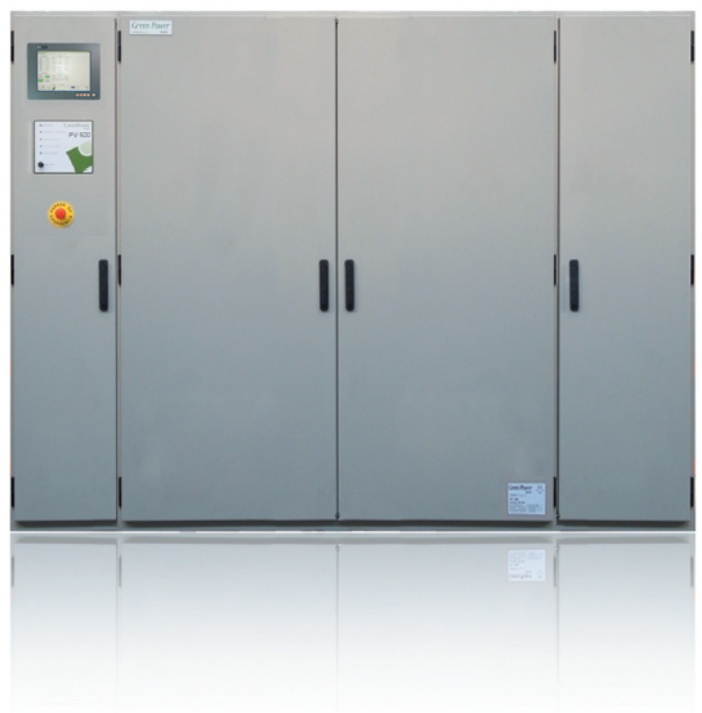

\section{Advanced DSP Technology}

The three-phase photovoltaic inverters of the POWER PV Serie have been entirely developed by GPtech. for the connection of photovoltaic power plants to the electric grid.

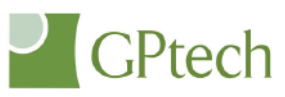

wnw.greenpower.es greenpower@greenpower.es

Technical Characteristics

- DC Input

Maximum input voltage

Maximum current

Recommended maximum PV-power

- AC Output

Line voltage output

Nominal Power

Maximum output curren

Total Harmonic Distorsion

Power Factor

Voltag sag compensation

- Efficiency

Maximum efficiency

European efficiency

Consumption at night

- Operating Characteristics

Maximum working/storage

temperature

Relative humidity

- Mechanical Characteristics

Size (mm)

Weight

Degree of IP protection

- Protections

DC

- Overload

Voltage swells. Class II

Inverse polarisation

EMI Filters

PV-field isolation detector

Automatic disconnection

Manual PV-filed disconnection with

emergency stop

Optional:

- Panel grounding kit

Further protections

Temperature

Overload and short-circuit of auxiliaries

Voltage swells of auxiliaries

Secure door opening

- Interfaces

7" TFT SVGA LCD Display with touchscreen.

Massive storage through Datalogger.

TCP/P over Ethernet. Web server.

Communications protocol MODBUS.

Field bus connection with RS485-DB9.

PC connection with RS232-DB9. Software included. (")

Optionals:

-32 analogical inputs for external sensors $( \pm 4 \mathrm{~V}$.

-6 digital output free of electric potential.

4 optocoupled digital inputs $0-15 \mathrm{~V}$

- GSM/GPRS Modem.

Server and remote control. Web portal access for clients with possibility to consult PV plant energy bill meters.

(7) Information about RMS grid voltages and currents, grid frequency, DC voltage and current, active, reactive and apparent $\mathrm{AC}$ power, efficiency, system failures.

- Legal Standards

EU Marking.

Directives: EMC 61000-6-2, EMC 61000-6-4, Low Voltage (EN 50178), DK 5940 and VDE 126-1-1.

In accordance with legal standards: RD 1663/2000 and RD 1578/2008.

- Monitoring and equipment control software

Harmonics and THO calculation.

Password-protected system configuration

Voltages, grid current and homopolar representation.

Internal system variables representation by software oscilloscope and historical

records generation.

Power factor, apparent and reactive power representation.

This report is available at no cost from the National Renewable Energy Laboratory (NREL) at www.nrel.gov/publications. 


\section{Appendix B: GPTech's Controls Description}

\section{Frequency Response}

Based on the MTR, the power plant will reduce its operational capacity if the grid frequency exceeds the limit of $60.012 \mathrm{~Hz}$. The reduction is linear from 60.012 to $63 \mathrm{~Hz}$. If the grid frequency is higher than $63 \mathrm{~Hz}$ the inverters will shut down (no power exporting). The operational capacity of the plant ( $\mathrm{Pavailable}$ or $\mathrm{Pa}$ ) is a function of the solar irradiance, and can be calculated by using the mean irradiance value of the 5 meteorological stations in the power plant. $\mathrm{Pa}$ (with units of MW) is calculated by the Power Plant Controller (PPC) using the following formula:

$$
\mathrm{Pa}=\mathrm{A} * \mathrm{Ir} *(\mathrm{X} / 40)-\mathrm{B} \text {, where }
$$

- $\mathrm{A}=$ constant based on historical performance of the plant

- $\mathrm{Ir}=$ the mean irradiance in $\mathrm{W} / \mathrm{m}^{\wedge} 2$

- $\mathrm{X}=$ the amount of inverters in operation at any given time

- $\quad \mathrm{B}=$ constant to account for the internal power consumption

- And Pa can never be higher than 20.0 MW.

The frequency response curve for Ilumina power plant is similar to the one shown in Figure 1. When there is an increment in the frequency $(\Delta \mathrm{f})$ the available active power must be reduced by $\Delta \mathrm{W}_{6}$. So once $\mathrm{Pa}$ is calculated, the Smartbridge will send a reference to the inverters so that their combined production will not exceed a maximum power of $\mathrm{Pa}-\Delta \mathrm{W}$. Namely, the power production may increase if irradiance increases while inverters execute the MPPT algorithm, but there will be a maximum power limit of $\mathrm{Pa}-\Delta \mathrm{W}$.

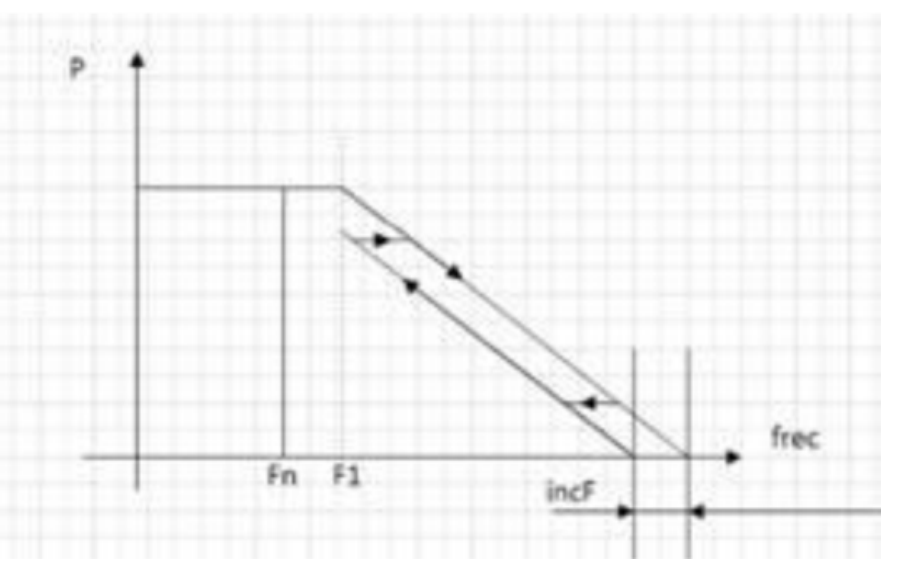

Figure 85: Frequency response behavior

${ }_{6} \Delta \mathrm{W}=$ Power variation due to frequency response, proportional to $\mathrm{Pa}$

MPPT: Maximum power point tracking

\section{Ramp Rate Control}

Originally, the ramp rate was locally implemented in every inverter, not in the interconnection point, so in many cases the real ramp rate in the interconnection point was less than $20 \%$ of the 
operational capacity per minute. Now the ramp rate control is implemented in the PPC, which in turns sends an active power reference to the inverters. The control diagram was presented and explained in the PSSE model documentation, but is included in Figure 2 below as reference. The ramp rate control works in parallel with the frequency response.

Ramp up rate $=0.2 * \mathrm{~Pa}$, in $\mathrm{MW} / \mathrm{min}$.

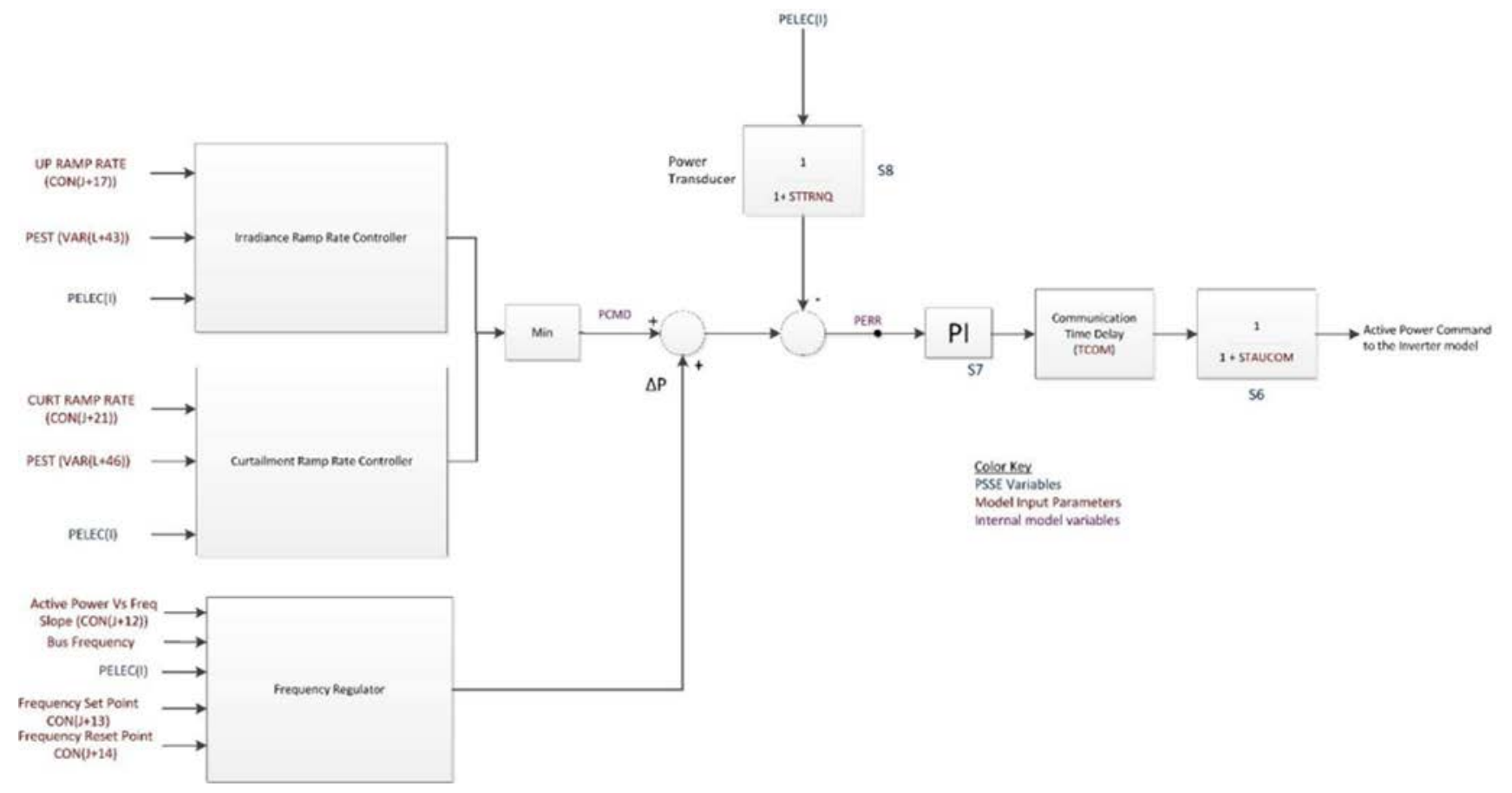

Figure 86: GPTech's ramp rate control diagram 


\section{Appendix C: GPTech Interface Description}

The signals of the interface between PREPA and Ilumina plant are shown in the table below. It is always PREPA that starts the communication, either to write a parameter (PREPA -> AES) or to read a parameter (PREPA <- AES). In fact, when speaking about PREPA, we mean the SEL-3530 device installed in the substation.

\begin{tabular}{|l|l|l|l|l|}
\hline Id & Name & Direction & Interface & Values \\
\hline 1 & AES SETP KV & PREPA -> AES & RS232 & KV $(-5 \%, 5 \%)$ \\
\hline 2 & AES SETP KVD & PREPA -> AES & Modbus TCP & $\%$ Droop $(0 \%, 10 \%)$ \\
\hline-3 & AES SETP KV & PREPA <- AES & Modbus TCP & KV \\
\cline { 5 - 6 } & AES SETP KVD & PREPA <- AES & Modbus TCP & $\%$ Droop \\
\hline 5 & AES CURTSP MW & PREPA -> AES & Modbus TCP & MW (0\% -100\%) \\
\hline 6 & Curtailment & PREPA -> AES & Modbus TCP & Enable (1) / Disable (0) \\
\hline 7 & AES CURTSP MW & PREPA <- AES & Modbus TCP & MW \\
\hline 8 & Curtailment & PREPA <- AES & Modbus TCP & Enable (1) / Disable (0) \\
\hline 9 & AESSolar Raise & PREPA <- AES & Modbus TCP & MW/Min \\
\hline 10 & AESSolar Lower & PREPA <- AES & Modbus TCP & MW/Min \\
\hline 11 & AES SETP FREQD & PREPA <- AES & Modbus TCP & \\
\hline
\end{tabular}

